\title{
WestVirginiaUniversity
}

THE RESEARCH REPOSITORY @ WVU

Graduate Theses, Dissertations, and Problem Reports

2021

\section{Recovery of Phosphorus from Florida Phosphatic Waste Clay}

Amir Eskanlou

West Virginia University, ae0032@mix.wvu.edu

Follow this and additional works at: https://researchrepository.wvu.edu/etd

Part of the Environmental Engineering Commons, Metallurgy Commons, Mining Engineering Commons, Natural Resources and Conservation Commons, Natural Resources Management and Policy Commons, Quantum Physics Commons, and the Sustainability Commons

\section{Recommended Citation}

Eskanlou, Amir, "Recovery of Phosphorus from Florida Phosphatic Waste Clay" (2021). Graduate Theses, Dissertations, and Problem Reports. 8301.

https://researchrepository.wvu.edu/etd/8301

This Thesis is protected by copyright and/or related rights. It has been brought to you by the The Research Repository @ WVU with permission from the rights-holder(s). You are free to use this Thesis in any way that is permitted by the copyright and related rights legislation that applies to your use. For other uses you must obtain permission from the rights-holder(s) directly, unless additional rights are indicated by a Creative Commons license in the record and/ or on the work itself. This Thesis has been accepted for inclusion in WVU Graduate Theses, Dissertations, and Problem Reports collection by an authorized administrator of The Research Repository @ WVU. For more information, please contact researchrepository@mail.wvu.edu. 


\title{
Recovery of Phosphorus from Florida Phosphatic Waste Clay
}

\author{
Amir Eskanlou
}

Thesis submitted

to the Benjamin M. Statler College of Engineering and Mineral Resources at West Virginia University

in partial fulfillment of the requirements for the degree of

Master of Science in

Mining Engineering

Qingqing Huang, Ph.D., Chair

Seyed Hassan Amini, Ph.D.

Aldo H. Romero, Ph.D.

Patrick Zhang, Ph.D.

Department of Mining Engineering

Morgantown, West Virginia

2021

Keywords: phosphorus, rare earth elements, waste clay, de-sliming, flotation, DFT Copyright $^{\oplus} 2021$ Amir Eskanlou 


\title{
ABSTRACT \\ Recovery of Phosphorus from Florida Phosphatic Waste Clay
}

\author{
Amir Eskanlou
}

This MS thesis examines the recovery of phosphorus (P) from Florida waste clay (WC). A comprehensive literature review revealed that: (i)-The most important values being lost to WC are $\mathrm{P}$ and rare earth elements (REEs). For the recovery of these values from WC, two crucial attempts are the removal of extremely fine-sized clays, followed by the recovery of phosphate content, which can pave the path for the recovery of REEs; (ii)-Any scientific/ technological solution should, at the same time, be economically and environmentally attractive to the industry. As such, moving from mostly chemical separation processes to the primarily physical/ physicochemical processes seems to be the ultimate solution.

De-sliming followed by froth flotation for the recovery of $\mathrm{P}$ and enrichment of REEs from WC showed that the direct flotation of apatite using both fatty acid and hydroxamates, even in the presence of various regulating agents, does not offer a solution for the recovery of $\mathrm{P}$ from WC. Hydroxamic acid collectors, despite their capability in the selective flotation of apatite and REE-bearing minerals, do not produce a successful selective separation of phosphate minerals from WC. The double-stage reverse flotation process in which the cationic removal of silicates is followed by the anionic rejection of carbonates both at fairly acidic conditions, becomes less attractive from the economic stance when the reagent consumption is taken as a determining factor. Added to this is the significant loss of REEs with this approach. The singlestage process where only a cationic removal of silicates following the cyclone-assisted removal of clays are employed, offers a more economically viable route for the conditional recovery of P from WC. This superiority also owes to its relative capability to avoid the loss of REEs as the other paramount value contained in WC. The removal of clays, silicates, and carbonates through the de-sliming followed by the single-stage reverse flotation process meets the specifications of the medium-grade phosphate rock that is routinely mixed with the high-grade 
rock to be sold to the fertilizer production industry. Removal of the associated gangues significantly alleviates the acid consumption in the subsequent chemical recovery of REEs from WC, which has long been alluded to by the industry and researchers as the limiting factor.

The results obtained from the multiscale investigation on the effect of $\mathrm{Al}^{3+}$ and $\mathrm{Mg}^{2+}$ ions on the flotation of apatite using fatty- and hydroxamic-acid collectors showed that fatty acid and hydroxamates adsorb on the bare mineral through a bidentate $\mathrm{Ca}-\mathrm{O}$ bond along with a $\mathrm{Na}^{+}$mediated $\mathrm{O}-\mathrm{O}$ bonding, and a mono-dentate $\mathrm{Ca}-\mathrm{O}$ bond along with a hydrogen bonding, respectively. On the $\mathrm{Al}^{3+}$-treated surface, fatty acid adsorbs through the bidentate interaction with both adsorbed $\mathrm{Al}^{3+}$ and lattice $\mathrm{Ca}^{2+}$ ions. The $\mathrm{Al}^{3+}$ site is preferred over $\mathrm{Ca}^{2+}$ lattice site by $\mathrm{OHA}$ to interact, resulting in stronger adsorption, and thus enhanced flotation. For BHA, however, $\mathrm{Al}^{3+}$ doesn't benefit collector adsorption, and thereby leads to a declined flotation. $\mathrm{Mg}^{2+}$ presence leads to a stronger bidentate/ tridentate interaction with both adsorbed $\mathrm{Mg}^{2+}$, and lattice $\mathrm{Ca}^{2+}$ ions for both collector types. Fatty acid establishes a stronger interaction with the bare and $\mathrm{Al}^{3+} / \mathrm{Mg}^{2+}$-treated mineral compared to the hydroxamates. Both $\mathrm{Al}^{3+}$ and $\mathrm{Mg}^{2+}$ ions enhance the adsorption of fatty acid, and thereby its flotation. $\mathrm{Mg}^{2+}$ is more favorable than $\mathrm{Al}^{3+}$ in apatite flotation using either fatty acid or hydroxamates. Interestingly, even though $\mathrm{Al}^{3+}$ deters the functionality of BHA on apatite surface, it contributes to a stronger mineralBHA bonding. This could possibly be because of rendered surface charge due to precipitation of $\mathrm{Al}^{3+}$ species. As well, the inconsistency between the two hydroxamates towards $\mathrm{Al}^{3+}$ could be attributed to the type of hydrocarbon group. Overall, to develop a more industrially applicable knowledge, the effects of the metal ions on the collector consumption by the known gangue minerals, and thereupon on the flotation selectivity, should also be studied in future endeavors. 


\section{Acknowledgements}

Foremost, I would like to express my sincere gratitude to my advisor and my committee chair Dr. Qingqing Huang, for her guidance, motivation, and continual support throughout this work. Without her guidance and persistent help, the achievement of this work would not be possible.

I would like to thank my committee member, Dr. Patrick Zhang and Florida Industrial and Phosphate Research Institute for kindly providing the waste clay samples for my research.

My sincere thanks to my committee member, Professor Aldo H. Romero for kindly giving me the access to use his VASP code, which is a proprietary package for performing ab initio quantum mechanical calculations.

I am grateful to my committee member, Dr. Seyed Hassan Amini for his valuable time, helpful suggestions, and friendly support on my thesis.

I appreciate the friendly help and technical supports from Dr. Michael Badawi, associate professor at University of Lorraine, France, and Dr. Yann Foucaud, post-doctoral researcher in Institut de Chimie Séparative de Marcoule at French Alternative Energies and Atomic Energy Commission (CEA).

My special thanks to my friends, Behzad Vaziri Hassas, Ph.D. candidate at Penn State University for his expertise, participation and helpful subject-related suggestions, and Pedram Tavadze, Ph.D. student at WVU Department of Physics for his friendly technical help on VASP code.

I would also take this opportunity to thank WVU Mining Department program assistant, Ms. Genette Chapman, and office administrator, Ms. Karen Centofanti for their kind help during my studies at West Virginia University. 


\section{Foreword}

This thesis is composed of four chapters and presented as articles in insertion form. The problem statement, objectives, and general methodology are presented in chapter 1. Chapter 1 is also a comprehensive critical literature review focusing on the origin, composition, physicochemical properties, challenges, values and possible remedies of phosphatic waste clay. Chapter 1 has been published in Journal of Minerals Engineering. Chapters 2 and 3 present the results of this research project in the form of scientific articles. Chapter 2 has been submitted to Journal of Resources, Conservation \& Recycling, and it is under revision. Chapter 3 has been submitted to Journal of Colloid and Interface Science, and it is under-review. Chapter 4 highlights the key contributions of this research and the recommendations for future studies. Chapter 4 is originally written by Amir Eskanlou and has never been published before. This project was supervised by Dr. QingQing Huang. 


\section{Table of Contents}

Chapter 1: Phosphatic waste clay: origin, composition, physicochemical properties, challenges, values and possible remedies - A review ................................. 1

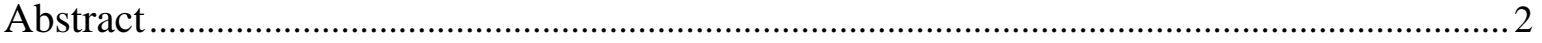

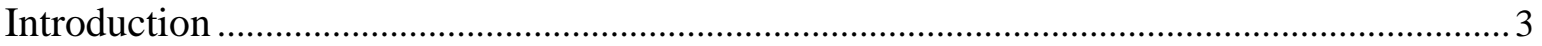

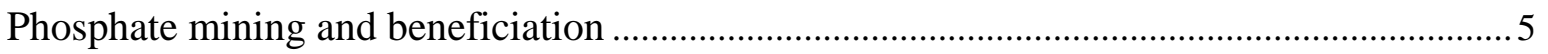

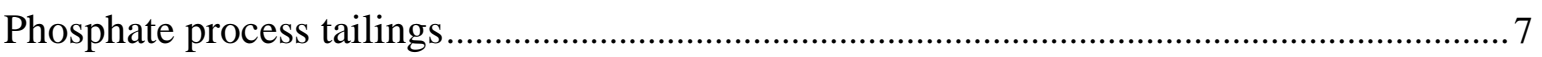

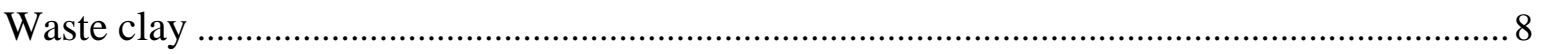

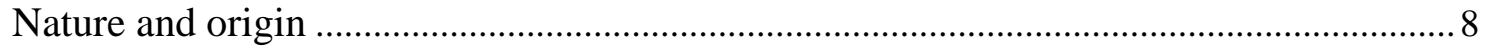

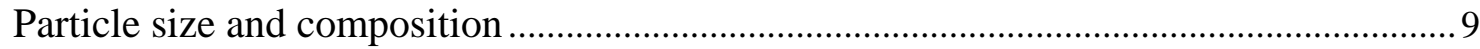

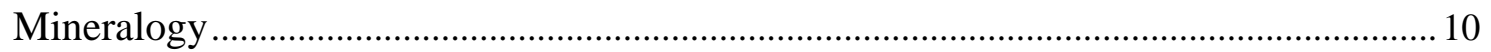

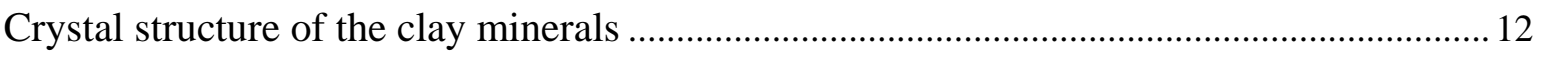

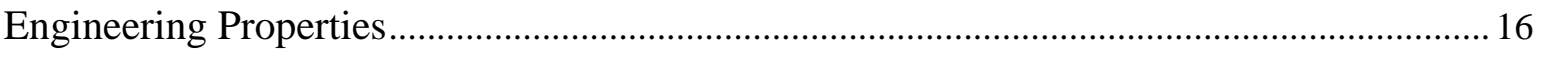

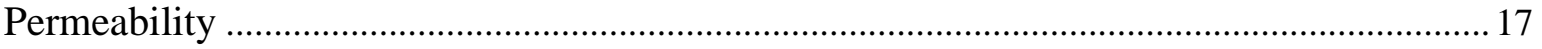

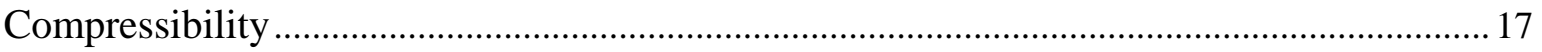

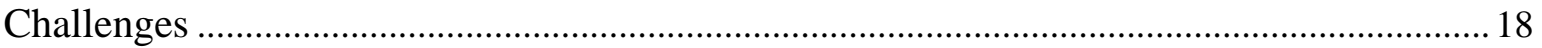

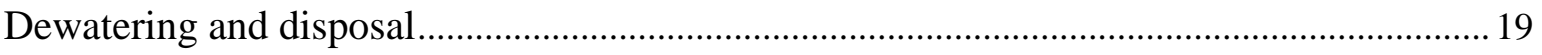

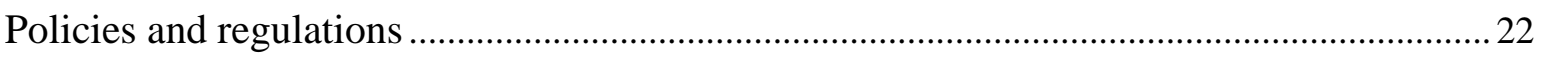

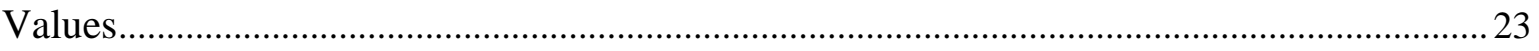

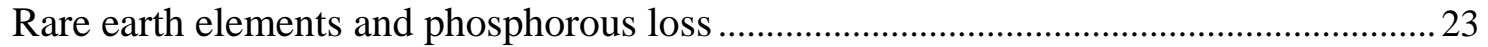

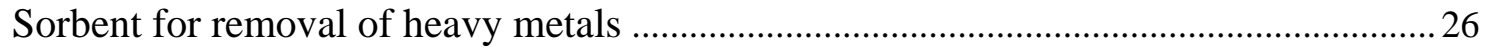

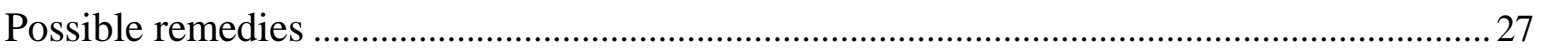

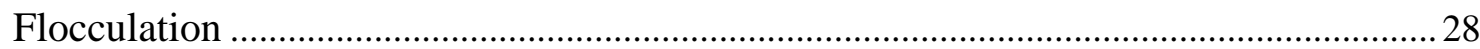

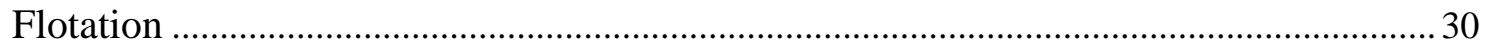

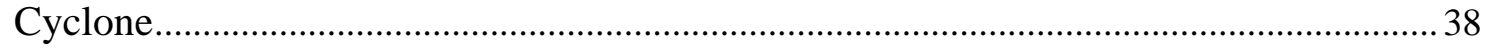

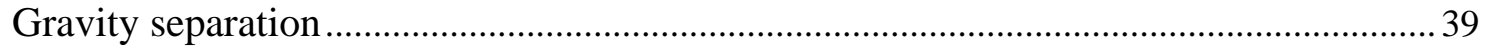

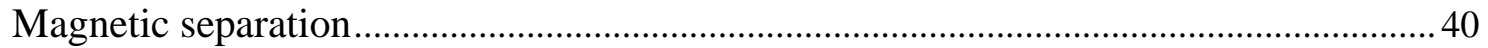

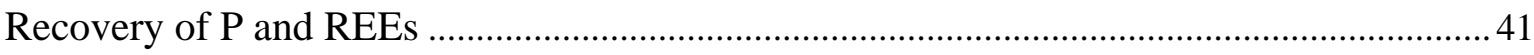

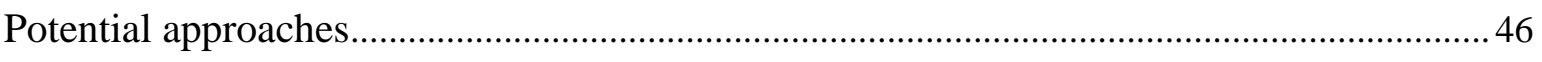

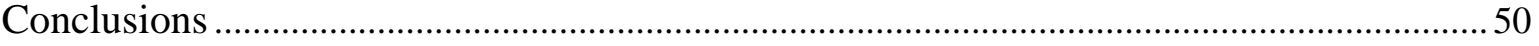

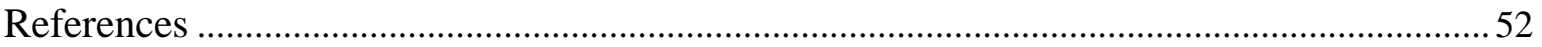


Chapter 2: De-sliming followed by froth flotation for the recovery of phosphorus and enrichment of rare earth elements from Florida waste clay ........................ 76

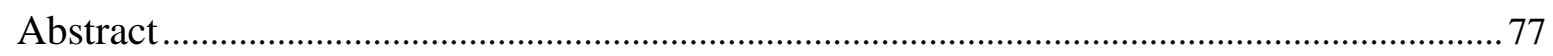

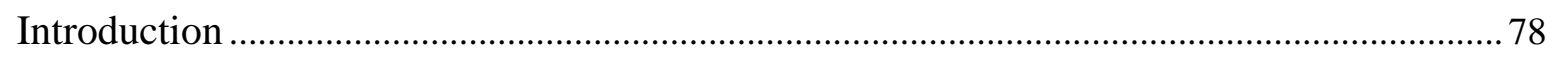

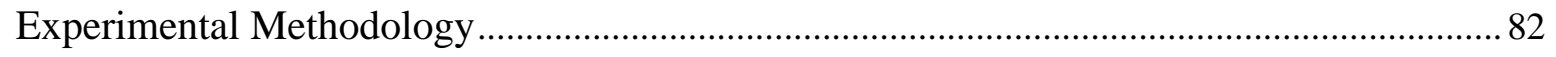

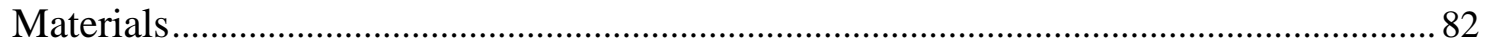

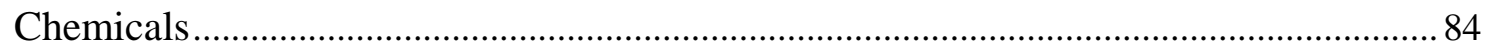

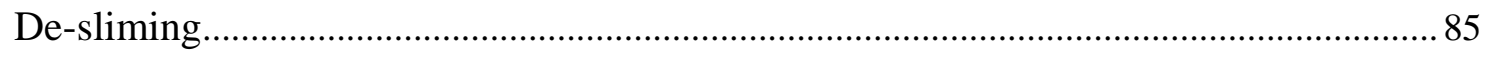

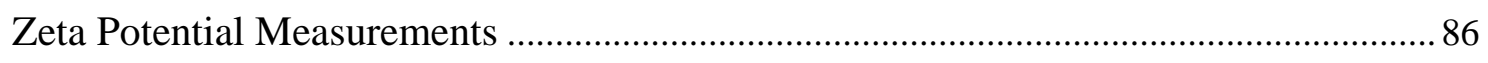

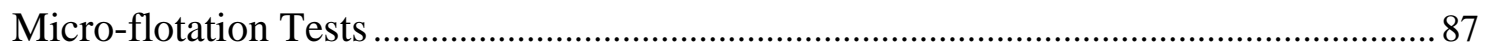

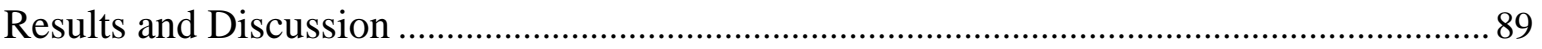

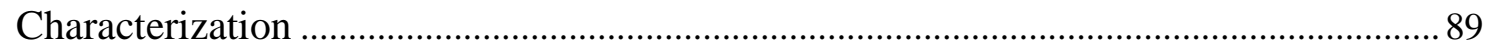

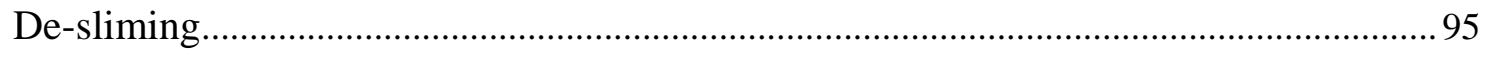

Zeta Potential Measurements .............................................................................................. 96

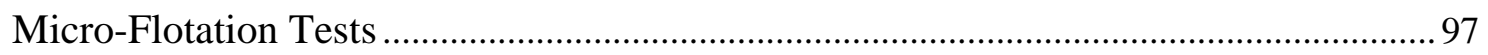

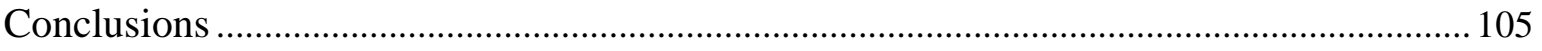

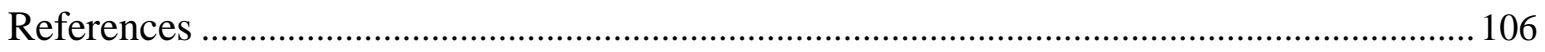

Chapter 3: Effect of $\mathrm{Al}^{3+}$ and $\mathrm{Mg}^{2+}$ on the flotation of apatite using fatty- and hydroxamicacid collectors - A multiscale investigation................................................... 113

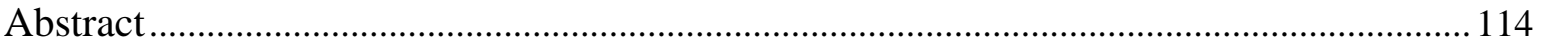

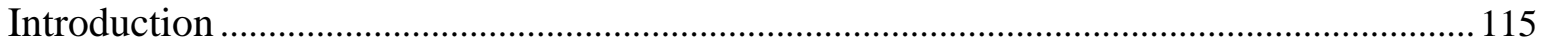

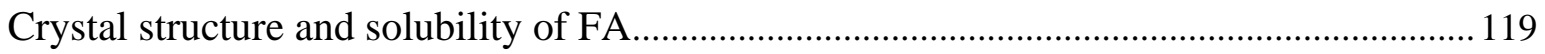

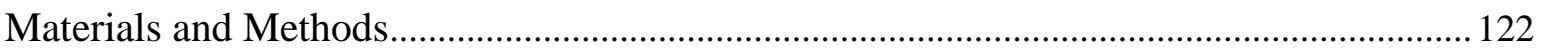

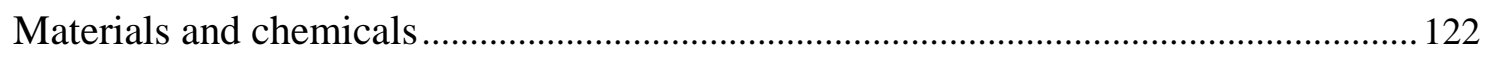

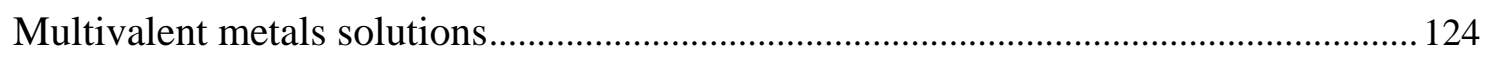

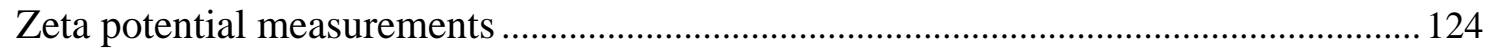

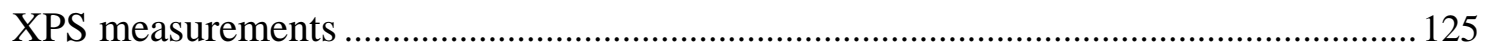

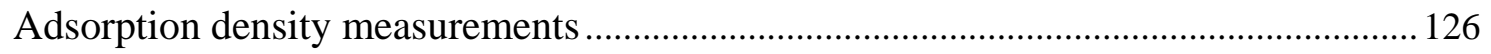

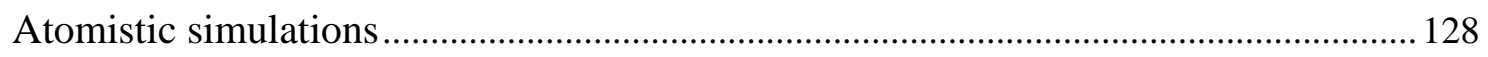

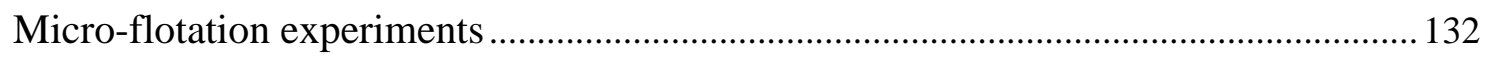

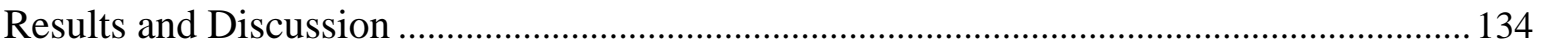

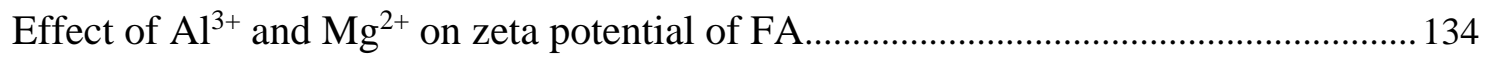

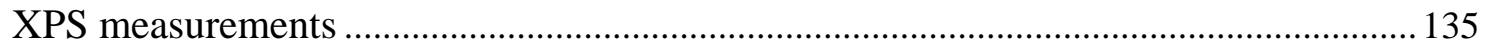




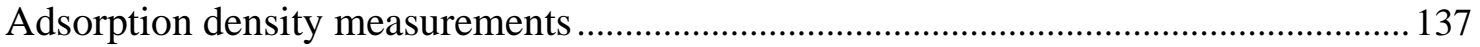

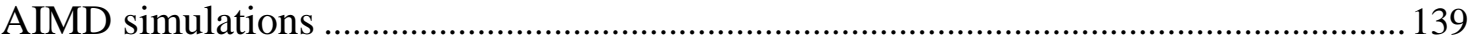

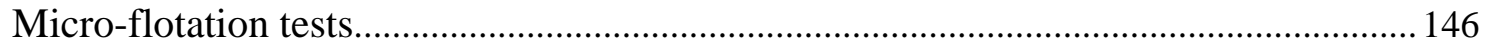

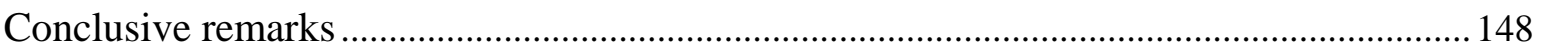

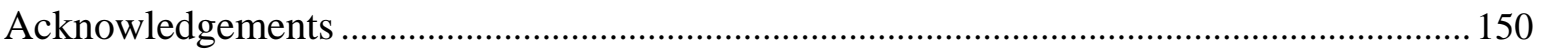

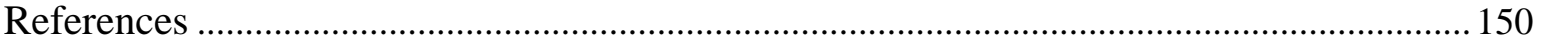

Chapter 4: Conclusions and Recommendations for Future Work.............................. 158

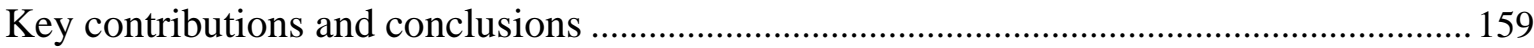

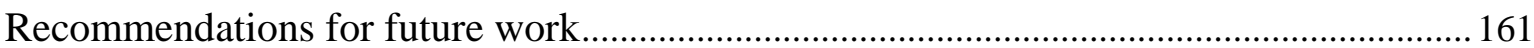

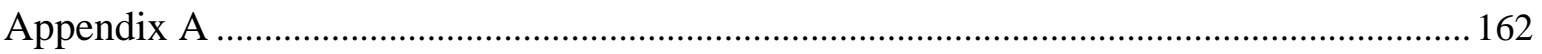

Appendix B

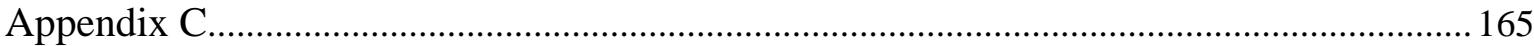

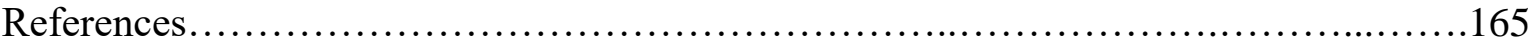




\section{CHAPTER 1}

Phosphatic waste clay: origin, composition, physicochemical properties, challenges, values and possible remedies - A review 


\title{
Phosphatic waste clay: origin, composition, physicochemical properties, challenges, values and possible remedies - A review
}

\author{
Amir Eskanlou, Qingqing Huang* \\ Department of Mining Engineering, West Virginia University, 365 Mineral Resources Building, 1374 \\ Evansdale Drive, Morgantown, WV 26506, USA \\ *Corresponding Author: qingqing.huang@mail.wvu.edu \\ Published in: Journal of Minerals Engineering, DOI: 10.1016/j.mineng.2020.106745
}

\begin{abstract}
The daily growing demand for critical materials has further highlighted the importance of secondary sources such as industrial waste streams. Waste clay, a phosphate ore process tailing, contains a remarkable amount of critical materials such as P and REEs so that comparing to different phosphate ore process streams, waste clay presents the highest concentration of REEs after phosphate rock. Due to the enormous volume of this waste accumulated in Florida to date, this reserve can satisfy a great portion of U.S. domestic demand for REEs, as an example. However, due to its troublesome nature, this reserve poses severe environmental problems along with economic loss. Two required attempts are the removal of extremely fine-sized clays, followed by the recovery of phosphate content, which can pave the path for the recovery of REE-bearing phases. Different possible remedies or a combination of them have been considered by various research/ industrial trials, including froth flotation, selective-flocculation, floc-flotation, cycloning, gravity separation, magnetic separation, leaching, etc., most of which have shown no promising solution because of failing to address economic and of course environmental concerns. Moving from mostly chemical separation processes to the primarily physical/ physicochemical processes with low operational costs and environmental impacts could be a general solution. This requires detailed mineralogical and elemental characterization, physicochemical, rheological, electrochemistry, surface chemistry, crystal chemistry, solution chemistry, and quantum chemistry investigations on each single and then mixed-phase systems composing waste clay. Such insights can help develop the fundamental knowledge, upon which more versatile and efficient solutions can be established.
\end{abstract}

Keywords: Phosphate, REEs, Waste, Clay, Environment 


\section{Introduction}

As the world population and global economies continue to grow at an increasingly fast pace, and due to advancements in science and technology, the demand for critical materials is rapidly rising. In such a context, critical materials are those with particularly high importance and, at the same time, with a high risk of supply disruptions [1]. Such ever-growing demand makes the recovery of these critical materials from wastes through reusing and recycling more attractive. As well, the transition to a circular economy is essential to develop a sustainable, low carbon, resource-efficient, and competitive economy in a country $[1,2]$. The concept of circular economy mandates the reduction, recycling, and re-use of mining and metallurgical wastes [2]. A sustainable future for human beings must include the effective recycling of waste streams to meet the demands and avoid adverse environmental consequences. Humanity faces many environmental challenges in the 21 st century. In light of this fact, during the World Summit on Sustainable Development in 2002, governments reaffirmed the importance of solidwaste management, calling for priority attention to be given to prevention, minimization, reusing, and recycling of wastes [3]. Despite remarkable efforts worldwide to reduce the amount of waste produced, solid mineral wastes from the processing plants remain one of the world's largest waste streams [4]. Changing circumstances may turn a particular waste into a valuable commodity, either because of the technology advancement or market demands that fuel the interest in waste reprocessing and the extraction of values from these kinds of sources. Mineral processing plant tailings may be regarded as worthless at the time of production, yet they can contain mineral and energy resources that may become valuable over time. An important example in this context is the phosphate mining and beneficiation industry, which strives day in day out to meet the needs and supplies for the production of adequate food for the ever-growing world population, which according to the Food and Agriculture Organization (FAO), is estimated to reach 9 billion in 2050 [5]. This means that there is a challenging task ahead for the fertilizer and agriculture industries to ensure food availability for the world population. Such a necessity for the inevitable growth of the phosphate industry has led to the ever-increasing volume of waste streams such as the phosphatic waste clay (also known as waste clay), a phosphate process tailing that contains massive quantities of phosphorous (P) and other critical and valuable elements [6]. In Florida, for example, more than one ton of waste clay is produced per each ton of phosphate rock product, which means about 20 million 
tons of this waste annually, and over two billion tons totally accumulated in Florida to date. Waste clay has been considered as an ultimate processing challenge in the industry, which now is considered as a precious reserve for $\mathrm{P}$ and rare earth elements (REEs), and other critical elements. Assuming 9\% $\mathrm{P}_{2} \mathrm{O}_{5}, 300$ ppm REEs, and 40 ppm Uranium (U), this reserve contains approximately 600 million tons of phosphate, 600 thousand tons of REEs including 200 thousand tons of Yttrium (Y) solely, 1.2 million tons of Magnesium (Mg), and 80 million kilograms of $U$. This clearly shows the importance of this reserve. However, waste clay poses severe challenges to the beneficiation process and the environment due to its extremely fine particle size (below 20 micron) [6].

REEs, as another value contained in the waste streams such as waste clay, are also becoming increasingly important in the transition to a low-carbon circular economy, considering their essential role in permanent magnets, lamp phosphors, rechargeable nickel metal hydride batteries, catalysts, and other green economy applications. The increasing popularity of hybrid and electric cars, wind turbines, and compact fluorescent lamps is causing an increase in the demand and price of REEs [7]. The European Commission considers the REEs as the most critical raw materials group, with the highest supply risk [8]. According to the medium-term criticality matrix of the U.S. Department of Energy (DOE), the five most critical REEs are neodymium (Nd), europium (Eu), terbium (Tb), dysprosium (Dy), and Y [9]. China is presently producing more than $90 \%$ of all rare earths, although this country possesses less than $40 \%$ of the proven reserves in the world. Due to tremendous and increasing domestic demands, China tightened its REE export quota from 50145 tons in 2009 to only 30258 tons in 2010, and so forth [10]. These export quota may cause severe problems for REE users outside China, and therefore, also for the development of a more sustainable, low-carbon circular economy. The uncertainties upon satisfying the growing global demand for these elements highlight the importance of nontraditional sources for these strategically prominent elements $[2,10]$. Phosphate ore and phosphate processing wastes have been identified as possible alternative sources for REEs. Waste streams such as waste clay may contain low REE concentrations, but are available in huge volumes, as pointed out earlier. This implies that these waste streams could provide significant amounts of rare earths if efficient recycling flow sheets can be developed [11]. Therefore, recovering critical elements like P and REEs from secondary 
sources like waste streams is a possible solution that can alleviate the disparity between supply and demand.

On the other hand, the $\mathrm{P}$ and the other certain elements present in these waste streams pose a threat to the environment through nutrient enrichment resulting in various complex ecological problems, including fresh and coastal water eutrophication [12]. To date, extensive research has been conducted to mitigate the environmental impacts and increase the valorization potential of the wastes. The most urgent problem facing scientists working on recycling and reusing of mining and processing wastes is the quantification and distribution of elements in wastes. The chemistry and mineralogy of the wastes, which can be heterogeneous depending on their geographical origin and processing practice, should be precisely described in order to understand their long-term behavior [4]. We need to drastically improve our scientific effort to explain the occurrence and distribution of elements and minerals in wastes on all scales since such knowledge is imperative to establish the recycling and reusing potential of wastes [3]. Because of vastly improved mineral processing technologies, which in turn leads to economic and environmental benefits, the targeted extraction of value from waste streams has become possible. Such careful extraction of targeted elements requires detailed knowledge of the waste's mineralogical, geochemical, and bulk physical properties [13].

In line with these emerging paradigms of environmental responsibility and sustainable development, the objective of this paper is to explore the origin, nature, physicochemical properties, processing challenges, potential values, and possible remedies for one of the current ultimate mineral processing challenges, waste clay. This study also provides a critical review of current and emerging research and industrial practices on the processing and valorization of waste clay in the phosphate industry, along with the reclamation policies and regulations. This study aims to enhance the scientists' and engineers' understanding of different properties and aspects of the issue, and therefore better define the possible routes to reach success in the recovery of values from waste clay and mitigating its environmental impacts.

\section{Phosphate mining and beneficiation}

Phosphorus is a common element that the average continental crust contains $0.27 \% \mathrm{P}_{2} \mathrm{O}_{5}$ [14]. Phosphorus is the primary resource for the production of fertilizers and numerous other phosphorous-based products [15]. Phosphorus is neither recyclable nor substitutable, and thus 
the total demand for this element must be met through the mining, beneficiation, and chemical processing of phosphate ores [16]. There are about 200 varieties of phosphate minerals, of which the Apatite group are the minable ones [16]. The Apatite group can be expressed as Ca5 $\left(\mathrm{PO}_{4}\right)_{3}(\mathrm{OH}, \mathrm{F}, \mathrm{Cl})$ depending on their type, whereas in the natural form, Ca can be replaced by $\mathrm{Sr}, \mathrm{Pb}, \mathrm{Ba}, \mathrm{Na}, \mathrm{Cd}, \mathrm{Mg}, \mathrm{Mn}, \mathrm{Fe}$, while $\mathrm{P}$ can be substituted by $\mathrm{PO}_{4}, \mathrm{Si}, \mathrm{SO}_{4}, \mathrm{As}_{2} \mathrm{CO}_{3}, \mathrm{~V}$, etc. [17]. The extraction of phosphate ores is mostly dominated by surface mining methods. However, surface mining such as strip mining can affect a wide area compared to underground mining, and therefore can be an influential factor concerning environmental degradation [18]. Although some small operations do exist for the recovery and recycling of phosphorus from various other sources, e.g., waste streams, phosphate rock is and will remain the only economically benign source of phosphorus for the production of phosphate-based products. In 2010, total world phosphate rock production exceeded 180 million tons. It will probably continue increasing or at least remain at that amount for three major reasons: the rapid improvement of living standards in developing nations, the ever-growing population, and the demand for green energy crops. For phosphate beneficiation, one or a combination of different methods is employed, of which the most common methods are flotation, de-sliming, and washing. Fig. 1-1 depicts the different processing steps for the production of phosphate rock suitable for the phosphoric acid production plant. Beneficiation methods for the siliceous phosphate ores include anionic flotation of phosphate and anionic flotation followed by cationic flotation for further removal of silica. For carbonaceous phosphate ores, heavy media separation and calcination have been discontinued gradually, leaving fine grinding followed by froth flotation as the dominant separation technology. This technology is mainly comprised of three aspects: 1) direct-reverse flotation where bulk anionic flotation at high $\mathrm{pH}$ is followed by flotation of carbonates under slightly acidic conditions; 2) double reverse flotation, involving flotation of carbonates at slightly acidic conditions followed by the flotation of silica at neutral $\mathrm{pH}$; and 3) direct flotation of phosphate along with the depression of carbonates/silica. Iron-bearing minerals such as hematite and magnetite are often found in igneous phosphate deposits that are commonly removed by magnetic separation $[19,20]$. 


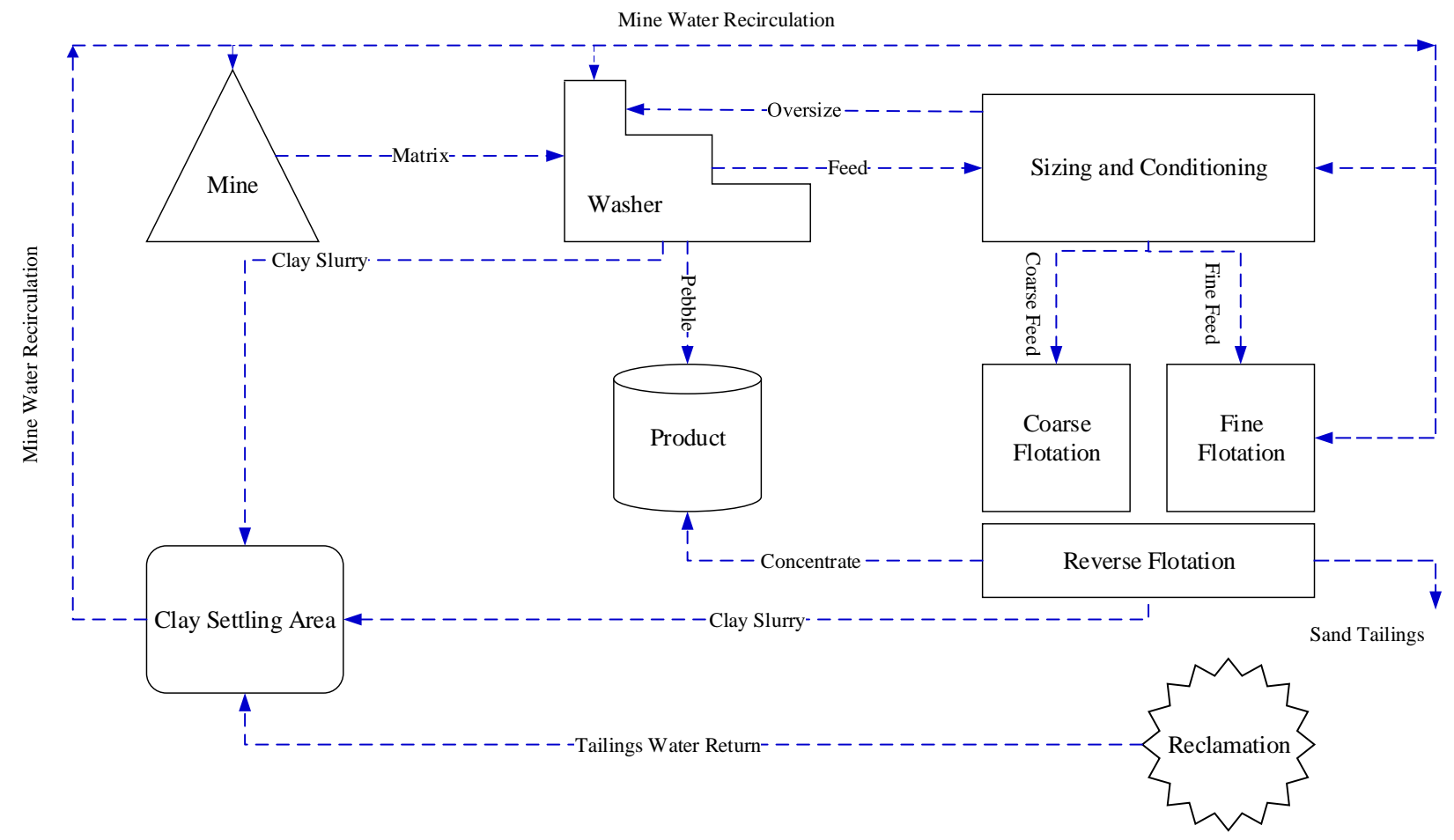

Figure 1-1: Phosphate rock processing flowsheet.

\section{Phosphate process tailings}

Phosphate ore (also known as "matrix") contains three different groups of minerals, which should be separated from each other. These minerals are phosphate minerals, clay minerals, and quartz, or sand. As mined, sand particles and the phosphate are embedded in clay-balls or compacted mud. Prior to separation, all the particles have to be liberated from the matrix [20, 6]. In the beneficiation process, a unit operation is to disaggregate the various particles, which begins as the matrix is flowing through the multi-mile pipeline from the mine to the processing plant. The matrix is exposed to shear forces as it passes through the various centrifugal pumps along the pipeline. These intense shear forces cause a significant portion of the phosphate and sand particles to be liberated from the clay-balls before arriving at the plant. Once arrived at the plant, the primary goal is to finish disaggregating the clay followed by a size separation at $1 \mathrm{~mm}$, which is performed in a washer consisting of a large rotating trammel screen and a few stages of log washer, screens, and hydro-cyclones. The washer is a large structure that receives the matrix, screens it, and then discharges a slurry of liberated clay, sand, and phosphate particles smaller than $1.0 \mathrm{~mm}$, and a pebble phosphate product larger than $1.0 \mathrm{~mm}[6,21]$. The next objective is to remove the clays finer than $0.1 \mathrm{~mm}$, and therefore should be sized at 0.1 
$\mathrm{mm}$ to discard the fine fraction. This can be accomplished using hydro-cyclones with a 50.8$\mathrm{cm}$ (20 in.) diameter. The fraction finer than $0.1 \mathrm{~mm}$, known as waste clay or phosphate slime, is pumped as a slurry of $3 \%$ solids into a clay settling pond $[6,21]$. This slime accounts for at least one-third of the mined ore. The coarse fraction is directed to the froth flotation unit, where phosphate rock is separated from sand tailing. Fig. 1-2 shows the phosphate ore processing streams.

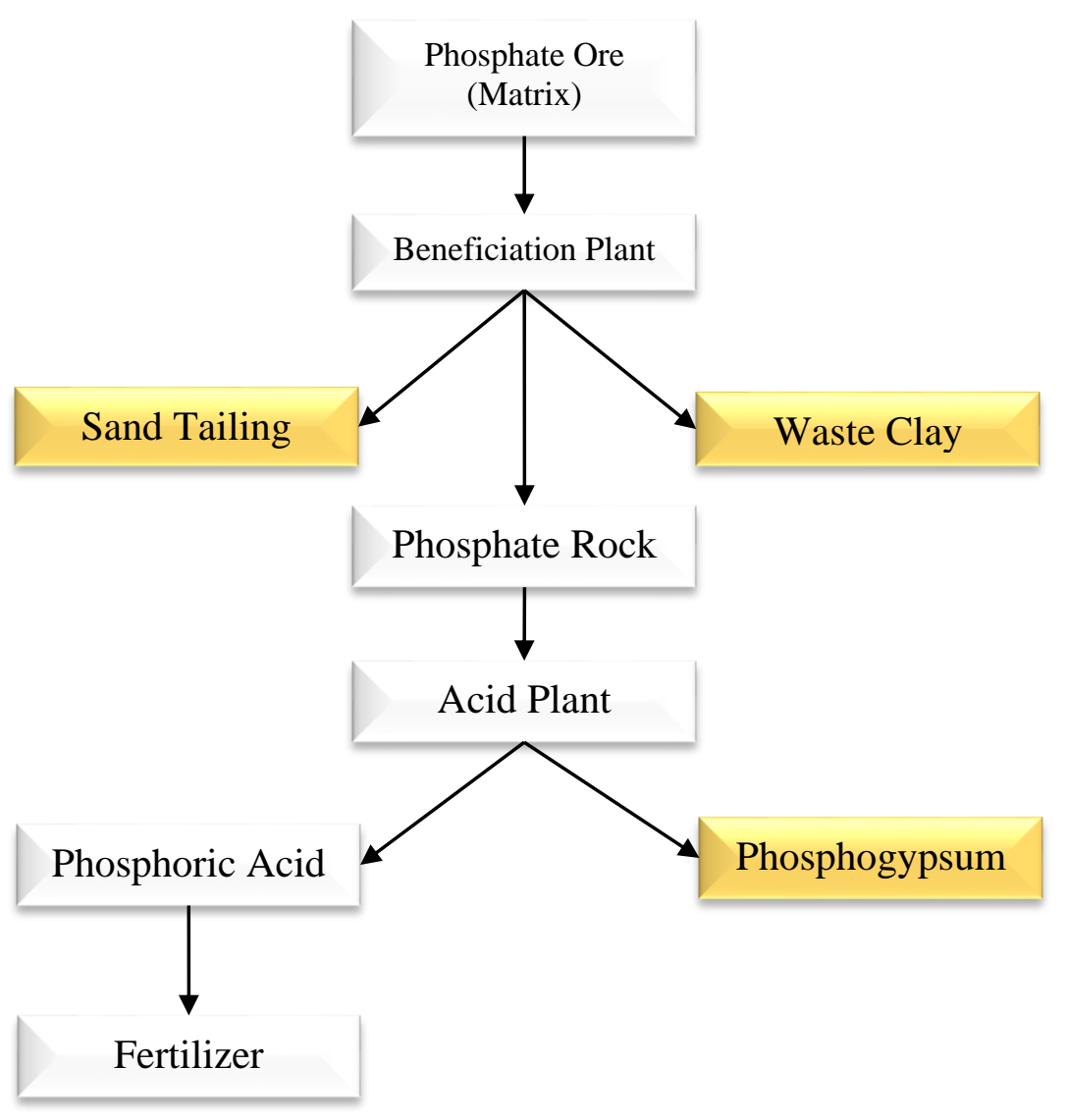

Figure 1-2: Phosphate ore processing streams with waste streams indicated as highlighted.

\section{Waste clay}

\section{Nature and origin}

During the beneficiation of phosphate ore, the fines fraction $(-106 \mu \mathrm{m})$ is separated by cyclones as a dilute (3-5\% solids by weight) aqueous slurry. The solids are a mixture of clay minerals, silica sand, carbonates, apatite, and other finely divided minerals. This slurry (commonly called waste clay) is pumped into large impoundment areas for natural settling. However, because of the colloidal nature and slow consolidation characteristics of such clays, 
large aboveground storage areas are required [22, 23]. Thus, a massive volume of water and large land areas are tied-up by impounding these clays for an extended period. In Florida, for example, more than one ton of waste clay is generated for each ton of phosphate rock product, which translates to over 100,000 tons of waste clay per day or 20 million tons (on dry basis) per year. Nearly 2 billion tons of this slime has been accumulated to date.

\section{Particle size and composition}

Waste clay slurry is perhaps the most difficult process tailing to dewater. Three major factors are attributed to this problem: extremely fine particle size, high clay content, and the electrochemistry of the system. Table 1-1 summarizes the weight $\%$ distribution of the particles in different size fractions for various waste clay samples [20,24]. The fineness of particles in waste clay is evident in Table 1-1. Due to its nature, waste clay hosts various elements in the form of multiple phases. Table 1-2 summarizes the major elemental analysis of some waste clay samples reported by [21] and [25], showing that the main elements in waste clay are $\mathrm{Ca}$ and $\mathrm{P}, \mathrm{Si}, \mathrm{Al}, \mathrm{Mg}$, and $\mathrm{Fe}$.

Table 1-1: Size distribution of some waste clay samples [20, 24].

\begin{tabular}{lllllllll}
\hline Sample & \multicolumn{7}{c}{ Weight $(\%)$ distribution in different size fractions $(\mu \mathrm{m})$} \\
\cline { 2 - 9 } & +105 & $105 * 74$ & $74 * 44$ & $44 * 20$ & $20 * 10$ & $10 * 5$ & $5 * 2$ & -2 \\
\hline Agrico-Saddle Creek & 0 & 3 & 1 & 3 & 4 & 9 & 11 & 69 \\
AMAX- Big Four & 0 & 1 & 9 & 20 & 10 & 9 & 5 & 46 \\
CF-Hardee & 0 & 0 & 4 & 4 & 6 & 7 & 22 & 57 \\
WR Grace-Four Corners & 3 & 2 & 2 & 2 & 4 & 36 & 10 & 41 \\
Mobil-Nichols & 0 & 1 & 8 & 5 & 6 & 12 & 15 & 53 \\
OXY-Suwannee Rive & 3 & 3 & 1 & 1 & 1 & 6 & 11 & 74 \\
\hline
\end{tabular}

Table 1-2: Elemental analysis of some waste clay samples (wt. \%) [21, 25].

\begin{tabular}{cccccccccccc}
\hline Source & P & L.O.I & $\mathrm{Al}$ & $\mathrm{Ca}$ & $\mathrm{Mg}$ & $\mathrm{Fe}$ & $\mathrm{Si}$ & $\mathrm{Na}$ & $\mathrm{K}$ & $\mathrm{Mn}$ & Ref. \\
\hline FL & 12.92 & 32.57 & 6.43 & 22.46 & 4.01 & 1.63 & - & - & - & - & {$[21]$} \\
FL & 14.56 & 35.36 & 8.75 & 22.04 & 1.79 & 2.87 & - & - & - & - & {$[21]$} \\
FL & 6.97 & 43.27 & 4.93 & 14.82 & 4.23 & 1.21 & - & - & - & - & {$[21]$} \\
FL & 6.09 & 48.51 & 4.88 & 15.86 & 5.36 & 2.01 & - & - & - & - & {$[21]$} \\
Vietnam & 32.80 & 2.23 & 2.94 & 41.52 & 0.25 & 1.37 & 16 & 0.04 & 0.31 & 0.43 & {$[25]$} \\
\hline
\end{tabular}

The total phosphorus contents and fractions in the clay samples can be determined by the extraction procedure following the Williams procedure of CRM BCR-684, which is one of the 
most widely used methods for the fractionation of phosphorus in soils and sediments $[25,26]$. This protocol characterized the following five types of phosphorus: total phosphorus (TP), inorganic phosphorus (IP), apatite phosphorus (AP), non-apatite inorganic phosphorus (NAIP), and organic phosphorus (OP) [26]. Table 1-3 presents the phosphorus types in a waste clay sample showing that the apatite phosphorous is the major form [25]. This is further supported by X-ray diffraction (XRD) spectra in a study conducted by Hwang et al. (2008b), suggesting the presence of fluorapatite $\left[\mathrm{Ca} 5\left(\mathrm{PO}_{4}\right)_{3} \mathrm{~F}\right]$ as the main P-bearing mineralogical phase in the waste clay [27].

Table 1-3: Phosphorus types in a waste clay sample (mg/kg) [25].

\begin{tabular}{ccccc}
\hline TP $(\mathrm{OP}+$ IP $)$ & OP & IP (AP+NAIP) & AP & NAIP \\
\hline 1808.3 & 173.33 & 1611.1 & 1543.4 & 46.3 \\
\hline
\end{tabular}

\section{Mineralogy}

Waste clay constituting minerals can be classified as clay and non-clay minerals. Major non-clay minerals are apatite, quartz, and dolomite, while clay minerals include smectite (montmorillonite), kaolin, and illite. Because of their complexity, accurate quantitative mineralogical analysis on waste clay is very challenging. Semi-quantitative mineralogical studies have shown that clay mineral compositions vary significantly from one processing unit to another. Another noticeable phenomenon is that with one exception, dolomite minerals are a substantial part of the slimes, posing another challenge even after the successful removal of clay minerals [21, 28-30].

Clay minerals, generally, do not appear in the XRD patterns of the samples, e.g., waste clay containing both clays and non-clay minerals. Different reasons may cause such observations, e.g., the interference of basal (00/) reflections posed by the presence of non-clay minerals, heterogeneity in both grain size and composition of the samples, and the amount and thickness of the samples mounted for XRD [31,32]. Thus, one solution is to separate clays from the non-clay minerals by sieving samples at a small enough screen size (e.g., $5 \mu \mathrm{m})$. For this purpose, samples should be lightly crushed to fine fractions, but not pulverized as nonclay minerals can also be reduced to clay sizes, and therefore become impossible to separate from the clays. Gentle crushing breaks apart the soft clays while keeping harder non-clays intact for easier removal [31]. Clay mineral peaks are generally distinguished by the width 
halfway up the peak (i.e., the full width at half maximum, FWHM). Well-defined crystalline minerals have sharp peaks while clays, which range from crystalline to non-crystalline, produce broad peaks with noticeable width on both sides. These broad peaks make it easy to pick out which peaks are contributed by clays. These peaks can be compared to known diffraction patterns for better identification, but if some peaks are broader than others, it is likely that multiple clays are present [31-33].

Florida Industrial and Phosphate Research Institute (FIPR) [29] and Lamont [28] characterized waste clays or "Phosphate Slimes" of Florida produced during the mining of phosphate rock. In general, montmorillonite and attapulgite (a hydrated Mg-silicate) were identified as the major clay minerals, attapulgite being primarily responsible for the very poor settling characteristics of the slimes. The prediction of the metallurgical behavior of phyllosilicate bearing ores is often complicated by difficulties in phyllosilicate mineral identification and characterization. The mineralogical characterization of these minerals has been a longstanding challenge. The application of auxiliary techniques, such as thermal and acid treatment, can be used to resolve some of these problems [34-37]. The identification of phyllosilicate minerals may be best achieved by using a combination of mineralogical (e.g., XRD, Mossbauer spectroscopy, Mineral Liberation Analysis (MLA), Differential Thermal Analysis spectroscopy (DTA)), colloidal (e.g., atomic force microscopy, zeta potential, settling tests, and rheology) and macroscopic (e.g., gamma ray logging, tri-axial shear strength) analytical techniques. However, such a comprehensive analysis may prove costly. Kaminsky et al. (2006, 2009) have extensively characterized clays [38, 39]. They used X-ray diffraction of oriented clay slides and random powder samples to quantify the clay minerals in the oil sands ore. They also used transmission electron microscopy lattice fringe imaging, and electron diffraction to evaluate the fundamental particle size of the clay minerals. Kaminsky et al. have shown that the mean fundamental particle thicknesses of kaolinite and illite in the minus $2 \mu \mathrm{m}$ fraction are less than $10 \mathrm{~nm}$, which would explain the large surface areas reported for these clays in the literature. A study by [21] on four waste clay samples showed that the approximate concentration of apatite and wavellite is $27.6 \%$ and insignificant (almost zero), respectively. This conclusion is very encouraging and extremely important in justifying the pursuit of phosphate recovery from waste clays. If the phosphate existed primarily as aluminum phosphates, it would make no sense to separate phosphate minerals from gangue, because the 
concentrate generated could not be used as a feed for phosphoric acid production. It should be emphasized that the current waste clays contain substantially less palygorskite than the past slimes, which is another encouraging sign because palygorskite is more colloidal in nature and more difficult to separate from phosphate minerals [21].

Characterization studies of 15 samples of Florida phosphate slimes performed by Lamont et al. (1975) [28] indicated that, although the physical, chemical, and mineralogical composition of phosphate slimes are highly variable, the clay mineral Attapulgite (Mgaluminum phyllosilicate) was determined as a common factor controlling several of the physical characteristics of the slimes, including the settling rate, terminal solids, viscosity, percent solids of filter cake, and flocculent requirements. It should be highlighted that whether or not clays are "mineral processing nightmare" also depends on their type and concentration. However, this statement is certainly more applicable to swelling clays [40]. As discussed earlier, mineralogical characterizations have shown that montmorillonite, kaolin, and illite are the main clay minerals present in waste clay, and therefore a profound insight into the crystal structure and behaviors of these minerals can help better understand the properties of waste clay.

\section{Crystal structure of the clay minerals}

Clay minerals fall within the phyllosilicate mineral family that are so named because they typically display a platy/leafy habit, reflecting their structure. The faces and edges of phyllosilicates carry different electrical charges, making these particles electrostatically anisotropic. The faces (or basal planes) tend to be negatively charged, while the edges carry a charge that alters from positive to negative as a function of $\mathrm{pH}$ [41]. Montmorillonite, kaolinite, and illite are the three main clay minerals present in waste clay, and thus it is worthwhile to study the crystal structure and crystallographic properties of these minerals. In the crystal structure of kaolinite, a two-layer (tetrahedral-octahedral, T-O) clay, the top surface is a tetrahedral silica surface. The bottom surface is a 'gibbsite layer' of exposed Al-OH groups. Thus, kaolinite is confined by two different types of surfaces that produce the overall electrostatic dipole [42, 43]. Montmorillonite, as another waste clay, is a member of the smectite group (di-octahedral and tri-octahedral planar 2:1 clay minerals with intermediate layer charge $(\chi)$ values ranging from 0.2 to 0.6 per formula unit). This clay is strongly hydrated, 
and water is a significant component of its structure. Illite is a non-swelling clay with a 2:1 structure of silica tetrahedron (T)-alumina octahedron $(\mathrm{O})$-silica tetrahedron $(\mathrm{T})$ layers. The space between this T-O-T sequence of layers is occupied by poorly hydrated potassium cations, which are responsible for the absence of swelling. The cation-exchange capacity of illite is smaller than that of montmorillonite but higher than that of kaolinite. Fig. 1-3 summarizes the crystal structure and scanning electron microscopy (SEM) images of the three aforementioned clay minerals constituting waste clay. Fig. 1-3-a shows the platy morphology of kaolinite. Fig. 1-3-b shows the characteristic formation of pores on the surface of montmorillonite, bringing about its swelling behavior [44]. Fig. 1-3-c shows interstratified illite, the form in which most phyllosilicate minerals exist, resulting in more complex mineral systems. The most common cations found in natural clay minerals are $\mathrm{Ca}^{2+}, \mathrm{Na}^{+}, \mathrm{Mg}^{2+}$, and $\mathrm{K}^{+}$; however, the charge can be balanced by any positively charged ion, including $\mathrm{H}_{3} \mathrm{O}^{+}, \mathrm{Al}^{3+}, \mathrm{Fe}^{3+}{ }^{2+}, \mathrm{Cs}^{+}, \mathrm{Sr}^{2+}$, or positively charged organic species. A distinguishing feature of the 'common' cations is that all have large negative enthalpies of hydration, meaning that $\mathrm{H}_{2} \mathrm{O}$ molecules are attracted to these interlayer cations resulting in the intrinsically high affinity of $\mathrm{H}_{2} \mathrm{O}$ for smectites [43]. In solutions, clay particles are charged so that broken edges of sheets can be positive if the breakage occurs at silica atoms, negative if it happens at oxygen atoms or, more often, both. A planar negative charge can develop through the disassociation of the attached cations. The platelets also have an electrostatic attraction for each other. The dissociation of cations results in the development of a negative surface charge, and consequently, a double layer around particles. The balance between repulsive energy of negatively charged clay particles, van der Waals attraction, and electrostatic attraction-repulsion interactions give rise to flocculation and aggregation of montmorillonite particles. At high ionic strength, solids content and temperature suspension (as those encountered in classic clay slurries in Florida), repulsive forces between platelets are reduced and subsequently link up takes place (edge to face or edge to edge or face to face) $[45-47]$.

Traditionally, the face surfaces are believed to carry a permanent structural negative charge due to isomorphous substitution of higher valence ions $\left(e . g ., \mathrm{Si}^{4+}\right)$ with lower valence ions (e.g., $\left.\mathrm{Al}^{3+}\right)$ [48-50]. However, advances in electro-kinetic, streaming potential and direct force measurements have revealed that the basal faces also show ionization trends, not inconsistent with the $\mathrm{pH}$-dependent hydrolysis of silicon in the surface plane. This is particularly the case 
in the $\mathrm{pH}$ regime 4-8, suggesting the presence of a small amount of $\mathrm{pH}$-dependent negative charge [51]. The exact contribution to the face charge of layered silicates due to either isomorphous substitution or ionization is not clearly understood, and more detailed research is required. However, it can generally be assumed that the charging on the phyllosilicate minerals' basal plane is largely due to isomorphous substitution. It results in a negative charge, whose change with $\mathrm{pH}$ may be attributed to the $\mathrm{pH}$-dependent ionization of exposed silanol groups on the surface. The charge derivation on the edges has not been conclusively established either but is thought to be due to the ionization of exposed hydroxyl groups, dependent on solution $\mathrm{pH}$. Therefore, in an acidic solution, the edge is expected to carry a positive charge, while in an alkaline solution, the edge is negatively charged. It is also noteworthy that the effective surface charge also depends on the ions adsorbed from the solution, which is influenced by the surface charge density and the ions available from the compounds used to adjust the $\mathrm{pH}$. While there is still much debate over the derivation of charges on different surfaces, there is common agreement that there is a charge disparity between the edges and faces, with the faces carrying a predominantly negative charge while the charge on the edges changes from positive to negative. This charge heterogeneity results in irregular stacking. Although there exist different schools of thought regarding the prevalent modes of particle interaction, three main modes have been identified, namely, edge-face (EF), edge-edge (EE), and face-face (FF), each with different implications on the suspension flow behavior [48, 5259]. FF association leads to the formation of lamellar structured aggregates with low yield stress requirements, while EF and EE associations lead to voluminous three-dimensional structures, which exacerbate the colloidal suspension behavior and give rise to more complex colloidal behavior and processing difficulties $[60,61]$. 

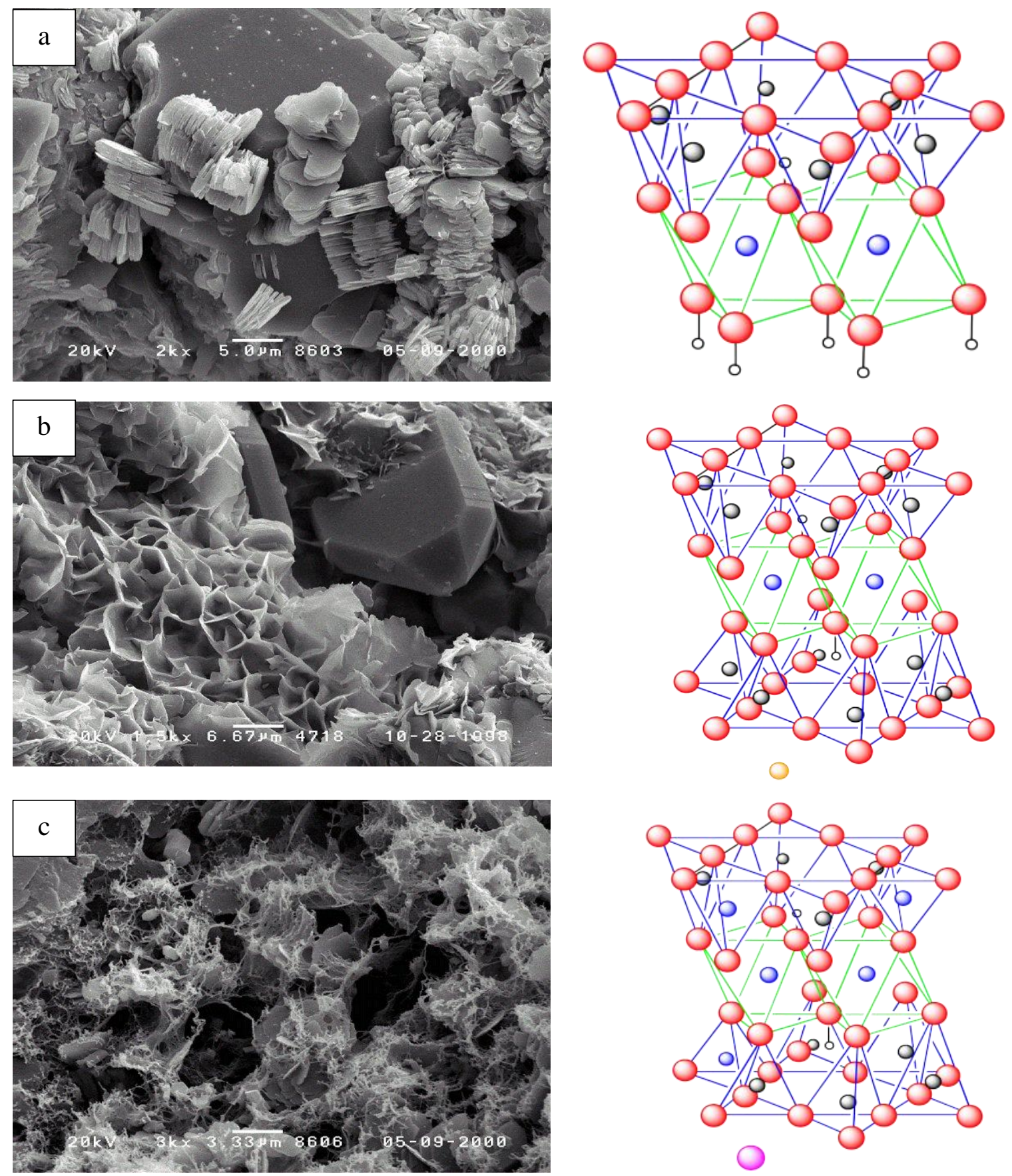
Oxygen
Aluminum/ Magnesium
- Silicon
O Hydrogen
Potassium
Sodium/ Calcium

Figure 1-3: Summary of SEM images and structures of (a) kaolinite, (b) montmorillonite, and (c) illite (borrowed from http://webmineral.com/ (copyright: OMNI Laboratories, Inc)).

Likely, these structures co-occur in suspension, resulting in 'hetero-coagulated' aggregates. The negatively charged surfaces of 2:1 clays attract positively charged water 
molecules, allowing them to enter between the layers [40]. Swelling is related to the hydration of clays, but not all clays swell when hydrated. For example, while kaolinite shows little or no swelling on hydration, montmorillonite considerably swells when water is present (up to $1500 \%$ [62]). These differences in the swelling characteristics of different clays are related to their chemical compositions and structures. The difficulty with clay minerals stems from their ability to change from one form to another (interstratification). They typically comprise alternate layers of other clays in either ordered and regular or highly unordered and irregular sequences. In such cases, mineral identification is difficult, as they tend to mask each other. A summary of the main differences in the mineral structure and para-genesis of different phyllosilicate groups is given in Table 1-4 [44].

Table 1-4: A summary of structure, para-genesis, and polymorphs of different major phyllosilicate groups present in waste clay [44].

\begin{tabular}{llll}
\hline Group & Structure & Para-genesis & Polymorphs \\
\hline Kaolinites & T-O & $\begin{array}{l}\text { Alteration of } \\
\text { feldspars micas and } \\
\text { other silicates, } \\
\text { usually in acid } \\
\text { rocks. }\end{array}$ & $\begin{array}{l}\text { Kaolinite (platy), } \\
\text { halloysite } \\
\text { (cylindrical), } \\
\text { dickite, nacrite, } \\
\text { allophane, imogolite } \\
\text { (rarer polymorphs) }\end{array}$ \\
& Formed by a variety \\
of precursors, e.g., \\
Illites
\end{tabular}

\section{Engineering Properties}

The engineering properties of interest for waste clay are strength, compressibility, and permeability. These properties are crucial as they control the rate at which waste clay consolidates under its own weight. Test results reported by Garlanger (1982) for samples of clay, sand tailings, and a sand-clay are summarized as the following [63]: 


\section{Permeability}

Permeability is defined as the rate at which water flows through a soil sample along a length, $\mathrm{L}$, when the difference in water level across the sample, $\mathrm{h}$, is equal to $\mathrm{L}$. Test results at different void ratios showed that waste clay has a permeability several orders of magnitude lower than that of the sand tailings. The tremendous reduction in permeability is observed when one unit of clay is mixed with two units of sand to form a sand-clay mixture.

\section{Compressibility}

Compressibility is defined as the change in void ratio divided by the change in applied pressure, $a_{v}=\Delta e / \Delta p$, which is determined by loading a soil sample and measuring its change in height. Results from compression tests showed that the compressibility of the sand is very small compared to that of waste clay. This is indicated by the relative magnitude of the changes in void ratio, $\Delta e$, for each soil under a pressure change of 100 psf. The change in void ratio for the clay, sand-clay mix, and sand is $0.98,0.32$, and 0.01 , respectively. The addition of one unit of the clay to two units of sand considerably increases the compressibility of the sand-clay mix, although it is still less compressible than the clay alone.

\section{- Shear Strength}

Shear strength is defined as the resistance to shear or sliding. Test results showed that the resistance to sliding for the clay is less than half of that for the sand. At the same applied pressure, the strength of the sand-clay mixture is essentially the same as that of waste clay. However, because sand-clay mixtures are heavier than clay alone, the strength at a given depth in a reclamation area is higher for the sand-clay mixtures.

\section{- Consolidation}

The centrifuge-modeling technique is a powerful tool used to predict the field consolidation of waste clays [64-66]. In this technique, a physical model is built with an at-rest weight of up to $1,000 \mathrm{lb}$, which is mounted in a large centrifuge (radius of 12 to $15 \mathrm{ft}$ ) [67]. Slower rates of consolidation are attributed to a higher content of smectite and/or palygorskite clays. As well, waste clays containing palygorskite and montmorillonite own the slowest settling rate compared to those containing other clay minerals. However, the fastest settling is generally associated with samples of high dolomite content [67-69]. 


\section{Challenges}

The presence of clay minerals leads to difficulties in processing units, such as the froth instability in a flotation process, which is related to the swelling behavior, an increase in pulp viscosity, overconsumption of reagents, slime coating, and mechanical entrainment of clays [46]. Some contemporary definitions have categorized 'clay' minerals as particles with a size less than $20 \mu \mathrm{m}$ and by their distinctive non-spherical particle shapes [44]. At these colloidal particle sizes, surface specific area is larger and the influence of surface charge is greater. The likelihood of fine gangue entrainment to the concentrate and slime coatings' poor settling rates are enhanced; the residence time is also increased [70]. When present in an ore, clays enter the processing circuit because of their ultrafine sizes making them virtually unavoidable [44]. In general, the problems associated with phyllosilicate-bearing ores are physicochemical, impacting all aspects of the processing circuit, with inefficiencies arising from slurry transportation and beneficiation to dewatering and disposal. Table 1-5 presents a summary of some of the problems typically encountered when treating clay-bearing ores, which also highlights the ubiquitous effects of these minerals throughout the processing circuit [71].

Table 1-5: Summary of the typical problems posed by clay-bearing ores to the processing circuits (modified from [71]).

\begin{tabular}{|c|c|c|}
\hline Beneficiation & Tailings treatment & Comminution \\
\hline $\begin{array}{l}\text { Restricted percolation } \\
\text { during leaching }\end{array}$ & Poor water recovery & $\begin{array}{l}\text { Clays stick to equipment } \\
\text { (conveyors, idlers, } \\
\text { screens) }\end{array}$ \\
\hline Preg robbing & Low wall stability & $\begin{array}{l}\text { Reduced crushing } \\
\text { capacity }\end{array}$ \\
\hline $\begin{array}{l}\text { Decreased hydrodynamic } \\
\text { performance }\end{array}$ & Blocked drainage holes & Decreased throughput \\
\hline Decreased selectivity & $\begin{array}{l}\text { Increased pulp residence } \\
\text { time }\end{array}$ & Decreased pump capacity \\
\hline Impeded flotation kinetics & Decrease permeability & $\begin{array}{l}\text { Decreased grinding } \\
\text { efficiency }\end{array}$ \\
\hline Slime coating & Increased settling time & \\
\hline Poor froth stability & & \\
\hline Low filtration rates & & \\
\hline
\end{tabular}

Of particular interest is the effect of clay minerals on the flotation performance of mineral suspensions. The characteristic high surface area of these minerals makes them highly reactive and responsive to changes. It has been observed that the presence of aluminum-silicate and 
Mg-silicate minerals in froth flotation affects performance through (i) slime coating on the mineral surfaces as well as air bubbles [72], (ii) higher reagent consumption, poorer selectivity, and impeded flotation kinetics [71], (iii) entrainment of large quantities to the concentrate during both roughing and scavenging stages [73-75], (iv) increasing pulp viscosity [70, 76], and (v) increasing or decreasing the froth stability [77-79]. The exact mechanisms of clay interactions with other minerals during flotation have not been clearly identified, but are thought to be largely due to their anisotropic surface charge properties, high surface area, complex suspension rheology, and hydrophobicity effects [22,31]. It is worth noting that even with such a broad understanding of this class of minerals' effects on process performance, phyllosilicate minerals behave differently and in some cases their behavior may vary from one ore type to another. Therefore, the effects of these minerals may be ore-specific [44]. Therefore, waste clay as a process stream hosting various types of these minerals poses serious processing and disposing difficulties to the phosphate industry owing much to the presence of clay minerals up to $50 \mathrm{wt} . \%$ of its content.

\section{Dewatering and disposal}

When dispersed in an aqueous media, the clay minerals exhibit a low dewatering rate due to the formation of porous structures by inherently charged clay layers in which a large amount of water is retained $[80,81]$. The Florida phosphate industry, as an example, currently produces more than $80 \%$ of the total U.S. supply of phosphate rock. The production of this critical mineral is accompanied by the generation of large quantities of dilute waste clays. The poor dewatering characteristic of waste clay dispersions is a major challenge for the phosphate mining industry. The suspensions, containing initially 3-5\% solids, are pumped to large impoundment areas known as clay settling areas [82]. Hindered settling and self-consolidation of these clays requires as much as 25 years to reach a $40 \mathrm{wt}$ \% solid content for which water recovery becomes possible [83]. The dispersions are pumped into large manufactured ponds for natural settling, occupying a considerable portion of the mined land [84]. In central Florida, for example, large amounts of water (mostly groundwater) are consumed for the beneficiation process (i.e., separating phosphate rock from clay and sand); the volumetric flow rate of waste clay dispersions produced from beneficiation is about 130,000 gal per minute (GPM) (i.e., 8.2 $\mathrm{m}^{3} / \mathrm{s}$ ) at a solid content of 2-3 wt.\%. Settling areas for such a massive volume of waste clay account for over $30 \%$ of the total mined land in Florida [85]. The disposal of waste clays has 
been a problem to the Florida phosphate industry since the 1920s and today represents probably one of the mining industry's largest waste-handling problems. The phosphate industry eventually found that the most practical way to handle the clays is to store them in large impoundments where they are allowed to slowly dewater naturally. This method was chosen on pragmatic and economic grounds; it worked at an acceptable cost [86]. As the industry underwent its vast expansion during the last decade, the clay management problem grew in size and importance. At the same time, the industry came under increasing attack from environmental interest groups and increasing attention from local, state, and national regulatory agencies. The conventional clay settling areas or ponds presented several problems. The storage of waste clays behind dams raised the ever-present possibility of a dam failure. The land used for clay storage areas meant land withdrawn from other uses and the loss of considerable acreage in a region where land values are increasing rapidly. Immense amounts of water were tied up in the clays that were desired for alternative uses, such as agricultural, residential, industrial, and even for further phosphate mining and processing [86].

The phosphate industry, as well as the former US Bureau of Mines, private consultants, and university researchers, have undertaken extensive research and development programs to seek a solution to the clay disposal challenge. The industry has been motivated both by a public spirit and by the economic imperative to reclaim expensive land and water for alternative uses. The further inducement was provided by the legal imperative to reclaim after the enactment of the Florida Severance Tax Act of 1972 [82, 86]. Growing public awareness of environmental issues has caused an increased interest in the waste clay problem and has led to the involvement of environmental and regulatory groups from outside the industry, which all have increased the pressure upon researchers for an economic, simple, quick, and environmentally safe dewatering technique $[87,88]$. Thereby, research and investigations aimed at finding an efficient solid-liquid separation method for the disposal of waste clay have been motivated since the1950s by the need to reduce both the water consumed in the mining and beneficiation operations and the land area occupied by clay storage [83]. In order to reduce both the land area occupation and water consumption for the settling process, different methods have been proposed by researchers, which vary greatly in efficiency and feasibility [86, 89, 90]. The proposed methods included the Freeze-Thaw technique, dewatering with Moving Screens, Sand-Clay Sandwich Process, Andco Process, Sand Wick (sand column drains), In-Line Sand- 
Clay Mixing, Sand-Clay Mix using the Enviro-Clear Thickener, Dredge-Mix Process, Dredge Process, Sand Spray Process, Gardinier Inc. Process, and Rotary Trommel (developed by the bureau of mines). These techniques are documented in the literature [67, 86-88, 91-117] with a detailed summary available in [91]. However, the complexity, cost, and energy consumption of these methods have prevented their on-site implementation. Technical practicality along with the extreme variability of the clays themselves have proven to be the biggest obstacle to developing universally effective dewatering techniques. Because of the widely variable nature of clays throughout the phosphate district and even within one mine, successful methods used for dewatering one type of clays failed tests on the other. Thus, dewatering processes were found to be highly site-specific. Some efforts have proved experimentally and further by mathematical models that the use of an electric field (electro-kinetic process) can enhance the separation of water from waste clay suspensions [83, 85, 101]. Electro-kinetic dewatering achieves separation based on the particle's inherent charge properties. In this process, an external electric field is applied across the dispersion driving the negatively charged clay particles to the anode (electrophoresis). Once a porous structure is formed, the electric field further induces the migration of water out of the porous media to the cathode (electro-osmosis) $[99,118]$. These two phenomena together contribute to a condensed clay structure and clear water. This process is considered as a promising method for water separation from clay dispersions in the mining industry. Various researches over the past few decades have been focused on the electro-kinetic dewatering process to identify potential performance improvements [83-85, 90, 101, 118]. Most recently, Peng et al. (2018) utilized SEM to study the impact of the electro-kinetic dewatering process on clay fabric microstructure to determine its water content [118]. They suggested that the formation of honeycomb clay microstructures is responsible for poor settling and an acidic environment promoted a more voluminous honeycomb with a higher water content. Under an electric field, a less-ordered structure than a honeycomb forms during the electrophoresis separation near the region where the $\mathrm{pH}$ is above the point of zero charge. This insight, as claimed by [118], can help improve the performance of the electro-kinetic separation process. Tao et al. (2010) investigated on the pilot-scale feasibility of the Deep Cone Thickening (DCT) process to thicken waste clay to a paste, without filtration, for mine backfilling or surface stacking [119]. They studied the effects of key operating parameters, including feed rate, sand addition rate, flocculent type and dosage, 
bed depth. This study demonstrated the simultaneous production of an underflow paste product and a clear overflow water stream with an overflow water recovery and underflow solids recovery of more than $88 \%$ and $98 \%$, respectively, with a residence time of as low as two hours.

\section{Policies and regulations}

The key to understanding the association between environmental pollution and phosphate rocks lies in appreciating the mining and processing effect of phosphate ores. Phosphorus is normally produced by mining and beneficiation of phosphate ores [120, 121]. Mines produce large amounts of waste including toxic metals and radioactive elements [122, 123]. Most of the impacts are being reflected in the form of changes to local hydrology, water contamination, water consumption, air pollution, and human risk [124, 125]. During the 1970's, the state of Florida enacted an aggressive program of environmental regulation. The clay waste material, so-called phosphate slimes, has been perhaps the most persistent of the difficulties that have faced the mining industry in the era of large-scale activity, dating from the 1950's [16, 126, 127]. Up to sixty percent of the mined land may be dedicated to waste clay disposal, creating what may be perceived as a monumental land use problem. Frequent dam failures leading to serious water pollution incidents, caused the implementation of strict rules to eliminate the above-grade storage of waste clays [126, 127]. Also at issue is the radionuclide content of waste clays. The U.S. Environmental Protection Agency (EPA) undertook an extensive study of the effect of radionuclides associated with phosphate mining in 1975. Findings indicated that with few exceptions, relatively low levels of exposure would be expected and that the health hazard is minimal. However, it was not zero, and consequently, it remained a factor that must be taken into account $[128,129]$. The regulation was first brought to bear in the late 1960s as a result of the spills. A slimes dam failure at the Sidney Mine in 1963, near Brandon, had turned the Alafia River brownish-white $3.2 \mathrm{~km}$ (2 miles) into the Gulf of Mexico. The Pollution Control Board, the predecessor of the Department of Environmental Regulation and the Department of Environmental Protection (DEP), sued the mine for damages but lost. Having lost a case, the state drafted the first earthen dam for phosphate waste rule. This made engineering design a requirement, as well as regular inspections. The first set of rules regarding waste clay pond construction was adopted in 1969. The "cast" method was, at the time of rule adoption, the predominant method by which clay ponds were constructed. In 1971, an 
estimated 3.79 GL (1 billion gallons) of waste clay slime spilled into Whidden Creek and then down the Peace River. Charlotte Harbor turned the color of chocolate milk. This prompted the revision of Chapter 17-9 Florida Administrative Code (FAC) to roughly its current form. The only substantial change to the previous rule was the requirement for positive seepage-control features $[130,131]$. As discussed earlier, clay wastes produced in the phosphate industry are generally colloidal and fine bringing about extremely poor settling behavior in the absence of polymeric assistance $[132,133]$. The settling of these clays is essential as an accidental discharge can substantially impact the wildlife and ecosystem. The EPA has referenced cases where the discharge of water can result in fines in the tens of millions of dollars, and at times causing the processing plants shut down, depending on the volume and quality of the discharged water $[134,135]$. The turbidity discharge criteria will vary from state to state. Florida's DEP has listed a turbidity maximum of 29 NTUs, or $60 \mathrm{mg} / \mathrm{L}$ total suspended solids, above the natural background condition [136-138].

\section{Values}

\section{Rare earth elements and phosphorous loss}

Waste clay not only creates one of the most challenging disposal problems but also represents a tremendous loss of $\mathrm{P}_{2} \mathrm{O}_{5}$. In some operations, about one-third of the $\mathrm{P}_{2} \mathrm{O}_{5}$ mined ends up in waste clay. This loss has been repeatedly verified by many researchers [139]. Based on the phosphate matrix analysis in 2001, waste clay with a $9 \%$ grade of $\mathrm{P}_{2} \mathrm{O}_{5}$ makes up about 20 wt.\% of the matrix. This means that about 3.27 million tons of $\mathrm{P}_{2} \mathrm{O}_{5}$ (27\% of annual production) are being wasted each year, assuming $100 \%$ recovery of phosphate in the pebble, $85 \%$ recovery of phosphate in the flotation feed, and Florida production of 40 million tons per year of phosphate rock at a grade of 30\% [139]. As Florida's phosphate reserves diminish, it becomes more imperative to recover the phosphate values from these slimes. Another prominent value being lost in waste clays of phosphate industry is REEs comprising 15 lanthanides plus $\mathrm{Y}$ and Sc that are normally contained in the phosphate rocks in various contents from 0.03 to $1 \mathrm{wt}$ \% [140, 141]. In the phosphate rock processing, most of the REEs from the phosphate ore (over 85\%) end up in the wastes (waste clay, flotation tailings, and phosphogypsum (PG)). Because these wastes have very fine grain sizes and complex mineralogical compositions, the reprocessing of them for REEs' economic recovery becomes very challenging [142]. Research has been carried out to verify whether the wastes might be 
useful as a source for REEs [143-151]. However, the extraction of REEs and other valuable elements from these wastes in phosphate processing has not been industrially realized so far [152]. A study by Zhang et al. (2018) [142] indicated that REEs during a phosphate ore processing are distributed approximately $40 \%$ in waste clay, $10 \%$ in amine tails, $38 \%$ in PG, and $12 \%$ in phosphoric acid, but how the REEs occur in these products was not fully investigated. Yang et al. (2019) studied rare earth occurrences, including the REE-bearing phases and their distributions, measured by rare earth oxides (REOs), in the processing streams of a phosphate ore by using MLA, the mineral liberation analysis, and EPMA, the electron probe microanalysis, as depicted in Fig. 1-4 [153]. They concluded that during the processing, $26 \%$ and $62 \%$ of the total rare earth oxide (TREO) from the phosphate ore end up in the beneficiation tailings and the PG, respectively. In the beneficiation tailings (i.e., waste clay and flotation tailings), the REEs mainly occur in the phases of apatite, monazite, allanite and pyrochlore. Fig. 1-5 presents the REO concentrations in the REE-bearing phases of the phosphate ore processing tailings obtained via the MLA+EPMA technique [153]. Laurino et al. (2019) reported that among the different Florida phosphate ore processing streams, the highest levels of REEs occur in phosphate rock, followed by waste clay, amine tailings, and PG, as depicted in Fig. 1-6 [149].

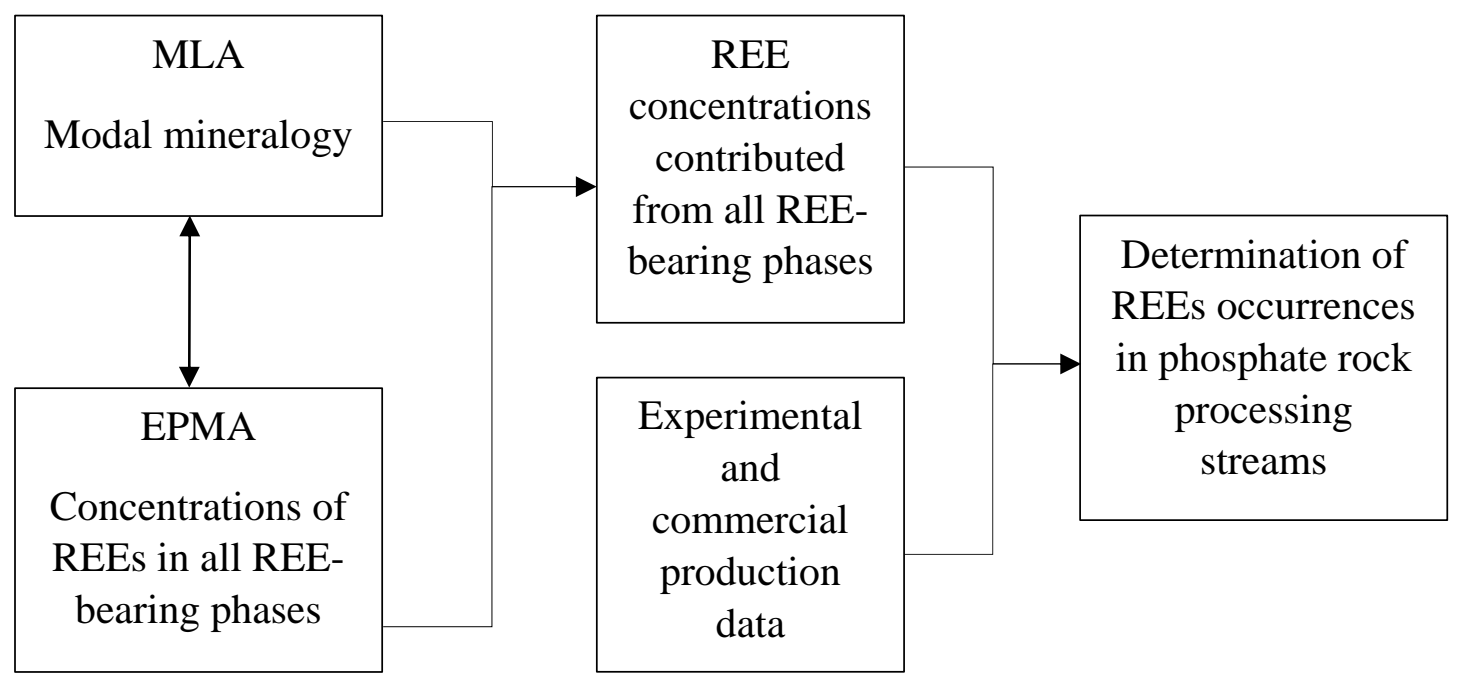

Figure 1-4: The analytical steps and strategy for determining rare earth occurrences in phosphate rock processing streams (modified and reproduced from [153]). 


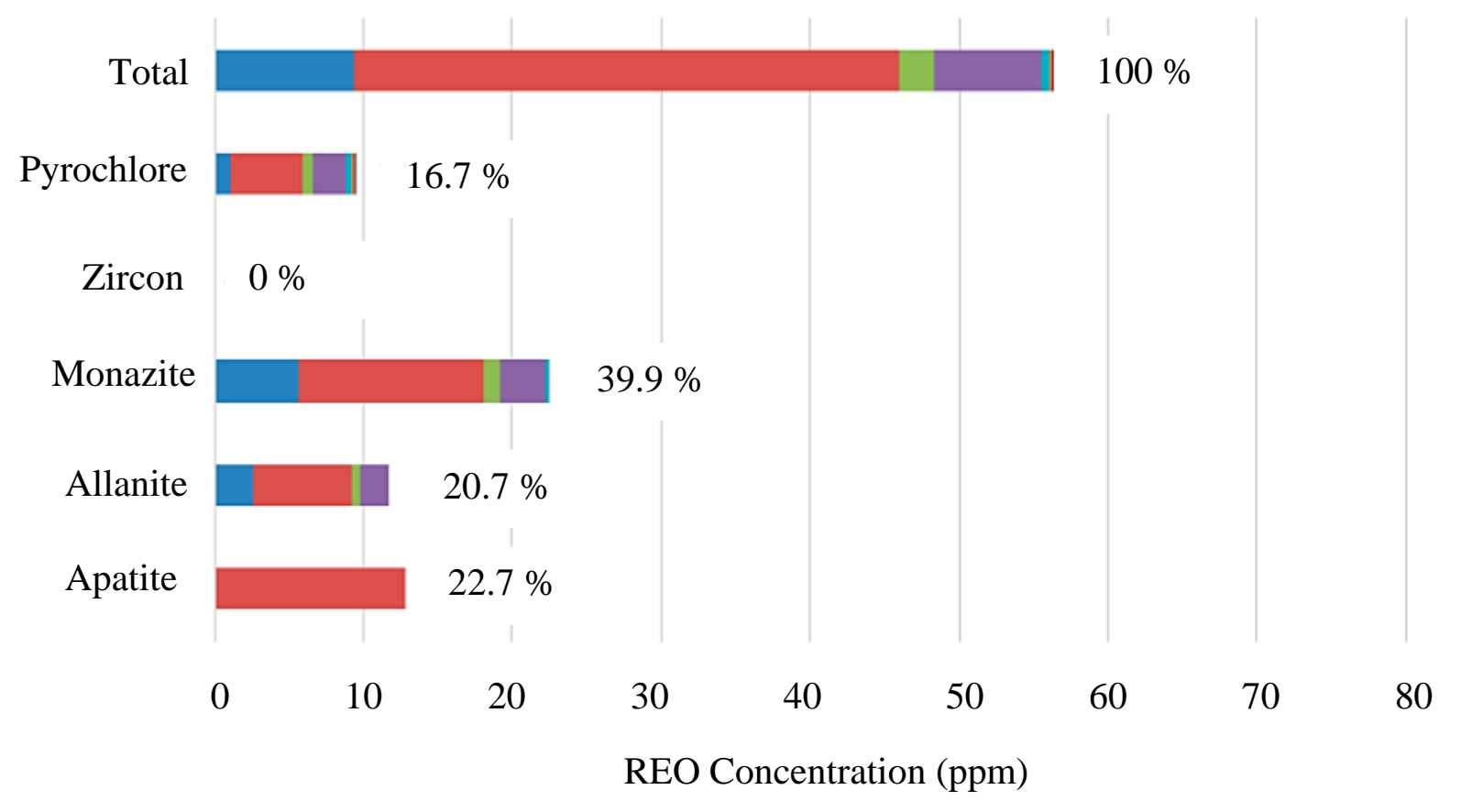
$\mathrm{La}_{2} \mathrm{O}_{3} \square \mathrm{Ce}_{2} \mathrm{O}_{3} \quad \square \mathrm{Pr}_{2} \mathrm{O}_{3} \square \mathrm{Nd}_{2} \mathrm{O}_{3} \quad \mathrm{Sm}_{2} \mathrm{O}_{3} \quad \mathrm{Gd}_{2} \mathrm{O}_{3}$
$\mathrm{Dy}_{2} \mathrm{O}_{3}-\mathrm{Dy}_{2} \mathrm{O}_{3}$

Figure 1-5: REO concentrations in the REE-bearing phases of the tailings ( $\mathrm{mg} / \mathrm{kg}$ ) (modified from [153]).

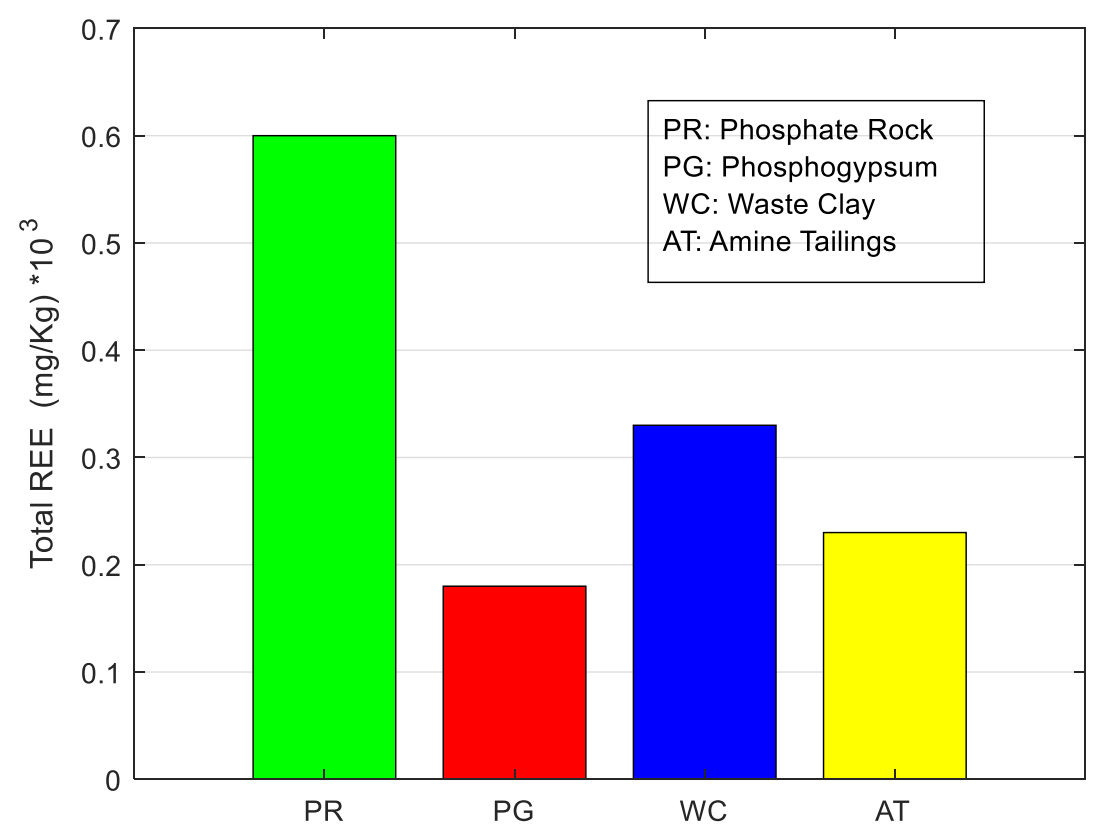

Figure 1-6: Occurrence of REEs in phosphate rock and phosphate waste materials (reproduced from [149]). 


\section{Sorbent for removal of heavy metals}

The mobility of contaminants can be reduced by trapping in a solid matrix and/or turning into a less mobile form in a solidification/stabilization process. Precipitation, as a chemical reaction, is one of the most important mechanisms for the fixation of heavy metals [27]. As some heavy metals form a new mineral with phosphate, which has extremely low solubility, as shown in Eqs. (1-1) to (1-3), significant effort has been made to evaluate the effectiveness of phosphate precipitation [154-157].

$$
\begin{aligned}
& \mathrm{Pb}_{5}\left(\mathrm{PO}_{4}\right)_{3} \mathrm{OH}(s), K_{s p}=10^{-82.3} \\
& \mathrm{Zn}_{5}\left(\mathrm{PO}_{4}\right)_{3} \mathrm{OH}(s), K_{s p}=10^{-63.1} \\
& \mathrm{Cd}_{3}\left(\mathrm{PO}_{4}\right)_{2}(s), K_{s p}=10^{-38.1}
\end{aligned}
$$

In the process of heavy metal stabilization with phosphate-containing solids, the availability of phosphate ions is critical. The phosphate release rate from a solid matrix varies significantly according to the environmental conditions and the materials. The properties of a solid, such as the chemical composition, phosphate type, available surface, pore size, and organic content, as well as those of an aqueous solution, such as $\mathrm{pH}$, temperature, presence of other ions, and the flow conditions, can affect the rate of phosphate release from such sources $[158,159]$. The primary mechanism of metal ion removal by waste clay as a P-rich source is shown in Eqs. (1-4) and (1-5):

$$
\begin{aligned}
& \mathrm{Ca}_{10}\left(\mathrm{PO}_{4}\right)_{6} \mathrm{~F}_{2}+12 \mathrm{H}^{+} \rightarrow 10 \mathrm{Ca}^{2+}+6 \mathrm{H}_{2} \mathrm{PO}^{4-}+2 \mathrm{~F}^{-}(\text {Dissolution }) \\
& \left.10 \mathrm{M}^{2+}+6 \mathrm{H}_{2} \mathrm{PO}^{4-}+2 \mathrm{~F}^{-} \rightarrow \mathrm{M}_{10}\left(\mathrm{PO}_{4}\right)_{6} \mathrm{~F}_{2}+12 \mathrm{H}^{+} \text {(Precipitation }\right)
\end{aligned}
$$

Such mechanism is governed by waste clay dissolution in an acidic condition followed by precipitation. Experimental evidence provided by Saxena et al. (2006) suggests that the removal is governed by a dissolution-precipitation mechanism, as shown in Fig. 1-7 [160]. 

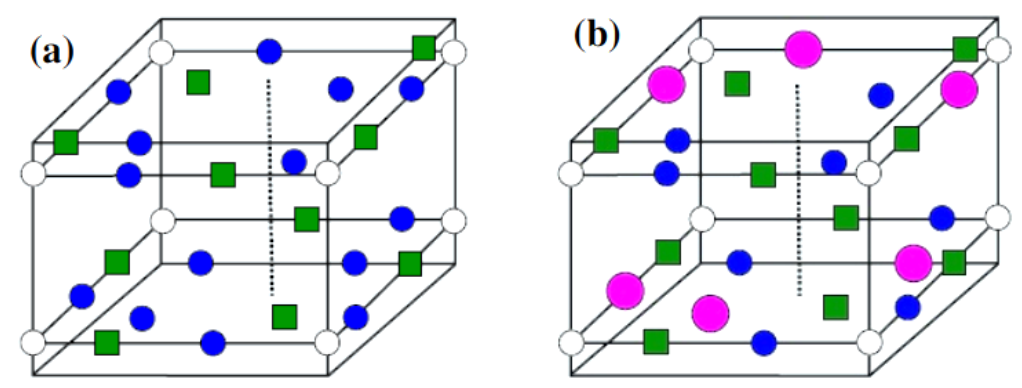

\section{$\mathrm{F}^{-} \odot \mathrm{M}^{2+} \odot \mathrm{Ca}^{2+} \square \mathrm{PO}_{4}^{3+}$}

Figure 1-7: Unit cell of rock phosphate (a) before and (b) after interaction with heavy metal ions (modified from [160]).

Ma et al. (1995) [154] and Chen et al. (1997) [161] used phosphate rocks with specific surface areas of 4.22-18.7 $\mathrm{m}^{2} / \mathrm{g}$ and $27 \mathrm{~m}^{2} / \mathrm{g}$, respectively, in heavy metal immobilization. Waste clay with a specific surface area of $33.65 \pm 1.19 \mathrm{~m}^{2} / \mathrm{g}$ was used for heavy metal removal by Singh et al. $(2001,2006)[162,163]$. Hwang et al. (2008a) reported the physical properties of a waste clay, such as the specific surface area of $7.56 \mathrm{~m}^{2} / \mathrm{g}$, a pore volume of $1.3 \times 10^{-2}$ $\mathrm{cm}^{3} / \mathrm{g}$, and the average pore diameter of $7.66 \times 10^{-7} \mathrm{~cm}$, using the desorption method [25]. Such insight into these properties can help explain the mass transfer phenomenon during the heavy metal immobilization process. Hwang et al. (2008b) [27] studied the physicochemical properties and mass transfer rate of phosphate from waste clay to the aqueous phase and the effect of $\mathrm{pH}$ on the rate of release. They concluded that the amount of phosphorus in the aqueous phase after $24 \mathrm{~h}$ reached about $0.01 \%$ at $\mathrm{pH} 7$, showing that waste clay could be used as a phosphorous source material for the immobilization of heavy metals.

\section{Possible remedies}

In general, the techniques to overcome clays in the processing circuits include mechanical size classification, as well as the use of chemical reagents such as selective flocculants. Despite the adverse effects of clay minerals, the industry's understanding of the processing issues, and potential solutions to treating clay-bearing ores, remains poor. In many cases, these problems are simply avoided by either not processing the ores at all, while some operations opt to run at significantly lower solid concentrations. Slurry dilution with water is also frequently used to reduce medium viscosity throughout the circuit [71]. However, this puts a strain on an increasingly scarce resource, especially since many mines are located in arid or desert regions. 
In view of these facts, waste clay as a typical clay-rich tailing stream poses various difficulties to not only the industry in terms of processing issues and value loss but also the environment, as discussed earlier. Hence, it is worthwhile to summarize different remedies that have been investigated/ applied to address clay-related issues in the various processing units. Such knowledge can pave the path for prescribing a possible remedy to the waste clay problem in the phosphate industry.

\section{Flocculation}

To avoid the deleterious effect of slimes, especially the impact of clays on the efficiency of various mineral processing unit operations such as classification, sedimentation and clarification, gravity separation, and flotation, several de-sliming techniques and chemical additives are employed, such as sodium carbonate, sulfuric acid, tri-polyphosphate, hexametaphosphate, etc. [28, 164-166]. In the case of the phosphate industry, the use of alkaline solutions of sodium silicate, phosphate compounds, lignin, sulfonic acid, sulfites, and caustic soda was proposed to improve de-sliming and settling of phosphate ore [167]. The use of hydroxides of K, Na, $\mathrm{NH}^{4+}$, and sodium silicate for the concentration of slimes [168, 169], and alkaline TPP solutions, and diluted solutions of selected acids have been applied to reduce the viscosity of phosphate slurries and increase consolidation of solids [170, 171]. Sulfonated acrylamide or acrylic acid polymers have been used as grinding aids for wet grinding of phosphate rock [172]. However, detrimental effects on downstream operations, high consumptions, and limited success have been obtained using these additives. Recently, the industry has shifted to the reagents that offer the most efficient and cost effective performance, mainly using organic polymers. For this purpose, it is required to understand the crystal chemistry of minerals, the chemistry of the aqueous media in solid-aqueous-gas interfaces, the interactions in solid-aqueous-gas interfaces, the rheology of the system, and the plant operating conditions and parameters [47]. Sotillo et al. (2003) developed Polymer $1111^{\circledR}$ to overcome the difficulties posed by slimes aiming at avoiding detrimental effects on downstream operations, such as clay settling or phosphate flotation [47]. The addition of flocculating agents brings about rapid but partial separation resulting in a suspension containing about $10 \mathrm{wt} \%$ solids [83]. Another remedy for slimes, e.g., clays, is selective flocculation. This technique has been well studied at laboratory levels for several mineral systems [173-178]. This process involves the effective dispersion of clays and other gangue minerals, such as quartz, and the 
flocculation of valuable minerals. The dispersed particles stay in the supernatant while the flocculated valuable minerals settle to the bottom and thus are separated from the gangue. In this process, the effective dispersion of clays is of critical importance. While the traditional dispersant (sodium silicate) was found ineffective in the dispersion of kaolinite, polyacrylic acid was an effective dispersant of the clay mineral under iron ore flotation conditions with the potential to significantly improve the process efficiency [176]. Clay binders as another remedy playing a crucial role as slime depressants that agglomerate clay particles to increase the size, lower the surface area, clean bubble and particle surfaces, and reduce the adsorption of surfactants, as depicted in Fig. 1-8. The selection of appropriate binders and dosage optimization is critical for flotation performance and selectivity. Two main adsorption mechanisms of clay binder are the dipole-dipole interaction and strong hydrogen bond. Because of amphiprotic characteristics and multiple binding and chelating sites, binding can be very selective $[179,180]$. As shown in Fig. 1-8, when clay minerals are present as individual particles, they adsorb a large amount of reagents due to their large surface areas. The clay will also be adsorbed on the particles and bubble surfaces as a result of electrostatic interactions referred to as slime coating. Clay binders have been used to agglomerate and depress clays as well as to reduce their surface areas and expose fresh particle and bubble surfaces [179]. Phosphate flotation using clay binders has resulted in about $5 \%$ and $1.5 \%$ increase in recovery and grade, respectively [181]. The agglomeration behavior of clays become further complicated due to their anisotropic surface charge resulting from clay edges and faces [44]. Novel dispersants reportedly have improved coal and phosphate flotation by agglomerating clay minerals and removing them from the surface of valuable minerals, as reported by Tao et al. (2007) [182]. It is a low molecular weight polymer that is the condensation product of urea and formaldehyde reacted under acidic conditions. Depending on the application, the properties of the condensation polymers can be tailored to suit the specific application requirements. The main factors governing their performance are the molar ratio of formaldehyde to urea, the addition of functional groups, the degree of functionalization, molecular weight, and crosslink density. The role of the surface mineralogy in the separation of waste clay using selective flocculation was noticed by Andersen and Somasundaran (1993) [183]. They performed thermodynamic stability calculations to determine the phase relationships in waste clay, which were then used to explain the separation behavior of the 
clay. It was concluded that fluorapatite reacts with montmorillonite type clays to form a calcium-aluminum phosphate during storage. This new phase forms at the clay-water interface, leading to the loss in selectivity during the selective flocculation of aged waste clay. A clay binder, GP374G41, showed an effective depression of clay particles in phosphate flotation so that its addition to flotation slurry significantly improved the $\mathrm{P}_{2} \mathrm{O}_{5}$ recovery from $82.25 \%$ to $87.75 \%$ at $0.1 \mathrm{lb} / \mathrm{t}$ dosage [180].

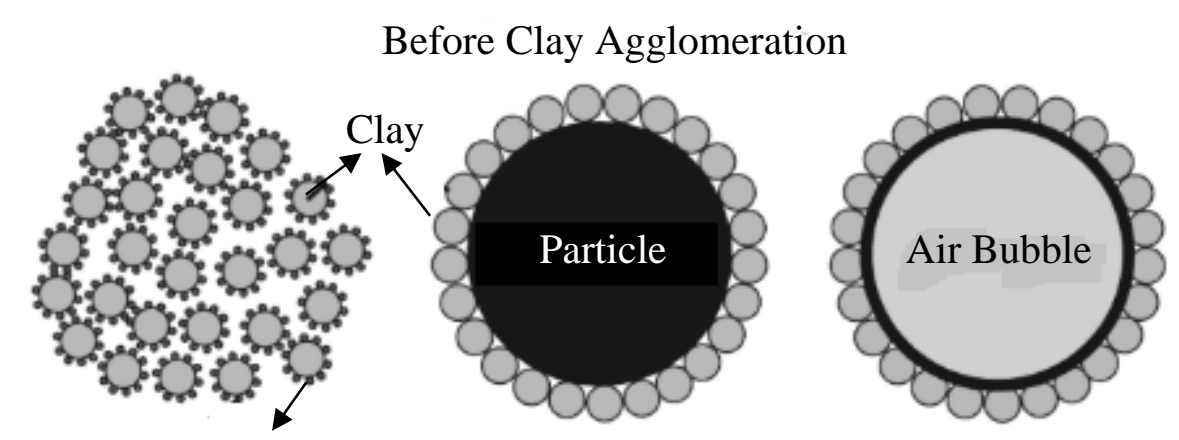

Reagent Molecule

After Clay Agglomeration
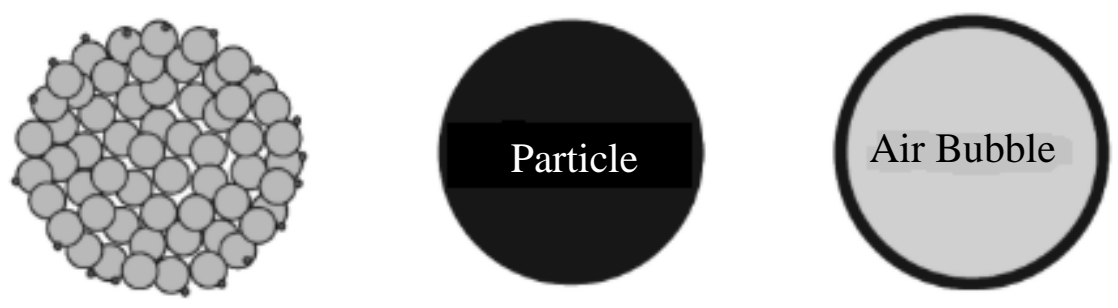

Figure 1-8: Clay agglomeration to remove slime coating from particle and bubble surfaces (borrowed from [179]).

\section{Flotation}

Flotation is a versatile, well-established, and widely used separation unit process designed to treat complex sulfide, oxide, and non-metallic ores. Separation is achieved when differences in the physio-chemical surface properties of the various minerals in the flotation feed are exploited with the aid of chemicals or reagents, which help to impart hydrophobicity on the particles to be floated. When air is bubbled into the ground-conditioned slurry in the flotation cells, the hydrophobic particles attach to the rising air bubbles and float to the top of the pulp where the so-called froth can be collected by skimming. This fraction is termed the flotation concentrate while the un-floated portion is called the flotation tailing [41]. One of the challenges in the flotation of fine particles is high gangue entrainment. Fine hydrophilic gangue 
particles easily entrain between bubbles getting into the fine pores and froth layer resulting in mechanical entrainment $[46,184]$. To discuss the ability of froth flotation to treat the slimes, e.g., waste clay, it is necessary to first understand the effect of the particles of such nature on the rheology (study of flow and deformation of matter) of mineral suspensions. The rheological properties of fluids are normally represented in the form of flow curves or rheograms where the fluid shear stress is plotted versus the shearing rate, as illustrated in Fig. 1-9. Rheology of suspensions is strongly affected by a large number of factors, including particle size and concentration [41]. A comprehensive description of the rheological behavior of ground minerals slurries has been discussed in detail in a number of review publications [185, 186]. There is a strong relationship between the rheological properties of pulp and flotation performance. The presence of clay minerals can cause adverse effects on the pulp rheology so that for instance, montmorillonite type clays, due to remarkable yield stress, strongly affect the viscosity of the suspension [46]. At low solids concentrations and a low proportion of fine particles $(<38 \mu \mathrm{m})$, mineral slurries behave like Newtonian fluids with no yield stress and a constant viscosity, as found by Shi and Napier-Munn (1996) [187]. However, as both solids content and fines proportion increase, slurries exhibit increasingly pseudo-plastic behavior, with increasingly large yield stress and apparent viscosity. In the context of mineral processing operations, the majority of process slurry streams behave as pseudo-plastic fluids and exhibit a yield stress [188]. However, other factors, such as surface chemistry and mineralogical properties of suspended particles, have also been shown to play a vital role. The change in the surface charge of minerals, e.g., clays, leads to significant variations in the inter-particle forces, following the classical DLVO theory [187]. These forces have a significant effect on the rheological properties of mineral suspensions, whereby an increased state of dispersion is characterized by a lower yield stress, and the opposite is true for an improved state of aggregation [48, 52, 189]. It follows that for oxide minerals (such as phyllosilicates/ clays) suspension, the rheology is strongly influenced by solution $\mathrm{pH}$ as well as the presence of other dispersing and flocculating reagents [41]. Rheological behavior of different mineral ores in aqueous environments differs significantly based on the proportion and type of clay minerals present as gangue species, independent of particle size [190]. 


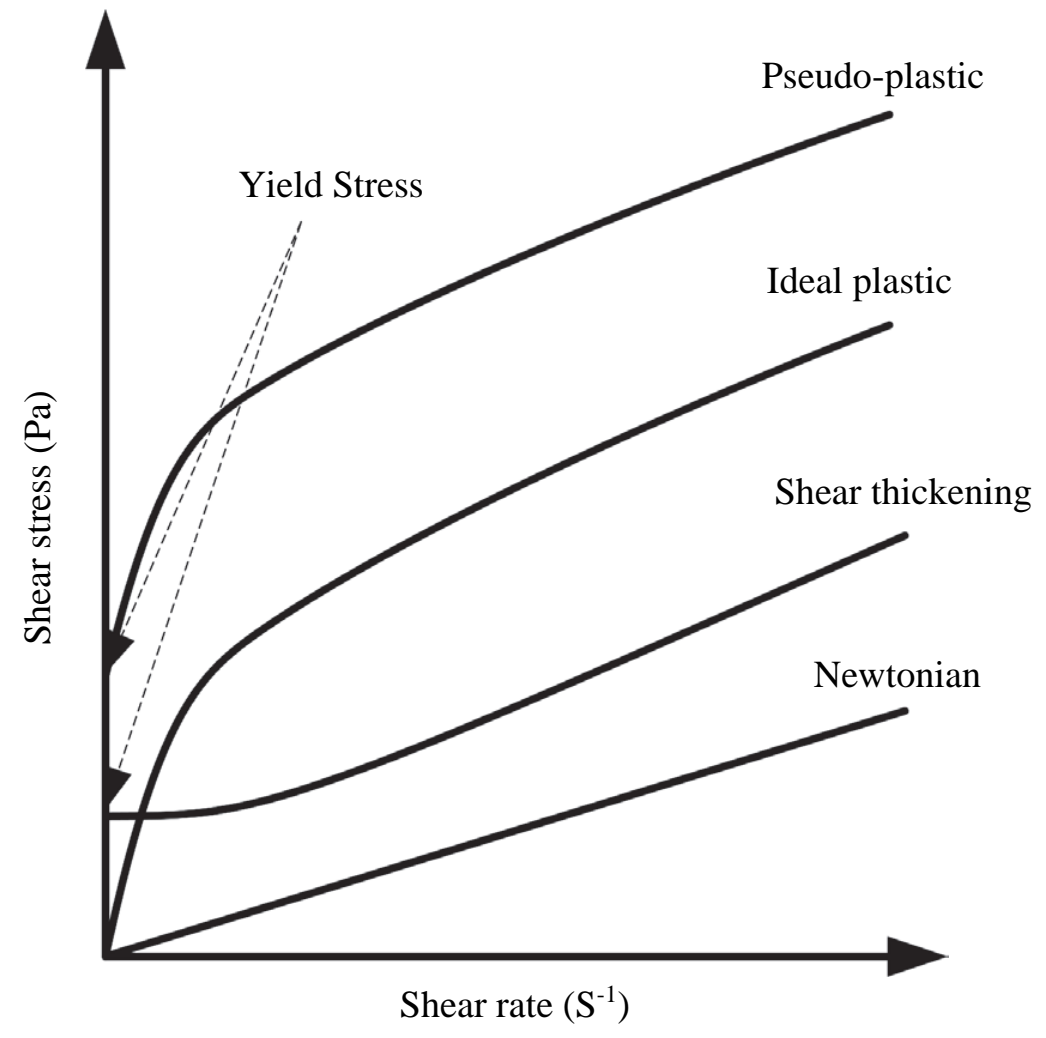

Figure 1-9: Rheograms of various types of fluids (borrowed from [41]).

Slurry rheological properties also depend strongly on the surface charge of anisotropic phyllosilicate particles, as discussed earlier, their shape (i.e., plates or fibers) and swelling capacity [59, 191]. It coincides well with the reports indicating that the presence of clay minerals causes problems in treating certain ore types due to their tendency to give rise to high pulp viscosities [192, 193]. A comprehensive review of pulp rheology's influence on the flotation process has been performed by Farrokhpay (2012) [185]. As rheology describes the flow properties of fluids, it also significantly impacts flotation cell hydrodynamics. Schubert (2008) argues that low pulp viscosity causes a reduction in turbulence damping (i.e., higher overall turbulence). While this aids flotation kinetics by increasing the probability of particle/bubble attachment, it also has a negative effect by increasing the bubble/particle detachment probability [194]. This was verified by Xu et al. (2011). They found that an increased pulp viscosity (and hence lower cell turbulence) results in increased stability of the bubble/particle aggregates, decreasing the detachment probability [195]. Forbes et al. (2014), however, demonstrated that the increase in flotation pulp viscosity could also significantly deter flotation performance, which was attributed to a decrease in particle/bubble contact 
through turbulence damping [196]. An increased pulp viscosity was also shown to have a detrimental effect on gas dispersion, through limiting the turbulent region of flotation cells to a small turbulent cavern surrounding the impeller [197-200]. Further, rheological properties of the flotation pulp have an impact on the rheological properties of the froth phase, which is still poorly understood with a very limited number of studies dedicated to [184, 201, 202]. While it is clear that froth rheological properties have a strong influence on factors, such as froth mobility and stability, the exact mechanisms involved are still unknown. Accurate measurement of the pulp's rheological properties is rather difficult because the solid particles tend to settle during measurements. Some researchers have used different methods such as pumping slurry [203], capillary viscometers [204] or stirring the suspension while measuring with Couette-type viscometer [205], to overcome this problem. However, finding a proper practical way to measure the rheology of such slurries remains a challenge [185].

In mineral processing terminology, it is common to refer to the slimes resulting from ores that contain large amounts of clay minerals and produce large amounts of fine particles. It is typically attributed to the soft nature of the clay minerals as they get preferentially ground compared to harder mineral particles [41]. The most noticeable consequence of the presence of very fine slime particles in froth flotation is entrainment, which has been described as a nonselective process whereby mineral particles report to the froth phase by being upswept in the wake of rising bubbles, while not actually being attached to them [206]. The phenomenon contributes to the decrease in the concentrate grade [207]. Montmorillonite has considerably impacted on the flotation grade and recovery due to its high swelling behavior, while it is possible to manage the deleterious effect of illite and kaolinite. Kaolinite and illite do not significantly affect the recovery, but rather contaminate the flotation concentrate by entrainment (at higher loading of illite compared to kaolinite) [40]. Ndlovu et al. (2013) have recently published a comprehensive review of the effect of clays on mineral processing [44]. They highlighted that clays have the potential to significantly affect the planning, operation, and economics of mineral processing projects.

Another detrimental and well-known effect of slimes on flotation is referred to as slime coating, which arises due to electrostatic forces between oppositely charged mineral particles $[208,209]$. In this phenomenon, relatively coarse valuable particles become either completely 
or partially coated by a layer of hydrophilic slimes, thereby rendering the valuables hydrophilic and inhibiting collector adsorption [208, 210]. The anisotropic charges on edges and surfaces of clays allow coating the surface of valuable minerals through the electrostatic attraction. Therefore, it causes inadequate surface hydrophobicity and reduces the flotation performance and quality of the concentrate [211]. Clay minerals particles of colloidal sizes also prevent adsorption between bubbles and minerals by coating air bubbles [212, 213]. An extensive review of slime coatings in froth flotation has been conducted by Yu et al. (2017), which provides a comprehensive overview of the slime coatings in froth flotation and reviews the measures taken to mitigate this problem in mineral flotation [209]. Various research works have attributed the formation of slime coatings to the electrostatic attractive forces between minerals and the clay particles of opposite surface charges at specific $\mathrm{pH}$ conditions $[69,75$, 212, 214, 215]. Attia and Deason (1989) concluded that slime coatings could be controlled by selective flocculation of fine clay particles using flocculants such as polyethylene glycol [216]. Arnold and Aplan (1986) suggested that clay slimes could be mitigated by the presence of ions in flotation pulp, where multivalent ions adsorb onto clay surfaces, masking their surface charge [70]. Clay minerals have a large active surface area supporting adsorption onto the ionic and molecular bond structure bringing about more consumption of flotation reagents and increasing the operational costs [217].

As also pointed out earlier from the rheological point of view, another important flotation property that is tremendously affected by the presence of ultrafine clay particles is froth stability. Froth stability plays a vital role in overall flotation performance through froth carrying capacity, entrainment, and drainage. It is well known that the froth stability is an essential factor determining the flotation performance. Phyllosilicate particles are likely to contribute to the formation of highly stable flotation froths, and hence have an adverse effect on drainage and froth recovery [218]. Choosing the right frother can be used to control the froth behavior when encountering clay-rich froths, using frother dosage as the control variable [202].

The role of the pulp conditioning temperature has been recognized as an area of potential for research. The pulp temperature goes up during conditioning, which has major effects on flotation performance. In phosphate processing, when the temperature goes down from $85^{\circ} \mathrm{F}$ 
in the summer to $65^{\circ} \mathrm{F}$ or so in the winter, the addition of hot water and/or heating the collector reagents has been found to be beneficial [219]. The rise in temperature during conditioning of clay pulp is dependent on the energy input during conditioning. It has been observed that performance is deficient if conditioning is performed at lower percentage solids than normal $[46,219]$.

The zeta $\zeta$ potential, one of the critical electro-kinetic properties of clay minerals, is defined as the electric potential developed at the solid-liquid interface in response to the relative movement of solid particles and water [220]. The potential is used as a metric to gauge the particles' stability in the colloidal environment; it is the electric potential at the slipping plane relative to a point in the bulk medium (see Fig. 1-10) and is not equal to the Stern potential or the surface potential as those defined at different locations on and about the particle [221]. For clays, the $\zeta$ potential is usually negative, which is strongly dependent on the pore-fluid chemistry. It is well known that the $\zeta$ potentials of clays are $\mathrm{pH}$-dependent so that its surface charge can drop to zero at a specific $\mathrm{pH}$ and ion concentration (PZC, point of zero charge). As such, naturally negatively charged clay surfaces can have positive charges at a certain $\mathrm{pH}$ and ion concentration [221]. Kaolinite, montmorillonite in water produce negative $\zeta$ potentials within a $\mathrm{pH}$ range of $3-11$ without attaining any $\mathrm{PZC}$ so that as $\mathrm{pH}$ increases, the $\zeta$ potential of these minerals become more negative in the presence of water due to the increase in $\mathrm{OH}^{-}$in the system as a result of $\mathrm{NaOH}$ addition [222]. As well, the $\zeta$ potentials of kaolinite and montmorillonite are close to each. When $\mathrm{Li}^{+}$or $\mathrm{Na}^{+}$ions are present in the solution, clay minerals (except montmorillonite) obtain more negative values for $\zeta$ potential than in water. These ions extend a diffuse electrical double layer according to the diffuse electrical double layer theory. However, in the presence of divalent cations, which compress the diffuse electrical double layer, the $\zeta$ potential becomes less negative as the concentration of these cations increases [222]. 


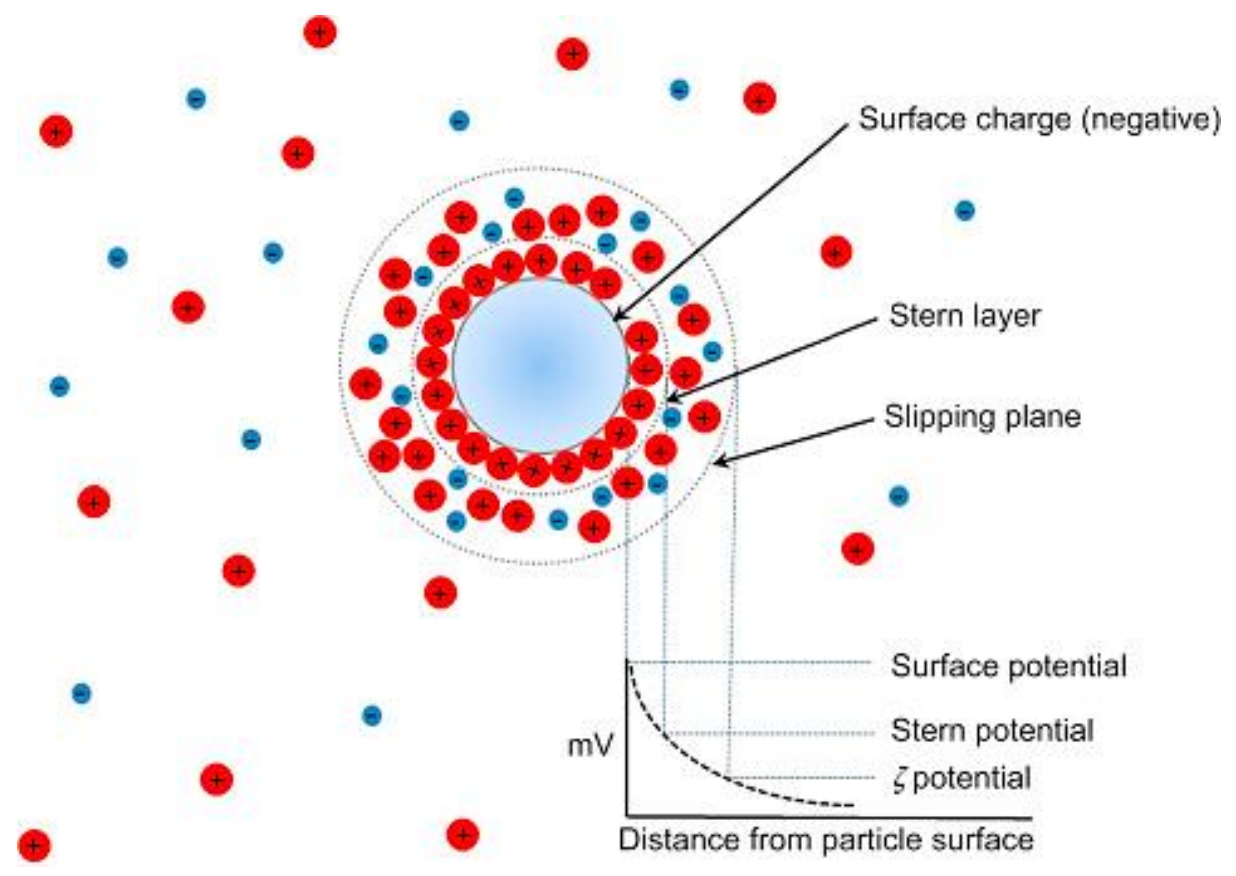

Figure 1-10: Definition sketch of zeta potential [221].

Zeta potentials of kaolinite and illite have been reported to be all negative ranging from 13.1 to $-49.5 \mathrm{mV}$ over a $\mathrm{pH}$ range from 2.5 to 11 , with kaolinite being more negative, exposing no PZC because of its permanent negative charge due to isomorphic substitution and/or structural defects. In contrast, illite exhibits a PZC at pH 2.5 [223]. However, Parks (1967); Ferris and Jepson (1975); Carroll-Webb and Walther (1988); Braggs et al. (1994), and Tschapek et al. (1974) reported the PZC of kaolinite as 3.3 and 4.6, 5, 4.25 and 3, respectively [224-228]. A method based on zeta potential distribution measurement to study heteroaggregation was introduced by [229]. Under conditions of full surface coverage of clays on value minerals, the value mineral' zeta potential will be replaced by that of the clay minerals. It is a useful technique to detect the interaction of binary particulate component suspensions. The interactions of coal-clay, alumina-quartz, montmorillonite-fluorite, and bitumen-clay in aqueous media have been studied by this technique [229-232].

It is generally accepted that only mineral particles larger than $10 \mu \mathrm{m}$ can be effectively beneficiated in flotation processes $[210,216]$. Beneficiation of phosphate ores through flotation is the general rule for endogenic apatite ores. It also constitutes the most widely used concentration process of sedimentary deposits with a siliceous gangue. Nowadays, plants use direct flotation (generally using a fatty acid collector) followed by reverse flotation of siliceous 
fines where careful removal of the clays is the key [233]. Although the flotation process is now drawing more attention and has been improved with the use of more efficient collectors and modifiers to obtain qualified phosphate concentrate, the high reagent consumption of the direct flotation stage due to the presence of clays, remains problematic. Prior studies have demonstrated that pre-recovery by spiral separation could significantly reduce the flotation reagent consumption in direct flotation and were capable of recovering apatite from ultra-fines [234]. Gravity-flotation process consisting of spiral gravity and reverse flotation for beneficiation of apatite from a clay-rich phosphate ore slime with the main purpose of reducing the reagent cost was proposed by Liu et al. (2017), as demonstrated in Fig. 1-11 [235]. This process produced a phosphate concentrate with a $\mathrm{P}_{2} \mathrm{O}_{5}$ grade and recovery of $30.51 \%$ and $89.00 \%$, respectively.

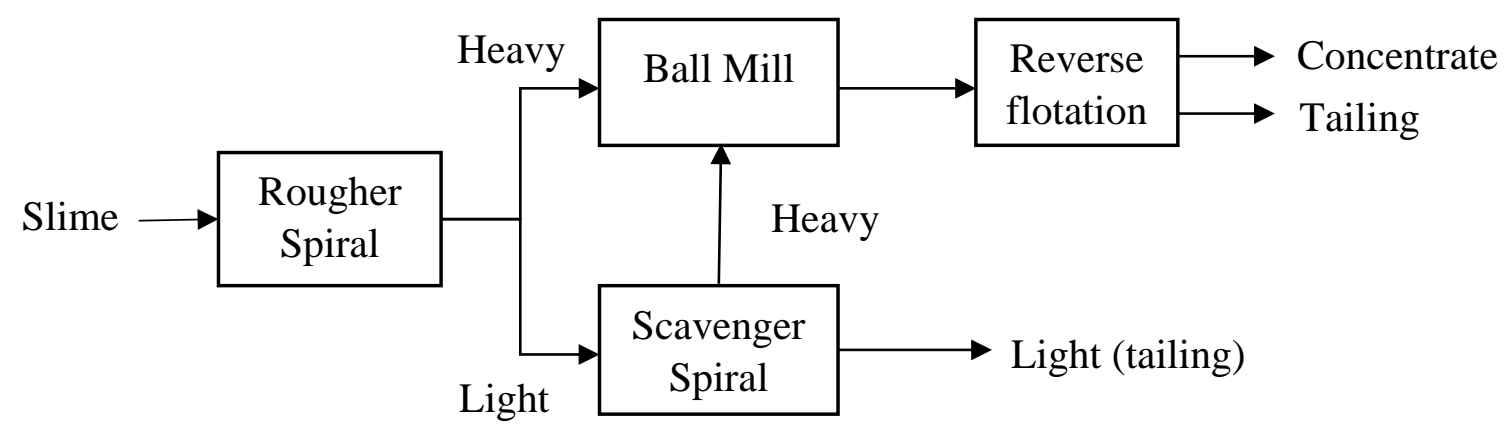

Figure 1-11: Flowsheet of the gravity-flotation process (modified from [235]).

Reverse flotation has also been employed for the rejection of clay minerals $[177,178]$. Ma et al. (2009) investigated the flotation mechanism of kaolinite and found that the $\mathrm{pH}$ dependence of kaolinite flotation was opposite to that of oxide minerals, with lower flotation recovery obtained at higher $\mathrm{pH}$ when using amines as collectors [236]. The ultrafine nature of kaolinite particles suggests that they are amenable to treatment by carrier flotation, which involves the utilization of coarse mineral particles, usually larger than $150 \mu \mathrm{m}$ in size, to act as coagulation sites. The ultrafine hetero-coagulate with the coarse mineral particles and then are carried into the froth product of the flotation process. Carrier flotation has been widely studied in the literature $[237,238]$. In the case of clay purification, the carrier flotation involves the use of tall oil as a collector and calcium carbonate as the carrier of very fine-sized impurity minerals [237, 239]. Browning and Johnson (1972) achieved promising results on the recovery of potash from high-clay and low-grade slimes of the Permian Basin of New Mexico using 
froth flotation [240]. They conditioned the clay fines with a starch solution to reduce the amine absorption of the amine by any clay present.

In flotation, sodium silicate has common use to depress silicate and carbonate minerals as gangue minerals. Sodium silicate is also an effective dispersant for clay slimes depending on the $\mathrm{SiO}_{2} / \mathrm{Na}_{2} \mathrm{O}$ ratio [77]. Sodium hexa-metaphosphate, commercially known as Calgon, prevents aggregation and slime coating of clays by forming complex ions with $\mathrm{Ca}^{2+}$ and $\mathrm{Mg}^{2+}$ ions, so minimizing effects in thinning the electrical double layer around these ions [77]. To summarize, the adverse effects posed by the presence of clay minerals in froth flotation can be reduced via the following remediation measures $[46,77,211,217,241]$ :

- Removal of clay minerals prior to flotation (applicable if the amount of valuable mineral in the discarded size is negligible),

- Viscosity modifiers,

- Removal of mechanically entrained clays by washing,

- Operation at low air flowrate(by reducing the amount of water transfer to concentrate),

- Flotation in low pulp densities,

- Using special frothers such as cycle-type frothers that are less sensitive to the presence of clays,

- Utilization of clay binders as a group of low molecular weight polymers.

For further information, researchers are encouraged to read an extensive review of managing clay minerals in froth flotation by Chen and Peng (2018) [200].

\section{Cyclone}

Hydro-cyclones have been widely used in the mining industry to reject clays before the beneficiation processes. For example, in the iron ore industry, hydro-cyclones are used as a desliming tool to reject ultrafine mineral particles prior to flotation. De-sliming significantly improves the subsequent froth flotation process by mitigating the deleterious effects posed by slimes described in the previous sections [173]. The major advantages of hydro-cyclones are mechanical simplicity, high throughput of mineral suspensions, small installation footprint, and low capital cost compared to other mechanical classifiers [242]. The disadvantage of using 
hydro-cyclones is that the fine particles of the valuable minerals are also rejected to the overflow, together with the clays and other slime minerals. Bhattacharyya et al. (1997) employed modified hydro-cyclone by exploiting the extremely high shear-fields inside a hydro-cyclone to effectively eliminate the stubborn sticky slime coating from Sukulu phosphate ore [243]. This attempt resulted in an increased $\mathrm{P}_{2} \mathrm{O}_{5}$ recovery for about $25 \%$ at a similar grade.

\section{Gravity separation}

The specific gravity of the clays is lower than most of the non-clay minerals in the phosphate slimes. Research has shown that separation of fine quartz from clay could be achieved using gravity-based methods. Although gravity methods may not be the first choice, centrifugal or cycloning gravity techniques should not be completely overlooked. Floatex Density Separator (FDS) has been proposed as a de-sliming tool for the removal of ultrafine, which operates as a hindered settling-based hydraulic classifier, incorporating counter-current and autogenous teetered-bed separators [244-246]. Gravity separation is a process based on the differential settling rates of particles in a fluid medium [247]. The main parameter determining the extent to which the minerals can be separated in gravity concentration is the concentration criterion [248], as defined in Eq. (1-6) where $D_{\mathrm{h}}$ and $D_{\mathrm{l}}$ are the densities of the heavier and lighter minerals, respectively, and $D_{\mathrm{m}}$ is the density of the medium (which is normally water, except in a heavy-medium separation):

$$
\frac{D_{h}-D_{m}}{D_{l}-D_{m}}
$$

The use of gravity concentration for minerals liberated at a coarse particle size can significantly reduce the mass and volume load in subsequent beneficiation processes and is inexpensive and environmentally friendly. Simple gravity concentration works most efficiently with coarser particle size ranges and a concentration criterion of at least 1.25 [248]. The change in the rheological characteristics of the clayish phosphate slurries allows fine ore particles to settle faster by reducing the slurry viscosity. Thus, better separation of the ore from the slimes is possible using gravitational or centrifugal forces [47]. 


\section{Magnetic separation}

Magnetic separation is a process for extracting magnetically susceptible mineral particles, such as magnetite, from ores using a non-homogeneous magnetic field [249]. Its selectivity depends on different responses of the susceptible mineral particles and gangue components to magnetic forces [250]. The amount of magnetization induced in the particles depends on the mass and the magnetic susceptibility of particles and the intensity of the applied magnetic field [251]. The process becomes more effective at higher magnetic gradients. A technical breakthrough in high gradient magnetic separator (HGMS) technology emerged with the first industrial application of superconducting HGMS. Using this technology, extremely high magnetic fields can be achieved with virtually zero power consumed by the magnet [251]. Superconducting HGMS units are capable of generating magnetic fields up to $50 \mathrm{KG}$ compared to the maximum magnetic fields of $20 \mathrm{KG}$ generated conventionally, and requiring only a fraction of the energy consumed by conventional magnetic separators [136]. A review of the history of HGMS for dilute suspension processing is available in [252]. A summary of different mineral processing techniques prescribed for the phosphate industry's waste clay problem is given in Table 1-6.

Other methods for mitigating clay effects include incorporating hydro-sizers upfront that aids the separation of clays from the feed. Similarly, the inclusion of scrubbers early on is beneficial in clay removal to the tailings dam in dense media separation. However, it is worth noting that the inclusion of such modifications may not necessarily improve recovery and throughput. Other methods include dilution and blending of high clay ores with less complex ores. However, these are limited to mixture concentrations below which the clay content starts to cause problems. Such information has not been clearly defined, and a better fundamental

understanding, particularly of the rheological properties of different phyllosilicate minerals, is required for long-term solutions to these processing problems [44]. 
Table 1-6: Summary of the potential mineral processing remedies for the waste clay problem.

\begin{tabular}{|c|c|c|c|}
\hline Technology & Mechanism & Limitations & Potentials \\
\hline Flocculation & $\begin{array}{l}\text { Surface charge } \\
\text { neutralization; } \\
\text { polymer bridging } \\
\text { between particles }\end{array}$ & $\begin{array}{l}\text { - Non-selective for } \\
\text { clays } \\
\text { - Loss of fine-sized } \\
\text { valuables }\end{array}$ & $\begin{array}{l}\text { - Novel polymers } \\
\text { - Electro-kinetics of slimes }\end{array}$ \\
\hline Flotation & Surface wettability & $\begin{array}{l}\text { - Extremely sensitive } \\
\text { to the presence of } \\
\text { ultrafine slimes } e . g . \\
\text { clays }\end{array}$ & $\begin{array}{l}\text { - Modified flotation } \\
\text { machines } \\
\text { - Novel reagents } \\
\text { - Novel bubble generators } \\
\text { - Floc-flotation }\end{array}$ \\
\hline Cyclone & $\begin{array}{l}\text { Centripetal/ } \\
\text { Centrifugal forces }\end{array}$ & $\begin{array}{l}\text { - Requires small size } \\
\text { cyclones for } \\
\text { ultrafine } \\
\text { - Not selective for } \\
\text { clays }\end{array}$ & $\begin{array}{l}\text { - Exploitation of high shear- } \\
\text { fields }\end{array}$ \\
\hline $\begin{array}{l}\text { Gravity } \\
\text { separation }\end{array}$ & $\begin{array}{l}\text { Differential } \\
\text { settling rates of } \\
\text { particles in a fluid } \\
\text { medium }\end{array}$ & $\begin{array}{l}\text { - Efficient for coarser } \\
\text { particle size ranges }\end{array}$ & $\begin{array}{l}\text { - Changes in the rheological } \\
\text { characteristics of the } \\
\text { clayish phosphate slurries } \\
\text { allow fine ore particles to } \\
\text { settle faster by reducing } \\
\text { the slurry viscosity }\end{array}$ \\
\hline $\begin{array}{l}\text { Magnetic } \\
\text { separation }\end{array}$ & $\begin{array}{l}\text { Responses of } \\
\text { mineral particles } \\
\text { to magnetic forces }\end{array}$ & $\begin{array}{l}\text { - Effective at higher } \\
\text { magnetic gradients }\end{array}$ & $\begin{array}{l}\text { - Development in the high } \\
\text { gradient magnetic } \\
\text { separator (HGMS) }\end{array}$ \\
\hline
\end{tabular}

\section{Recovery of $P$ and REEs}

The recovery of valuable elements from waste clay has been one of the most challenging mineral processing endeavors in mineral processing due to its extremely dilute nature, with an average solids concentration of $3 \%$ plus its ultrafine size containing nearly $50 \%$ of clay minerals. Besides, large amounts of magnesium, iron, and aluminum are present in clay minerals. All of these poses various difficulties in the extraction of critical elements from waste clay [6]. Zhang et al. (2001) thoroughly characterized thirty waste clay samples in order to identify some feasible techniques for recovering the phosphate values [139]. They found that three major characteristics of the waste slimes create extreme difficulty in recovering its phosphate content economically. These features are the high content (30-50\%) of clay minerals, the ultra-fine particle size (35-50\% below 1 micron), and the nearly even distribution of phosphate among the different size fractions. Preliminary tests excluded magnetic separation and an electrical method as potential solutions. However, a small hydro-cyclone 
showed some potential of recovering a significant portion of the phosphate values economically. Batch sizing tests using a 6-inch cyclone generated an underflow product of approximately plus 20 microns with $18 \% \mathrm{P}_{2} \mathrm{O}_{5}, 0.5 \% \mathrm{MgO}$, and $3.3 \% \mathrm{Al}_{2} \mathrm{O}_{3}$. The cyclone also performed well under continuous operation, delivering a relatively sharp cut at 20 microns. A second stage processing via the cyclone further reduced the fines and unwanted components ( $\mathrm{Al}, \mathrm{Mg}$, and $\mathrm{Fe}$ ) from the primary underflow product. Tests on pure minerals indicated that all the dispersants could maintain the clay minerals suspended at a concentration of $100 \mathrm{ppm}$ for 24 hours, while most of the other minerals were not dispersed. Therefore, there may be a potential to separate clay minerals from non-clay minerals by dispersion-settling. However, dispersion tests on a phosphate/clay mixture showed that significant dispersion occurred only at a high dosage of dispersant, e.g., 1000 ppm. Flocculation with simultaneous dispersion using sodium silicate failed to separate the clay minerals selectively from phosphate. It should be noted that all the above tests were conducted at natural $\mathrm{pH}$. Based on the physicochemical analyses and preliminary separation tests, Zhang et al. concluded that the most viable approaches for reclaiming the phosphate in waste clay seem to be sizing followed by flotation, selective dispersion-settling/flocculation, and perhaps bioleaching. Hazen Research issued a patent in 1969 to leach the clays with sulfuric acid, then recover the $\mathrm{P}_{2} \mathrm{O}_{5}$ content from the acid leachate with mixtures of amine and alcohol through solvent extraction [253]. Ribas and Nickerson proposed to recover the phosphate values by consolidating, calcining at 870-1093 ${ }^{\circ} \mathrm{C}$, and then digesting the clay in mineral acid to produce phosphoric acid [120]. The process was energy-intensive and created severe dusting problems during calcination because of the dry, finely-dispersed particles.

The U.S. Bureau of Mines carried out a detailed investigation in 1985 in which the clay was first sized using hydro-cyclones and hydro-separators. Up to $96 \%$ of the $-37 \mu \mathrm{m}$ material was recovered during the sizing stage. Subsequent flotation of $-37 \mu \mathrm{m}$ fraction gave a concentrate of over $30 \% \mathrm{P}_{2} \mathrm{O}_{5}$ at an $88 \%$ recovery. However, $\mathrm{P}_{2} \mathrm{O}_{5}$ recovery from the total clay was low [139]. In 1983, FIPR sponsored a project that used an autoclave acidulation technique to recover the phosphate values from clays. At a temperature of $175^{\circ} \mathrm{C}$, more than $90 \%$ of the $\mathrm{P}_{2} \mathrm{O}_{5}$ was extracted in less than an hour. After acid treatment, the clay residue quickly consolidated to a 35-45\% solids level. Longer leaching time led to larger PG crystals, which helped the entire mass to filter more readily. However, the equipment investment and low acid 
quality prevented this process from being commercialized [122]. Previous research efforts at phosphate recovery from the slimes can be summarized as follows [139, 124]:

\section{- $\quad$ Sulfuric acid leaching}

This process has two significant drawbacks: first, tremendous acid consumption because of adsorption and unwanted chemical reactions, and second, significant leaching of iron and aluminum. As a result, the phosphoric acid product requires expensive purification steps.

\section{- Flocculation}

Treatment of the entire clay suspension with certain polyelectrolytes can also separate apatite from the clay minerals, but the reagent consumption is horrendous.

\section{- Calcination}

Calcining is uneconomical because both dewatering/drying the clays and calcining are energy-intensive.

\section{- Sizing-flotation}

This approach could effectively recover phosphate from the coarse portion of the slimes at a reasonable cost. However, since the phosphate is distributed almost evenly among different size fractions, sizing-flotation of waste clay can only recover a small fraction of the phosphate, if conventional sizing (cutting at 37-74 $\mu \mathrm{m}$ ) is practiced.

\section{- Flotation}

Flotation of the entire clay mass without any pretreatment can ensure a high recovery of phosphate. However, the collector consumption of this approach is prohibitive. Any process that uses chemicals or flotation reagents on the entire mass is too expensive because of the high reagent consumption, due to adsorption on, and chemical reaction of the reagents with the clay minerals. Generally, direct flotation by anionic surfactants or reverse flotation by cationic surfactants is conducted to remove the silicate gangues from phosphate ores. During the direct flotation process, the pulp $\mathrm{pH}$ is adjusted to around 9.5 by adding soda ash, and a proper amount of sodium silicate is required to depress silicate minerals simultaneously. For the reverse flotation process, silica is floated using cationic surfactants in a weakly acidic or neutral solution, and the phosphate minerals (dominantly apatite) are obtained from the underflow product. The superior adsorption of cationic surfactants on silica rather than apatite probably can be attributed to the more negatively 
charged silica surfaces [126]. Due to the higher fatty acid prices, lower feed grade, and stricter environmental regulations, a so-called "Crago" process comprising amine-fatty acid flotation has been developed for the beneficiation of Florida phosphate ore, as demonstrated in Fig. 1-12 [128]. For the removal of carbonate gangues, high separation efficiency can be achieved using reverse anionic flotation at around $\mathrm{pH} 4.5$ without the addition of a phosphate depressant $[130,132]$. Different types of phosphate ores should be subjected to specific flotation processes for upgrading with regard to mineral compositions. Both of the anionic direct flotation and cationic reverse flotation is applied for the beneficiation of siliceous phosphate rock, while the single anionic reverse flotation is preferred to beneficiate the calcareous phosphate rock. A two-step flotation process, named direct-reverse flotation (Fig. 1-13) or double reverse flotation, is usually carried out to remove silica and carbonate gangue minerals stepwise from the calcareous-siliceous phosphate rock $[124,134,137]$. A review of the beneficiation techniques and reagents used for phosphate ores with emphasis on froth flotation has been published by Ruan et al. (2019) [124].

The recovery of REEs from waste clay, however, has not attracted much attention so far. In addition to the troublesome nature of waste clay, this is also attributed to the lack of sufficient fundamental knowledge on the occurrence modes of these elements in waste clay, thereby on the physicochemical properties of the REE-bearing minerals in the presence of the associated gangues. Zhang et al. (2017) reported chemical and mineralogical analyses of Florida waste clay, showing that REEs in waste clay occurs in three primary forms: Monazite, Xenotime, and as a substation of calcium in phosphate crystals [6]. REEs in waste clay follow $\mathrm{P}$, meaning that the key to recovering REEs and $\mathrm{U}$ from waste clay is to concentrate phosphate values first. As such, two potential approaches have been proposed. First, three-stage cycloning of waste clay using $12.4 \mathrm{~cm}$ (5 in.), $5.08 \mathrm{~cm}$ ( 2 in.), and $2.54 \mathrm{~cm}$ (1 in.) cyclones, respectively, to remove clay minerals followed by flotation and leaching of the coarse fraction (underflow). The flotation process resulted in a concentrate product with $54.18 \%$ yield containing 420.38 ppm TREE with $88.16 \%$ recovery, and $12.68 \% \mathrm{P}_{2} \mathrm{O}_{5}$ with $94.22 \%$ recovery. Second, a twostep leaching process where in the first step, selective leaching is employed at $\mathrm{pH} 3.2$ to remove magnesium (up to $80 \%$ achieved), paving the path for the production of phosphoric acid proper for the production of di-ammonium phosphate (DAP) in the second step of leaching. In another 
attempt, Laurino et al. (2019) investigated the feasibility of extracting REEs from Florida phosphate mining materials using a chelating polymer, 1-octadecene, polymer with 2, 5furandione, sodium salt. At $\mathrm{pH} 1.5$, the chelation polymer effectively bound nearly $100 \%$ of the rare earth elements extracted from the solids. Overall extraction and recovery yields were between $80 \%$ for gadolinium and $8 \%$ for praseodymium from amine tailings, between $70 \%$ for terbium and $7 \%$ for praseodymium from PG, between $56 \%$ for scandium and $15 \%$ for praseodymium from phosphate rock, and between $77 \%$ for samarium and $31 \%$ for praseodymium from waste clay. These results suggest that this chelating polymer efficiently recovers rare earth elements from acidic extracts of phosphate mining waste products [149]. In this scope, one can find invaluable information in a review by Peiravi et al. (2020) [254].

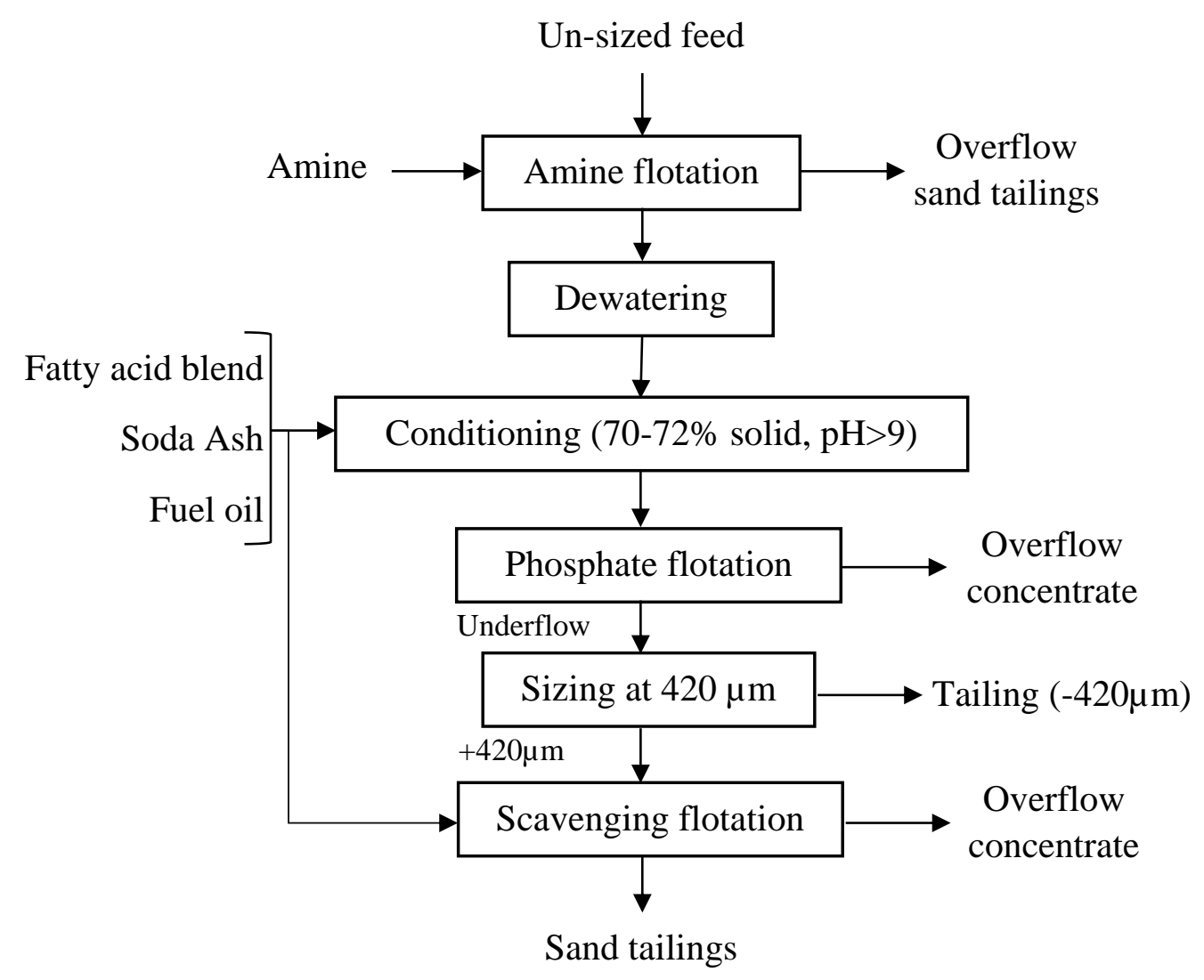

Figure 1-12: The "Crago" process for the beneficiation of Florida phosphate ore (modified from [124]). 


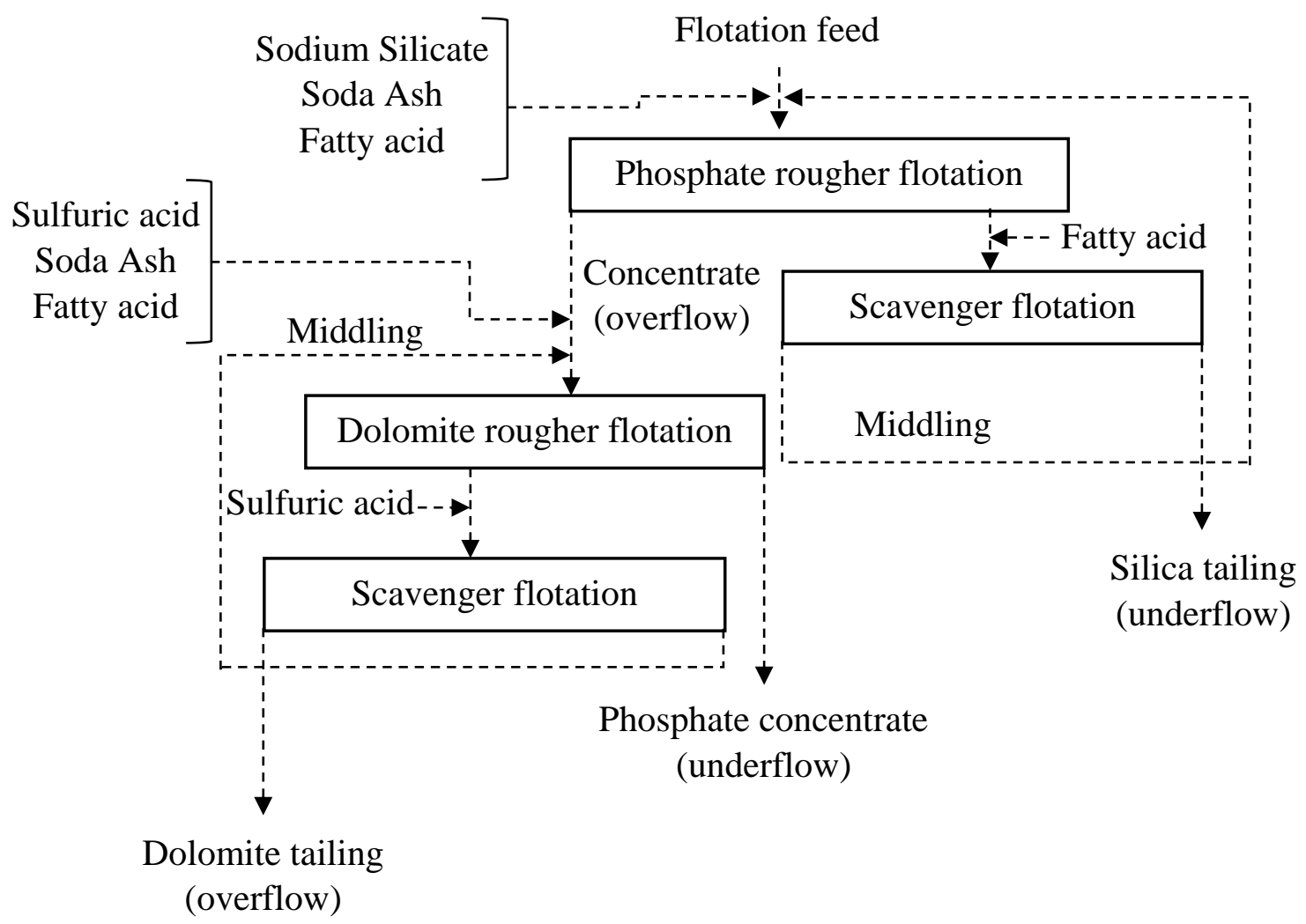

Figure 1-13: Direct-reverse flotation process for the beneficiation of calcareous-siliceous phosphate (adopted and modified from [124]).

\section{Potential approaches}

As discussed earlier, mineralogical analyses of waste clay samples have confirmed that clay minerals constitute more than half of the total weight. Therefore, the removal of clay is critical to the economic recovery of phosphate values from waste clay. Although the colloidal nature of waste clays masks many differences in the physicochemical and surface properties of the clay and non-clay minerals, their differences in size, surface charge, and specific gravity could offer a window for effective separation. The advance of fine flotation technology, understanding of flocculation mechanisms, and the emergence of new flocculants should encourage researchers to take a fresh look at recovering the phosphate values from waste clay. Recent advances in the formulation of new flotation reagents that can selectively interact with certain target minerals (by incorporating functional groups capable of chemisorbing or chelating with metals) or better control particle dispersion/ aggregation, and bubble stability, have opened new windows for the beneficiation of difficult-to-treat ores. As well, for ultrafines and colloids, it is important to recognize that in addition to the measurable properties 
such as size and porosity, it is essential to determine the surface chemical composition and surface mineralogical heterogeneity since surface forces will start to dominate over all the other forces [255]. These highlight the importance of fundamental computational chemistry investigations on the interactions of both conventional and potential reagents with certain mineral surfaces, as well as on the effects of multivalent metallic cations and dissolved mineral species on those interactions. This topic has been of great interest to scientists globally [256269]. Further, the application of ionic liquids as environmentally friendly reagents in the physical, e.g., froth flotation and liquid-liquid extraction, and chemical beneficiation, e.g., solvent extraction of valuable minerals/ elements, has also gained a promising momentum [270-272]. The design, formulation, and properties of these newly emerging reagents can be tailored to ameliorate the separation of the valuables from waste clay.

Moreover, recent developments in flotation machines, such as the packed column, baffled column, air-sparged hydro-cyclone, etc. have made it possible to float ultrafine minerals. Poor recovery of fine particles is mainly attributed to the low chance of collision between particles and bubbles, high specific surface area, high surface energy, and most importantly, low particle inertial force [273-276]. To improve fine particle recovery in flotation, one must either increase the particle size or decrease the bubble diameter. In this regard, the particle sizes can be enlarged by flocculants, while the small bubbles can be generated via dissolved-air flotation, induced-air flotation, hydrodynamic cavitation, electro-flotation, and microbubble generators. The most common belief is creating an intense turbulent environment to increase particlebubble collision efficiency, which is an extremely energy-consuming process [194, 277, 278]. Shear flocculation or high-intensity conditioning is another technique used to upgrade the recovery of fines [279]. Mechanical vibration and the acoustic wave pre-treatments are also reported as promising approaches to enhance the recovery of fine-sized fractions by a cleaning effect on the surface of the minerals and the heterogeneous nucleation of microbubbles on the particle surfaces [280, 281]. Jameson (2010) [282] presented theoretical backgrounds regarding the main difficulties in recovering ultra-fine and coarse particles. He developed the Concorde $^{\mathrm{TM}}$ flotation cell and applied fluidization principles to upgrade the recovery of ultrafines. In this regard, FLSmidth Inc., as a pioneer company in flotation processes, offers two solutions; I) forced-air flotation machines (Dorr-Oliver) designed for recovering fine particles through imposing high energy to these particles, and II) forced-air and induced-air cells (Dorr- 
Oliver and Wemco) [283]. Further, it is well documented that pneumatic flotation is more effective than the conventional cells in processing fine particles [284]. Two commonly used pneumatic flotation machines are Jameson ${ }^{\mathrm{TM}}$ and Imhoflot ${ }^{\mathrm{TM}}$ cells. The Jameson cell was successfully operated in the cleaning stage to beneficiate the porphyry gold-copper ore by Minera Alumbrera Ltd in Argentina for particles finer than $10 \mu \mathrm{m}$ that resulted in gold and copper recoveries of about $80 \%$ and $90 \%$, respectively [285]. The Imhoflot ${ }^{\mathrm{TM}}$ flotation cell has also been successfully applied and practically demonstrated its capability in recovering ultrafines [284].

Oscillating Grid Cell (OGC) is another flotation technology offering a promising solution for the flotation of ultrafines. For example, the apatite flotation results indicated that the flotation rate constant for the finer particles $(<38 \mu \mathrm{m})$ increases by around $200 \%$ with an increase in energy input from 0.1 to $2 \mathrm{~W} / \mathrm{kg}$ [286]. This is due to an increased bubble-particle collision/ attachment offered by the OGC. The survey results clearly demonstrated that the OGC has a great potential in recovering fine particles by optimizing the collision, attachment, and stability efficiencies along with controlling the hydrodynamic parameters like energy input and bubble size [287].

Furthermore, Reflux Flotation Cell (RFC), similar to the Jameson Cell, benefits from a high gas hold-up leading to thin-film migration that may play a role in the particle collection [288]. A high volumetric flow rate combined with the narrow spacing within the RFC's multichanneled downcomer generates a high shear rate, ideal for forming tiny bubbles and enhancing collisions between the fines and bubbles. Due to its design and mechanism of operation [289], RFC maximizes the kinetics of particle-bubble attachment, the bubble interfacial flux for particle extraction, and the rate of bubble-liquid segregation.

Recently, Helmholtz-Zentrum Dresden Rossendorf (HZDR) research institute in Germany has initiated a project named MultiDimFlot aiming at the development of the processing technology for separating ultrafine particles (e.g., $-10 \mu \mathrm{m})$ based on several, even combined particle properties, i.e., size, shape, roughness, and surface energy. This concept is based on froth flotation targeting the multidimensional separation of ultrafine particles through high collision rates within mechanical flotation in a rotor-stator cell and the fractionating properties of a deep, water-washed froth. However, one foreseeable drawback of this technology that 
might limit its large-scale/ industrial applications could be the highest energy consumption required. The high energy is needed to generate significantly higher turbulence and fine-sized bubbles for the successful collisions between particles of extremely ultrafine sizes with bubbles of the same nature in a rotor-stator-based cell. Added to this is the need for higher surfactant consumption to produce fine-sized air bubbles suitable for this application, which is another concern.

As noted earlier, the principal issue concerning poor floatability of fine and ultrafine particles is generally attributed to their low momentum and inertial force under conventional hydrodynamic and thermodynamic properties of flotation cells [290]. This leads to a low probability of collision and, consequently, poor flotation kinetics [291]. Floc-flotation, as discussed earlier, is a technique to aggregate the fine particles using a polymer flocculent, hydrophobic interactions, and micro-organisms to obtain coarse-sized particles/ flocs to tackle those issues. There are many successfully reported progress in a laboratory scale for coal [292], malachite [293], hematite [294], quartz and galena [295], calcite and talc [296]. The crucial aspect of this approach is linked to the type of polymer and a low selectivity due to heterocoagulation and entrapment phenomena. Specificity can be induced by incorporating active groups into the polymers. However, for most ores, selective flocculation is not easily achieved, even under conditions when higher selectivity is expected [255]. More detailed information can be found elsewhere [297].

Oil-assisted flotation approaches, i.e., emulsion flotation and agglomerate flotation, are the other technologies that we need to look into regarding fine/ ultrafine processing. Due to the extensive surface area of water-insoluble oil droplets in emulsions, emulsion flotation offers possibilities for the recovery of finely divided mineral particles. In the case of agglomerate flotation, conditioning at high pulp density with an appropriate collector to render the particles hydrophobic is followed by bridging particles together by oil to enlarge their size. Pulp dilution and conventional flotation come next to recover the solid phase [298]. Oil agglomeration, a sizing-based separation method, and liquid-liquid extraction, a phase-separation method are the other technologies that need to be given further consideration with regard to the processing of ultrafine-sized ores such as waste clay. Oil-assisted fine particle processing technologies are extensively discussed by Laskowski (1992) [298]. 
Magnetization of mineral particles to enhance their magnetic properties is another technique to selectively recover or remove weakly magnetic fine particles. There are a number of well-documented methods for this purpose, such as roasting or reduction to chemically alter the magnetic composition of particles, and microwave or x-ray as the external energy applied to the mineral system to selectively manipulate the magnetic properties of target mineral grains to be effectively separated by subsequent magnetic separation [299]. As a case in point, magnetization of pyrite fines has reportedly improved the removal of pyrite from coal by the high gradient magnetic separation (HGMS) [299]. Another alternative magnetization technique without chemically altering the minerals is by incorporating a discrete magnetic phase onto the particles to be made more magnetic. This method is referred to as the magnetic carrier separation, which employs the adsorption of magnetic reagent or the attachment of magnetite onto particles to be separated, to make them more magnetic. The detailed mechanism of this approach as well as case studies can be followed in the literature [265, 299].

Finally yet importantly, the selection of proper particulate systems requires precise and appropriate mineralogical characterization. Recent developments indicate that scanning electron microscopy (SEM)-based methods like mineral liberation analysis (MLA) and QEMSCAN (quantitative evaluation of materials by scanning electron microscopy) have been extensively utilized to characterize a variety of particle properties in the scope of process mineralogy [300]. QEMSCAN allows for a 2D quantitative analysis of mineral essays by combining back-scattered electron (BSE) images with energy-dispersive X-ray spectroscopy (EDS) [301]. For fine particles, these techniques are inevitably subjected to a stereological bias along with a statistical dispersion in the light of the number of analyzed particles [302], which results in an overestimation of mineral liberation degrees. Moreover, there are natural uncertainties inherently linked to representativity and sample preparation shortcomings [303]. According to the raised assertions, there is an urgent need to tackle these issues related to fine process mineralogy.

\section{Conclusions}

With such an ever-growing world population and global economies owed to science and technology advancements, the demand for critical materials is rapidly rising. Critical materials are characterized by particularly high importance and high risk of supply disruptions. A 
solution to this concern is the recovery of these materials from secondary sources such as industrial waste streams, e.g., waste clay, a phosphate ore process tailing. Due to its troublesome composition and nature, this waste poses severe issues to the phosphate industry in terms of value loss, disposal, dewatering challenges, and environmental impacts. The most important values being lost to this waste stream are phosphate rock and REEs, which are both categorized as critical materials. Due to the tremendous volume of this waste accumulated in Florida to date, the recovery of these values from waste clay can remarkably alleviate the U.S.'s reliance on foreign countries for these critical materials, which at the same time can help minimize its environmental footprint. To reach this goal, two crucial attempts are the removal of extremely fine-sized clays, followed by the recovery of phosphate content, which according to the prior research endeavors, can pave the path for the recovery of REE-bearing minerals. To overcome this problem, the nature, composition, structure, engineering properties, chemistry, and mineralogy of waste clay should be thoroughly understood. Different possible remedies or combinations of them can be proposed, some of which have been considered by various research works. These remedies include froth flotation, selective-flocculation, flocflotation, cycloning, gravity separation, magnetic separation, etc. To date, almost all of the known remedies have been considered by various research and industrial attempts to address the issues posed by waste clay. However, mostly, no economically viable solution has been proposed to date, indicating that any scientific/ technological solution should, at the same time, be economically and, of course, environmentally attractive to the industry. With such a goal in mind and taking into account the economy and environment, the first that comes to mind would be moving from mostly chemical separation processes to the primarily physical/ physicochemical processes with lower operational costs and environmental impacts. This thought highlights the significance of redefining the problem by deeply understanding its composition and how each composing phase interacts with the other associated phases when exposed to a specific chemical or physical separation environment. This requires detailed mineralogical and elemental characterization, physicochemical, rheological, electrochemistry, surface chemistry, crystal chemistry, solution chemistry, and quantum chemistry investigations on each single and then mixed-phase systems constituting waste clay. Such information can help develop the fundamental knowledge, upon which more versatile and efficient solutions can be established. 


\section{References:}

[1] Blengini, G.A., Mathieux, F., Mancini, L., Nyberg, M. and Viegas, H.M., 2019. Recovery of critical and other raw materials from mining waste and landfills. Publications Office of the European Union, Luxembourg.

[2] Matinde, E., Simate, G.S. and Ndlovu, S., 2018. Mining and metallurgical wastes: a review of recycling and re-use practices. Journal of the Southern African Institute of Mining and Metallurgy, 118(8), pp.825-844.

[3] Lottermoser, B.G., 2011. Recycling, reuse and rehabilitation of mine wastes. Elements, 7(6), pp.405-410.

[4] Bian, Z., Miao, X., Lei, S., Chen, S.E., Wang, W. and Struthers, S., 2012. The challenges of reusing mining and mineral-processing wastes. Science, 337(6095), pp.702-703.

[5] Karunanithi, R., Szogi, A.A., Bolan, N., Naidu, R., Loganathan, P., Hunt, P.G., Vanotti, M.B., Saint, C.P., Ok, Y.S. and Krishnamoorthy, S., 2015. Phosphorus recovery and reuse from waste streams. In Advances in agronomy (Vol. 131, pp. 173-250). Academic Press.

[6] Zhang, P., Liang, H., Jin, Z. and DePaoli, D., 2017. The ultimate mineral processing challenge: Recovery of rare earths, phosphorus and uranium from Florida phosphatic clay. Minerals \& Metallurgical Processing, 34(4), pp.183-188.

[7] Binnemans, K., Pontikes, Y., Jones, P.T., Van Gerven, T. and Blanpain, B., 2013. Recovery of rare earths from industrial waste residues: a concise review. In Proceedings of the 3rd International Slag Valorisation Symposium: the Transition to Sustainable Materials Management (pp. 191-205).

[8] European Commission, 2018. Report on critical raw materials and the circular economy. Commission Staff Working Document. Brussels, Belgium.

[9] U.S. Department of Energy 2011 Critical Materials Strategy. http://energy.gov/sites/prod/files/DOE_CMS2011_FINAL_Full.pdf.

[10] Mancheri, N.A., Sprecher, B., Bailey, G., Ge, J. and Tukker, A., 2019. Effect of Chinese policies on rare earth supply chain resilience. Resources, Conservation and Recycling, 142, pp.101-112.

[11] He, J. and Kappler, A., 2017. Recovery of precious metals from waste streams. Microbial biotechnology, 10(5), pp.1194-1198.

[12] Kleinman, P.J., Sharpley, A.N., McDowell, R.W., Flaten, D.N., Buda, A.R., Tao, L., Bergstrom, L. and Zhu, Q., 2011. Managing agricultural phosphorus for water quality protection: principles for progress. Plant and soil, 349(1-2), pp.169-182. 
[13] Geise, G., LeGalley, E. and Krekeler, M.P., 2011. Mineralogical and geochemical investigations of silicate-rich mine waste from a kyanite mine in central Virginia: implications for mine waste recycling. Environmental Earth Sciences, 62(1), pp.185196.

[14] McKelvey, V.E., 1967. Phosphate deposits (No. 1252-D). US Govt. Print Off.

[15] Beavers, C., Ellis, R., Hanlon, C.D.E. and MacDonald, G., 2013. An overview of phosphate mining and reclamation in Florida.

[16] Reta, G., Dong, X., Li, Z., Su, B., Hu, X., Bo, H., Yu, D., Wan, H., Liu, J., Li, Y. and $\mathrm{Xu}$, G., 2018. Environmental impact of phosphate mining and beneficiation review. International Journal of Hydrology, 2(2).

[17] Sudarsanan, K., Mackie, P.E. and Young, R.A., 1972. Comparison of synthetic and mineral fluorapatite, $\mathrm{Ca}_{5}\left(\mathrm{PO}_{4}\right)_{3} \mathrm{~F}$, in crystallographic detail. Materials Research Bulletin, 7(11), pp.1331-1337.

[18] Dudka, S. and Adriano, D.C., 1997. Environmental impacts of metal ore mining and processing: a review. Journal of environmental quality, 26(3), pp.590-602.

[19] USGS Statistics, 2020. http://minerals.usgs.gov/minerals/pubs/commodity/. Accessed $5 / 15 / 2020$.

[20] Zhang, P., 2014. Comprehensive recovery and sustainable development of phosphate resources. Procedia Engineering, 83, pp.37-51.

[21] Zhang, P. and Bogan, M., 1995. Recovery of phosphate from Florida beneficiation slimes I. Re-identifying the problem. Minerals engineering, 8(4-5), pp.523-534.

[22] McFarlane, A., Bremmell, K. and Addai-Mensah, J., 2005. Microstructure, rheology and dewatering behaviour of smectite dispersions during orthokinetic flocculation. Minerals Engineering, 18(12), pp.1173-1182.

[23] El-Shall, H. and Zhang, P., 2004. Process for dewatering and utilization of mining wastes. Minerals engineering, 17(2), pp.269-277.

[24] Wissa, A.E.Z., Fuleihan, N.F. and Ingra, T.S., 1983. Evaluation of phosphatic clay disposal and reclamation methods, Volume 4, Consolidation behavior of phosphatic clays. Florida Institute of Phosphate Research, Research Project FIPR-80-02-002.

[25] Hwang, A. and Khim, J., 2008a. Characteristics of phosphatic clay for immobilizing heavy metals. In GeoCongress 2008: Geotechnics of Waste Management and Remediation (pp. 835-839).

[26] Pardo, P., Lopez-Sanchez, J.F. and Rauret, G., 2003. Relationships between phosphorus fractionation and major components in sediments using the SMT harmonised extraction 
procedure. Analytical and Bioanalytical Chemistry, 376(2), pp.248-254.

[27] Hwang, A., Ji, W., Kweon, B. and Khim, J., 2008b. The physicochemical properties and leaching behaviors of phosphatic clay for immobilizing heavy metals. Chemosphere, 70(6), pp.1141-1145.

[28] Lamont, W.E., McLendon, J.T. and Clements, L.W., 1975. Characterization studies of Florida phosphate slimes. United States, Bureau of Mines, Investigative Report, (8089), pp.1-24.

[29] Wissa, A.E.Z., Fuleihan, N.F. and Ingra, T.S., 1986. Evaluation of phosphatic clay disposal and reclamation methods. Volume 7: Engineering properties of flocculated phosphatic clays. Evaluation of phosphatic clay disposal and reclamation methods. Volume 7: Engineering properties of flocculated phosphatic clays. Final Report, Research Project FIPR 83-02-042, pp. 1-1 to 1-5.

[30] Starkey, H.C., Blackmon, P.D. and Hauff, P.L., 1984. The routine mineralogical analysis of clay-bearing samples. Geological Survey bulletin (USA). no. 1563.

[31] Moore, D.M. and Reynolds Jr, R.C., 1989. X-ray Diffraction and the identification and analysis of clay minerals. Oxford University Press.

[32] Zhou, X., Liu, D., Bu, H., Deng, L., Liu, H., Yuan, P., Du, P. and Song, H., 2018. XRDbased quantitative analysis of clay minerals using reference intensity ratios, mineral intensity factors, Rietveld, and full pattern summation methods: A critical review. Solid Earth Sciences, 3(1), pp.16-29.

[33] Brindley, G.W., 1952. Identification of clay minerals by X-ray diffraction analysis. Clays and Clay Minerals, 1(1), pp.119-129.

[34] Brewster, G.R., 1980. Effect of chemical pretreatment on X-ray powder diffraction characteristics of clay minerals derived from volcanic ash. Clays and Clay Minerals, 28(4), pp.303-310.

[35] Hassellöv, M., Lyvén, B., Bengtsson, H., Jansen, R., Turner, D.R. and Beckett, R., 2001. Particle size distributions of clay-rich sediments and pure clay minerals: a comparison of grain size analysis with sedimentation field-flow fractionation. Aquatic Geochemistry, 7(2), pp.155-171.

[36] Środoń, J., 2006. Identification and quantitative analysis of clay minerals. Developments in Clay Science, 1, pp.765-787.

[37] Deng, Y., White, G.N. and Dixon, J.B., 2009. Soil mineralogy. Texas A\&M University Electron Microscopy Center. 
[38] Kaminsky, H., Etsell, T.O.M., Ivey, D.G. and Omotso, O., 2006. Fundamental particle size of clay minerals in Athabasca oil sands tailings. Clay science, 12(Supplement2), pp.217-222.

[39] Kaminsky, H.A., Etsell, T.H., Ivey, D.G. and Omotoso, O., 2009. Distribution of clay minerals in the process streams produced by the extraction of bitumen from Athabasca oil sands. The Canadian Journal of Chemical Engineering, 87(1), pp.85-93.

[40] Farrokhpay, S., Ndlovu, B. and Bradshaw, D., 2016. Behaviour of swelling clays versus non-swelling clays in flotation. Minerals Engineering, 96, pp.59-66.

[41] Forbes, E., Ma, M., and Bruckard, W., 2017. Clay minerals in flotation and comminution operations. In: M. Gräfe, C. Klauber, A.J. McFarlane and D.J. Robinson, eds., Clays in the Minerals Processing Value Chain. Cambridge: Cambridge University Press, pp.302-326.

[42] Hu, X.L. and Michaelides, A., 2010. The kaolinite (001) polar basal plane. Surface science, 604(2), pp.111-117.

[43] Johnston, C.T., 2018. Clay mineral-water interactions. In Developments in Clay Science (Vol. 9, pp. 89-124). Elsevier.

[44] Ndlovu, B., Farrokhpay, S. and Bradshaw, D., 2013. The effect of phyllosilicate minerals on mineral processing industry. International Journal of Mineral Processing, 125, pp.149-156.

[45] Deryagin, B.V. and Landau, L.D., 1941. Theory of stability of strongly charged lyophobic sols and adhesion of strongly charged particles in electrolytic solutions. $J$. Exp. Theor. Phys, 11, p.802.

[46] Taner, H.A. and Onen, V., 2016. Control of clay minerals effect in flotation. A review. In E3S Web of Conferences (Vol. 8, p. 01062). EDP Sciences.

[47] Sotillo, F.J., Irwin, L.P., Yap, S., Utsey, F.M., 2003. On improving desliming: The use of rheology and surface chemistry interactions. SME Annual Meeting, Cincinnati, Ohio, preprint 03-012.

[48] Johnson, S.B., Franks, G.V., Scales, P.J., Boger, D.V. and Healy, T.W., 2000. Surface chemistry-rheology relationships in concentrated mineral suspensions. International Journal of Mineral Processing, 58(1-4), pp.267-304.

[49] Okuda, S., Inoue, K. and Williamson, W.O., 1969. Negative surface charges of pyrophyllite and talc. In Proc. Clay Conf. Tokyo (pp. 31-41).

[50] Zhou, Z. and Gunter, W.D., 1992. The nature of the surface charge of kaolinite. Clays and Clay minerals, 40(3), pp.365-368. 
[51] Scales, P.J., Grieser, F. and Healy, T.W., 1990. Electrokinetics of the muscovite micaaqueous solution interface. Langmuir, 6(3), pp.582-589.

[52] Burdukova, E., Bradshaw, D.J. and Laskowski, J.S., 2007. Effect of CMC and pH on the rheology of suspensions of isotropic and anisotropic minerals. Canadian Metallurgical Quarterly, 46(3), pp.273-278.

[53] Swartzen-Allen, S.L. and Matijevic, E., 1974. Surface and colloid chemistry of clays. Chemical Reviews, 74(3), pp.385-400.

[54] Rand, B. and Melton, I.E., 1977. Particle interactions in aqueous kaolinite suspensions: I. Effect of $\mathrm{pH}$ and electrolyte upon the mode of particle interaction in homoionic sodium kaolinite suspensions. Journal of Colloid and Interface Science, 60(2), pp.308320.

[55] James, A.E. and Williams, D.J.A., 1982. Flocculation and rheology of kaolinite/quartz suspensions. Rheologica Acta, 21(2), pp.176-183.

[56] Permien, T. and Lagaly, G., 1994. The rheological and colloidal properties of bentonite dispersions in the presence of organic compounds IV. Sodium montmorillonite and acids. Applied Clay Science, 9(4), pp.251-263.

[57] Lagaly, G. and Ziesmer, S., 2003. Colloid chemistry of clay minerals: the coagulation of montmorillonite dispersions. Advances in Colloid and Interface Science, 100, pp.105-128.

[58] Benna, M., Kbir-Ariguib, N., Magnin, A. and Bergaya, F., 1999. Effect of pH on rheological properties of purified sodium bentonite suspensions. Journal of Colloid and Interface Science, 218(2), pp.442-455.

[59] Ndlovu, B.N., Forbes, E., Becker, M., Deglon, D.A., Franzidis, J.P. and Laskowski, J.S., 2011. The effects of chrysotile mineralogical properties on the rheology of chrysotile suspensions. Minerals Engineering, 24(9), pp.1004-1009.

[60] Tombácz, E. and Szekeres, M., 2006. Surface charge heterogeneity of kaolinite in aqueous suspension in comparison with montmorillonite. Applied Clay Science, 34(14), pp.105-124.

[61] Gupta, V., Hampton, M.A., Stokes, J.R., Nguyen, A.V. and Miller, J.D., 2011. Particle interactions in kaolinite suspensions and corresponding aggregate structures. Journal of Colloid and Interface Science, 359(1), pp.95-103.

[62] Taylor, R.K. and Smith, T.J., 1986. The engineering geology of clay minerals: swelling, shrinking and mudrock breakdown. Clay Minerals, 21(3), pp.235-260.

[63] Clark S.W., 1982. Phosphatic clay workshop. Florida Institute of Phosphate Research 
Institute of Phosphate Research, Bartow, Florida.

[64] Bloomquist, D., 1982. Centrifuge modeling of large strain consolidation phenomena in phosphatic clay retention ponds (Doctoral dissertation, University of Florida).

[65] Lawver, J.E. and Carrier III, W.D., 1983. Mathematical and centrifuge modeling of phosphatic clay disposal systems. In SME-AIME Annual Meeting, Atlanta, GA, March (pp. 6-10).

[66] Townsend, F.C. and Hernandez, J., 1986. Predictions of phosphatic clay consolidation by numerical and centrifugal models.

[67] El-Shall, H., Moudgil, B. and Bogan, M., 1996. Centrifugal modeling of the consolidation of solid suspensions. Mining, Metallurgy \& Exploration, 13(3), pp.98102.

[68] Abu-Hejleh, A.N., Znidarčić, D. and Barnes, B.L., 1996. Consolidation characteristics of phosphatic clays. Journal of geotechnical engineering, 122(4), pp.295-301.

[69] McVay, M., Townsend, F. and Bloomquist, D., 1986. Quiescent consolidation of phosphatic waste clays. Journal of Geotechnical Engineering, 112(11), pp.1033-1049.

[70] Arnold, B.J. and Aplan, F.F., 1986. The effect of clay slimes on coal flotation, part II: The role of water quality. International Journal of Mineral Processing, 17(3-4), pp.243260.

[71] Connelly, D., 2011. High clay ores a mineral processing nightmare. Australian Journal of Mining, 24, pp.28-29.

[72] Tao, D., Dopico, P.G., Hines, J. and Kennedy, D., 2010. An experimental study of clay binders in fine coal froth flotation. In Proceedings of the International Coal Preparation Congress (pp. 478-487).

[73] Patra, P., Bhambhani, T., Nagaraj, D.R. and Somasundaran, P., 2010. Effect of morphology of altered silicate minerals on metallurgical performance: Transport of $\mathrm{Mg}$ silicates to the froth phase. In Rheology in Mineral Processing in Proc. 49th Conference of Metallurgists of CIM (pp. 31-42).

[74] Vasudevan, M., Nagaraj, D.R., Patra, P. and Somasundaran, P., 2010. Effect of altered silicates in flotation performance: role of changes in pulp rheology. In Proceedings of 8th UBC-McGill-UA International Symposium on the Fundamentals of Mineral Processing: Rheology and Processing of Fine Particles (pp. 21-30). Vancouver.

[75] Jorjani, E., Barkhordari, H.R., Khorami, M.T. and Fazeli, A., 2011. Effects of aluminosilicate minerals on copper-molybdenum flotation from Sarcheshmeh porphyry ores. Minerals Engineering, 24(8), pp.754-759. 
[76] Genc, A.M., Kilickaplan, I. and Laskowski, J.S., 2010, October. Pulp rheology in the flotation of serpentinised ultramafic nickel sulfide ore and its effect on flotation. In 8th UBC-McGill-UA International Symposium on the Fundamentals of Mineral Processing: Rheology and processing of fine particles. Canadian Insititute of Mining and Metallurgy (pp. 13-20).

[77] Bulatovic, S.M., 2007. Handbook of flotation reagents: chemistry, theory and practice: Volume 1: flotation of sulfide ores. Elsevier.

[78] Dippenaar, A., 1978. The effect of particles on the stability of flotation froths. National Institute for Metallurgy, , p.34.

[79] Farrokhpay, S., 2011. The significance of froth stability in mineral flotation-A review. Advances in colloid and interface science, 166(1-2), pp.1-7.

[80] Kotlyar, L.S., Sparks, B.D., LePage, Y. and Woods, J.R., 1998. Effect of particle size on the flocculation behaviour of ultra-fine clays in salt solutions. Clay Minerals, 33(1), pp.103-107.

[81] Morris, G.E. and Żbik, M.S., 2009. Smectite suspension structural behaviour. International Journal of Mineral Processing, 93(1), pp.20-25.

[82] Carrier, W.D., 2001. Rapid Clay Dewatering: Phase II: Field-scale Tests, Final Report. Florida Institute of Phosphate Research.

[83] McKinney, J.P. and Orazem, M.E., 2011. A constitutive relationship for electrokinetic dewatering of phosphatic clay slurries. Mining, Metallurgy \& Exploration, 28(1), pp.4954.

[84] Kong, R. and Orazem, M.E., 2014. Semi-continuous electrokinetic dewatering of phosphatic clay suspensions. Electrochimica Acta, 140, pp.438-446.

[85] McKinney, J.P. and Orazem, M.E., 2011. Electrokinetic dewatering of phosphatic clay settling areas: numerical simulation and economic assessment. Mining, Metallurgy \& Exploration, 28(2), pp.71-76.

[86] Pittman, W.E., McLendon, J.T. and Sweeney, J.W., 1984. A review of phosphatic clay dewatering research (Vol. 8980). US Department of the Interior, Bureau of Mines.

[87] Moudgil, B.M., BM, M., TP, O. and Gy, O., 1981. Field test of a seepage technique for dewatering waste phosphatic clays.

[88] Scheiner, B.J. and Ragin, M.M., 1987. Factors affecting dewatering of phosphatic clay waste slurries. SME preprint 87-47.

[89] Rahman, M.A.E., 2000. Dewatering of phosphatic clay waste by flocculation. Chemical Engineering \& Technology: Industrial Chemistry-Plant Equipment-Process 
Engineering-Biotechnology, 23(5), pp.457-461.

[90] Dentel, S.K., Abu-Orf, M.M. and Walker, C.A., 2000. Optimization of slurry flocculation and dewatering based on electrokinetic and rheological phenomena. Chemical engineering journal, 80(1-3), pp.65-72.

[91] https://www.911metallurgist.com.

[92] Deason, D.M. and Onoda, G.Y., 1984. Controlled dispersion of clays and its effects on phosphate clay waste dewatering. Mining, Metallurgy \& Exploration, 1(2), pp.149-152.

[93] Phillips, W.M., 1963. Dewatering and processing kaolin clays. Transactions of the American Institute of Mining, Metallurgical and Petroleum Engineers, 226, p.219.

[94] Smelley, A.G. and Feld, I.L., 1979. Flocculation dewatering of Florida phosphatic clay wastes (Vol. 8349). Department of the Interior, Bureau of Mines.

[95] Scheiner, B.J. and Smelley, A.G., 1984. Dewatering of fine particle mining wastes using polyethylene oxide flocculant. Mining, Metallurgy \& Exploration, 1(1), pp.71-75.

[96] Smelley, A.G., Scheiner, B.J. and Zatko, J.R., 1980. Dewatering of industrial clay wastes (Vol. 8498). US Department of the Interior, Bureau of Mines.

[97] Deal, T.M., Deal Troy M, 1986. Continuous process for the dewatering of phosphate slimes. U.S. Patent 4,608,179.

[98] Scheiner, B.J., Smelley, A.G. and Brooks, D.R., 1982. Large scale dewatering of phosphatic clay waste from central Florida. US Department of the Interior, Bureau of Mines.

[99] Shang, J.Q., 1997. Electokinetic dewatering of clay slurries as engineered soil covers. Canadian Geotechnical Journal, 34(1), pp.78-86.

[100] Houston, E.C. and POWELL, L., 1949. Electrical eewatering of phosphate tailing. Transactions of the american institute of mining and metallurgical engineers, 184(10), pp.365-370.

[101] Dizon, A. and Orazem, M.E., 2019. Efficient continuous electrokinetic dewatering of phosphatic clay suspensions. Electrochimica Acta, 298, pp.134-141.

[102] Horton, M.D., Vital, D., Spaulding, S., Albarelli, G. and Defino, P., 2018. Enhancing percolation in phosphatic clay using diatoms under laboratory conditions. bioRxiv, p.357889.

[103] Smelley, A.G. and Scheiner, B.J., 1985. Large-scale dewatering of phosphatic clay waste from Northern Florida (Vol. 8928). US Department of the Interior, Bureau of Mines. 
[104] Nagaraj, D.R., Lister, L. and Somasundaran, P., 1977. Subsidence of suspensions of phosphatic slime and its major constituents. International J. of Mineral Processing, 4, pp.111-129.

[105] Smith, C.W. and McLendon, J.T., 1989. Well point dewatering of phosphatic clays (Vol. 9285). US Department of the Interior, Bureau of Mines.

[106] El-Shall, H., 1993. Dewatering method and agent for phosphatic clay slurries. U.S. Patent no. 5262064.

[107] El-Shall, H., 1995a. Evaluation of FIPR/DIPR process as a reclamation technique, Publication no. 02-093-120. Florida Institute of Phosphate Research, Bartow, FL.

[108] Brierley, C. and Lanza, G., 1982. The microbial flocculation of phosphate and potash slimes.

[109] Bromwell, L.G., 1981. Evaluation of alternative processes for disposal of fine-grained waste materials. In Seminar on Consolidation Behavior of Fine-Grained Waste Materials, Lakeland, Florida.

[110] El-Shall, H., 1992. A new process for rapid dewatering of waste slurries. Emerging Process Technologies for a Cleaner Environment, pp.211-217.

[111] Gardinier Inc., 1980, Clariflux-superflocculation process: method for treatment and disposal of phosphatic slimes. Gardinier, Inc., Tampa, FL.

[112] HALE, A., 1982. New reclamation and restoration trends in Florida phosphate mines.

[113] Laros, T.J., Envirotech Corp, 1990. Flocculating agent combinations for mineral slime filtration systems. U.S. Patent 4,931,190.

[114] McLendon, J.T., Boyle, J.R. and Sweeney, J.W., 1983. A Technical evaluation of conventional versus developing processes of phosphatic clay disposal. FIPR Publication, (02-017), p.022.

[115] Moudgil, B.M., BM, M., TP, O. and GY, O., 1981. Field test of a seepage technique for dewatering waste phosphatic clays.

[116] Smelley, A.G. and Scheiner, B.J., 1980. Synergism in polyethylene on dewatering of phosphatic clay waste. US Bureau of Mines, RI, 843.

[117] Smelley, A.G. and Feld, I.L., 1979. Flocculation dewatering of Florida phosphatic clay wastes (Vol. 8349). Department of the Interior, Bureau of Mines.

[118] Peng, C., Lai, H., Orazem, M.E. and Moghaddam, S., 2018. Microstructure of clay fabric in electrokinetic dewatering of phosphatic clay dispersions. Applied Clay Science, 158, pp.94-101. 
[119] Tao, D., Parekh, B.K., Zhao, Y. and Zhang, P., 2010. Pilot-scale demonstration of deep cone $^{\mathrm{TM}}$ paste thickening process for phosphatic clay/sand disposal. Separation Science and Technology, 45(10), pp.1418-1425.

[120] Ribas, R.S. and Nickerson, J.D., United States Steel Corp, 1976. Process for the manufacture of phosphoric acid with minimized environmental effects. U.S. Patent $3,932,591$.

[121] Szilas, C., 2002. The Tanzanian Minjingu phosphate rock: possibilities and limitations for direct application (Doctoral dissertation, Center for Skov, Landskab og Planlægning/Københavns Universitet).

[122] Jha, M.C., Lussiez, G.W. and Beckstead, L.W., 1985. Autoclave acidulation of phosphate slimes. AMAX Extractive Research \& Development.

[123] Menzel, R.G., 1968. Uranium, radium, and thorium content in phosphate rocks and their possible radiation hazard. Journal of Agricultural and Food Chemistry, 16(2), pp.231234.

[124] Ruan, Y., He, D. and Chi, R., 2019. Review on beneficiation techniques and reagents used for phosphate ores. Minerals, 9(4), p.253.

[125] International Fertilizer Industry Association, 2001. Environmental aspects of phosphate and potash mining. UNEP.

[126] Ruan, Y., Zhang, Z., Luo, H., Xiao, C., Zhou, F. and Chi, R., 2018. Effects of metal ions on the flotation of apatite, dolomite and quartz. Minerals, 8(4), p.141.

[127] McFarlin, R. F., 1992. Florida phosphate and the environemnt: practices, problems and emerging thechnologies. In Chander, S. (ed.), Emerging Process Technologies for a Cleaner Environement. Littleton CO: Society for Mining, Metallurgy and Exploration, pp. 29-39.

[128] Zhang, P., Yu, Y. and Bogan, M., 1997. Challenging the "Crago" double float process II. Amine-fatty acid flotation of siliceous phosphates. Minerals engineering, 10(9), pp.983-994.

[129] Guimond, R.J., 1976. Radiation and the phosphate industry: an overview. In Tenth midyear topical symposium of the Northeastern New York Chapter, Health Physics Society, on natural radioactivity in man's environment.

[130] Abouzeid, A.Z., Negm, A.T. and Elgillani, D.A., 2009. Upgrading of calcareous phosphate ores by flotation: Effect of ore characteristics. International Journal of Mineral Processing, 90(1-4), pp.81-89.

[131] Partney, S.H., 1998. Regulatory status of waste clay ponds in Florida. Mining 
engineering, 50(4), pp.39-47.

[132] Moore, L. R., Wang, G., Xiong, Y., Gu, J., 2017. Impact of clay on phosphate beneficiation. SME Annual Meeting, Feb. 19 - 22, 2017, Denver, CO, preprint 17-071.

[133] Chen, G., Tao, D., Parekh, B. K., Honakay, R., 2003. Flocculation dewatering of phosphatic clay. SME Annual Meeting, preprint 06-029, 1-7.

[134] Miller, J.D., Wang, X. and Li, M., University of Utah Research Foundation (UURF), 2002. Selective flotation of phosphate minerals with hydroxamate collectors. U.S. Patent 6,341,697.

[135] Environmental Protection Agency (EPA), 1997. Damage cases and environmental releases from mines and mineral processing sites.

[136] Prasad, M.S., Reid, K.J. and Murray, H.H., 1991. Kaolin: processing, properties and applications. Applied clay science, 6(2), pp.87-119.

[137] Ruan, Y., Zhang, Z., Luo, H., Xiao, C., Zhou, F. and Chi, R., 2017. Ambient temperature flotation of sedimentary phosphate ore using cottonseed oil as a collector. Minerals, 7(5), p.65.

[138] Florida Department of Environmental Protection, 2016. Surface water quality standards - Rule: 62-302.530.

[139] Zhang, P., Snow, R., Yu, Y. and Bogan, M., 2001. Recovery of phosphate from Florida phosphatic clays. Final report, FIPR Publication, pp.02-096.

[140] Binnemans, K., Jones, P.T., Blanpain, B., Van Gerven, T. and Pontikes, Y., 2015. Towards zero-waste valorisation of rare-earth-containing industrial process residues: a critical review. Journal of Cleaner Production, 99, pp.17-38.

[141] Grabas, K., Pawełczyk, A., Stręk, W., Szełęg, E. and Stręk, S., 2019. Study on the properties of waste apatite phosphogypsum as a raw material of prospective applications. Waste and Biomass valorization, 10(10), pp.3143-3155.

[142] Zhang, P., Liang, H. and DePaoli, D., 2018. Recovery of rare earths and P from a phosphate flotation tails. In Proceedings of the IMPC 2018 Physical EnrichmentGravity, Magnetic and Electrostatic Separation, Moscow, Russia, 17-21 September.

[143] Hammas-Nasri, I., Horchani-Naifer, K., Férid, M. and Barca, D., 2016. Rare earths concentration from phosphogypsum waste by two-step leaching method. International Journal of Mineral Processing, 149, pp.78-83.

[144] Jarosiński, A., Kowalczyk, J. and Mazanek, C., 1993. Development of the Polish wasteless technology of apatite phosphogypsum utilization with recovery of rare earths. Journal of alloys and compounds, 200(1-2), pp.147-150. 
[145] Walawalkar, M., Nichol, C.K. and Azimi, G., 2016. Process investigation of the acid leaching of rare earth elements from phosphogypsum using $\mathrm{HCl}, \mathrm{HNO}_{3}$, and $\mathrm{H}_{2} \mathrm{SO}_{4}$. Hydrometallurgy, 166, pp.195-204.

[146] Azimi, G., Papangelakis, V.G. and Dutrizac, J.E., 2007. Modelling of calcium sulphate solubility in concentrated multi-component sulphate solutions. Fluid Phase Equilibria, 260(2), pp.300-315.

[147] Azimi, G., Papangelakis, V.G. and Dutrizac, J.E., 2008. Development of an MSE-based chemical model for the solubility of calcium sulphate in mixed chloride-sulphate solutions. Fluid Phase Equilibria, 266(1-2), pp.172-186.

[148] Ismail, Z., Elgoud, E., Hai, F., Ibraheem, O., Gasser, A. and Aly, H., 2015. Leaching of some lanthanides from phosphogypsum fertilizers by mineral acids. Arab J. Nucl. Sci. Appl, 48(2), pp.37-50.

[149] Laurino, J.P., Mustacato, J. and Huba, Z.J., 2019. Rare earth element recovery from acidic extracts of Florida Phosphate mining materials using Chelating polymer 1Octadecene, polymer with 2, 5-Furandione, Sodium salt. Minerals, 9(8), p.477.

[150] Reid, S., Walawalkar, M. and Azimi, G., 2017. Valorization of rare earth-containing landfilled stocks of industrial process residues: Phosphogypsum and red mud. Proceedings of the Eres.

[151] Preston, J.S., Cole, P.M., Craig, W.M. and Feather, A.M., 1996. The recovery of rare earth oxides from a phosphoric acid by-product. Part 1: Leaching of rare earth values and recovery of a mixed rare earth oxide by solvent extraction. Hydrometallurgy, 4l(1), pp.1-19.

[152] Rutherford, P.M., Dudas, M.J. and Samek, R.A., 1994. Environmental impacts of phosphogypsum. Science of the Total Environment, 149(1-2), pp.1-38.

[153] Yang, X., Makkonen, H.T. and Pakkanen, L., 2019. Rare earth occurrences in streams of processing a phosphate ore. Minerals, 9(5), p.262.

[154] Ma, Q.Y., Logan, T.J. and Traina, S.J., 1995. Lead immobilization from aqueous solutions and contaminated soils using phosphate rocks. Environmental Science \& Technology, 29(4), pp.1118-1126.

[155] Cotter-Howells, J. and Caporn, S., 1996. Remediation of contaminated land by formation of heavy metal phosphates. Applied Geochemistry, 11(1-2), pp.335-342.

[156] Basta, N.T., Gradwohl, R., Snethen, K.L. and Schroder, J.L., 2001. Chemical immobilization of lead, zinc, and cadmium in smelter-contaminated soils using biosolids and rock phosphate. Journal of Environmental Quality, 30(4), pp.1222-1230. 
[157] Yang, J., Mosby, D.E., Casteel, S.W. and Blanchar, R.W., 2001. Lead immobilization using phosphoric acid in a smelter-contaminated urban soil. Environmental Science \& Technology, 35(17), pp.3553-3559.

[158] Wellman, D.M., Icenhower, J.P., Gamerdinger, A.P. and Forrester, S.W., 2006. Effects of $\mathrm{pH}$, temperature, and aqueous organic material on the dissolution kinetics of metaautunite minerals, $(\mathrm{Na}, \mathrm{Ca}) 2-1\left[\left(\mathrm{UO}_{2}\right)\left(\mathrm{PO}_{4}\right)\right]_{2} \cdot 3 \mathrm{H}_{2} \mathrm{O}$. American Mineralogist, $91(1)$, pp.143-158.

[159] Hamdi, M. and Ide-Ektessabi, A., 2007. Dissolution behavior of simultaneous vapor deposited calcium phosphate coatings in vitro. Materials Science and Engineering: C, 27(4), pp.670-674.

[160] Saxena, S. and D'Souza, S.F., 2006. Heavy metal pollution abatement using rock phosphate mineral. Environment international, 32(2), pp.199-202.

[161] Chen, X., Wright, J.V., Conca, J.L. and Peurrung, L.M., 1997. Effects of pH on heavy metal sorption on mineral apatite. Environmental Science \& Technology, 31(3), pp.624631.

[162] Singh, S.P., Ma, L.Q. and Harris, W.G., 2001. Heavy metal interactions with phosphatic clay. Journal of Environmental Quality, 30(6), pp.1961-1968.

[163] Singh, S.P., Ma, L.Q. and Hendry, M.J., 2006. Characterization of aqueous lead removal by phosphatic clay: equilibrium and kinetic studies. Journal of Hazardous Materials, 136(3), pp.654-662.

[164] Fitch, B. and Roberts, E.J., 1985. Classification theory. SME Mineral Processing Handbook D, 3, pp.1-10.

[165] Tarr, D.T., 1985. Hydrocyclones. SME Mineral Processing Handbook, SME, Littleton, CO.

[166] Pradip, 1989. Selective flocculation of phophate slimes. Challenges in Mineral Processing, Chapter 24, Sastry K. V. S. and Fuerstenau M. C. Eds., SME, Inc., Littleton, Colorado, pp. 409-420.

[167] Phelps, D.S., American Agricultural Chemical Co, 1945. Settling of phosphate ore materials. U.S. Patent 2,381,514.

[168] Greene, E.W., Chemicals Philipp Corp, 1967. Phosphate matrix beneficiation process. U.S. Patent 3,302,785.

[169] Krofchak, D., 1981. Process for treating phosphatic clay suspensions. U.S. Patent $4,279,635$.

[170] Lehman, R.L. and Shepherd, J.A., FMC Corp, 1983. Formulation of phosphate rock 
slurries. U.S. Patent 4,374,817.

[171] Kremer, R.A. and Saunders, S.W., Mobil Oil Corp, 1986. Ore beneficiation process. U.S. Patent 4,615,869.

[172] Malito, J.T. and Layman, C.M., Nalco Chemical Co, 1993. Chemical aids for wetgrinding phosphate rock. U.S. Patent 5,183,211.

[173] Ma, M., 2011a. The dispersive effect of sodium silicate on kaolinite particles in process water: Implications for iron-ore processing. Clays and Clay Minerals, 59(3), pp.233239.

[174] Filippov, L.O., Duverger, A., Filippova, I.V., Kasaini, H. and Thiry, J., 2012. Selective flotation of silicates and Ca-bearing minerals: The role of non-ionic reagent on cationic flotation. Minerals Engineering, 36, pp.314-323.

[175] Liu, W.L., Wei, S.U.N. and Hu, Y.H., 2012. Effects of water hardness on selective flocculation of diasporic bauxite. Transactions of Nonferrous Metals Society of China, 22(9), pp.2248-2254.

[176] Ma, M., 2011b. Enhancement of hematite flocculation in the hematite-starch-(lowmolecular-weight) poly (acrylic acid) system. Industrial \& engineering chemistry research, 50(21), pp.11950-11953.

[177] Ma, M., 2012a. The dispersive effect of sodium hexametaphosphate on kaolinite in saline water. Clays and clay minerals, 60(4), pp.405-410.

[178] Ma, M., 2012b. The significance of dosing sequence in the flocculation of hematite. Chemical engineering science, 73, pp.51-54.

[179] Tao, D., Dopico, P.G., Hines, J. and Kennedy, D., 2010. An experimental study of clay binders in fine coal froth flotation. In Proceedings of the International Coal Preparation Congress (pp. 478-487).

[180] Tao, D., Zhou, X., Kennedy, D., Dopico, P. and Hines, J., 2010. Improved phosphate flotation using clay binder. Separation science and technology, 45(5), pp.604-609.

[181] Kou, J., Xu, G., Tao, D., Dopico, P.G., Hines, J. and Kennedy, D., 2012. Phosphate flotation enhancement using clay binder. Beneficiation of Phosphates: New Thought, New Technology, New Development, p.335.

[182] Tao, D., Zhou, X.H., Zhao, C., Fan, M.M., Chen, G.L., Aron, A. and Wright, J., 2007. Coal and potash flotation enhancement using a clay binder. Canadian Metallurgical Quarterly, 46(3), pp.243-250.

[183] Andersen, J.B. and Somasundaran, P., 1993. The role of changing surface mineralogy on the separation of phosphatic clay waste. International journal of mineral 
processing, 38(3-4), pp.189-203.

[184] Li, C., Farrokhpay, S., Shi, F. and Runge, K., 2015. A novel approach to measure froth rheology in flotation. Minerals Engineering, 71, pp.89-96.

[185] Farrokhpay, S., 2012. The importance of rheology in mineral flotation: A review. Minerals Engineering, 36, pp.272-278.

[186] He, M., Wang, Y. and Forssberg, E., 2004. Slurry rheology in wet ultrafine grinding of industrial minerals: a review. Powder technology, 147(1-3), pp.94-112.

[187] Shi, F.N. and Napier-Munn, T.J., 1996. A model for slurry rheology. International journal of mineral processing, 47(1-2), pp.103-123.

[188] Boger, D.V., 2000. Rheology and the minerals industry. Mineral Procesing and Extractive Metallurgy Review, 20(1), pp.1-25.

[189] Scales, P.J., Johnson, S.B. and Kapur, P.C., 2000. The influence of surface chemistry on the rheology and flow of flocculated particulate suspensions. Mineral Procesing and Extractive Metallurgy Review, 20(1), pp.27-40.

[190] Burdukova, E., Becker, M., Ndlovu, B., Mokgethi, B. and Deglon, D.A., 2008, January. Relationship between slurry rheology and its mineralogical content. In 24th Int. Minerals Processing Congress, China (pp. 2169-2178).

[191] Ndlovu, B., Burdukova, E., Becker, M., Deglon, D., Franzidis, J.P. and Laskowski, J.S., 2010, September. An investigation on the effect of chrysotile particle shape and anisotropic properties on the rheology of chrysotile suspensions. In Proceedings of XXV International Mineral Processing Congress, Brisbane (pp. 6-10).

[192] Bulatovic, S.M., Wyslouzil, D.M. and Kant, C., 1998. Operating practices in the beneficiation of major porphyry copper/molybdenum plants from Chile: Innovated technology and opportunities, a review. Minerals engineering, 11(4), pp.313-331.

[193] Senior, G.D. and Thomas, S.A., 2005. Development and implementation of a new flowsheet for the flotation of a low grade nickel ore. International Journal of Mineral Processing, 78(1), pp.49-61.

[194] Schubert, H., 2008. On the optimization of hydrodynamics in fine particle flotation. Minerals Engineering, 21(12-14), pp.930-936.

[195] Xu, D., Ametov, I. and Grano, S.R., 2011. Detachment of coarse particles from oscillating bubbles-The effect of particle contact angle, shape and medium viscosity. International Journal of Mineral Processing, 101(1-4), pp.50-57.

[196] Forbes, E., Davey, K.J. and Smith, L., 2014. Decoupling rehology and slime coatings effect on the natural flotability of chalcopyrite in a clay-rich flotation pulp. Minerals 
Engineering, 56, pp.136-144.

[197] Bakker, C.W., Meyer, C.J. and Deglon, D.A., 2009. Numerical modelling of nonNewtonian slurry in a mechanical flotation cell. Minerals Engineering, 22(11), pp.944950.

[198] Shabalala, N.Z.P., Harris, M., Leal Filho, L.S. and Deglon, D.A., 2011. Effect of slurry rheology on gas dispersion in a pilot-scale mechanical flotation cell. Minerals Engineering, 24(13), pp.1448-1453.

[199] Bakker, C.W., Meyer, C.J. and Deglon, D.A., 2009. Numerical modelling of nonNewtonian slurry in a mechanical flotation cell. Minerals Engineering, 22(11), pp.944950.

[200] Shabalala, N.Z.P., Harris, M., Leal Filho, L.S. and Deglon, D.A., 2011. Effect of slurry rheology on gas dispersion in a pilot-scale mechanical flotation cell. Minerals Engineering, 24(13), pp.1448-1453.

[201] Shi, F.N. and Zheng, X.F., 2003. The rheology of flotation froths. International Journal of Mineral Processing, 69(1-4), pp.115-128.

[202] Li, C., Runge, K., Shi, F. and Farrokhpay, S., 2016. Effect of flotation froth properties on froth rheology. Powder Technology, 294, pp.55-65.

[203] Boudrias-Chapleau, C., Bazin, C. and Cotnoir, D., 2010. The use of slurry rheology measurement in mineral processing. In 49th Annual Conference of Metallurgists of CIM. Vancouver, BC, Canada (pp. 43-55).

[204] Kawatra, S.K. and Bakshi, A.K., 1996. On-line measurement of viscosity and determination of flow types for mineral suspensions. International Journal of Mineral Processing, 47(3-4), pp.275-283.

[205] Gustafsson, J., Toivakka, M. and Koskinen, K.K., 2005. Rheology of strongly sedimenting magnetite suspensions. Annu. Trans. Nord. Rheol. Soc, 13, pp.277-281.

[206] Gaudin, A. M. 1957. Flotation. New York: McGraw-Hill.

[207] Fornasiero, D., Ralston, C., 2006. Effect of $\mathrm{MgO}$ minerals on pentlandite flotation. In: Proc. XXIII. Int. Miner. Process. Congr., Istanbul, vol. 1, pp. 750-755.

[208] Chen, X. and Peng, Y., 2018. Managing clay minerals in froth flotation - A critical review. Mineral Processing and Extractive Metallurgy Review, 39(5), pp.289-307.

[209] Yu, Y., Ma, L., Cao, M. and Liu, Q., 2017. Slime coatings in froth flotation: A review. Minerals Engineering, 114, pp.26-36.

[210] Edwards, C.R., Kipkie, W.B. and Agar, G.E., 1980. The effect of slime coatings of the 
serpentine minerals, chrysotile and lizardite, on pentlandite flotation. International Journal of Mineral Processing, 7(1), pp.33-42.

[211] Zhang, M. and Peng, Y., 2015. Effect of clay minerals on pulp rheology and the flotation of copper and gold minerals. Minerals Engineering, 70, pp.8-13.

[212] Guidice, G.R.M.D., 1934. A study of slime coatings in flotation. Trans. Metall. Soc. AIME

$112,398-409$.

[213] Wen, W.W. and Sun, S.C., 1977. Electrokinetic study on the amine flotation of oxidized coal.[For separation from ash and pyrites]. Trans. Soc. Min. Eng. AIME ;(United States), 262(2).

[214] Fuerstenau, D.W., Gaudin, A.M. and Miaw, H.L., 1958. Iron oxide slime coatings in flotation. Trans. AIME, 211, pp.792-793.

[215] Fornasiero, D., 2006. Effect of $M g O$ minerals on pentlandite flotation (Doctoral dissertation, Promed advertising limited).

[216] Attia, Y.A. and Deason, D.M., 1989. Control of slimes coating in mineral suspensions. Colloids and Surfaces, 39(1), pp.227-238.

[217] Oats, W.J., Ozdemir, O. and Nguyen, A.V., 2010. Effect of mechanical and chemical clay removals by hydrocyclone and dispersants on coal flotation. Minerals Engineering, 23(5), pp.413-419.

[218] Barbian, N., Hadler, K., Ventura-Medina, E. and Cilliers, J.J., 2005. The froth stability column: linking froth stability and flotation performance. Minerals Engineering, 18(3), pp.317-324.

[219] Sennett, P. and Young, R.H., 1979. Current problems in beneficiation of kaolin clay. In Beneficiation of Mineral Fines (pp. 115-133). AIME Publication Michigan.

[220] Sparks, D.L. ed., 1998. Soil physical chemistry. CRC press.

[221] Pate, K. and Safier, P., 2016. Chemical metrology methods for CMP quality. In Advances in Chemical Mechanical Planarization (CMP) (pp. 299-325). Woodhead Publishing.

[222] Kaya, A. and Yukselen, Y., 2005. Zeta potential of clay minerals and quartz contaminated by heavy metals. Canadian Geotechnical Journal, 42(5), pp.1280-1289.

[223] Hussain, S.A., Demirci, Ş. and Özbayoğlu, G., 1996. Zeta potential measurements on three clays from Turkey and effects of clays on coal flotation. Journal of Colloid and Interface Science, 184(2), pp.535-541. 
[224] Parks, G.A., 1967. Aqueous surface chemistry of oxides and complex oxide minerals: Isoelectric point and zero point of charge.

[225] Ferris, A.P. and Jepson, W.B., 1975. The exchange capacities of kaolinite and the preparation of homoionic clays. Journal of Colloid and Interface Science, 51(2), pp.245-259.

[226] Carroll-Webb, S.A. and Walther, J.V., 1988. A surface complex reaction model for the $\mathrm{pH}$-dependence of corundum and kaolinite dissolution rates. Geochimica et Cosmochimica Acta, 52(11), pp.2609-262.

[227] Braggs, B., Fornasiero, D., Ralston, J. and Smart, R.S., 1994. The effect of surface modification by an organosilane on the electrochemical properties of kaolinite. Clays and Clay Minerals, 42(2), pp.123-136.

[228] Tschapek, M., Tcheichvili, L. and Wasowski, C., 1974. The point of zero charge (pzc) of kaolinite and $\mathrm{SiO}_{2}+\mathrm{Al}_{2} \mathrm{O}_{3}$ mixtures. Clay Minerals, 10(4), pp.219-229.

[229] Xu, Z., Liu, J., Choung, J.W. and Zhou, Z., 2003. Electrokinetic study of clay interactions with coal in flotation. International Journal of Mineral Processing, 68(14), pp.183-196.

[230] Chen, T., Zhao, Y. and Song, S., 2017. Electrophoretic mobility study for heterocoagulation of montmorillonite with fluorite in aqueous solutions. Powder Technology, 309, pp.61-67.

[231] Liang, L., Wang, L., Nguyen, A.V. and Xie, G., 2017. Heterocoagulation of alumina and quartz studied by zeta potential distribution and particle size distribution measurements. Powder Technology, 309, pp.1-12.

[232] Tamiz Bakhtiari, M., Harbottle, D., Curran, M., Ng, S., Spence, J., Siy, R., Liu, Q., Masliyah, J. and Xu, Z., 2015. Role of caustic addition in bitumen-clay interactions. Energy \& Fuels, 29(1), pp.58-69.

[233] Houot, R., 1982. Beneficiation of phosphatic ores through flotation: Review of industrial applications and potential developments. International Journal of Mineral Processing, 9(4), pp.353-384.

[234] Liu, X., Zhang, Y., Liu, T., Cai, Z., Chen, T. and Sun, K., 2016. Beneficiation of a sedimentary phosphate ore by a combination of spiral gravity and direct-reverse flotation. Minerals, 6(2), p.38.

[235] Liu, X., Zhang, Y., Liu, T., Cai, Z. and Sun, K., 2017. Characterization and separation studies of a fine sedimentary phosphate ore slime. Minerals, 7(6), p.94.

[236] Ma, X., Bruckard, W.J. and Holmes, R., 2009. Effect of collector, pH and ionic strength 
on the cationic flotation of kaolinite. International Journal of Mineral Processing, 93(1), pp.54-58.

[237] Matis, K.A., Gallios, G.P. and Kydros, K.A., 1993. Separation of fines by flotation techniques. Separations Technology, 3(2), pp.76-90.

[238] Trahar, W.J., 1981. A rational interpretation of the role of particle size in flotation. International Journal of Mineral Processing, 8(4), pp.289-327.

[239] Basilio, C., Lowe, R.A., Gorken, A., Magliocco, L. and Hagy, R., 2000. Modified hydroxamate collectors for kaolin flotation. In Developments in Mineral Processing (Vol. 13, pp. C8b-51). Elsevier.

[240] Browning, J.S. and Johnson, A.B., 1972. Beneficiation of high clay potash ores by flotation. Trans. SEM/AIME, 252, pp.50-53.

[241] Maoming, F., Daniel, T., Honaker, R. and Zhenfu, L.U.O., 2010. Nanobubble generation and its applications in froth flotation (part II): fundamental study and theoretical analysis. Mining Science and Technology (China), 20(2), pp.159-177.

[242] Mohanty, S. and Das, B., 2010. Optimization studies of hydrocyclone for beneficiation of iron ore slimes. Mineral Processing \& Extractive Metallurgy Review, 31(2), pp.8696.

[243] Bhattacharyya, P., Chakrabarti, D.M., Sarkhel, B.R., Saha, P., Chattoraj, U.S. and Banerjee, B., 1997. Modified hydrocycloning for effective elimination of stubborn slimes.

[244] Mohanty, S. and Das, B., 2010. Optimization studies of hydrocyclone for beneficiation of iron ore slimes. Mineral Processing \& Extractive Metallurgy Review, 31(2), pp.8696.

[245] Raghu Kumar, C., Tripathy, S.K., Mohanan, S., Venugopalan, T. and Suresh, N., 2010. Evaluation of floatex density separator performance using silica sand. In Proceedings of the XI International Seminar on Mineral Processing Technology (MPT-2010) (Vol. 2, No. Section 9, pp. 701-706). Allied Publishers, New Delhi.

[246] Raghukumar, C., Tripathy, S.K. and Mohanan, S., 2012. Beneficiation of Indian high alumina iron ore fines-a case study. International Journal of Mining Engineering and Mineral Processing, 1(2), pp.94-100.

[247] Das, A. and Sarkar, B., 2018. Advanced gravity concentration of fine particles: A review. Mineral processing and extractive metallurgy review, 39(6), pp.359-394.

[248] Wills, B. A. \& Finch, J. A. 2016. Gravity concentration. In: Wills' Mineral Processing Technology, 8th edition. Boston, MA: Butterworth-Heinemann. 
[249] Svoboda, J. and Fujita, T., 2003. Recent developments in magnetic methods of material separation. Minerals Engineering, 16(9), pp.785-792.

[250] Wasmuth, H.D. and Unkelbach, K.H., 1991. Recent developments in magnetic separation of feebly magnetic minerals. Minerals Engineering, 4(7-11), pp.825-837.

[251] Notebaart, C.W. and Van Der Meer, F.P., 1992. High selectivity in HGMS by capture on the downstream side of matrix elements. Minerals Engineering, 5(10-12), pp.11351145 .

[252] Ohara, T., 2014. Progress in Magnetic separation technology for processing large quantities of dilute suspensions. Journal of the Japan Society of Powder and Powder Metallurgy, 61(S1), pp.S139-S144.

[253] Hazen, W.C., Henrickson, A.V. and Hadzeriga, P., Hazen Research Inc, 1969. Recovery of phosphate values from phosphatic slimes. U.S. Patent 3,425,799.

[254] Peiravi, M., Dehghani, F., Ackah, L., Baharlouei, A., Godbold, J., Liu, J., Mohanty, M. and Ghosh, T., 2020. A Review of Rare-Earth Elements Extraction with Emphasis on Non-conventional Sources: Coal and Coal Byproducts, Iron Ore Tailings, Apatite, and Phosphate Byproducts. Mining, Metallurgy \& Exploration, pp.1-26.

[255] Laskowski, J.S., 1992. Oil assisted fine particle processing. In Colloid chemistry in mineral processing (pp. 361-394). Elsevier Amsterdam.

[256] Jordens, A., McCarthy, S. and Waters, K.E., 2014. The effect of activating ions on the adsorption of a benzohydroxamic acid collector onto a rare earth silicate. In COM 2014Conference of Metallurgists Proceedings (pp. 1-12).

[257] Espiritu, E.R.L., da Silva, G.R., Azizi, D., Larachi, F. and Waters, K.E., 2018. The effect of dissolved mineral species on bastnäsite, monazite and dolomite flotation using benzohydroxamate collector. Colloids and Surfaces A: Physicochemical and Engineering Aspects, 539, pp.319-334.

[258] Marion, C., Li, R. and Waters, K.E., 2020. A review of reagents applied to rare-earth mineral flotation. Advances in Colloid and Interface Science, p.102142.

[259] Urbina, R.H., 2003. Recent developments and advances in formulations and applications of chemical reagents used in froth flotation. Mineral Processing and Extractive Metallurgy Review, 24(2), pp.139-182.

[260] Foucaud, Y., Badawi, M., Filippov, L., Filippova, I. and Lebègue, S., 2019. A review of atomistic simulation methods for surface physical-chemistry phenomena applied to froth flotation. Minerals Engineering, 143, p.106020.

[261] Foucaud, Y., Lebègue, S., Filippov, L.O., Filippova, I.V. and Badawi, M., 2018. 
Molecular insight into fatty acid adsorption on bare and hydrated (111) fluorite surface. The Journal of Physical Chemistry B, 122(51), pp.12403-12410.

[262] Foucaud, Y., Filippova, I.V. and Filippov, L.O., 2019. Investigation of the depressants involved in the selective flotation of scheelite from apatite, fluorite, and calcium silicates: Focus on the sodium silicate/sodium carbonate system. Powder technology, 352, pp.501-512.

[263] Foucaud, Y., Lainé, J., Filippov, L.O., Barrès, O., Kim, W.J., Filippova, I.V., Pastore, M., Lebègue, S. and Badawi, M., 2020. Adsorption mechanisms of fatty acids on fluorite unraveled by infrared spectroscopy and first-principles calculations. Journal of Colloid and Interface Science, 583, pp.692-703.

[264] Filippov, L.O., Foucaud, Y., Filippova, I.V. and Badawi, M., 2018. New reagent formulations for selective flotation of scheelite from a skarn ore with complex calcium minerals gangue. Minerals Engineering, 123, pp.85-94.

[265] Honaker, R.Q., Saracoglu, M. and Huang, Q., 2016. Application of hydrophobic and magnetic plastic particles for enhanced flotation recovery. Minerals Engineering, 98, pp.223-231.

[266] Eskanlou, A., Chegeni, M.H., Khalesi, M.R., Abdollahy, M. and Huang, Q., 2019. Modeling the bubble loading based on force balance on the particles attached to the bubble. Colloids and Surfaces A: Physicochemical and Engineering Aspects, 582, p.123892.

[267] Huang, Q., Yang, X. and Honaker, R.Q., 2019. Evaluation of Frother Types for Improved Flotation Recovery and Selectivity. Minerals, 9(10), p.590.

[268] Eskanlou, A., Khalesi, M.R., Abdollahy, M. and Hemmati Chegeni, M., 2018. Interactional effects of bubble size, particle size, and collector dosage on bubble loading in column flotation. Journal of Mining and Environment, 9(1), pp.107-116.

[269] Yeşilyurt, Z., Vaziri Hassas, B., Karakaş, F. and Boylu, F., 2017. Ultrafine coal flotation and dewatering: Selecting the surfactants of proper hydrophilic-lipophilic balance (HLB). International Journal of Coal Preparation and Utilization, pp.1-17.

[270] Sun, X. and Waters, K.E., 2014. Synergistic effect between bifunctional ionic liquids and a molecular extractant for lanthanide separation. ACS Sustainable Chemistry \& Engineering, 2(12), pp.2758-2764.

[271] Hidayah, N.N. and Abidin, S.Z., 2018. The evolution of mineral processing in extraction of rare earth elements using liquid-liquid extraction: A review. Minerals Engineering, 121, pp.146-157.

[272] Park, J., Jung, Y., Kusumah, P., Lee, J., Kwon, K. and Lee, C.K., 2014. Application of 
ionic liquids in hydrometallurgy. International journal of molecular sciences, 15(9), pp.15320-15343.

[273] Leistner, T., Embrechts, M., Leißner, T., Chelgani, S.C., Osbahr, I., Möckel, R., Peuker, U.A. and Rudolph, M., 2016. A study of the reprocessing of fine and ultrafine cassiterite from gravity tailing residues by using various flotation techniques. Minerals Engineering, 96, pp.94-98.

[274] Leistner, T., Peuker, U.A. and Rudolph, M., 2017. How gangue particle size can affect the recovery of ultrafine and fine particles during froth flotation. Minerals Engineering, 109, pp.1-9.

[275] Hoang, D.H., Kupka, N., Peuker, U.A. and Rudolph, M., 2018. Flotation study of fine grained carbonaceous sedimentary apatite ore-Challenges in process mineralogy and impact of hydrodynamics. Minerals Engineering, 121, pp.196-204.

[276] Kouachi, S., Hassas, B.V., Hassanzadeh, A., Çelik, M.S. and Bouhenguel, M., 2017. Effect of negative inertial forces on bubble-particle collision via implementation of Schulze collision efficiency in general flotation rate constant equation. Colloids and Surfaces A: Physicochemical and Engineering Aspects, 517, pp.72-83.

[277] Safari, M., Harris, M. and Deglon, D., 2017. The effect of energy input on the flotation of a platinum ore in a pilot-scale oscillating grid flotation cell. Minerals Engineering, 110, pp.69-74.

[278] Hassanzadeh, A., Firouzi, M., Albijanic, B. and Celik, M.S., 2018. A review on determination of particle-bubble encounter using analytical, experimental and numerical methods. Minerals Engineering, 122, pp.296-311.

[279] Small, G.L., Grano, S.R., Ralston, J. and Johnson, N.W., 1997. Methods to increase fine mineral recovery in the Mount Isa Mines lead/zinc concentrator. Minerals engineering, 10(1), pp.1-15.

[280] Nicol, S.K., Engel, M.D. and Teh, K.C., 1986. Fine-particle flotation in an acoustic field. International journal of mineral processing, 17(1-2), pp.143-150.

[281] Videla, A.R., Morales, R., Saint-Jean, T., Gaete, L., Vargas, Y. and Miller, J.D., 2016. Ultrasound treatment on tailings to enhance copper flotation recovery. Minerals Engineering, 99, pp.89-95.

[282] Jameson, G.J., 2010. Advances in fine and coarse particle flotation. Canadian Metallurgical Quarterly, 49(4), pp.325-330.

[283] Govender, D., Lelinski, D. and Traczyk, F., 2013. Hybrid Energy FlotationTM-on the optimization of fine and coarse particle kinetics in a single ro. Journal of the Southern African Institute of Mining and Metallurgy, 113(3), pp.00-00. 
[284] Battersby, M., Battersby, R.M., Flatman, S., Imhof, R., Sprenger, H. and Bragado, T., 2011. Recovery of ultra fines using imhoflot pneumatic flotation-Two pilot plant case studies recovering nickel and zinc from tailings streams. In MEI Conference.

[285] Young, M.F., Barnes, K.E., Anderson, G.S., Pease, J.D. and Zinc, X., 2006, January. Jameson cell: The "comeback" in base metals applications using improved design and flowsheet. In Proceedings 38th Annual Meeting of the Canadian Mineral Processors (pp. 311-322).

[286] Safari, M., Harris, M., Deglon, D., Leal Filho, L. and Testa, F., 2016. The effect of energy input on flotation kinetics. International Journal of Mineral Processing, 156, pp.108-115.

[287] Deglon, D.A., 2005. The effect of agitation on the flotation of platinum ores. Minerals Engineering, 18(8), pp.839-844.

[288] Harbort, G.J., Manlapig, E.V. and DeBono, S.K., 2002. Particle collection within the Jameson cell downcomer. Mineral Processing and Extractive Metallurgy, 111(1), pp.110.

[289] Dickinson, J.E., Jiang, K. and Galvin, K.P., 2015. Fast flotation of coal at low pulp density using the Reflux Flotation Cell. Chemical Engineering Research and Design, 101, pp.74-81.

[290] Hassanzadeh, A. and Karakaş, F., 2017. Recovery improvement of coarse particles by stage addition of reagents in industrial copper flotation circuit. Journal of Dispersion Science and Technology, 38(2), pp.309-316.

[291] Eskanlou, A., Shahbazi, B. and Vaziri Hassas, B., 2018. Estimation of flotation rate constant and collision efficiency using regression and artificial neural networks. Separation Science and Technology, 53(2), pp.374-388.

[292] Tian, Q., Zhang, Y., Li, G. and Wang, Y., 2017. Floc-flotation of ultrafine coal slimes achieved by flotation column. Energy Sources, Part A: Recovery, Utilization, and Environmental Effects, 39(9), pp.899-904.

[293] Li, Z., Rao, F., Lou, X., Song, S. and López-Valdivieso, A., 2019. Floc-Flotation of Malachite Fines with an Octyl Hydroxamate and Kerosene Mixture. Minerals, 9(5), p.301.

[294] Hong, Z., Wanxiong, C. and Jin, C., 1988. Co-flocculation with polymer and surfactant. In Production and Processing of Fine Particles (pp. 279-288). Pergamon.

[295] Wightman, E.M., Grano, S.R. and Ralston, J., 2000. Selectivity in the polymer assisted separation of galena from quartz by flotation. Minerals engineering, 13(8-9), pp.843856. 
[296] Soto, H. and Barbery, G., 1988. Separation of fine particles by floc flotation. In Production and Processing of Fine Particles (pp. 297-308). Pergamon.

[297] Song, S., Lopez-Valdivieso, A. and Reyes-Bahena, J.L., 1999. Hydrophobic flocculation applied to fine mineral and coal processing.

[298] Somasundaran, P., 1986. An overview of the ultrafine problem. In Mineral Processing at a Crossroads (pp. 1-36). Springer, Dordrecht.

[299] Liu, Q. and Friedlaender, F.J., 1994. Fine particle processing by magnetic carrier methods. Minerals Engineering, 7(4), pp.449-463.

[300] Evans, C.L., Wightman, E.M. and Yuan, X., 2015. Quantifying mineral grain size distributions for process modelling using X-ray micro-tomography. Minerals Engineering, 82, pp.78-83.

[301] Reyes, F., Lin, Q., Udoudo, O., Dodds, C., Lee, P.D. and Neethling, S.J., 2017. Calibrated X-ray micro-tomography for mineral ore quantification. Minerals Engineering, 110, pp.122-130.

[302] Ueda, T., Oki, T. and Koyanaka, S., 2016. Statistical effect of sampling particle number on mineral liberation assessment. Minerals Engineering, 98, pp.204-212.

[303] Evans, C.L. and Napier-Munn, T.J., 2013. Estimating error in measurements of mineral grain size distribution. Minerals Engineering, 52, pp.198-203. 


\section{CHAPTER 2}

De-sliming followed by froth flotation for the recovery of phosphorus and enrichment of rare earth elements from Florida waste clay 


\title{
De-sliming followed by froth flotation for the recovery of phosphorus and enrichment of rare earth elements from Florida waste clay
}

\author{
Amir Eskanlou ${ }^{1}$, Qingqing Huang ${ }^{* 1}$, Patrick Zhang ${ }^{2}$ \\ 1- Department of Mining Engineering, West Virginia University, 365 Mineral Resources Building, 1374 \\ Evansdale Drive, Morgantown, WV 26506, USA \\ 2- Florida Industrial and Phosphate Research Institute (FIPR), Florida Polytechnic University, Bartow, FL, USA \\ * Corresponding Author: qingqing.huang@mail.wvu.edu \\ Under Review: Journal of Resources, Conservation \& Recycling
}

\begin{abstract}
Reprocessing and valorization of secondary resources is a possible solution to alleviate the supply-demand disparity for critical materials. In the current study, the recovery of $\mathrm{P}$ and enrichment of REEs from Florida waste clay (WC) were investigated. Clays, dolomite, and quartz are the main associated gangue minerals, while apatite is the predominant P-bearing mineral, and monazite and xenotime are the rare earth minerals in this WC. A 1.5-in. diam. hydro-cyclone unit was initially employed for the removal of clays. Froth flotation was then examined for the separation of values from the cyclone underflow. Various depressants and surface modifying agents were assessed for both direct and reverse flotation separations. Results showed that the direct flotation does not offer a solution for the selective recovery of P from WC. Despite their documented affinity for apatite and rare earths, hydroxamic acid collectors do not produce a selective separation. A single-stage reverse cationic process provides a more economically viable route, also owing to its relative capability to avoid the loss of REEs. Test results of the single-stage reverse cationic process indicated that the $\mathrm{P}_{2} \mathrm{O}_{5}$ grade was increased to $21 \mathrm{wt} . \%$ from an initial grade of $\sim 8 \mathrm{wt} . \%$ with a corresponding recovery of approximately $80 \%$. The REE content was elevated from an initial value of $307.1 \mathrm{ppm}$ to $800 \mathrm{ppm}$ with an $80 \%$ recovery resulting from the same process. The removal of clays, silicates, and carbonates up to a point to meet the medium-grade phosphate ore specifications also facilitates the subsequent recovery of REEs using chemical separation. The process is of significance as the removal of such troublesome gangues alleviates the acid consumption issue and thereby the economic and environmental concerns upon the recovery of REEs from WC, which has long been alluded to as the restricting factor.
\end{abstract}

Keywords: Phosphorus, waste, clay, flotation, de-sliming, REE 


\section{Introduction}

Phosphorus (P), a nonrenewable and non-substitutable element with the average continental crust occurrence of $0.27 \%$ as $\mathrm{P}_{2} \mathrm{O}_{5}$, is the primary resource for the production of fertilizers and chemical products. Hence, the demand for this element must be met through the mining, beneficiation, and chemical processing of phosphate ores [1]. Rock phosphate occurs as high-grade $\left(+30 \% \mathrm{P}_{2} \mathrm{O}_{5}\right)$, medium-grade $\left(20 \%-30 \% \mathrm{P}_{2} \mathrm{O}_{5}\right)$, and low-grade ore $(15 \%-20 \%$ $\mathrm{P}_{2} \mathrm{O}_{5}$ ). The high-grade ore blends with medium-grade ore for direct sale. The low-grade ore is beneficiated to produce either possibly high grade or medium-grade phosphate rock suitable for subsequent processes [2]. Phosphate mining and beneficiation industry strives to meet the needs and supplies for the production of adequate food for the ever-growing world population [3]. This means that there is a challenging task ahead for the fertilizer and agriculture industries to ensure food availability for the world population. Such a necessity for the inevitable growth of the phosphate industry has led to the ever-increasing volume of waste streams $[1,3]$. Thus, reprocessing and valorization of secondary resources is a possible solution that can alleviate the disparity between supply and demand. During the beneficiation of phosphate ore, the fines fraction $(-106 \mu \mathrm{m})$ is separated by cyclones as a dilute (3-5\% solids by weight) aqueous slurry. The solids are a mixture of clay minerals, silica sand, carbonates, apatite (the most common phosphate mineral), and other finely divided minerals [4]. This slurry (commonly called waste clay (WC)) is pumped into large impoundment areas for natural settling. However, because of the colloidal nature and slow consolidation characteristics of this slurry, large aboveground storage areas are required $[4,5]$. Therefore, a massive volume of water and large land areas are tied-up by impounding these clays for an extended period. In Florida, more than one ton of WC is produced per ton of phosphate rock product, which means about 20 million tons of this waste annually, and over two billion tons totally accumulated in Florida to date. Eskanlou and Huang (2021) [6] have conducted a comprehensive and critical literature review on WC. Waste clay, long known as an ultimate processing challenge in the industry, is now considered as a precious reserve for $\mathrm{P}$ and other critical elements. Assuming 9\% $\mathrm{P}_{2} \mathrm{O}_{5}$, this reserve contains approximately 600 million tons of phosphate, which highlights the importance of this reserve as a $\mathrm{P}$-rich resource [7]. In some operations, about one-third of the $\mathrm{P}_{2} \mathrm{O}_{5}$ mined ends up in WC [8]. Based on the phosphate matrix analysis in 2001 , WC with a $9 \%$ grade of $\mathrm{P}_{2} \mathrm{O}_{5}$ makes up about 20 wt. $\%$ of the matrix. This means that about 3.27 million tons of $\mathrm{P}_{2} \mathrm{O}_{5}(27 \%$ of annual 
production) are being wasted each year, assuming $100 \%$ recovery of phosphate in the pebble, $85 \%$ recovery of phosphate in the flotation feed, and Florida production of 40 million tons per year of phosphate rock [8]. As Florida's phosphate reserves diminish, it becomes more imperative to recover the phosphate values from these slimes.

Another prominent value being lost in WC is rare earth elements (REEs) comprising 15 lanthanides plus Yttrium (Y) and Scandium (Sc). Assuming a $300 \mathrm{ppm}$ total REE (TREE) content, this reserve contains 600 thousand tons of REEs including 200 thousand tons of Y solely. REEs, as well-documented in the literature [7, 9, 10], are becoming increasingly important in the transition to a low-carbon circular economy, considering their essential role in permanent magnets, rechargeable nickel hydride batteries, catalysts, and other green economy applications [11]. Generally, phosphate rock contains about 500 ppm REEs on average [10]. According to a study by Zhang et al. (2018) [12], approximately $40 \%$ of REEs in phosphate ore ends up in WC during the processing operation. All these highly suggest the importance of WC as a valuable source for REEs. Besides, P. Zhang et al. (2017) reported that REEs in Florida WC occurs in three primary forms: monazite, xenotime, and as a substitution of calcium in phosphate crystals [7]. REEs in WC follow P, meaning that the key to recovering REEs from WC is to concentrate phosphate values first $[7,8]$.

However, due to its troublesome nature, WC poses severe environmental problems along with economic loss. Two prerequisites are the removal of extremely fine-sized clays and the recovery of phosphate, which can pave the path for the recovery of other valuable elements e.g. REEs. Different possible schemes or a combination of them have been considered by various research/ industrial trials, including froth flotation [13-19], selective-flocculation and floc-flotation [20-23], cycloning [24, 25], gravity separation [26-28], magnetic separation [2932], leaching [7, 8, 33, 34], etc. Most of the efforts have shown no promising solution for failing to address economic and/or environmental concerns. Overall, moving from mostly chemical separation processes to the primarily physical/ physicochemical processes with low operational costs and environmental impacts could be a more feasible solution.

Froth flotation constitutes the most widely used concentration process for sedimentary deposits with siliceous/ dolomitic gangues. In the case of ultrafine deposits such as WC, however, the flotation process faces severe challenges due to its extremely fine particle size, 
which causes processing difficulties. The presence of clays, along with siliceous and dolomitic slimes in phosphate fines, e.g., WC, consumes a huge portion of reagents, decreases the collision probability between bubbles and minerals, prevents phosphate particle attachment to air bubbles, and thus considerably reducing the metallurgical performance [37]. Zhang et al. (2019) recognize the separation of dolomite from phosphate as one of the most challenging tasks in phosphate beneficiation, such that over $50 \%$ of the future phosphate reserve in Florida contains too much dolomite to process using the current industry practice [37]. This challenge arises not only from the ultrafine size of these gangue slimes but also from the similarity between the surface physico-chemical properties of these associated gangues with the phosphate-bearing minerals. In collaboration with worldwide experts in the field, the Florida Industrial and Phosphate (FIPR) Institute have attempted to address the dolomite issue in beneficiating various Florida phosphate resources by developing promising solutions [7, 37]. Currently, plants use direct flotation (generally using a fatty acid collector) followed by reverse flotation of siliceous fines in which the removal of the clays is the key [38]. Prior studies have demonstrated that pre-recovery by gravity/size could significantly reduce the flotation reagent consumption in direct flotation and was capable of recovering apatite from ultra-fines [39]. A gravity-flotation process consisting of spiral separation followed by reverse flotation for recovering apatite from a clay-rich phosphate ore slime was proposed by Liu et al. (2017) to mainly reduce the reagent cost [40]. Managing clay minerals and their roles in a froth flotation process has been the subject of several studies globally [41-43].

Hydro-cyclones have been widely used in the mining industry to reject clays before the beneficiation processes. De-sliming significantly improves the subsequent froth flotation process by mitigating the deleterious effects posed by slimes, as noted earlier. The major advantages of hydro-cyclones are mechanical simplicity, high throughput of mineral suspensions, small installation footprint, and low capital cost compared to other mechanical classifiers $[44,45]$. The disadvantage of using hydro-cyclones is that the fine valuables are also rejected to the overflow, together with the clays and other slime minerals. Bhattacharyya et al. (1997) employed a modified hydro-cyclone by exploiting the extremely high shear-fields inside a hydro-cyclone to effectively eliminate the stubborn sticky slime coating Sukulu phosphate ore [46]. This attempt resulted in an increased $\mathrm{P}_{2} \mathrm{O}_{5}$ recovery up to $25 \%$ at a similar grade. 
Reverse flotation has also been employed for the rejection of slimes from the valuables. Various research endeavors have investigated the reverse flotation for the separation of dolomitic and siliceous slimes from different phosphate ores [18, 47-54]. Browning and Johnson (1972) achieved promising results on the recovery of potash from high-clay and lowgrade slimes of the Permian Basin of New Mexico using froth flotation [47]. They conditioned the clay fines with a starch solution to reduce the amine absorption by any clay present. Peng and $\mathrm{Gu}$ (2005) employed a double reverse fine flotation process to remove carbonate gangues from Florida dolomitic phosphate pebble [50]. They produced a phosphate concentrate with $31.6 \% \mathrm{P}_{2} \mathrm{O}_{5}$ and $0.8 \% \mathrm{MgO}$, with a $92 \% \mathrm{P}_{2} \mathrm{O}_{5}$ recovery, from a feed containing $26.7 \%$ $\mathrm{P}_{2} \mathrm{O}_{5}$ and 2.2\% $\mathrm{MgO}$. Fortes et al. (2007) developed an alternative process to separate the siliceous gangue from a Brazilian phosphate ore [51].

There is no doubt that achieving a successful separation of materials using froth flotation requires scrutiny of flotation reagents along with surface- and electro-chemistry conditions suitable for the desired interaction between target minerals and the chemical reagents. Sis and Chander (2003) have performed a critical review study on the reagents used in phosphate ore flotation [52]. In the flotation of phosphate ores, fatty acids and their salts are commonly used as collectors to float phosphate minerals due to their low cost and strong collecting ability [53]. Due to the relatively low selectivity of fatty acids and their derivatives, cationic collectors are also used for floating magnesium carbonates and silicates under controlled conditions and with the use of modifiers /depressants $[13,54,55]$. The application of hydroxamic acid collectors as an alternative to the commonly used fatty acids in the flotation of phosphate-rich minerals has drawn remarkable attention in recent decades [56, 57]. Miller et al. (2002) employed hydroxamic acid collectors for the single stage bench-scale flotation of sedimentary phosphate rock, where a phosphate recovery of $95 \%$ with a concentrate grade of $31 \% \mathrm{P}_{2} \mathrm{O}_{5}$ was achieved [56]. All in all, a successful beneficiation of phosphate minerals from their associated gangues, mainly known to be magnesium carbonates and silicates, several parameters, i.e., particle size, surface properties, solubility, collector type and concentration, modifier/ depressant types and their concentrations, etc., have to be adequately optimized. To date, extensive research and industrial endeavors have been devoted to the flotation separation of phosphate values from various deposits and processing streams, which have led to the development of a number of promising routes [58]. However, despite its significant economic potential, WC has remained 
an industrial processing challenge due to its troublesome nature and high content of ultrafine impurities.

In light of this fact, this study aimed to investigate the recovery of $\mathrm{P}$ along with the enrichment of REEs from Florida WC considering both economic and environmental aspects. Due to WC's troublesome nature, the goal of this study was set to produce a medium-grade P product suitable for the subsequent processes. Hence, after evaluating different possible routes applied to various deposits of similar nature, de-sliming followed by froth flotation was identified as the approach to achieve the set goal. As WC also hosts REEs as critical elements, the enrichment of REEs was also considered for facilitating an efficient recovery of these critical elements through suitable subsequent processes. The recovery of REEs from WC will be the focus of a future study by the authors.

\section{Experimental Methodology}

\section{Materials}

The WC sample was supplied by the FIPR Institute. The received WC sample was the underflow slurry of a 2-inch diam. hydro-cyclone cluster with some water decanted to $59 \%$ solid by weight. To obtain a representative dry sample, the slurry was well mixed using an overhead stirrer for 10 minutes. Later on, while mixing, a five-litter sample was collected from the total of $19 \mathrm{~L}$ slurry using a peristaltic pump. Then, the same procedure was repeated for the $5 \mathrm{~L}$ slurry so that a $1.25 \mathrm{~L}$ representative sample was collected. The collected representative slurry sample was left to dry overnight inside an oven at $150{ }^{\circ} \mathrm{C}$. Finally, using the coning and quartering technique, a representative powder sample was obtained from the bulk sample. The representative dried powder sample of "as received" WC was subjected to mineralogical, morphological and elemental characterization studies.

Panalytical X-ray powder diffraction (XRD) technique was employed to investigate the crystalline phases and mineral associations within WC. Portable X-ray fluorescence (PXRF) analyzer manufactured by Olympus Vanta ${ }^{\circledR}$ was mainly employed for the elemental analysis. Inductively coupled plasma mass spectrometry and - atomic emission spectroscopy, i.e., ICPMS \& -OES methods were used for the quantification of rare earth as well as radioactive elements. For the ICP, fusion coupled with calcination sample preparation technique was found to be the most suitable approach for the current study. Results of the PXRF were compared 
and validated with those obtained from the ICP methods for several randomly selected feed and product samples. The morphological characteristics of the samples were investigated using Hitachi S-4700 Scanning Electron Microscope (SEM) coupled with energy dispersive X-ray spectroscopy (EDS), which allows for targeted analysis of sample surfaces. The particle size distribution (PSD) was analyzed for the representative samples using CILAS 1190 particle size analyzer.

Pure minerals were employed for electro-kinetic studies. Apatite (calcium fluorophosphate) and dolomite were purchased from Ward's Science (USA). Monazite was kindly provided by the Department of Mining and Minerals Engineering at Virginia Polytechnic Institute and State University. Xenotime (from Clara May Mine, Colorado) was procured from Mineralogical Research Company (USA). Quartz sand was obtained from Fisher Scientific. Fig. 2-1 presents the XRD patterns of apatite, monazite, dolomite, quartz and xenotime samples used for the current study. As well, the main elemental composition of the mineral samples as obtained from XRF analysis is summarized in Table 2-1.

Table 2-1: Concentration of main metal elements of model mineral samples obtained from XRF.

\begin{tabular}{lllllllllll}
\hline \multicolumn{1}{c}{ Mineral } & \multicolumn{10}{c}{ Distribution of main elements (wt.\%) } \\
\hline & $\mathrm{Ca}$ & $\mathrm{P}$ & $\mathrm{Ce}$ & $\mathrm{La}$ & $\mathrm{Al}$ & $\mathrm{Mg}$ & $\mathrm{Th}$ & $\mathrm{Y}$ & $\mathrm{Si}$ & $\mathrm{Fe}$ \\
\cline { 2 - 11 } Apatite & 31.9 & 10.9 & 0.3 & 0.18 & - & - & 0.24 & 0.04 & 0.32 & 0.019 \\
Monazite & 0.1 & 1.95 & 17 & 12.2 & 0.26 & 0.33 & 0.56 & 0.12 & 0.35 & 0.19 \\
Xenotime & 0.07 & 11.4 & 0.02 & - & 1.56 & 1.33 & 0.48 & 16.1 & 3.2 & 1.67 \\
Dolomite & 22.8 & 0.05 & - & - & 1.93 & 8.15 & - & - & 6.65 & 1.06 \\
Quartz & 0.02 & 0.03 & - & - & 0.12 & - & - & - & 44.9 & 0.027 \\
\hline
\end{tabular}




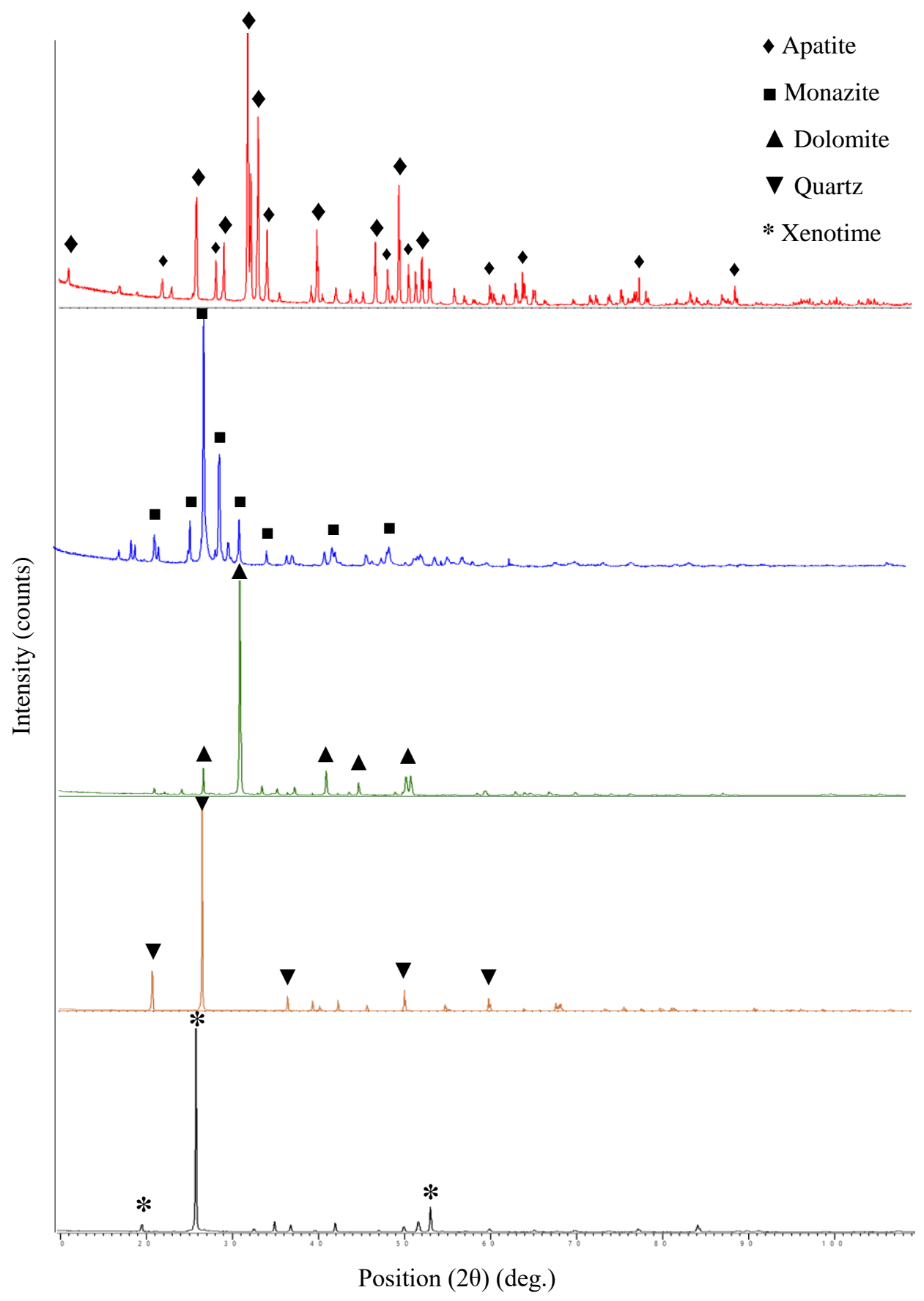

Figure 2-1: X-ray powder diffractograms of pure apatite, monazite, dolomite, quartz and xenotime samples.

\section{Chemicals}

In the current study, octanohydroxamic acid (OHA), benzohydroxamic acid (BHA), and sodium oleate $(\mathrm{NaOl})$ were used as the collectors for the flotation of phosphate-bearing minerals. Dodecylammonium chloride $(\mathrm{DDA}, 0.5 \mathrm{~g} / \mathrm{L}$ dodecylamine solution in $\mathrm{HCl}$ at $\mathrm{pH}=$ 
3) was used as the collector for silica flotation in the reverse flotation process. Citric acid (CA), sodium silicate (SS), and disodium sulfide (DS) were used as depressants to avoid the flotation of associated gangue minerals. Ethylenediaminetetraacetic acid (EDTA), sodium carbonate (SC), and sodium polyacrylate (SP) were used as surface modifiers to mitigate the negative effect of depressants on the flotation efficiency of valuable minerals. Methyl isobutyl carbinol (MIBC) was used as the frothing agent in all flotation experiments. Hydrochloric acid ( $\mathrm{HCl})$ and sodium hydroxide $(\mathrm{NaOH})$ solutions of proper concentrations were used as $\mathrm{pH}$ regulators. Potassium chloride $(\mathrm{KCl})$ solution of $10^{-3}$ mol. $\mathrm{L}^{-1}$ concentration was used as the supporting electrolyte for zeta potential measurements. Details of the chemicals used in the present study are listed in Table 2-2.

Table 2-2: Details of the chemical reagents used in the current study.

\begin{tabular}{lllll}
\hline Chemical & Formula & $\mathrm{MW}^{1}(\mathrm{~g} /$ mole $)$ & Purity & Supplier \\
\hline OHA & $\mathrm{C}_{8} \mathrm{H}_{17} \mathrm{NO}_{2}$ & 159.23 & $98 \%$ & Fisher Scientific \\
BHA & $\mathrm{C}_{7} \mathrm{H}_{7} \mathrm{NO}_{2}$ & 137.14 & $98 \%$ & Fisher Scientific \\
$\mathrm{NaOl}$ & $\mathrm{C}_{18} \mathrm{H}_{33} \mathrm{NaO}_{2}$ & 304.44 & $\geq 95 \%$ & TCI America \\
DDA & $\mathrm{C}_{12} \mathrm{H}_{27} \mathrm{~N}$ & 185.35 & $98 \%$ & Sigma Aldrich \\
$\mathrm{CA}$ & $\mathrm{C}_{6} \mathrm{H}_{8} \mathrm{O}_{7}$ & 192.123 & $\geq 99 \%$ & Sigma Aldrich \\
SS & $\mathrm{Na}_{2} \mathrm{SiO}_{3}$ & 212.14 & $\geq 99 \%$ & Sigma Aldrich \\
DSS & $\mathrm{Na}_{2} \mathrm{~S}$ & 240.18 & $\geq 99 \%$ & VWR \\
EDTA & $\mathrm{C}_{10} \mathrm{H}_{16} \mathrm{~N}_{2} \mathrm{O}_{8}$ & 292.24 & $\geq 99 \%$ & Fisher Scientific \\
SC & $\mathrm{Na}_{2} \mathrm{CO}_{3}$ & 105.98 & $\geq 99 \%$ & VWR \\
SP & $\left(\mathrm{C}_{3} \mathrm{H}_{3} \mathrm{NaO}_{2}\right)_{n}$ & 94.04 & $\geq 99 \%$ & VWR \\
$\mathrm{MIBC}$ & $\mathrm{C}_{6} \mathrm{H}_{14} \mathrm{O}$ & 102.174 & $\geq 99 \%$ & Sigma Aldrich \\
$\mathrm{HCl}$ & $\mathrm{HCl}$ & 36.45 & $30 \%$ & Fisher Scientific \\
$\mathrm{NaOH}$ & $\mathrm{NaOH}$ & 39.99 & $\geq 99 \%$ & Sigma Aldrich \\
$\mathrm{KCl}$ & $\mathrm{KCl}$ & 74.5 & $\geq 99 \%$ & Fisher Scientific \\
\hline
\end{tabular}

\section{De-sliming}

A 1.5-inch laboratory hydro-cyclone unit (see Fig. 2-2) was used for WC de-sliming with the major aim of removing the clay content to avoid the deleterious effect of these pseudoplastic minerals on flotation process. In order to enhance the efficiency of the de-sliming process, a diluted slurry with 5\% solid by weight was prepared from WC and was used as the feed to the cyclone unit. The overflow and underflow products of the cyclone were properly collected, dewatered, dried, and weighed. They then were analyzed for PSD, mineralogical and

\footnotetext{
${ }^{1}$ Molecular Weight
} 
elemental compositions to evaluate the distribution of different minerals/ elements in different size fractions. The underflow product was used as the feed for flotation experiments.

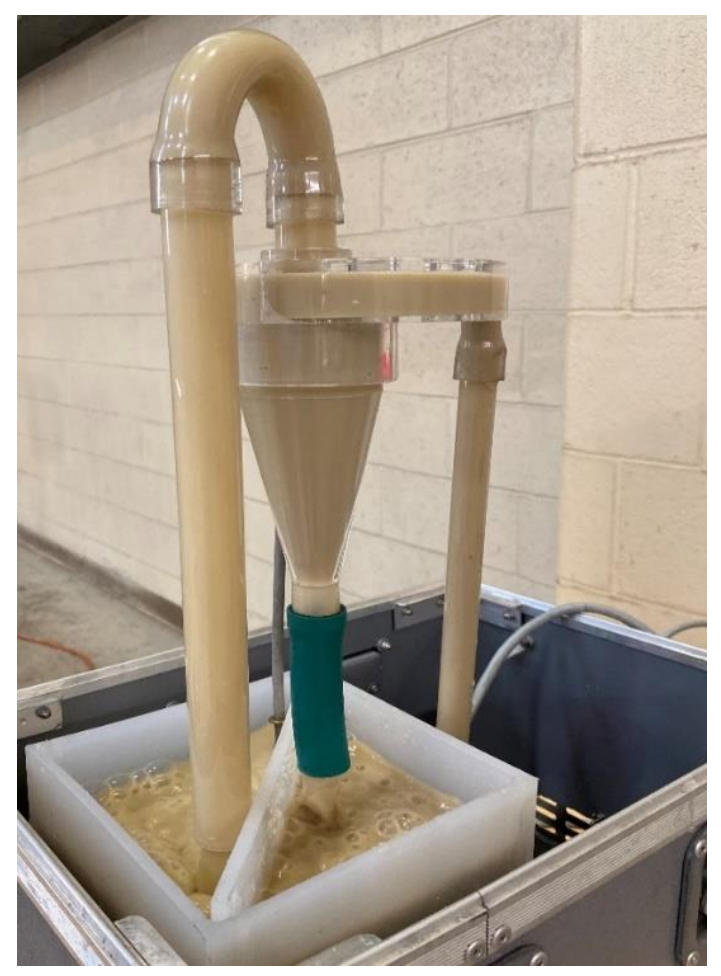

Figure 2-2: 1.5-in. laboratory hydro-cyclone.

\section{Zeta Potential Measurements}

For zeta potential measurements, a small amount of each pure mineral was ground using an agate pestle and mortar to pass a $5-\mu \mathrm{m}$ molecular sieve, and then 0.5 gram of the ground material was mixed with $100 \mathrm{~mL}$ of prepared supporting electrolyte solution $\left(10^{-3} \mathrm{~mol} . \mathrm{L}^{-1} \mathrm{KCl}\right)$ in a $200 \mathrm{~mL}$ glass beaker. The suspension was stirred for 10 minutes at $25^{\circ} \mathrm{C}$ using a magnetic stirrer at a constant rotating speed. In the meantime, using separate $50 \mathrm{~mL}$ glass beakers, a 40 $\mathrm{mL}$ supporting electrolyte solution was prepared for each target $\mathrm{pH}$ point by adjusting the $\mathrm{pH}$ values using dilute solutions of $\mathrm{NaOH}$ and $\mathrm{HCl}$ via a micropipette. Afterward, the well-mixed mineral suspension was allowed to naturally settle for 2 minutes. A small portion of the supernatant was then collected and added to each $40 \mathrm{~mL}$ solution with an already set $\mathrm{pH}$ value. Finally, the prepared suspensions were placed and kept inside an ultrasonic bath until being subjected to zeta potential measurements using Malvern Nano ZS Zetasizer, which employs Dynamic Light Scattering as a measurement principle. The sensitivity of this instrument is 0.1 
$\mathrm{mg} / \mathrm{mL}$ that works for a particle size range of $0.3 \mathrm{~nm}$ to $10 \mu \mathrm{m}$. Zeta potentials were measured for every point from $\mathrm{pH} 1$ to $\mathrm{pH} 12$. The final $\mathrm{pH}$ value of each suspension was recorded right before the zeta potential measurement, and was reported as the reference value in the current study. Each recorded zeta potential was the average of three separate measurements with a standard deviation of less than $2 \mathrm{mV}$, where each separate trial itself was the average of 100 automatically repeated measurements. Deionized (DI) water was used for the preparation of supporting electrolyte, $\mathrm{HCl}, \mathrm{NaOH}$ solution, and zeta potential measurements.

\section{Micro-flotation Tests}

For the recovery of $\mathrm{P}$ from $\mathrm{WC}$, direct flotation of apatite as the primary P-bearing mineral and/ or reverse flotation of the associated gangue minerals were examined. Traditionally, fatty acids and their salts have been used as the collector for the flotation separation of phosphates. The major drawback of this type of collectors in the flotation of phosphates is being nonselective, mainly due to the surface property similarity between phosphate minerals, e.g., apatite and their associated gangue minerals, e.g., dolomite and calcite. Therefore, in recent years, research efforts have been devoted to potential alternatives that can selectively interact with the target minerals. Consequently, the application of hydroxamic acids in the selective flotation of phosphates has been of great interest among different researchers globally [56, 57].

The application of various flotation modifiers and the collector reagents has shown promising results in the selective separation of phosphates from their associated gangues. In light of these, in the current study, a fatty acid collector, i.e., $\mathrm{NaOl}$ as well as two hydroxamic acids, including a short-chain, i.e., BHA, and a long-chain, i.e., OHA, collectors were tested. Various reagents, i.e., SS, DSS, and CA, were examined as the depressants of carbonates and silicates through the direct flotation of phosphate minerals. To enhance the selective interaction of depressants with target minerals, various surface modifying agents, i.e., EDTA, SC, and SP, were tested. For the flotation of silicates through the reverse flotation process, DDA was examined as the well-proven cationic collector for this purpose.

To obtain the optimum testing conditions, a number of exploratory experiments were conducted using single and mixed-mineral systems of pure minerals at different $\mathrm{pH}$ values. $\mathrm{pH}$ 9 was found to be the optimum $\mathrm{pH}$ value for the flotation of apatite in the presence of all three examined collectors. Later on, starting with the lowest dosages, the optimum dosages for each 
reagent were explored through evaluating the grade and recovery of flotation products. The optimum dosage for each collector was defined as the minimum concentration at which a single-mineral flotation recovery of $\geq 90 \%$ is attainable. For the cationic flotation of silicates using DDA, pH 3, 5 and 7 were tested. For the anionic acidic flotation of carbonates, following the proposed routes in the literature $[19,37,48], \mathrm{pH} 3$, and 4 were tested. A multi-level categorical factorial experimental design using the Statistics Toolbox in MATLAB environment was employed for the flotation experiments after obtaining the optimum testing procedure and conditions. $20 \mathrm{ppm}$ MIBC was used as the frothing agent for all the flotation experiments. The $\mathrm{pH}$ of suspensions was regulated by the addition of diluted $\mathrm{HCl}$ and/ or $\mathrm{NaOH}$. Table 2-3 summarizes the dosages of the reagents used for the current study. Flotation experiments were conducted using a $\sim 75 \mathrm{~mL}$ volume modified Partridge-Smith micro flotation cell. A schematic diagram of the flotation apparatus is depicted in Fig. 2-3. The glass cell consists of three main parts - the lower part including a porosity $\mathrm{E}(<5 \mu \mathrm{m})$ silicate frit; the main cylindrical body; and the upper part where floated fractions can be collected. For each experiment, one gram of dried powder sample with $\mathrm{d} 80$ of $\sim 39 \mu \mathrm{m}$ was placed in a glass beaker containing $50 \mathrm{~mL}$ deionized water with an adjusted $\mathrm{pH}$ value. Suspension of the particles was achieved using a magnetic stirrer and a magnet bar. Suspension $\mathrm{pH}$ was readjusted to the desired value prior to the addition of flotation reagents. As per the testing purpose, different flotation reagents were sequentially added, with each conditioned for $\sim 2$ minutes at room temperature followed by the addition of the frothing agent conditioned for 1 minute. The suspension $\mathrm{pH}$ was monitored and maintained in real-time during the conditioning process. The ultimate suspension was then transferred into the flotation cell mounted on top of a magnetic stirrer, using an extra $25 \mathrm{~mL}$ of $\mathrm{pH}$-adjusted deionized water. To keep the material in suspension inside the cell, a magnet bar was placed directly on top of the frit. The flotation process was performed for 1 minute by passing the gas at a flowrate of $30 \mathrm{~mL} / \mathrm{min}$ through the porous frit. Pure nitrogen $\left(\mathrm{N}_{2}\right)$ gas was employed instead of lab air in order to eliminate any possible interference of carbon dioxide. The floated and non-floated fractions were collected, dried, weighed, and analyzed to calculate the grade and recovery. Replicate tests were conducted under the same conditions to determine the experimental error. 
Table 2-3: Dosage of the reagents used for the current study.

\begin{tabular}{llc}
\hline Chemical & Function & Dosage $\left(\mathrm{mol}^{-\mathrm{L}^{-1}}\right)$ \\
\hline OHA & Collector & $2.51 \times 10^{-4}$ \\
BHA & Collector & $3.50 \times 10^{-4}$ \\
NaOl & Collector & $9.85 \times 10^{-5}$ \\
DDA & Collector & $1.20 \times 10^{-5}$ \\
CA & Depressant & $2.89 \times 10^{-5}$ \\
SS & Depressant & $1.121 \times 10^{-3}$ \\
DSS & Depressant & $6.25 \times 10^{-4}$ \\
EDTA & Surf. Modifier & $1.9 \times 10^{-5}$ \\
SC & Surf. Modifier & $5.24 \times 10^{-5}$ \\
SP & Surf. Modifier & $5.91 \times 10^{-5}$ \\
MIBC & Frothing agent & $1.95 \times 10^{-4}(20 \mathrm{ppm})$ \\
\hline
\end{tabular}

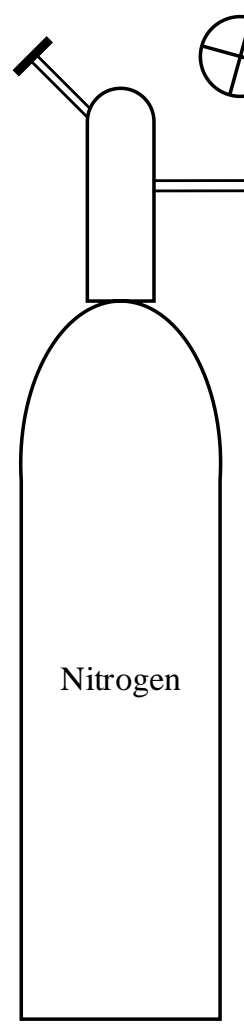

Digital Flowmeter

Regulator

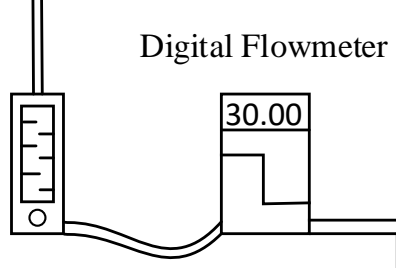

Mechanical Flowmeter

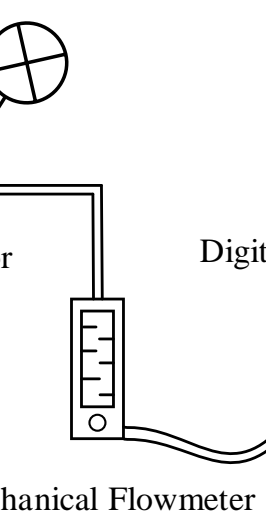


$\left(\mathrm{Ca}_{10}\left(\mathrm{PO}_{4}\right)_{6} \mathrm{~F}_{2}\right)$ and wavellite $\left(\mathrm{Al}_{3}\left(\mathrm{PO}_{4}\right)_{2}(\mathrm{OH}, \mathrm{F})_{3} \cdot 5 \mathrm{H}_{2} \mathrm{O}\right)$. The mineralogical constituents of phosphate clays can be classified as clay and non-clay minerals [59-61]. Major non-clay minerals are apatite, quartz and dolomite. Clay minerals include smectite (montmorillonite), kaolin, and illite. Because of their complexity, accurate quantitative mineralogical analysis on the phosphate clays is very difficult. As such, clay minerals did not appear in the mineralogical analysis of WC in the current study.

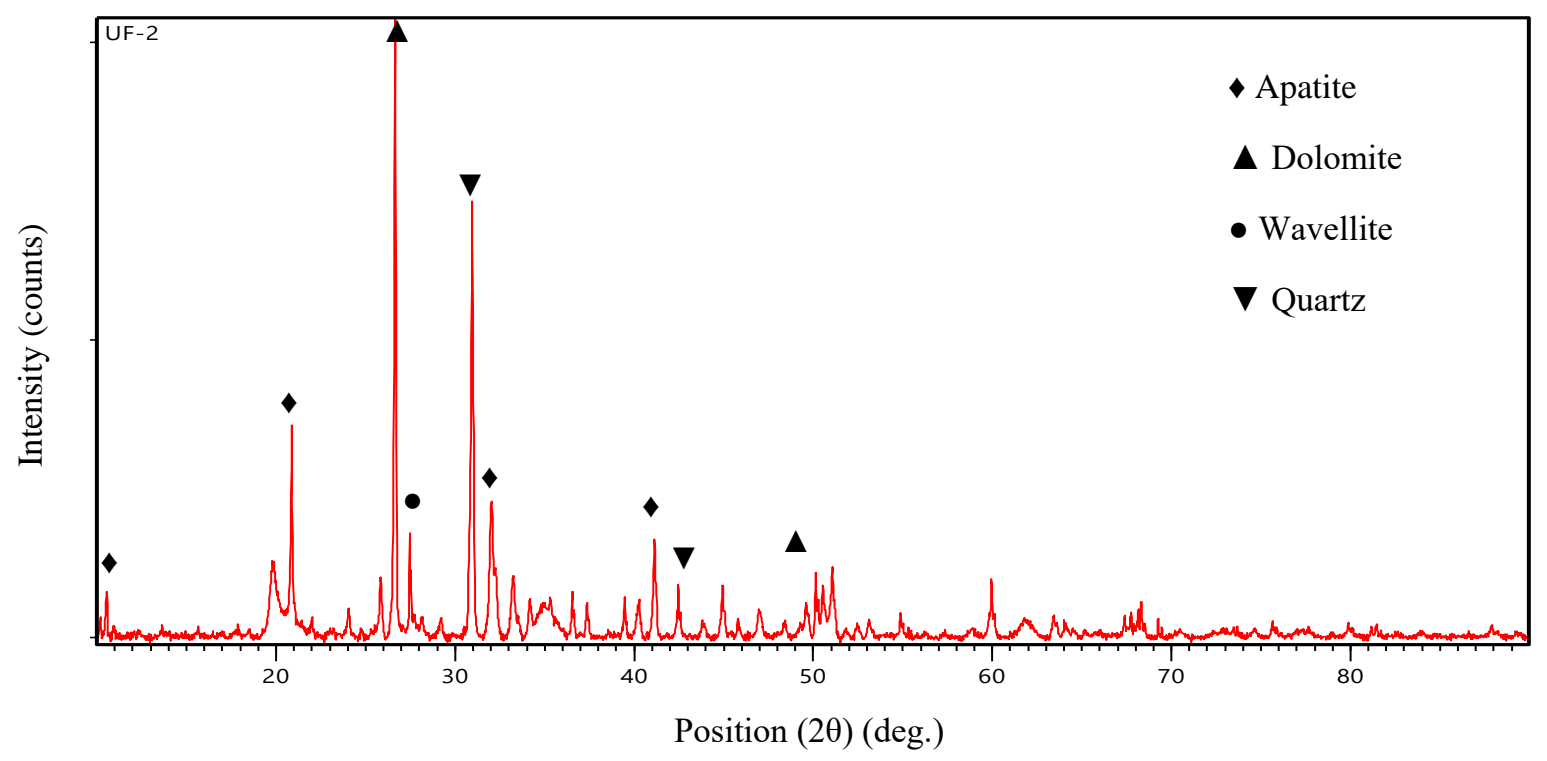

Figure 2-4: XRD results for WC sample.

There may be different reasons for this observation, e.g., the interference of basal (00/) reflections posed by the presence of non-clay minerals, heterogeneity in both grain size and composition of the samples and amount and thickness of the samples mounted for XRD [62, 63]. Thus, one solution is to separate clays from the non-clay minerals by sieving samples at a small enough aperture size $($ e.g., $5 \mu \mathrm{m})$. For this purpose, samples should be lightly crushed to fine fractions but not pulverized since non-clay minerals can also be reduced to clay sizes, and therefore become impossible to separate from the clays. Lightly crushing breaks apart the soft clays while keeping harder non-clays intact for easier removal [62].

Clay mineral peaks are generally distinguished by the width halfway up the peak (i.e., the full width at half maximum, FWHM) [63]. Well-defined crystalline minerals have sharp peaks while clays, which range from crystalline to mostly non-crystalline, produce broad peaks with noticeable widths on both sides. These broad peaks make it easy to identify which peaks are 
attributed to clays. These peaks can be compared to known diffraction patterns for better identification, but if some peaks are broader than others, it is likely that multiple clays are present [64]. FIPR institute [60] and Lamont [59] characterized Florida WCs. In general, Montmorillonite and Attapulgite (a hydrated magnesium silicate) were identified as the major clay minerals, Attapulgite being primarily responsible for the very poor settling characteristics of the slimes. A study by [61] on four WC samples showed that the approximate concentration of apatite and wavellite is $27.6 \%$ and insignificant (almost zero), respectively. This conclusion is very encouraging and extremely important in justifying phosphate recovery from the phosphate clays. If the phosphate existed primarily as aluminum phosphates, it would be meaningless to separate phosphate minerals from gangue, because the concentrate generated could not be used as a feed for phosphoric acid production. It should be emphasized that current phosphate clays contain substantially less palygorskite than the past slimes [61]. This is another encouraging sign because palygorskite is more colloidal in nature and more difficult to separate from phosphate minerals.

To overcome the difficulties in the mineralogical identification of clay minerals from WC, two molecular sieves of $5 \mu \mathrm{m}$ and $10 \mu \mathrm{m}$ were used in the current study to produce two WC ultrafine fractions, i.e., $-5 \mu \mathrm{m}$ and $-10 \mu \mathrm{m}$. Two products were then subjected to XRD analysis and the results are presented in Fig. 2-5. The phase candidates obtained from XRD analysis were compared one by one with the patterns obtained for the pure clay minerals so that the presence of the three clays, i.e., Montmorillonite, Illite, and Kaolin, in the WC sample was confirmed. The presence of other minerals such as apatite as the major P-rich valuable mineral, and dolomite as the carbonate gangue mineral is also remarkable in these size fractions. Considering aluminum ( $\mathrm{Al})$ and silicon $(\mathrm{Si})$ as the two target elements representing the alumino-silicates that compose kaolin and other clay minerals, the elemental compositions indicate that when a fine particle size is achieved, the presence of these minerals becomes substantial and easy to identify. As evident from Fig. 2-6, the wt.\% of clays is higher in the -5 $\mu \mathrm{m}$ fraction compared to the $-10 \mu \mathrm{m}$ fraction. 


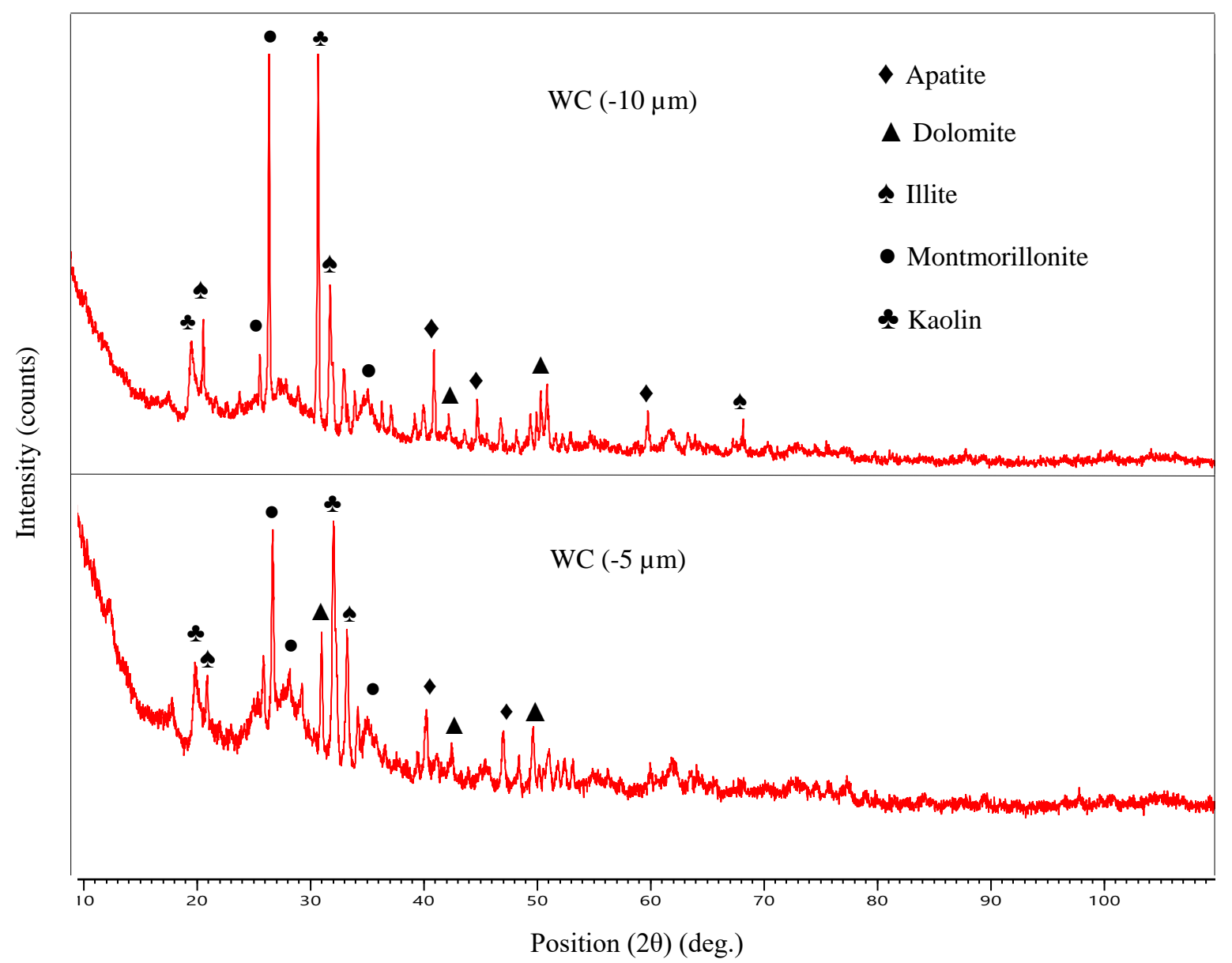

Figure 2-5: XRD pattern of ultrafine clay fractions.

Interestingly, the relative occurrence of apatite as the main P-bearing phase in WC becomes remarkable in the $-5 \mu \mathrm{m}$ fraction compared to the relatively coarse fractions, as can be seen from Fig. 2-6. This means that $\mathrm{P}$ in WC is not limited to a specific size fraction, but rather is distributed to all the size fractions ranging from $-5 \mu \mathrm{m}$ to $+20 \mu \mathrm{m}$. The finding suggests that any successful removal of clay minerals will inevitably result in a loss of the P content.

Besides, in order to validate the presence of REEs, detailed quantitative elemental analysis of WC for REEs was conducted using ICP-MS \& -OES methods and the results are summarized in Fig. 2-7. As can be seen, 103.6 ppm or 33\% are HREEs (Y, Eu, Gd, Tb, Dy, Ho, Er, Tm, Yb, Lu, Sc) including Y with 63.6 ppm or $21 \%$ solely, while 203.5 ppm or $66.8 \%$ are LREEs ( $\mathrm{La}, \mathrm{Ce}, \mathrm{Pr}, \mathrm{Nd}, \mathrm{Sm}$ ). The elemental analysis results indicate that in addition to $\mathrm{P}$, WC is a valuable source for REEs as well. Seredin and Dai (2012) proposed an index known as the outlook coefficient of REE-bearing ores that evaluates the quality of the ore in terms of 
its valuable REE content so that the ideal composition should contain as many critical individual REEs along with as few excessive elements as possible. This index is calculated as the ratio of the relative amount of critical rare earth elements to the relative amount of excessive elements, according to Eq. (2-1):

$$
C_{\text {outlook }}=\frac{C R E E}{E R E E}=\frac{(N d+E u+T b+D y+E r+Y) / \sum R E E}{(C e+H o+T m+Y b+L u) / \sum R E E}
$$

The higher this coefficient is, the more promising the REE ore with respect to the potential industrial value [65]. As such, in the current study, the outlook coefficient $\left(C_{\text {outlook }}\right)$ was determined for WC. A $C_{\text {outlook }}$ of 1.3 and a heavy to light (H/L) REE ratio of 0.5 (on average) were obtained for WC of the current study. Table 2-4 summarizes $C_{\text {outlook }}$ values for some conventional and secondary REE sources. A comparison between $C_{\text {outlook }}$ values for various sources, especially for those located in the US indicates that WC can be considered a promising source for REEs in terms of its potential industrial value. This evidence further highlights that any attempt to recover phosphate values from $\mathrm{WC}$ should also take into account the recovery of REE-bearing phases as a determining factor.

Table 2-4: Outlook coefficient value for some conventional and secondary sources.

\begin{tabular}{|c|c|c|c|}
\hline Location & Primary source & $C_{\text {outlook }}$ & Ref. \\
\hline Mountain Pass, CA & Bastnäsite & 0.23 & \\
\cline { 1 - 3 } Bayan Obo, China & Bastnäsite & 0.38 & \multirow{2}{*}{ [66] } \\
\cline { 1 - 3 } Green Cove Spring, FL & Monazite & 0.49 & \\
\hline Lehat, Malaysia & Xenotime & 13.13 & \\
\hline Longnan, China & Xenotime & 3.85 & [67] \\
\hline West Kentucky, KY & Natural coal-based leachate & $1.3(\mathrm{avg.})$ & This Study \\
\hline FL & Waste Clay & &
\end{tabular}




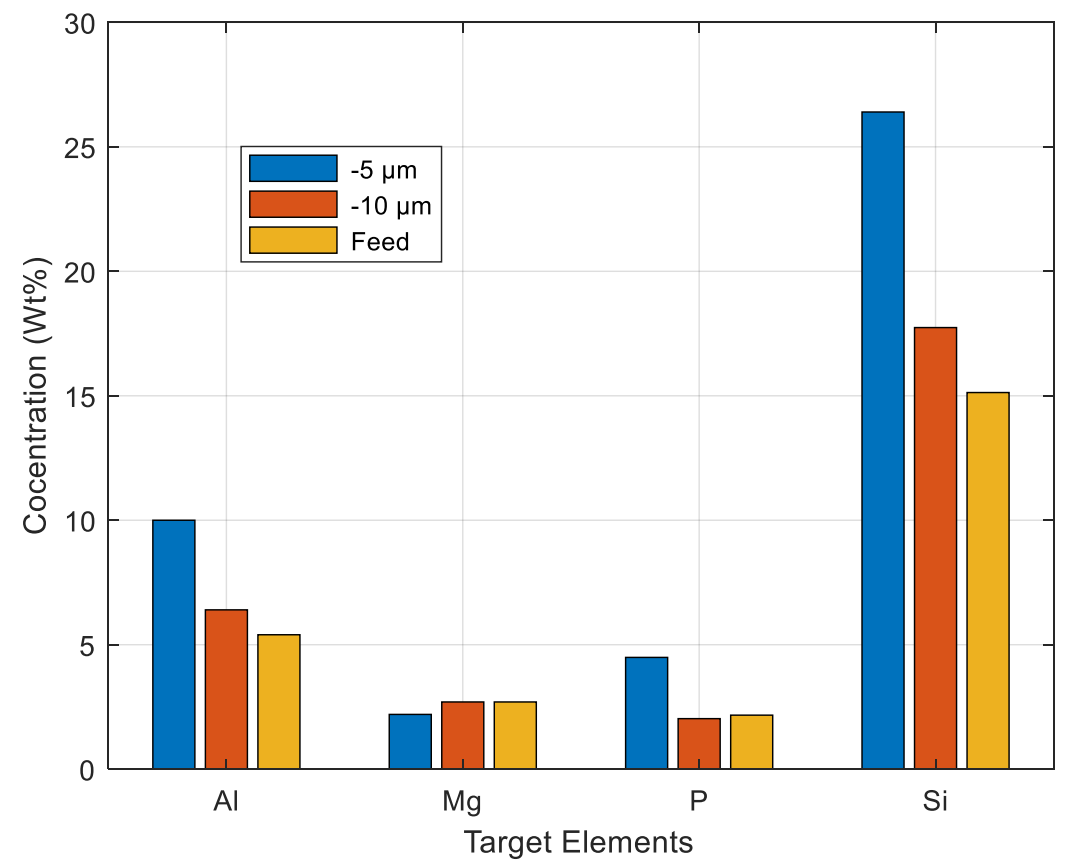

Figure 2-6: Comparison of the target elements in the various size fractions of WC.

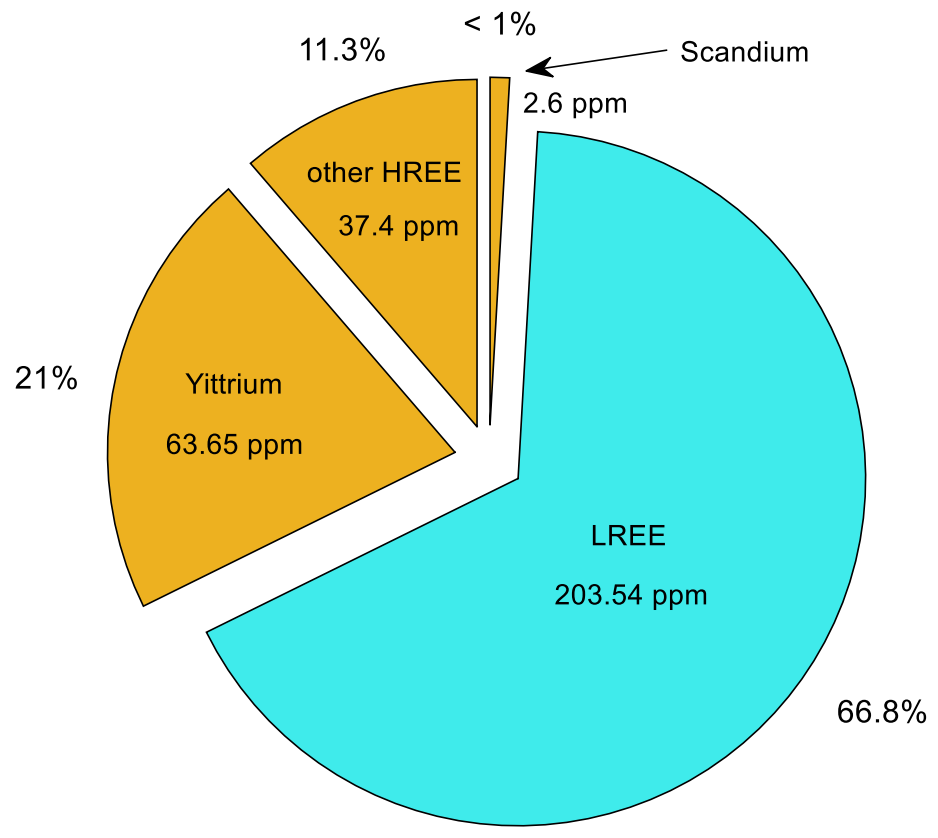

Figure 2-7: REE content of WC obtained from ICP-MS \& -OES.

The SEM micrograph and EDS elemental mapping of WC are presented in Fig. 2-8. As can be seen, the presence of $\mathrm{P}, \mathrm{Mg}, \mathrm{Al}$ and $\mathrm{Si}$ as the major composing elements is evident, which further supports the mineralogical and elemental characterization results. 

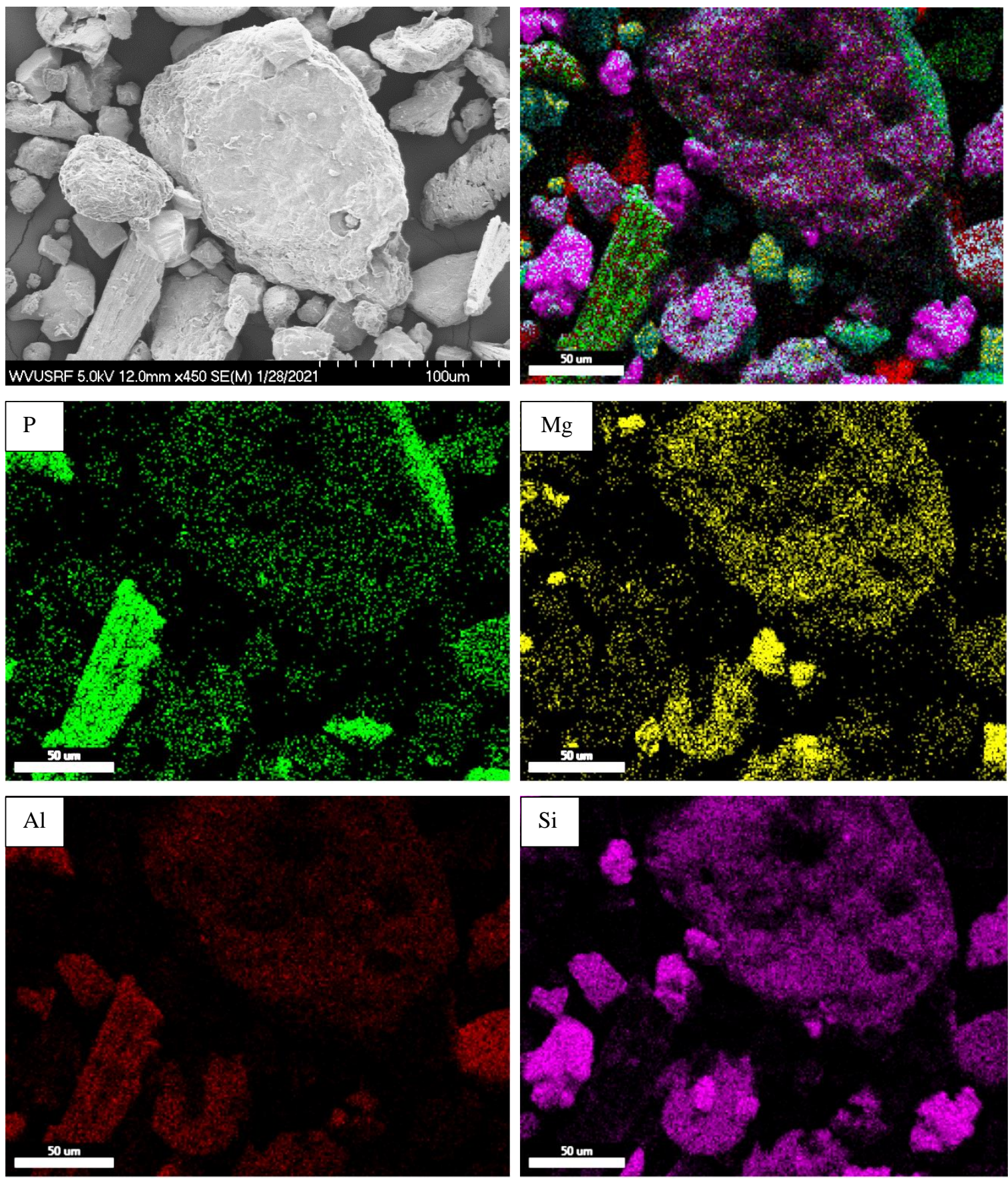

Figure 2-8: SEM micrograph and EDS elemental mapping of WC.

\section{De-sliming}

The de-sliming of WC by a 1.5-in. hydro-cyclone unit resulted in the underflow and overflow products of $\mathrm{d} 80=38.2 \mu \mathrm{m}$ and $14.8 \mu \mathrm{m}$, respectively, as shown in Fig. 2-9-a. This indicates that the de-sliming process has been successful in a size separation. A dry representative portion of the cyclone products was subjected to elemental analysis to evaluate 
whether the process has been successful in clay removal. The results are presented and compared in Fig. 2-9-b for target elements. Comparing the occurrence of target elements, it is evident that the $\mathrm{Al}$ and $\mathrm{Si}$ contents have dropped by several wt.\% in the underflow product compared to the feed. This indicates that the clay removal has been successful to a remarkable extent.
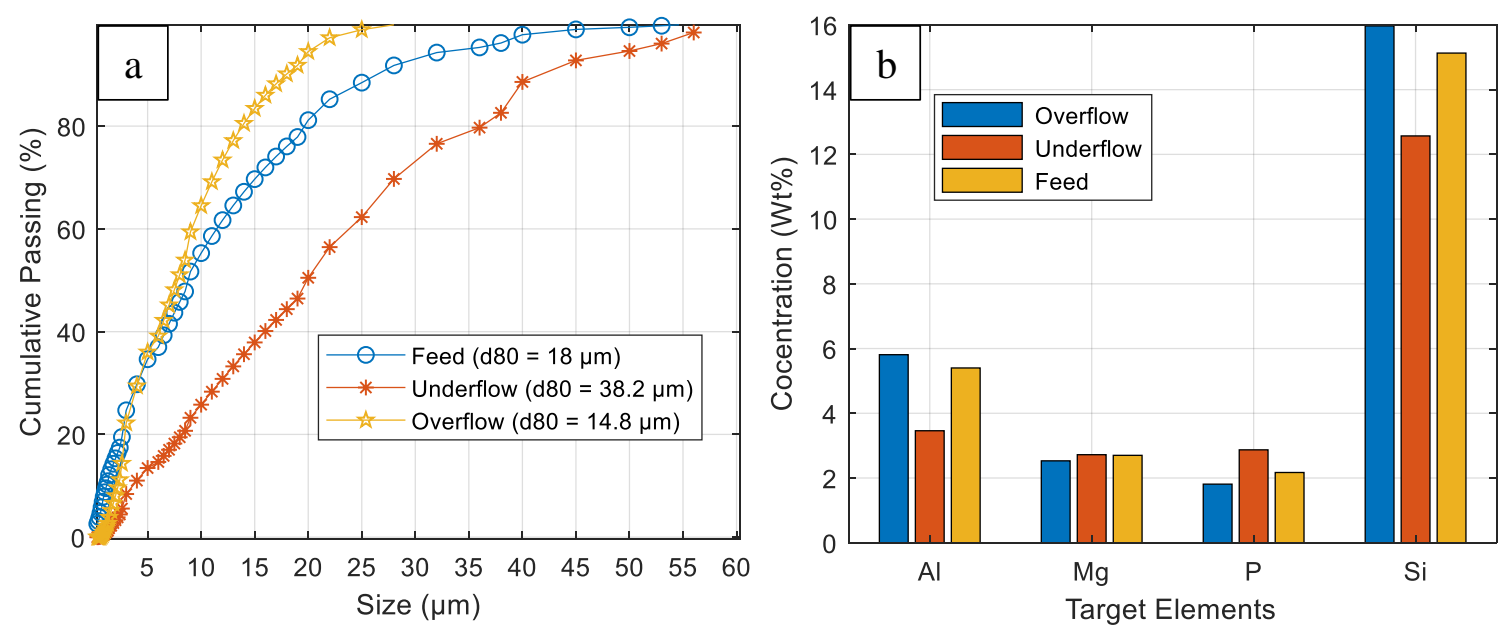

Figure 2-9: Particle size analysis for the different streams of 1.5-in. cyclone (a), and comparison of the presence of the target elements in different cyclone products (b).

\section{Zeta Potential Measurements}

Zeta potential is a useful measure to evaluate the relationship between the mineral particle surface charges and the adsorption behavior of reagents in froth flotation [52]. In the current study, zeta potential of the pure minerals, i.e., apatite, dolomite, quartz, monazite, and xenotime as the major non-clay minerals composing $\mathrm{WC}$ was measured as a function of $\mathrm{pH}$ in the presence of $10^{-3} \mathrm{M} \mathrm{KCl}$ (supporting electrolyte). The results are depicted in Fig. 2-10. As shown, the isoelectric point (IEP) of apatite occurs around $\mathrm{pH} 3$. The IEP of dolomite can be found to be between $\mathrm{pH} 6$ and 7, quartz at around $\mathrm{pH} 2$, monazite at $\mathrm{pH} 6$ and xenotime at $\mathrm{pH}$ 4. These values agree with those reported in the literature for apatite [68], dolomite [69], quartz [70], monazite [71] and xenotime [72], respectively. Mineral dissolution primarily activates the surface charge of salt-type minerals, e.g., $\mathrm{Mg}$ carbonates and apatite are under the influence of water molecules at various $\mathrm{pH}$ values; $\mathrm{Mg}$ carbonates are noted to be highly affected in acidic regions [19, 52]. Electro-kinetic measurements have revealed that anionic and cationic collectors pronouncedly affect the surface charge of $\mathrm{Mg}$ carbonates. It has been observed that DDA shifts the IEP of Mg carbonates to basic $\mathrm{pH} 9$ so that it exhibits a negative surface charge 
up to $\mathrm{pH} 12[19,73]$. However, with $\mathrm{NaOl}$, the carbonates present a negative surface charge from $\mathrm{pH} 3$ to $\mathrm{pH} 11[19,74]$. It is also noteworthy that the zeta potential of the carbonates becomes negative as $\mathrm{NaOl}$ concentration increases $[19,75]$.

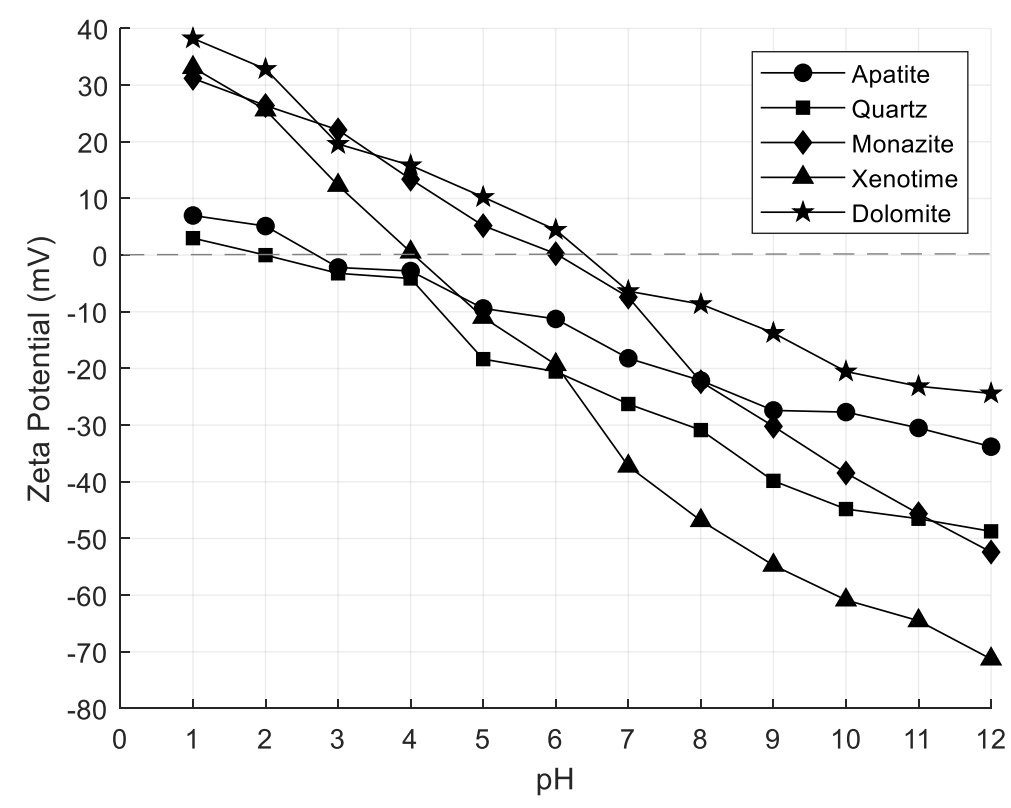

Figure 2-10: Zeta potential of various pure minerals.

\section{Micro-Flotation Tests}

For the flotation recovery of $\mathrm{P}$ from Florida $\mathrm{WC}$, various possible routes of both direct and reverse flotation were evaluated. The goal of this endeavor was basically tied to meet three major criteria: first, the $\mathrm{P}$ content should meet the minimum of $20 \mathrm{wt} . \% \mathrm{P}_{2} \mathrm{O}_{5}$ representing the medium grade $\mathrm{P}$ ore; second, the clays, dolomite, and silicates content should be minimized as much as possible; third, the loss of REEs should be minimum so that a threshold TREE recovery of $80 \%$ should be met. As such, to monitor the occurrence of various associated gangue phases in the flotation products, $\mathrm{Al}, \mathrm{Mg}$, and $\mathrm{Si}$ were considered the major target elements representing the major associated gangues in WC, i.e., clays, dolomite, and silicates, respectively. The results of the flotation experiments are summarized in Figs. 2-11 and 2-12 for convenience of comparison. As shown, the direct flotation of phosphate using both fatty acid and hydroxamates, even in the presence of various regulating agents, does not offer a solution for the recovery of $\mathrm{P}$ from WC. This outcome was not consistent with the results obtained from single-mineral exploratory flotation tests using the pure apatite in the presence of both $\mathrm{NaOl}$ and hydroxamates. Such inconsistency could mainly be attributed to the 
similarity between the surface- and electro-chemistry of the valuable and gangue minerals in WC, and thereupon their flotation behavior at alkaline conditions [37]. Added to this is the side effect of regulating agents, e.g., depressants, whose concentration may play an essential role in controlling the alkalinity or acidity of the pulp and thereby can affect the performance of flotation through modifying the surface charge of the minerals. This becomes critical where $\mathrm{Mg}$ carbonates are present as their flotation behavior is remarkably sensitive to the solution $\mathrm{pH}$.

Moreover, carbonate ultrafines can coat their associated valuable minerals, and change their flotation behavior [53]. $\mathrm{Mg}$ carbonates are hydrophilic and semi-soluble, dissolved species of which may undergo reactions, such as hydrolysis, complexation, adsorption, and bulk precipitations, in aqueous environments. This might affect the selective interaction of reagents with target valuable minerals. Further insight in this regard could be obtained through molecular dynamics simulations via ab initio computational chemistry techniques, e.g., density functional theory (DFT). The influence of the metal cations and their various hydrolysis species on the behavior of silicates, e.g., quartz, and carbonates, e.g., dolomite, in the flotation of phosphate is another concern, which can be the subject of a separate investigation. It will help understand how the presence of the lattice metal cations can interfere with the functionality of flotation reagents on both the valuable and gangue minerals in phosphate flotation. In general, in the flotation separation of valuable minerals with $\mathrm{Mg}$ carbonates as the associated gangues, rejection of the carbonates prior to the subsequent process has been recommended. However, even with such rejection, when the valuable mineral is also a salttype mineral, e.g., apatite, selectivity in flotation separation remains a major challenge. As such, opting for proper surface modifying reagents for valuable minerals in the direct flotation of $\mathrm{Mg}$ carbonates is a crucial step in achieving an efficient separation [12, 17].

Both the characterization and flotation separation results suggest that unlike other P-rich sources and ores where dolomitic gangues are the main concern, the presence of silicates and clays is the main challenge in achieving a satisfactory separation of P from Florida WC. In the current study, among various scenarios tested for the recovery of $\mathrm{P}$ from the $\mathrm{WC}$, the two reverse flotation routes of (i)-cationic flotation of silicates using DDA at $\mathrm{pH} 3$, and (ii)- cationic flotation of silicates using DDA at $\mathrm{pH} 3$ followed by the anionic flotation of carbonates at $\mathrm{pH}$ 
4 present promising results, as shown in Fig. 2-11-b. This is because pH 3 is near the IEP of Apatite where its surface tends to present a slightly positive zeta potential that results in its depression at fairly acidic conditions. For dolomite, chemisorption between $\mathrm{NaOl}$ and the mineral occurs mainly in alkaline conditions. In an acidic environment, the fatty acid is mainly in its soap form i.e. the soap dimer complex, which is known to enhance the collector-mineral interaction [76]. Thus, dolomite favors an acidic environment for enhanced floatability. The first route, i.e., de-sliming using a small-diam. hydro-cyclone followed by the cationic reverse flotation (single-stage process) produced a phosphate product of $\sim 21 \mathrm{wt} . \% \mathrm{P}_{2} \mathrm{O}_{5}$ with $\sim 80 \% \mathrm{P}$ recovery. The second route, i.e., the de-sliming followed by the cationic reverse flotation of silicates plus the anionic flotation of carbonates (double-stage process) resulted in a phosphate product of $\sim 22 \mathrm{wt} . \% \mathrm{P}_{2} \mathrm{O}_{5}$ with $\sim 73 \% \mathrm{P}$ recovery. The current study results are in agreement with Mohammadkhani et al. (2011) [53], where an anionic-cationic double reverse flotation process was found to be a suitable method to upgrade a very low grade sedimentary phosphate rock, rich in carbonate and silicate. They produced a final flotation product with $\mathrm{P}_{2} \mathrm{O}_{5}$ grade and recovery of $21.67 \mathrm{wt} . \%$ and $65.5 \%$, respectively. One important factor to be considered here is, as noted earlier, that $\mathrm{Mg}$ carbonate flotation is $\mathrm{pH}$ dependent; therefore, due to the high consumption of collectors by the lattice dissolution of dolomite, its flotation is generally not recommended at an acidic $\mathrm{pH}[13,17,76]$. This makes the second route less attractive from an economic standpoint. Another important criterion to consider is the minimum loss of REEs. As such, the products of the two single- and double-stage processes were submitted to ICP MS $\&$ OES elemental analysis for a detailed rare earth quantification. The results are summarized and compared in Fig. 2-13. As seen from Fig. 2-13-a, the double-stage process results in a product with a $\mathrm{P}$ grade and recovery of respectively slightly higher and lower than those obtained from the single-stage process. However, the single-stage process offers a more promising route for the recovery of REEs from WC as compared to the double-stage reverse flotation process, as shown in Fig. 2-13-b. The single-stage process elevates the TREE concentration from $\sim 300 \mathrm{ppm}$ in the feed to $\sim 800 \mathrm{ppm}$ in the product with a total recovery of above $80 \%$. The reason why the double-stage process lags behind the single-stage cationic process in terms of REE concentration and recovery would partly be attributed to the flotation of xenotime along with dolomite at $\mathrm{pH} 4$ in the presence of $\mathrm{NaOl}$. To further study the occurrence of REE-bearing phases in WC, a representative dry powder sample of the flotation 
products was studied by SEM-EDS, which allows for the analysis of targeted sample surfaces. According to the results shown in Figs. 2-14 \& 2-15, the major mineralogical forms of REEs in $\mathrm{WC}$ are $\mathrm{Y}, \mathrm{P}, \mathrm{Ce}, \mathrm{La}$ plus Th, and U-bearing minerals. Such evidence clearly points to the two phosphate rare earth minerals, i.e., xenotime and monazite. It is also evident from the comparative representation of the individual REEs from both WC and the two products of the single- and double-stage reverse flotation processes, as shown in Fig. 2-15.

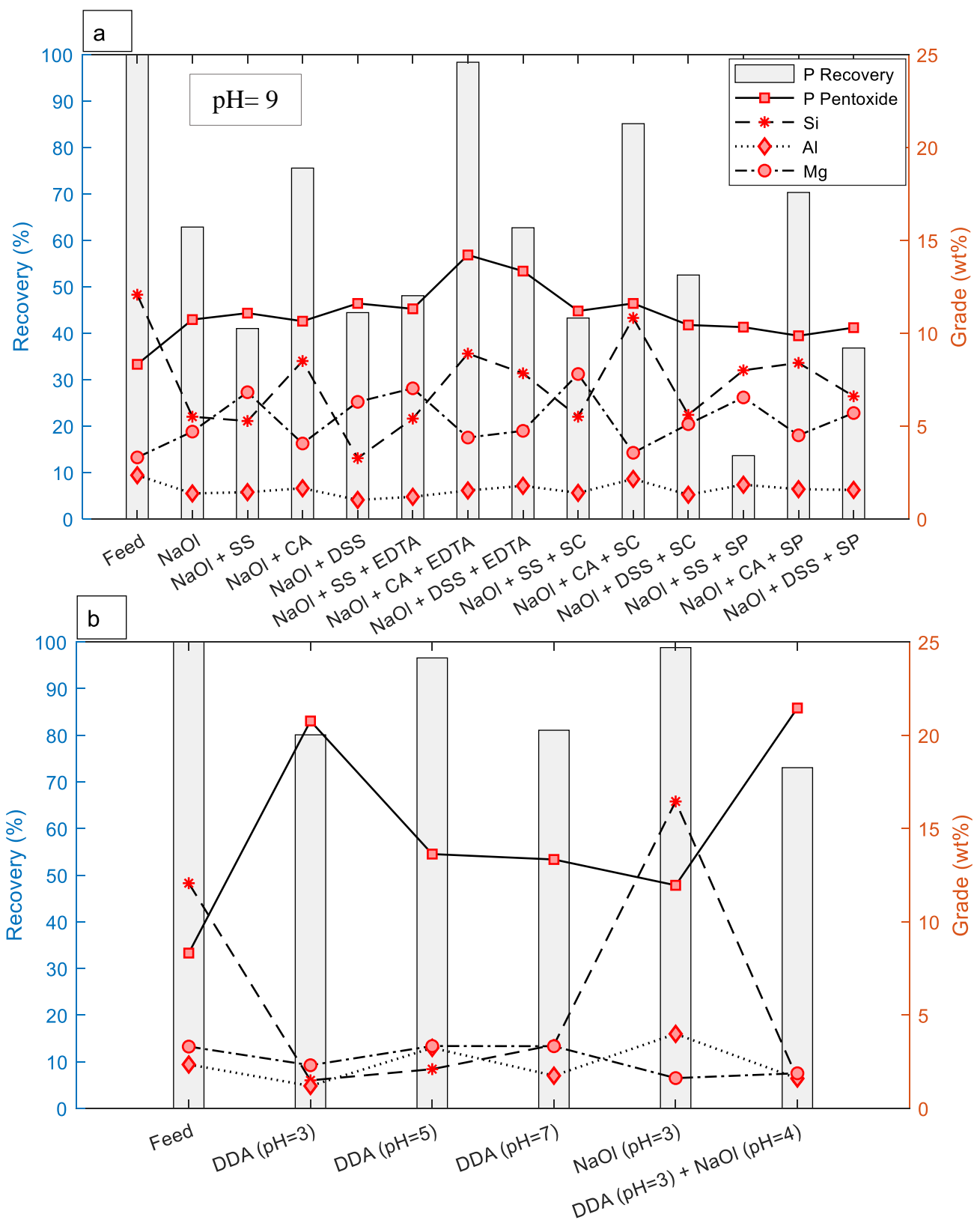

Figure 2-11: Summarized results of the flotation experiments with fatty acid and amine collectors. 


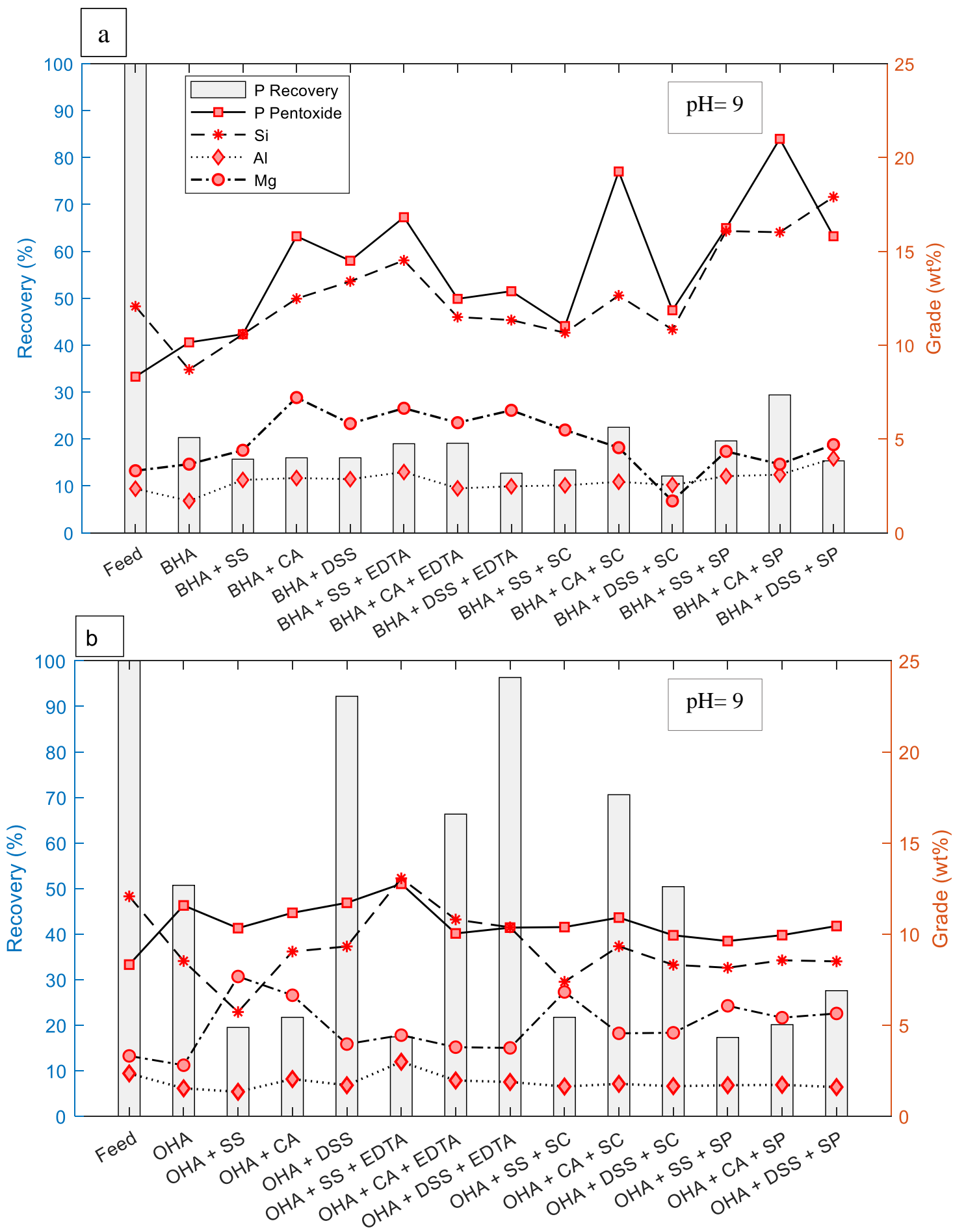

Figure 2-12: Summarized results of the flotation experiments with hydroxamate collectors. 

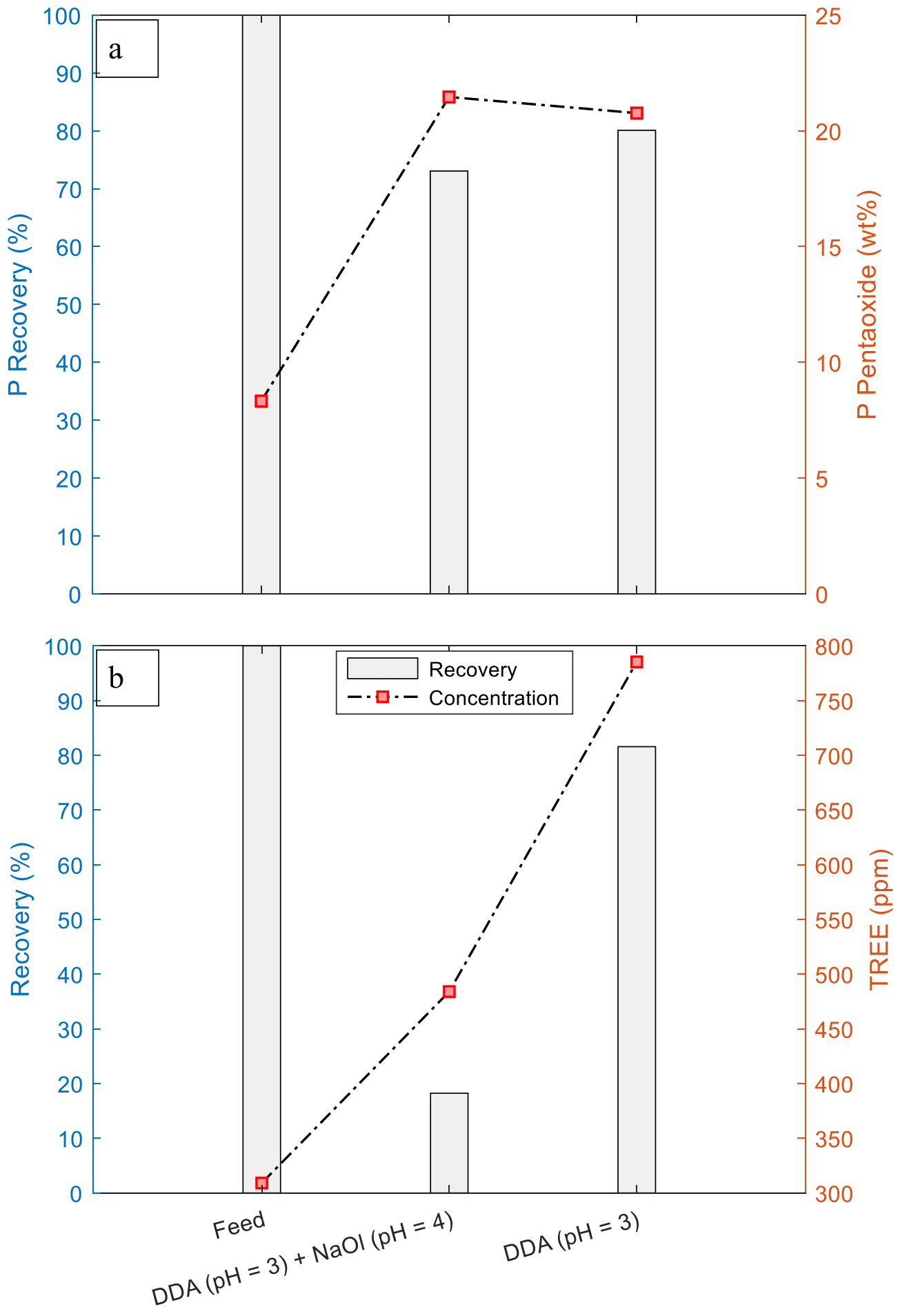

Figure 2-13: Comparison between the results of the single- and double-stage reverse flotation processes. 

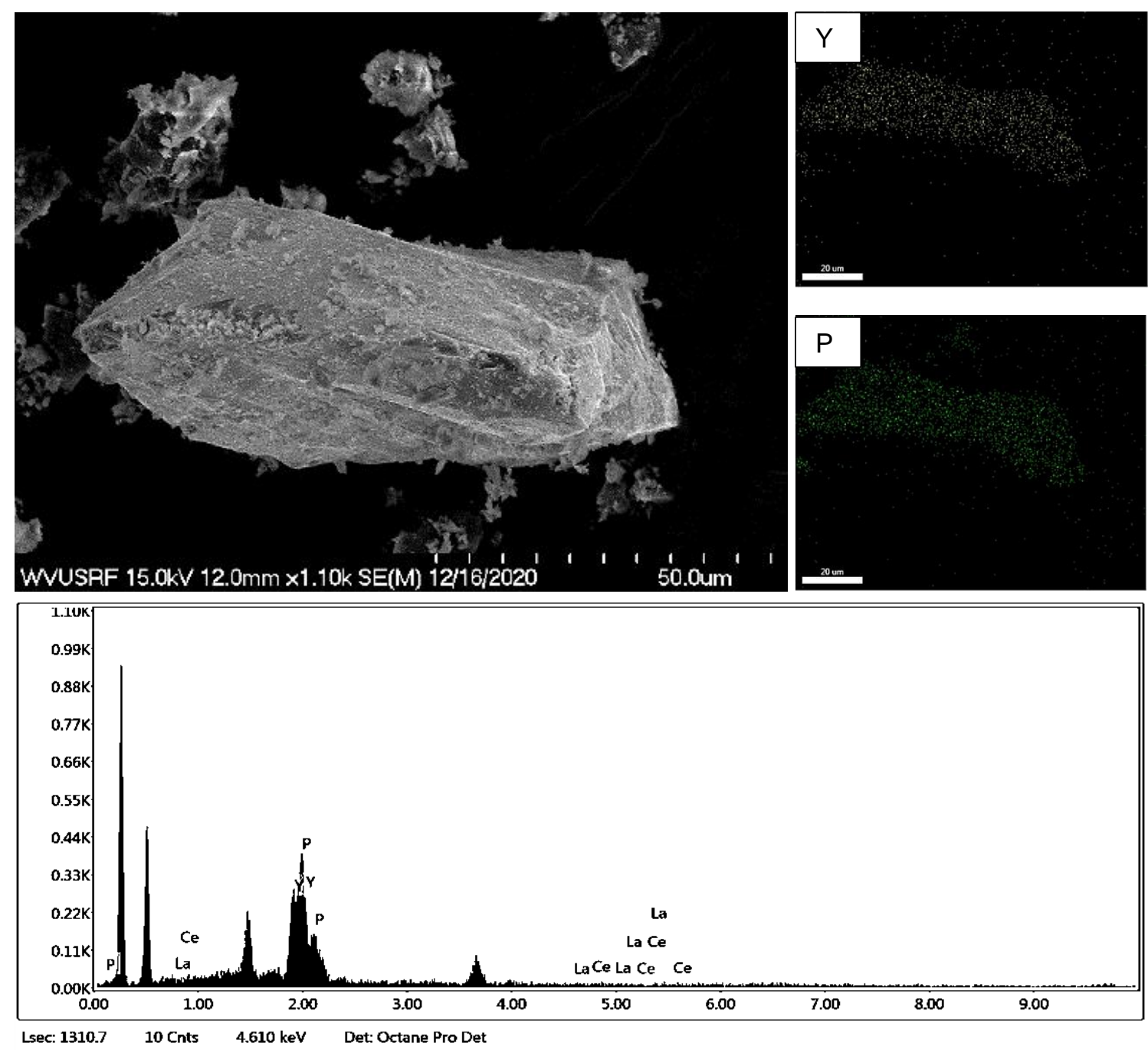

Figure 2-14: SEM micrograph and EDS mapping of the single stage reverse flotation product. 

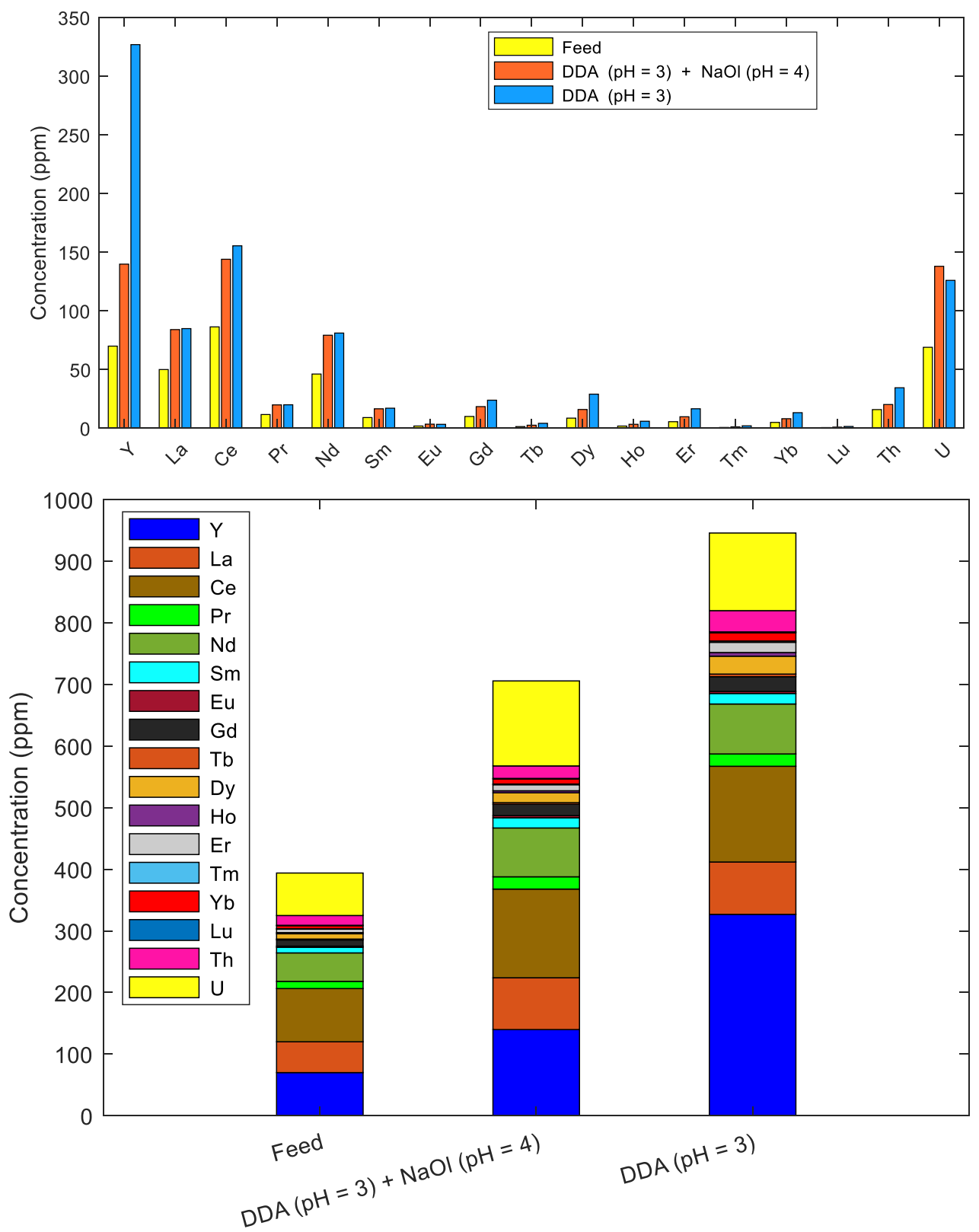

Figure 2-15: Comparative bar and stacked representation of REEs present in WC and the flotation products. 


\section{Conclusions}

In the current study, the recovery of $\mathrm{P}$ from Florida WC was investigated using froth flotation. Three major conditions were considered to be met; (i)- the P content should meet the minimum of $20 \mathrm{wt} . \% \mathrm{P}_{2} \mathrm{O}_{5}$ representing the medium grade $\mathrm{P}$ ore, (ii)- the clays, dolomite, and silicates content should be reduced by as much as possible, and (iii)- a minimum TREE recovery of $80 \%$ should be satisfied. Characterization studies indicated that clays, dolomite, and quartz are the main associated gangue minerals, while apatite is the main P-bearing mineral in WC. For the initial separation, a 1.5-in. diameter hydro-cyclone unit was employed for the removal of clays. Later on, froth flotation was investigated for the separation of apatite from the underflow product of the cyclone unit. Sodium oleate as a short-chain fatty acid and longchain hydroxamic acid collectors were tested for the direct flotation of apatite from the WC. To enhance the selectivity in the direct flotation of apatite, various depressing along with surface modifying flotation agents were examined. Besides, two reverse flotation routes, i.e., the cationic flotation of quartz at $\mathrm{pH} 3$, and the cationic flotation followed by an anionic flotation of dolomite at $\mathrm{pH} 4$ were examined for the reverse flotation of apatite from the WC. The following conclusions were mainly obtained:

- The direct flotation of apatite using both fatty acid and hydroxamates, even in the presence of various regulating agents, does not offer a solution for the recovery of $\mathrm{P}$ from the WC. This can be attributed to the similarity in the surface behavior of apatite and its associated silicate and carbonate gangues in the WC, effect of the regulating agents on the solution electro-chemistry, and interference of the lattice metal cations with functionality and interactions of the flotation agents with the target minerals. The latter item requires a computational chemistry insight by molecular dynamics simulation using ab initio methods.

- Hydroxamic acid collectors, despite their capability in the selective flotation of apatite and REE-bearing minerals revealed during the exploratory experiments using singleand mixed mineral systems, do not produce a successful selective separation of phosphate minerals from the WC. Such inconsistency can mainly be attributed to the effect of certain lattice metal cations present in the WC flotation environment, which may interfere with the desirable interactions of these reagents with the valuable minerals. 
- The double-stage reverse flotation process in which the cationic removal of silicates is followed by the anionic rejection of carbonates both at fairly acidic conditions, becomes less attractive from the economic stance when the reagent consumption is taken as a determining factor. Added to this is the significant loss of REEs with this approach.

- The single-stage process where only a cationic removal of silicates following the cyclone-assisted removal of clays offers a more economically viable route for the conditional recovery of $\mathrm{P}$ from the WC. This superiority also owes to its relative capability to avoid the loss of REEs as the other paramount value contained in the WC.

- The removal of clays, silicates, and carbonates up to a satisfactory degree where the obtained product meets the specifications of the medium-grade phosphate ore that is routinely mixed with the high-grade ore to be sold to the fertilizer production industry. It facilitates the subsequent recovery of REEs using chemical separation methods. The process is crucial since such removal of troublesome associated gangues significantly alleviates the acid consumption in the subsequent chemical recovery of REEs from WC, which has long been alluded to by the industry and researchers as the limiting factor.

\section{Acknowledgements}

We are thankful to WVU Shared Research Facilities (SRF) managers, Dr. Marcela Redigolo for her assistance in performing SEM/ EDS analyses, and Dr. Qiang Wang for his assistance in performing the XRD analyses.

\section{References:}

[1] Karunanithi, R., Szogi, A.A., Bolan, N., Naidu, R., Loganathan, P., Hunt, P.G., Vanotti, M.B., Saint, C.P., Ok, Y.S. and Krishnamoorthy, S., 2015. Phosphorus recovery and reuse from waste streams. In Advances in agronomy (Vol. 131, pp. 173-250). Academic Press.

[2] Haldar, S.K., 2018. Mineral exploration: principles and applications. Elsevier.

[3] Matinde, E., Simate, G.S. and Ndlovu, S., 2018. Mining and metallurgical wastes: a review of recycling and re-use practices. Journal of the Southern African Institute of Mining and Metallurgy, 118(8), pp.825-844.

[4] El-Shall, H. and Zhang, P., 2004. Process for dewatering and utilization of mining 
wastes. Minerals engineering, 17(2), pp.269-277.

[5] McFarlane, A., Bremmell, K. and Addai-Mensah, J., 2005. Microstructure, rheology and dewatering behaviour of smectite dispersions during orthokinetic flocculation. Minerals Engineering, 18(12), pp.1173-1182.

[6] Eskanlou, A. and Huang, Q., Phosphatic waste clay: Origin, composition, physicochemical properties, challenges, values and possible remedies-A review. Minerals Engineering, 162, p.106745.

[7] Zhang, P., Liang, H., Jin, Z. and DePaoli, D., 2017. The ultimate mineral processing challenge: Recovery of rare earths, phosphorus and uranium from Florida phosphatic clay. Minerals \& Metallurgical Processing, 34(4), pp.183-188.

[8] Zhang, P., Snow, R., Yu, Y. and Bogan, M., 2001. Recovery of phosphate from Florida phosphatic clays. Final report, FIPR Publication, pp.02-096.

[9] Laurino, J.P., Mustacato, J. and Huba, Z.J., 2019. Rare earth element recovery from acidic extracts of Florida Phosphate mining materials using Chelating polymer 1Octadecene, polymer with 2, 5-Furandione, Sodium salt. Minerals, 9(8), p.477.

[10] Wu, S., Wang, L., Zhao, L., Zhang, P., El-Shall, H., Moudgil, B., Huang, X. and Zhang, L., 2018. Recovery of rare earth elements from phosphate rock by hydrometallurgical processes-A critical review. Chemical Engineering Journal, 335, pp.774-800.

[11] He, J. and Kappler, A., 2017. Recovery of precious metals from waste streams. Microbial biotechnology, 10(5), pp.1194-1198.

[12] Zhang, P., Liang, H. and DePaoli, D., 2018. Recovery of rare earths and P from a phosphate flotation tails. In Proceedings of the IMPC 2018 Physical EnrichmentGravity, Magnetic and Electrostatic Separation, Moscow, Russia, 17-21 September.

[13] Soto, H. and Iwasaki, I., 1986. Selective flotation of phosphates from dolomite using cationic collectors. I. Effect of collector and nonpolar hydrocarbons. International journal of mineral processing, 16(1-2), pp.3-16.

[14] Al-Fariss, T.F., Ozbelge, H.O. and Abdulrazik, A.M., 1991. Flotation of a carbonate rich sedimentary phosphate rock. Fertilizer research, 29(2), pp.203-208.

[15] Hernainz, F., Calero, M. and Blazquez, G., 2004. Flotation of low-grade phosphate ore. Advanced powder technology, 15(4), pp.421-433.

[16] Oliveira, M.S., Santana, R.C., Ataíde, C.H. and Barrozo, M.A., 2011. Recovery of apatite from flotation tailings. Separation and purification technology, 79(1), pp.79-84.

[17] Ahmed, E., Salah, E.M., Mohamed, A.K., Nagui, A.K. and Ayman, E.M., 2013. Dolomite-apatite separation by amphoteric collector in presence of bacteria. Journal of 
Central South University, 20(6), pp.1645-1652.

[18] Liu, X., Li, C., Luo, H., Cheng, R. and Liu, F., 2017. Selective reverse flotation of apatite from dolomite in collophanite ore using saponified gutter oil fatty acid as a collector. International Journal of Mineral Processing, 165, pp.20-27.

[19] Wonyen, D.G., Kromah, V., Gibson, B., Nah, S. and Chelgani, S.C., 2018. A review of flotation separation of $\mathrm{Mg}$ carbonates (dolomite and magnesite). Minerals, 8(8), p.354.

[20] Brierley, C. and Lanza, G., 1982. The microbial flocculation of phosphate and potash slimes.

[21] Pradip, 1989. Selective flocculation of phophate slimes. Challenges in Mineral Processing, Chapter 24, Sastry K. V. S. and Fuerstenau M. C. Eds., SME, Inc., Littleton, Colorado, pp. 409-420.

[22] Rahman, M.A.E., 2000. Dewatering of phosphatic clay waste by flocculation. Chemical Engineering \& Technology: Industrial Chemistry-Plant Equipment-Process Engineering-Biotechnology, 23(5), pp.457-461.

[23] Chen, G., Tao, D., Parekh, B. K., Honakay, R., 2003. Flocculation dewatering of phosphatic clay. SME Annual Meeting, preprint 06-029, 1-7.

[24] Mohanty, S. and Das, B., 2010. Optimization studies of hydrocyclone for beneficiation of iron ore slimes. Mineral Processing \& Extractive Metallurgy Review, 31(2), pp.8696.

[25] Bhattacharyya, P., Chakrabarti, D.M., Sarkhel, B.R., Saha, P., Chattoraj, U.S. and Banerjee, B., 1997. Modified hydrocycloning for effective elimination of stubborn slimes.

[26] Raghu Kumar, C., Tripathy, S.K., Mohanan, S., Venugopalan, T. and Suresh, N., 2010. Evaluation of floatex density separator performance using silica sand. In Proceedings of the XI International Seminar on Mineral Processing Technology (MPT-2010) (Vol. 2, No. Section 9, pp. 701-706). Allied Publishers, New Delhi.

[27] Wills, B. A. \& Finch, J. A. 2016. Gravity concentration. In: Wills' Mineral Processing Technology, 8th edition. Boston, MA: Butterworth-Heinemann.

[28] Das, A. and Sarkar, B., 2018. Advanced gravity concentration of fine particles: A review. Mineral processing and extractive metallurgy review, 39(6), pp.359-394.

[29] Wasmuth, H.D. and Unkelbach, K.H., 1991. Recent developments in magnetic separation of feebly magnetic minerals. Minerals Engineering, 4(7-11), pp.825-837.

[30] Notebaart, C.W. and Van Der Meer, F.P., 1992. High selectivity in HGMS by capture on the downstream side of matrix elements. Minerals Engineering, 5(10-12), pp.1135- 
1145.

[31] Svoboda, J. and Fujita, T., 2003. Recent developments in magnetic methods of material separation. Minerals Engineering, 16(9), pp.785-792.

[32] Ohara, T., 2014. Progress in Magnetic separation technology for processing large quantities of dilute suspensions. Journal of the Japan Society of Powder and Powder Metallurgy, 61(S1), pp.S139-S144.

[33] Hwang, A., Ji, W., Kweon, B. and Khim, J., 2008. The physicochemical properties and leaching behaviors of phosphatic clay for immobilizing heavy metals. Chemosphere, 70(6), pp.1141-1145.

[34] Forbes, E., Ma, M., and Bruckard, W., 2017. Clay minerals in flotation and comminution operations. In: M. Gräfe, C. Klauber, A.J. McFarlane and D.J. Robinson, eds., Clays in the Minerals Processing Value Chain. Cambridge: Cambridge University Press, pp.302-326.

[35] Edwards, C.R., Kipkie, W.B. and Agar, G.E., 1980. The effect of slime coatings of the serpentine minerals, chrysotile and lizardite, on pentlandite flotation. International Journal of Mineral Processing, 7(1), pp.33-42.

[36] Farrokhpay, S., Filippov, L. and Fornasiero, D., 2020. Flotation of Fine Particles: A Review. Mineral Processing and Extractive Metallurgy Review, pp.1-11.

[37] Zhang, P., Zheng, S., Song, W., Feng, C., Moudgil, B., Xiao, W. and Zhang, D., 2019. Promising options for solving the dolomite problem of the Florida phosphate resources - a brief review. Mining, Metallurgy \& Exploration, 36(1), pp.117-129.

[38] Houot, R., 1982. Beneficiation of phosphatic ores through flotation: Review of industrial applications and potential developments. International Journal of Mineral Processing, 9(4), pp.353-384.

[39] Liu, X., Zhang, Y., Liu, T., Cai, Z., Chen, T. and Sun, K., 2016. Beneficiation of a sedimentary phosphate ore by a combination of spiral gravity and direct-reverse flotation. Minerals, 6(2), p.38.

[40] Liu, X., Zhang, Y., Liu, T., Cai, Z. and Sun, K., 2017. Characterization and separation studies of a fine sedimentary phosphate ore slime. Minerals, 7(6), p.94.

[41] Chen, X. and Peng, Y., 2018. Managing clay minerals in froth flotation - A critical review. Mineral Processing and Extractive Metallurgy Review, 39(5), pp.289-307.

[42] Taner, H.A. and Onen, V., 2016. Control of clay minerals effect in flotation. A review. In E3S Web of Conferences (Vol. 8, p. 01062). EDP Sciences.

[43] Yu, Y., Ma, L., Cao, M. and Liu, Q., 2017. Slime coatings in froth flotation: A 
review. Minerals Engineering, 114, pp.26-36.

[44] Mohanty, S. and Das, B., 2010. Optimization studies of hydrocyclone for beneficiation of iron ore slimes. Mineral Processing \& Extractive Metallurgy Review, 31(2), pp.8696.

[45] Oats, W.J., Ozdemir, O. and Nguyen, A.V., 2010. Effect of mechanical and chemical clay removals by hydrocyclone and dispersants on coal flotation. Minerals Engineering, 23(5), pp.413-419.

[46] Bhattacharyya, P., Chakrabarti, D.M., Sarkhel, B.R., Saha, P., Chattoraj, U.S. and Banerjee, B., 1997. Modified hydrocycloning for effective elimination of stubborn slimes.

[47] Browning, J.S. and Johnson, A.B., 1972. Beneficiation of high clay potash ores by flotation. Trans. SEM/AIME, 252, pp.50-53.

[48] Moudgil, B.M., Blanchard, F.N., Shah, D.O., Onoda, G.Y. and Whitney, E.D., 1987. Separation of dolomite from the South Florida phosphate rock. U. of Florida, Department of Materials Science \& Eng.

[49] Matis, K.A., Gallios, G.P. and Kydros, K.A., 1993. Separation of fines by flotation techniques. Separations Technology, 3(2), pp.76-90.

[50] Peng, F.F. and Gu, Z., 2005. Processing Florida dolomitic phosphate pebble in a double reverse fine flotation process. Mining, Metallurgy \& Exploration, 22(1), pp.23-30.

[51] Fortes, M.C., Silva, A.A., Guimarães, R.C., Ataíde, C.H. and Barrozo, M.A., 2007. Preseparation of siliceous gangue in apatite flotation. Industrial \& engineering chemistry research, 46(21), pp.7027-7029.

[52] Sis, H.İ.K.M.E.T. and Chander, S., 2003. Reagents used in the flotation of phosphate ores: a critical review. Minerals Engineering, 16(7), pp.577-585.

[53] Mohammadkhani, M., Noaparast, M., Shafaei, S.Z., Amini, A., Amini, E. and Abdollahi, H., 2011. Double reverse flotation of a very low grade sedimentary phosphate rock, rich in carbonate and silicate. International Journal of Mineral Processing, 100(3-4), pp.157-165.

[54] Teague, A.J. and Lollback, M.C., 2012. The beneficiation of ultrafine phosphate. Minerals Engineering, 27, pp.52-59.

[55] Luo, X., Wang, Y., Wen, S., Ma, M., Sun, C., Yin, W. and Ma, Y., 2016. Effect of carbonate minerals on quartz flotation behavior under conditions of reverse anionic flotation of iron ores. International Journal of Mineral Processing, 152, pp.1-6.

[56] Miller, J.D., Wang, X. and Li, M., 2002, October. Bench scale flotation of sedimentary 
phosphate rock with hydroxamic acid collectors. In Proceedings of the engineering foundation conference, beneficiation of phosphates III: fundamentals and technology (pp. 93-101).

[57] Wang, L., Tian, M., Khoso, S.A., Hu, Y., Sun, W. and Gao, Z., 2019. Improved Flotation Separation of Apatite from Calcite with Benzohydroxamic Acid Collector. Mineral Processing and Extractive Metallurgy Review, 40(6), pp.427-436.

[58] Ruan, Y., He, D. and Chi, R., 2019. Review on beneficiation techniques and reagents used for phosphate ores. Minerals, 9(4), p.253.

[59] Lamont, W.E., McLendon, J.T. and Clements, L.W., 1975. Characterization studies of Florida phosphate slimes. United States, Bureau of Mines, Investigative Report, (8089), pp.1-24.

[60] Zhang, P. and Bogan, M., 1995. Recovery of phosphate from Florida beneficiation slimes I. Re-identifying the problem. Minerals engineering, 8(4-5), pp.523-534.

[61] Starkey, H.C., Blackmon, P.D. and Hauff, P.L., 1984. The routine mineralogical analysis of clay-bearing samples. Geological Survey bulletin (USA). no. 1563.

[62] Moore, D.M. and Reynolds Jr, R.C., 1989. X-ray Diffraction and the Identification and Analysis of Clay Minerals. Oxford University Press (OUP).

[63] Zhou, X., Liu, D., Bu, H., Deng, L., Liu, H., Yuan, P., Du, P. and Song, H., 2018. XRDbased quantitative analysis of clay minerals using reference intensity ratios, mineral intensity factors, Rietveld, and full pattern summation methods: A critical review. Solid Earth Sciences, 3(1), pp.16-29.

[64] Brindley, G.W., 1952. Identification of clay minerals by X-ray diffraction analysis. Clays and Clay Minerals, 1(1), pp.119-129.

[65] Seredin, V.V. and Dai, S., 2012. Coal deposits as potential alternative sources for lanthanides and yttrium. International Journal of Coal Geology, 94, pp.67-93.

[66] Seredin, V.V., 2010. A new method for primary evaluation of the outlook for rare earth element ores. Geology of Ore Deposits, 52(5), pp.428-433.

[67] Zhang, W. and Honaker, R.Q., University of Kentucky Research Foundation, 2019. Low-cost selective precipitation circuit for recovery of rare earth elements from acid leachate of coal waste. U.S. Patent Application 16/185,120.

[68] Yang, H., Tang, Q., Wang, C. and Zhang, J., 2013. Flocculation and flotation response of Rhodococcus erythropolis to pure minerals in hematite ores. Minerals Engineering, 45, pp.67-72.

[69] Espiritu, E.R.L., Da Silva, G.R., Azizi, D., Larachi, F. and Waters, K.E., 2018. The effect of dissolved mineral species on bastnäsite, monazite and dolomite flotation using benzohydroxamate collector. Colloids and Surfaces A: Physicochemical and Engineering Aspects, 539, pp.319-334. 
[70] Zhang, W., Honaker, R.Q. and Groppo, J.G., 2017. Flotation of monazite in the presence of calcite part I: Calcium ion effects on the adsorption of hydroxamic acid. Minerals Engineering, 100, pp.40-48.

[71] Júnior, J.A.A. and Baldo, J.B., 2014. The behavior of zeta potential of silica suspensions. New Journal of Glass and Ceramics, 4(02), p.29.

[72] Chelgani, S.C., Rudolph, M., Leistner, T., Gutzmer, J. and Peuker, U.A., 2015. A review of rare earth minerals flotation: monazite and xenotime. International Journal of Mining Science and Technology, 25(6), pp.877-883.

[73] Yao, J., Yin, W. and Gong, E., 2016. Depressing effect of fine hydrophilic particles on magnesite reverse flotation. International Journal of Mineral Processing, 149, pp.8493.

[74] Espiritu, E.R.L. and Waters, K.E., 2018. Flotation studies of monazite and dolomite. Minerals Engineering, 116, pp.101-106.

[75] Duzyol, S. and Ozkan, A., 2011. Correlation of flocculation and agglomeration of dolomite with its wettability. Separation Science and Technology, 46(5), pp.876-881.

[76] Qi, Z., Sun, C., 2013. Study of flotation behavior and mechanism of dolomite with fatty acid as collector. J. China Univ. Min. Technol. 3, 461-465. 


\section{CHAPTER 3}

Effect of $\mathrm{Al}^{3+}$ and $\mathrm{Mg}^{2+}$ on the flotation of apatite using fatty- and hydroxamic-acid collectors - A multiscale investigation 


\title{
Effect of $\mathrm{Al}^{3+}$ and $\mathrm{Mg}^{2+}$ on the flotation of apatite using fatty- and hydroxamic-acid collectors - A multiscale investigation
}

\author{
Amir Eskanlou ${ }^{1}$, Qingqing Huang ${ }^{* 1}$, Yann Foucaud ${ }^{* 2}$, Michael Badawi ${ }^{3}$, Aldo H. Romero ${ }^{4}$ \\ 1- Department of Mining Engineering, West Virginia University, Morgantown, WV 26506, USA \\ 2- ICSM, University of Montpellier, CEA, CNRS, ENSCM, Marcoule, Bagnols-sur-Cèze 30207, France \\ 3- Laboratoire de Physique et Chimie Théoriques UMR CNRS 7019, Université de Lorraine, France \\ 4- Department of Physics and Astronomy, West Virginia University, Morgantown, WV 26505-6315, USA \\ *Corresponding Author: qingqing.huang@mail.wvu.edu ; yann.foucaud@univ-lorraine.fr
}

\begin{abstract}
Here we show how $\mathrm{Al}^{3+}$ and $\mathrm{Mg}^{2+}$ ions influence apatite flotation using fatty- and hydroxamic-acid collectors. An original multiscale approach has been developed involving AIMD simulations and flotation experiments. Fatty acid and hydroxamates adsorb on the bare mineral through a bidentate $\mathrm{Ca}-\mathrm{O}$ bond along with a $\mathrm{Na}^{+}$mediated $\mathrm{O}-\mathrm{O}$ bonding, and a mono-dentate $\mathrm{Ca}-\mathrm{O}$ bond along with a hydrogen bonding, respectively. On the $\mathrm{Al}^{3+}$-treated surface, fatty acid adsorbs through the bidentate interaction with both adsorbed $\mathrm{Al}^{3+}$ and lattice $\mathrm{Ca}^{2+}$ ions. The $\mathrm{Al}^{3+}$ site is preferred over $\mathrm{Ca}^{2+}$ lattice site by OHA to interact, resulting in stronger adsorption, and thus enhanced flotation. For BHA, however, $\mathrm{Al}^{3+}$ doesn't benefit collector adsorption, and thereby leads to a declined flotation. $\mathrm{Mg}^{2+}$ presence leads to a stronger bidentate/ tridentate interaction with both adsorbed $\mathrm{Mg}^{2+}$, and lattice $\mathrm{Ca}^{2+}$ ions for both collector types. Fatty acid establishes a stronger interaction with the bare and $\mathrm{Al}^{3+} / \mathrm{Mg}^{2+}$-treated mineral compared to the hydroxamates. Both $\mathrm{Al}^{3+}$ and $\mathrm{Mg}^{2+}$ ions enhance the adsorption of fatty acid, and thereby its flotation. $\mathrm{Mg}^{2+}$ is more favorable than $\mathrm{Al}^{3+}$ in apatite flotation using either fatty acid or hydroxamates. Interestingly, even though $\mathrm{Al}^{3+}$ deters the functionality of BHA on apatite surface, it contributes to a stronger mineral-BHA bonding. This could possibly be because of rendered surface charge due to precipitation of $\mathrm{Al}^{3+}$ species. As well, the inconsistency between the two hydroxamates towards $\mathrm{Al}^{3+}$ could be attributed to the type of hydrocarbon group. Overall, to develop a more industrially applicable knowledge, the effects of the metal ions on the collector consumption by the known gangue minerals, and thereupon on the flotation selectivity, should also be studied in future endeavors.
\end{abstract}

Keywords: Apatite, Metal ions, Flotation, Collector, Adsorption, AIMD 


\section{Introduction}

Apatite $\left[\mathrm{Ca}_{5}\left(\mathrm{PO}_{4}\right)_{3}(\mathrm{OH}, \mathrm{F}, \mathrm{Cl})\right]$ is the primary source for phosphorus $(\mathrm{P})$, which is essential for the production of fertilizers that supplement the nutrition of many agricultural crops by providing a valuable source of phosphate [1]. Apatite is also a possible host material for the storage of nuclear waste owed to the capability of this class of materials in accepting various substitutions from a large variety of ions $[1,2]$. Besides, apatite generally contains significant amounts of rare-earth elements (REEs), uranium (U), and thorium (Th) and can therefore be used as a source for those elements [2]. These strategic elements play significant roles in the development of future energy, high-end equipment, and other advancements of various key technologies [3]. Other important applications for apatite group minerals are in biological science, as biomaterials due to their intrinsic biocompatibility and bioactivity, as a host for solid-state diode lasers when doped with the REEs, and in the development of P-containing compounds, e.g., detergents, phosphor used in fluorescent lamps and plasma display panels, dentifrices, insecticides, etc. [4].

Fluorapatite (FA) $\left[\mathrm{Ca} 5\left(\mathrm{PO}_{4}\right)_{3} \mathrm{~F}\right]$ is the most abundant and well-characterized member of the apatite group due to its large natural reserves [5]. The main gangue minerals that naturally coexist with FA are carbonates, e.g., dolomite, silicates, e.g., quartz, and clays, e.g., kaolinite [6]. Froth flotation is the most efficient beneficiation technology for the separation of FA from its associated gangue minerals: more than $60 \%$ of the global marketable phosphate is beneficiated via flotation [7]. Froth flotation is based on the modification of the surface physicochemical properties of solid particles by the addition of chemical reagents such as collectors, depressants, and surface modifiers, to ultimately separate the valuable minerals from the gangue minerals using air bubbles in an aqueous environment [8]. In the flotation of phosphate minerals, fatty acids and their salts are commonly used as the collector, i.e., the molecule that renders surfaces hydrophobic, due to their low cost and strong collecting ability [9]. Nonetheless, the high affinity of fatty acids for a large number of cations, including transition metals, alkali-earth elements, and REE, entails a lack of selectivity in the flotation process [7]. As an alternative to fatty acids, hydroxamic acids (HA) have recently drawn remarkable attention in phosphate flotation for their collecting ability and good affinity [10, 11]. HA refers to a group of reagents capable of chelating with metallic atoms that have been 
successfully used for the flotation of clays, oxide copper, cassiterite, and other mineral types [12-16].

Sis and Chander (2003) have performed a critical review study on the reagents used in phosphate ore flotation [17]. The separation efficiency in flotation strongly depends upon the selectivity during the adsorption process, which itself is affected by a number of factors such as solution $\mathrm{pH}$, differences in surface characteristics of associated minerals, selective functionality of chemical reagents, etc. [8]. The beneficiation of FA by flotation is complicated, especially from low-grade secondary resources such as waste streams [6]. The valorization and reprocessing of these secondary resources are inevitable to overcome the depletion of highgrade phosphate deposits associated with the growing global demand for $\mathrm{P}$ and other critical elements.

Among the various known waste streams that can be considered as P-bearing secondary resources, waste clay (WC), a tailing of the phosphate ore process, presents a remarkable potential source for $\mathrm{P}$ as well as for other critical elements, e.g., REEs [18]. This stream is a dilute aqueous slurry (3-5 wt.\% solids) consisting of a mixture of clay minerals, silica sand, carbonates, FA, and other fine-grained minerals [19]. A comprehensive and critical literature review on WC has been conducted by Eskanlou and Huang (2021) [20]. The large difficulties in the flotation recovery of FA from secondary resources such as the WC are generally attributed to the close similarities in composition and physicochemical properties of the coexisting minerals, slime-coating, unfavorable rheological properties of pulp, high gangue entrainment, and effect of dissolved lattice metal ions $[6,7,21]$. The presence of metal ions in the flotation environment can result from the water quality, the dissolution of host minerals, or the consumption of the grinding medium during the comminution process $[22,23]$.

As such, in the flotation of FA from either high- or low-grade deposits, the presence of certain ions such as $\mathrm{Ca}^{2+}$ and $\mathrm{Mg}^{2+}$ is inevitable due to the presence of semi-soluble salt-type gangue minerals, as dolomite and calcite [7]. This is further highlighted for low-grade secondary resources such as the WC, where not only the common phosphate minerals but also aluminum (Al)-rich phyllosilicates, e.g., clays, are present in extremely fine size, i.e., below $10 \mu \mathrm{m}$ [20]. This very low particle size facilitates the mineral dissolution and therefore the release of various metal ions such as $\mathrm{Al}^{3+}$ into the flotation environment, which increases the 
complexity of the flotation process. In water, these ions can undergo various reactions, including hydrolysis, complexation, and adsorption that can significantly affect interactions between mineral surfaces and chemical reagents [17]. The adsorption is a complicated integration owing to the fact that the solid-liquid interface can develop a surface charge by various mechanisms, including the substitution of surface ions, preferential dissolution of solid surface, specific ion adsorption from the bulk solution, ionization of surface groups, and charges driven from the specific crystal structure [24]. Hence, the presence of metal ions in a flotation environment renders the surface charge of minerals, brings about surface charge reversals, and the precipitation of their hydrolysis products on the surface of mineral particles interferes with the interaction of collector molecules with the mineral surfaces [24].

The nature and mechanisms of the above-mentioned interactions may be unique for each individual metal ion-mineral system. This still remains unraveled from various aspects for numerous cases of such systems in the context of froth flotation. Many studies have been devoted to investigating the influence of certain metal ions, e.g., $\mathrm{Ca}^{2+}$ and $\mathrm{Mg}^{2+}$, on the flotation of FA using fatty acid collectors $[25,26]$. However, there is no consensus among the previous studies on the influence of these metal ions on the flotation of FA using fatty acids and the results are inconsistent in most cases. As few cases in point, Santos et al. [27], Al-Thyabat and Al-Zoubi [28], Elgillani and Abuozeid [29], and Sis and Chander [30] reported that $\mathrm{Ca}^{2+}$ and/or $\mathrm{Mg}^{2+}$ ions inhibit the flotation of phosphate minerals. In contrast, Al-Fariss et al. [25], Liu et al. [31], Ruan et al. [7], and Horta et al. [32] showed that an appropriate amount of $\mathrm{Ca}^{2+}$ and/or $\mathrm{Mg}^{2+}$ ions could improve the floatability of FA through enhanced collector adsorption.

Those inconsistencies can be attributed to the fact that most of these studies have been conducted via experimental techniques, such as zeta potential measurements, contact angle measurements, X-ray photoelectron spectroscopy (XPS), flotation experiments, etc. The outcomes may be unique to their respective testing conditions, nature and purity of the material, experimental error, and the accuracy and precision of the utilized methodology. Moreover, the previous studies have been limited to the case of fatty acid collectors. Thus, various aspects as well as mechanisms of the influence of these metal ions on the flotation of FA in the presence of other alternative collectors, e.g., HA, still remain to be addressed. Also, the effect of other unavoidable lattice metal ions such as $\mathrm{Al}^{3+}$ on the flotation of $\mathrm{FA}$ has not 
been given the deserved attention yet. This highlights the importance of fundamental theoretical studies supported by the experimental trials to better shed light on the mysteries of the influence of dissolved metal ions on the flotation of valuable minerals, e.g., FA.

Thanks to the technological advances in computer software and hardware capabilities within the past two decades, it is possible nowadays to obtain more thorough insights into the complex natural phenomena through computer-aided simulations. Molecular dynamics simulations based on first-principles calculations techniques such as density functional theory (DFT), known as ab initio molecular dynamics (AIMD) simulations, can be considered as powerful tools to unveil new insights on such interactions in the context of froth flotation at an atomic level [33]. The question is how and under what mechanisms do the metal ions interfere with the interactions of various flotation reagents with the mineral surface, which ultimately dictates the separation efficiency. To this end, integrated approaches merging experimental observations with AIMD simulations are purported to be of significant value to help to grasp the effect of the metal ions on the flotation of valuable minerals such as FA.

Mkhonto et al. [34] performed a series of DFT simulations in vacuum to investigate the adsorption of different organic molecules with various functional groups at various FA crystal surfaces. They concluded that the strongest interactions between reagents and FA surfaces are found where the molecules are capable of forming multiple interactions with surface calcium (Ca) ions. Cui et al. [3] studied the effect of hydration behavior on the FA structure by means of DFT and AIMD, where it was concluded that a single $\mathrm{H}_{2} \mathrm{O}$ molecule could form stable chemisorption structures with the FA (001) surface in the form of single-site, two-site, and three-site adsorptions. Xie et al. [35] employed surface characterization means and contact angle measurements coupled with DFT calculations to explore the anisotropic crystal plane nature and wettability of FA crystal. Their findings showed that the exposure degree of different FA surfaces follows the order of $(001)>(100)>(101)>(111)$, which agreed quite well with the trend obtained for the surface roughness and wettability. Xie et al. [36] studied the interaction between fatty acid collectors and FA (001) surface by DFT calculations. They showed that the oxygen $(\mathrm{O})$ atoms of fatty acid collectors form stable chemisorption configurations at $\mathrm{Ca}_{1}$ site of the FA surface. It was also shown that a hydrogen $(\mathrm{H})$ bond is formed between the $\mathrm{H}$ atom of the collector and the $\mathrm{O}$ atoms of -[PO 4$]-$ at the FA surface. 
Several other studies have also been performed so far regarding the effect of $\mathrm{Ca}$ minerals reactivity on fatty acid adsorption [37], effects of crystal chemistry on sodium oleate adsorption [38], electronic structure, bonding, and charge distribution of (001) FA surface [39], first principles NMR study of FA [40], electronic structure and floatability of REE-bearing FA [41], mechanism of benzohydroxamic acid (BHA) collector interaction with FA [11], interfacial properties and equilibria in the FA-aqueous system [4], kinetics and mechanism of natural FA dissolution [42], mechanism of oleate interaction on salt-type minerals [43], surface chemistry and flotation behavior of FA with octanohydroxamic acid (OHA) collector [44], surface complexation of hydrous FA [6], and surface electrical behaviors of FA in the presence of $\mathrm{Ca}^{2+}$ and $\mathrm{Mg}^{2+}[21]$.

The present study endeavored to investigate the interactions of fatty- and hydroxamic acid collectors with $\mathrm{FA}$ in the presence of $\mathrm{Al}^{3+}$ and $\mathrm{Mg}^{2+}$ metal ions by combining AIMD simulations and various experimental studies. We aimed at unraveling how the presence of those metal ions influences the adsorption of the target collectors on the FA surface, and thereupon its selective flotation performance. For this purpose, zeta potential measurements, XPS studies, adsorption density measurements, and micro-flotation tests were carried out to gain and compare the insights from different experimental perspectives. In addition, AIMD simulations helped rationalize the experimental observations in terms of interaction energies and adsorption configurations of both collector and hydrolysis products of the metal ions with the mineral surface. The findings from the current study will be beneficial for improving the flotation performance of FA as the most recognized P-rich mineral from the low-grade primary and secondary resources such as WC.

\section{Crystal structure and solubility of FA}

FA, mainly composed of calcium fluoro-phosphate, has a hexagonal di-pyramidal crystal system with a space group of $\mathrm{P} 6_{3} / \mathrm{m}^{2}$, having $\mathrm{a}=\mathrm{b}=0.9224 \mathrm{~nm}$ and $\mathrm{c}=0.6805 \mathrm{~nm}$ and $\alpha=\beta=90^{\circ}$ and $\lambda=120^{\circ}$ [45], as shown in Fig. 3-1. The monoclinic (P21/B) polymorph for FA has also been reported in the literature [46]. According to Werner's coordination theory [47], FA is

\footnotetext{
${ }^{2}$ Hermann-Mauguin notation
} 
considered as a compound formed by the substitution of calcium phosphate $\left(\mathrm{Ca}_{3}\left(\mathrm{PO}_{4}\right)_{2}\right)$ into calcium fluoride, $\left(\mathrm{CaF}_{2}\right)$. The coordination formula of FA can then be written as

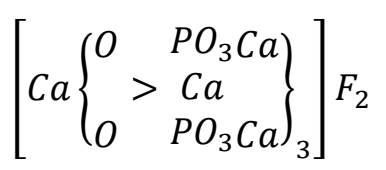

The $\mathrm{P}_{3} / \mathrm{M}$ structure of FA consists of individual orthophosphate tetrahedra linked by $\mathrm{Ca}$ cations. The orthophosphate groups form the skeleton with two types of Ca sites; first, the [Ca1] site is occupied by four $\mathrm{Ca}$ atoms with nine-fold coordination, while the second [Ca2] site is occupied by six $\mathrm{Ca}$ atoms having seven-fold coordination. Fluoride $\left(\mathrm{F}^{-}\right)$anions are located within the same channels as the $\mathrm{Ca} 2$ sites and have high mobility $[48,49]$. Thus, the FA structure contains $\mathrm{Ca}-\mathrm{F}, \mathrm{Ca}-\mathrm{O}$, and $\mathrm{P}-\mathrm{O}$ bonds; consideration of the relative electrostatic strength of these bonds suggests that their relative destruction rate is consistent with: $\mathrm{Ca}-\mathrm{F}>\mathrm{Ca}_{1}-\mathrm{O}>\mathrm{Ca}_{2}-\mathrm{O}>\mathrm{P}-\mathrm{O}$. Considering its structure, once all $\mathrm{Ca}-\mathrm{F}$ and $\mathrm{Ca}-$ $\mathrm{O}$ bonds are broken, FA is destroyed, while breaking $\mathrm{P}-\mathrm{O}$ bonds is unnecessary for FA dissolution [48, 50, 51]. The most abundant crystal faces of FA after pulverization possess the Miller-Bravais indices of (001), (100), (101), and (111) [50, 51].
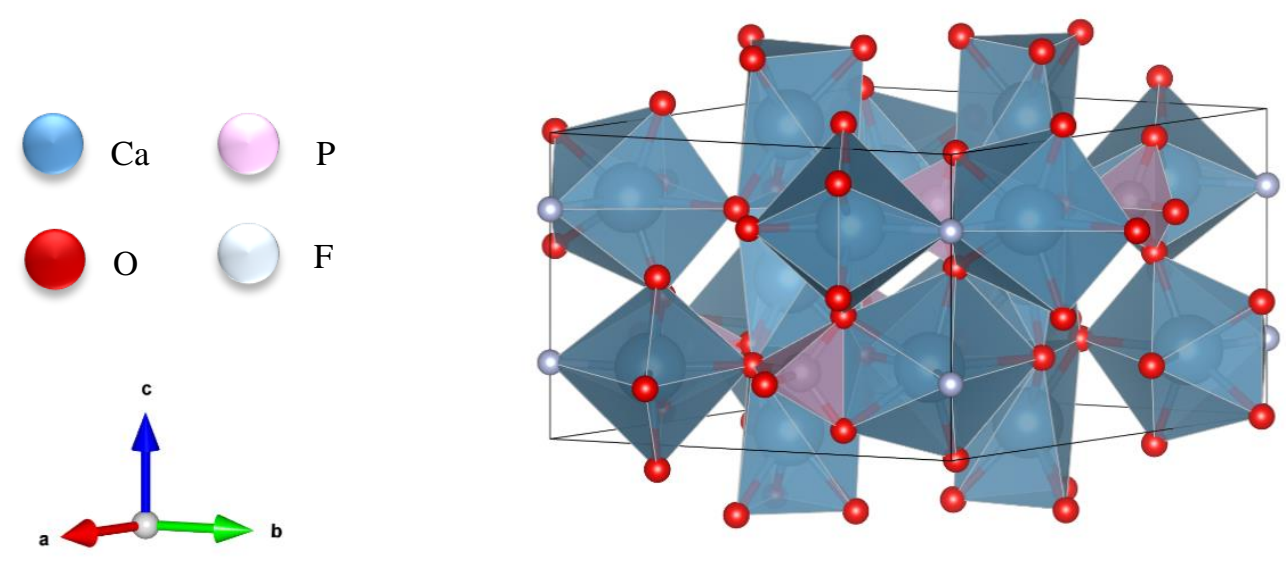

Figure 3-1: Crystal structure of FA.

Although apatite-group minerals are generally considered as semi-soluble salt-type minerals, FA is a highly insoluble calcium phosphate compared to other apatite-group minerals. The solubility product of stoichiometric FA at $37^{\circ} \mathrm{C}$ is $3.19 \pm 0.14 \times 10^{-61}$ mol. $\mathrm{L}^{-1}$ as reported by Moreno et al. [52]. A suggested explanation for this very low solubility product is that cohesive forces are relatively stronger in FA due to its smaller unit-cell dimensions [53, 
54]. FA can be completely dissolved in $\mathrm{HCl}$ and $\mathrm{HNO}_{3}$ [53]. As proposed by [48], to describe the chemical processes of FA dissolution at $25^{\circ} \mathrm{C}$, a sequence of four successive chemical reactions can be considered:

$$
\begin{aligned}
& \mathrm{Ca}_{5}\left(\mathrm{PO}_{4}\right)_{3} \mathrm{~F}+\mathrm{H}_{2} \mathrm{O}+\mathrm{H}^{+}=\mathrm{Ca}_{5}\left(\mathrm{PO}_{4}\right)_{3}\left(\mathrm{H}_{2} \mathrm{O}\right)^{+}+\mathrm{HF} \\
& 2 \mathrm{Ca}_{5}\left(\mathrm{PO}_{4}\right)_{3}\left(\mathrm{H}_{2} \mathrm{O}\right)^{+}=3 \mathrm{Ca}_{3}\left(\mathrm{PO}_{4}\right)_{2}+\mathrm{Ca}^{2+}+2 \mathrm{H}_{2} \mathrm{O} \\
& \mathrm{Ca}_{3}\left(\mathrm{PO}_{4}\right)_{2}+2 \mathrm{H}^{+}=\mathrm{Ca}^{2+}+2 \mathrm{CaHPO}_{4} \\
& \mathrm{CaHPO}_{4}+\mathrm{H}^{+}=\mathrm{Ca}^{2+}+\mathrm{H}_{2} \mathrm{PO}_{4}^{-}
\end{aligned}
$$

Fig. 3-2 shows a schematic representation of surface protonation of apatite at different solution $\mathrm{pH}$ values, where the adsorption of protons onto negatively charged $\mathrm{O}$ ions of the orthophosphate group surfaces is depicted. This process is referred to as the hydrogen catalytic dissolution model for apatite $[48,55]$. Recent computer simulations have revealed that in the case of FA, $\mathrm{F}^{-}$ions located on the surface are poorly protonated, and these ions exhibit a $\mathrm{pK}_{\mathrm{B}}=$ 10.8 indicating a weak base [56]. An obvious trend in apatite dissolution is that the dissolution rate is increased as the solution $\mathrm{pH}$ decreases, which is a general phenomenon observed in the dissolution of other minerals. This indicates that dissolution proceeds by surface protonation, which promotes the breaking of $\mathrm{Ca}-\mathrm{O}$ bonds [48]. In the course of proton uptake, the charge of the surface anions is reduced and the Coulomb attraction to the crystal surface is lowered considerably, which brings about a catalytic effect on the dissolution of FA, as noted earlier $[48,54]$.

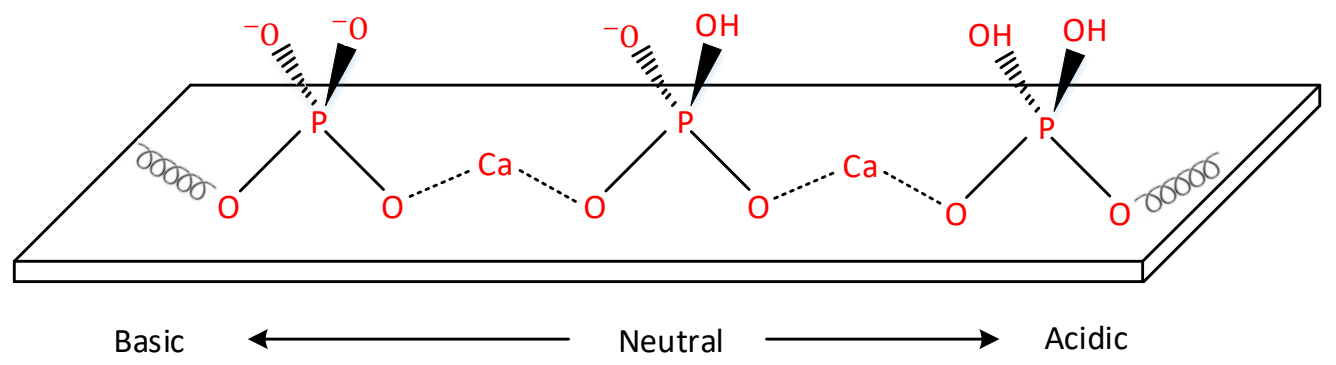

Figure 3-2: A schematic representation of surface protonation of apatite at different solution $\mathrm{pH}$ ranges (reproduced from [48]).

The $\mathrm{Ca}^{2+}$ sites in FA can be replaced by REEs, e.g., cerium (Ce), lanthanum (La), and yttrium (Y), via a charge-balancing coupled substitution, resulting in lattice defects that exert a 
considerable influence on the FA surface properties [57]. The presence of REE impurities makes FA receive electrons more readily and hence increases its oxidation ability, especially when a reductive collector, e.g., fatty acid, is employed [57, 58].

\section{Materials and Methods \\ Materials and chemicals}

FA (calcium fluorophosphate) was purchased from Ward's Science (USA). Panalytical Xray powder diffraction (XRD) in the $2 \theta$ range of $10-100^{\circ}$ and $\mathrm{Cu}-\mathrm{K} \alpha$ radiation $(\lambda=1.5406 \AA)$ was employed to investigate the crystalline phases and mineral associations. The morphological characteristics of the sample were investigated using scanning electron microscopy (SEM) coupled with energy-dispersive X-ray spectroscopy (EDS), which allows for targeted analysis of sample surfaces. The XRD and SEM results are presented in Fig. 3-3. The morphological characterization showed that the FA particles had irregular shapes. Inductively coupled plasma mass spectrometry, i.e., ICP-MS method was employed for the elemental characterization of the sample, and the results are tabulated in Table 3-1. It can be seen that $\mathrm{Ca}, \mathrm{P}$ and not-detectable elements, i.e., $\mathrm{F}$ and $\mathrm{O}$ accounted for the major components of the FA, corresponding to a total of 96.5 wt. \%. Other elements, including $\mathrm{Si}, \mathrm{Ce}, \mathrm{Th}, \mathrm{La}$, etc., were also detected in negligible amounts. The particle size distribution (PSD) was analyzed for the representative samples using CILAS 1190 particle size analyzer. 


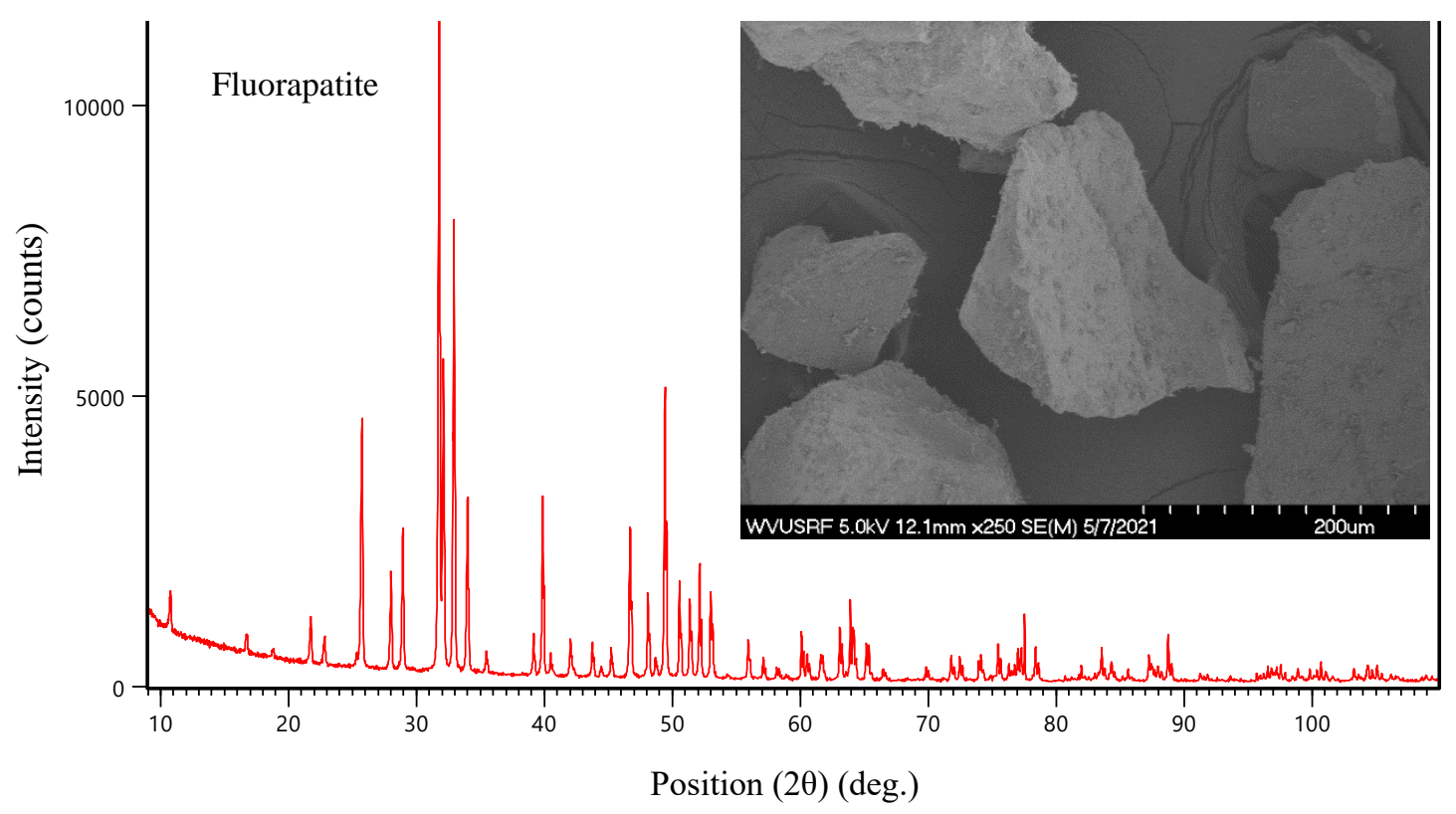

Figure 3-3: X-ray powder diffractogram and SEM micrograph of the FA sample used for the current study.

Table 3-1: Elemental composition (ICP-MS results) of the FA mineral sample.

\begin{tabular}{|c|c|c|c|c|}
\hline Mineral & Composition & wt.\% /ppm & Composition & $\mathrm{ppm}$ \\
\hline \multirow{16}{*}{ Fluorapatite } & ND & $36.90(\%)$ & $\mathrm{Mg}$ & 193 \\
\hline & $\mathrm{Ca}$ & 40.20 & $\mathrm{Gd}$ & 191 \\
\hline & $\mathrm{P}$ & 19.40 & $\mathrm{U}$ & 153 \\
\hline & $\mathrm{Si}$ & 0.93 & Dy & 85 \\
\hline & $\mathrm{S}$ & 0.65 & $\mathrm{Zn}$ & 50 \\
\hline & $\mathrm{Ce}$ & 0.58 & Er & 43.9 \\
\hline & Th & 0.38 & $\mathrm{Eu}$ & 31 \\
\hline & $\mathrm{La}$ & 0.27 & $\mathrm{Yb}$ & 29.3 \\
\hline & $\mathrm{Nd}$ & 0.23 & $\mathrm{~Tb}$ & 18.3 \\
\hline & $\mathrm{Fe}$ & 0.10 & Ho & 14.9 \\
\hline & $\mathrm{Al}$ & 751 (ppm) & $\mathrm{Cl}$ & 11 \\
\hline & $\operatorname{Pr}$ & 605 & $\mathrm{Tm}$ & 5 \\
\hline & $\mathrm{Mn}$ & 503 & $\mathrm{Lu}$ & 3.8 \\
\hline & $\mathrm{Y}$ & 415 & Co & 1.9 \\
\hline & $\mathrm{Sm}$ & 261 & $\mathrm{Sc}$ & 1 \\
\hline & $\mathrm{Ni}$ & 257 & & \\
\hline
\end{tabular}

In the current study, OHA, BHA, and sodium oleate $(\mathrm{NaOl})$ were used as the collectors for the flotation of the FA. Methyl isobutyl carbinol (MIBC) was used as the frothing agent in all flotation experiments. Hydrochloric acid $(\mathrm{HCl})$ and sodium hydroxide $(\mathrm{NaOH})$ solutions of relevant concentrations were used as $\mathrm{pH}$ regulators. Magnesium chloride $\left(\mathrm{MgCl}_{2}\right)$ and aluminum chloride $\left(\mathrm{AlCl}_{3}\right)$ were used to prepare multivalent metal solutions. Iron (III) chloride 
$\left(\mathrm{FeCl}_{3}\right)$ was used for preparing the ferric solution for the coloring of hydroxamates in UV-Vis spectroscopy. A solution of potassium chloride $(\mathrm{KCl})$ at $1 \times 10^{-3} \mathrm{~mol} . \mathrm{L}^{-1}$ was used as the supporting electrolyte for zeta potential measurements. Potassium nitrate $\left(\mathrm{KNO}_{3}\right)$ was used as the indifferent background electrolyte for the adjustment of the ionic strength (IS) of the synthetic metal solutions. Details of the chemicals used in the present study are listed in Table 3-2. Milli-Q deionized (DI) water (18.2 M $\Omega . c m)$ was used for the stock solution preparations, zeta potential and adsorption density measurements, as well as for micro-flotation experiments.

Table 3-2: Details of the chemical reagents used in the current study.

\begin{tabular}{lllll}
\hline Chemical & Formula & $\mathrm{MW}^{3}(\mathrm{~g} /$ mole) & Purity & Supplier \\
\hline $\mathrm{OHA}$ & $\mathrm{C}_{8} \mathrm{H}_{17} \mathrm{NO}_{2}$ & 159.23 & $98 \%$ & Fisher Scientific \\
$\mathrm{BHA}$ & $\mathrm{C}_{7} \mathrm{H}_{7} \mathrm{NO}_{2}$ & 137.14 & $98 \%$ & Fisher Scientific \\
$\mathrm{NaOl}$ & $\mathrm{C}_{18} \mathrm{H}_{33} \mathrm{NaO}_{2}$ & 304.44 & $\geq 95 \%$ & TCI America \\
$\mathrm{MIBC}$ & $\mathrm{C}_{6} \mathrm{H}_{14} \mathrm{O}$ & 102.174 & $\geq 99 \%$ & Sigma Aldrich \\
$\mathrm{HCl}$ & $\mathrm{HCl}$ & 36.45 & $30 \%$ & Fisher Scientific \\
$\mathrm{NaOH}$ & $\mathrm{NaOH}$ & 39.99 & $\geq 99 \%$ & Sigma Aldrich \\
$\mathrm{AlCl}_{3}$ & $\mathrm{AlCl}_{3}$ & 133.34 & $\geq 99 \%$ & Sigma-Aldrich \\
$\mathrm{MgCl}_{2}$ & $\mathrm{MgCl}_{2}$ & 95.211 & $\geq 99 \%$ & Sigma-Aldrich \\
$\mathrm{FeCl}_{3}$ & $\mathrm{FeCl}_{3}$ & 162.2 & $\geq 99 \%$ & Sigma-Aldrich \\
$\mathrm{KNO}_{3}$ & $\mathrm{KNO}_{3}$ & 101.13 & $\geq 99 \%$ & Fisher Scientific \\
$\mathrm{KCl}$ & $\mathrm{KCl}$ & 74.5 & $\geq 99 \%$ & Fisher Scientific \\
\hline
\end{tabular}

\section{Multivalent metals solutions}

Stock solutions of $10^{-5}, 10^{-4}$, and $10^{-3}$ mol. $\mathrm{L}^{-1}$ of $\mathrm{Mg}^{2+}$ and $\mathrm{Al}^{3+}$ were prepared by dissolving the appropriate amount of their corresponding chloride salts using DI water. The IS of all synthetic solutions was adjusted to $2 \mathrm{mM}$ using $\mathrm{KNO}_{3}$ as an indifferent background electrolyte. Solution $\mathrm{pH}$ was adjusted using $0.1 \mathrm{~mol} . \mathrm{L}^{-1} \mathrm{NaOH}$ and diluted $\mathrm{HCl}$ solutions.

\section{Zeta potential measurements}

Because of lattice substitution and surface dissolution, the mineral surfaces carry electric charges in an aqueous environment. As electrostatic interactions play a vital role in the adsorption of flotation reagents onto mineral surfaces, understanding surface charges is critical, and surface charges are usually modified via adjusting solution $\mathrm{pH}[24,59]$. Hence, to determine the possible surface charge changes of FA in the presence of the multivalent metal ions, the zeta potential of FA was measured in the presence of hydrolyzed divalent $\mathrm{Mg}^{2+}$ and trivalent $\mathrm{Al}^{3+}$ metal ions as a function of solution $\mathrm{pH}$. Surface charge can be affected by both

\footnotetext{
${ }^{3}$ Molecular Weight
} 
the ion valence, $z$, and the ion concentration, $C_{i}$, as described by the Debye constant, which is proportional to the solution IS, $I=\frac{1}{2} \sum C_{i} z_{i}^{2}$. Therefore, a constant concentration $\left(10^{-3}\right.$ mol.L$\left.{ }^{1}\right)$ of the cations with the same valence $(z=+2 / z=+3)$ was used to keep a fixed IS during the electro-kinetic measurements [24].

For zeta potential measurements, a small amount of the pure FA mineral was ground using an agate pestle and mortar until the particles passed a $5 \mu \mathrm{m}$ molecular sieve, and then 0.5 gram of the ground material was mixed with $100 \mathrm{~mL}$ of already prepared supporting electrolyte solution $\left(10^{-3} \mathrm{~mol} . \mathrm{L}^{-1} \mathrm{KCl}\right)$ in a $200 \mathrm{~mL}$ glass beaker. The suspension was stirred for 10 minutes at $25{ }^{\circ} \mathrm{C}$ using a magnetic stirrer at a constant rotating speed. In the meantime, using separate $50 \mathrm{~mL}$ glass beakers, a $40 \mathrm{~mL}$ supporting electrolyte solution was prepared for each target $\mathrm{pH}$ point by adjusting the $\mathrm{pH}$ values using dilute $\mathrm{NaOH}$ and $\mathrm{HCl}$ solutions via a micropipette. Later on, the well-mixed mineral suspension was allowed to naturally settle for 2 minutes. Then, a small portion of the supernatant was collected and added to each $40 \mathrm{~mL}$ solution with an already set $\mathrm{pH}$ value. Finally, the prepared suspensions were placed and kept inside an ultrasonic bath until being subjected to zeta potential measurements using Malvern Nano ZS Zetasizer, which employs Dynamic Light Scattering as for the measurement principle. The sensitivity of this instrument is $0.1 \mathrm{mg} \cdot \mathrm{mL}^{-1}$ that works for a particle size range of $0.3 \mathrm{~nm}$ to $10 \mu \mathrm{m}$. Zeta potentials were measured for every $\mathrm{pH}$ set point from $\mathrm{pH} 2$ to $\mathrm{pH} 12$. The final $\mathrm{pH}$ value of each suspension was recorded right before the zeta potential measurement and was reported as the reference value in the current study. Each recorded zeta potential was the average of three separate measurements, where each separate trial itself was the average of 100 automatically repeated measurements. A standard deviation of $0.63 \mathrm{mV}$ was determined for the zeta potential measurements.

\section{XPS measurements}

XPS, also known as electron spectroscopy for chemical analysis (ESCA), is an advanced surface-sensitive method for studying the materials surface chemistry and probing the chemical species and chemical components at the surfaces [60]. XPS works based on the measurement of the kinetic energy and the number of the photoelectrons emitted from the surface as a result of irradiation of the sample by single-energy X-ray photons [60]. This technique is one of the most suitable methods for analyzing material surfaces because of its ability to probe a limited 
depth $(0-10 \mathrm{~nm})$ of the surface to provide quantitative and qualitative information, i.e., the chemical shift of the surface species $[60,24]$. XPS has been widely employed for investigating the interaction mechanism of various ions on different material surfaces $[61,24]$. For this purpose in the current study, three different solutions of $10^{-3}, 10^{-4}$, and $10^{-5}$ mol. $\mathrm{L}^{-1}$ of $\mathrm{Al}^{3+}$ and $\mathrm{Mg}^{2+}$, separately, at $\mathrm{pH} 9$ were prepared and treated for 24 hours with $0.5 \mathrm{~g}$ FA sample using a magnetic stirrer. The treated powder samples were thoroughly rinsed with DI water. The washed samples were then placed in a desiccator under partial vacuum for overnight soft drying prior to being subjected to the XPS analysis. XPS measurements were performed using a Physical Electronics PHI 5000 VersaProbe system. The system is equipped with a monochromatic Al K- $\alpha$ X-ray source at $1486.6 \mathrm{eV}$ with a $100 \mu \mathrm{m}$ beam size. All XPS measurements were carried out at room temperature at a pressure below $10^{-7}$ Torr. Compositional survey scans were obtained using a pass energy of $117.4 \mathrm{eV}$ and energy step of $0.5 \mathrm{eV}$. High-resolution, detailed scans of each element were acquired using a pass energy of $23.5 \mathrm{eV}$ and an energy step of $0.1 \mathrm{eV}$. The obtained binding energies were calibrated using standard carbon peak C $1 \mathrm{~s}$ for $\mathrm{C}-\mathrm{C}$ at $284.8 \mathrm{eV}$ [62] and were fitted using Thermo Advantage 4.60 (Thermo Fisher Scientific Inc., USA) software.

\section{Adsorption density measurements}

The adsorption of $\mathrm{NaOl}, \mathrm{BHA}$, and $\mathrm{OHA}$ collectors on FA under various conditions was investigated by the adsorption from solution technique. For this purpose, the concentration difference of the collector in the solution before and after being treated with the apatite powder was measured. The FA powder was ground to a mean diameter $\left(\mathrm{d}_{50}\right)$ of $3.5 \mu \mathrm{m}\left(\mathrm{BET}^{4}\right.$ surface area of $2.3741 \mathrm{~m}^{2} / \mathrm{g}$ ) using an agate mortar and pestle. The ground sample was thoroughly washed with DI water, and then the dried powder was used for the adsorption tests. Adsorption experiments were performed using a $20 \mathrm{~mL}$ glass beaker. For each experiment, $0.05 \mathrm{~g}$ FA powder was added into the beaker containing $10 \mathrm{~mL}$ collector solution (solid-liquid ratio of 5:100). The conditioning procedure was similar to that used for micro-flotation experiments. The $\mathrm{pH}$ of the system was adjusted using $\mathrm{HCl}$ and/ or $\mathrm{NaOH}$. Then, the slurry mixture together with a magnet bar within the beaker was tightly sealed and conditioned for 10 minutes at a constant stirring speed on top of a magnetic stirrer at room temperature. Later on, the

\footnotetext{
${ }^{4}$ Brunauer-Emmett-Teller
} 
conditioned slurry was transferred into a centrifuge tube and centrifuged for 10 minutes using a Cole-Parmer variable speed clinical centrifuge at 3200 RPM.

Collector concentration of the supernatant was determined using a Shimadzu 1280 UVVisible spectrophotometer (wavelength scanning from 190-1100 nm, spectral bandwidth of 5 $\mathrm{nm}$ ) based on the respective calibration curve established for each reagent. To construct the calibration curve for each target reagent, a set of aqueous solution samples of various concentrations were prepared and added into 3-mL standard polystyrene cuvettes. Then, spectrum analysis was performed for each sample so that the absorbance (Abs: 0 to 1) versus wavelength $(\lambda: 190$ to $1100 \mathrm{~nm})$ data were recorded and saved as a CSV file. The recorded spectrum data for different samples of a target collector were plotted and compared. Consequently, the $\lambda$ at which all the samples showed an absorbance peak between the range of 0 to 1 , was opted as the proper wavelength for subsequent measurements. Later on, at the obtained wavelength, the absorbance value was set to zero for the reference background solution. Then, using the photometric functionality, the absorbance of the collector solutions with various concentrations was determined at the target wavelength. Finally, the recorded absorbance values were scatter plotted versus the corresponding solution concentrations in mg. $\mathrm{L}^{-1}$, to which a linear trend-line was fitted in order to obtain the governing relationship between the absorbance and solution collector concentration. For BHA and OHA, the solution collector concentrations were determined using the above-mentioned procedure coupled with the ferric-hydroxamate technique $[63,64]$. For this purpose, $2 \mathrm{~mL}$ ferric chloride $\left(\mathrm{FeCl}_{3}\right)$ of 5 mmol. $\mathrm{L}^{-1}$ was added to $1 \mathrm{~mL}$ of centrifuged supernatant and conditioned within a glass tube. This mixture forms a purple-colored complex of ferric hydroxamate, which is detectable by the spectrometer. Full-wave scanning of the obtained solutions was performed to achieve the suitable $\lambda$ for the respective subsequent measurements. To avoid any possible contamination, all the employed laboratory tools and glassware were cleaned before and after each experiment using acetone, isopropyl alcohol followed by being rinsed with DI water. The adsorption density $\left(\Gamma, \mathrm{mg} . \mathrm{g}^{-1}\right)$ of $\mathrm{NaOl}, \mathrm{BHA}$, and OHA on FA was calculated using Eq. (3-6) as follows:

$$
\Gamma=\frac{\left(c_{i}-c_{f}\right) \times v}{w}
$$


where $c_{i}$ and $c_{f}\left(\mathrm{mg} . \mathrm{L}^{-1}\right)$ represents the initial and final concentration of the collector in solution, respectively. $v(\mathrm{~L})$ and $w(\mathrm{~g})$ is the solution volume (i.e., $0.01 \mathrm{~L})$ and the powder sample weight (i.e., $0.05 \mathrm{~g}$ ), respectively. In order to determine the measurement error, several tests were conducted under the same condition, and a standard deviation value of $0.10 \mathrm{mg} . \mathrm{g}^{-1}$ was achieved. In this study, the ultimate adsorption density values are reported as the mole of the reagent per the unit surface area of the mineral, i.e., $\mathrm{mol} / \mathrm{m}^{2}$.

\section{Atomistic simulations}

As the starting point for the AIMD simulations, a primitive unit cell of $\mathrm{Ca}_{5}\left(\mathrm{P} \mathrm{O}_{4}\right)_{3} \mathrm{~F}$ was obtained from the American Mineralogist Crystal Structure Database (AMCSD) [65]. The lattice parameters of the unit cell were determined as $\mathrm{a}=\mathrm{b}=9.37 \AA$ and $\mathrm{c}=6.88 \AA$ with $\alpha=\beta=$ $90^{\circ}$ and $\gamma=120^{\circ}$. DFT and AIMD calculations were performed using the Vienna Ab initio Simulation Package (VASP), version 5.4.4 [66]. The semi-local exchange-correlation function of Perdew-Burke-Ernzrhof (PBE) in the general gradient approximation (GGA) [67] was employed. The Kohn-Sham equations [68] were solved self-consistently [69] with an energy convergence criterion of $10^{-6} \mathrm{eV}$. The electron-ion interactions were described using the Projected Augmented Wave (PAW) method [70]. To help the electronic convergence, a Methfessel Paxton smearing [71] of $\sigma=0.1 \mathrm{eV}$ was applied. The structural relaxations were conducted until all forces were smaller than $0.03 \mathrm{eV} . \AA^{-1}$. Based on the cut-off kinetic energy (ENCUT) and K-points convergence test results presented in Fig. 3-4, the FA unit cell was fully relaxed using an ENCUT of $450 \mathrm{eV}$ and a K-points grid of $2 \times 2 \times 2$ [72]. The optimized lattice parameters of the relaxed unit cell were obtained as $a=b=9.462 \AA, c=6.891 \AA$, and $\alpha=\beta=90^{\circ}, \gamma=120^{\circ}$, which were in good agreement with the experimental values. Later on, using the fully-relaxed unit cell, a FA slab of $\mathrm{a} \times \mathrm{b} \times \mathrm{c}=2 \times 2 \times 1$ comprising a total number of 168 atoms was constructed, as shown in Fig. 3-5. The (001) surface, which represents the most exposed and stable (lowest surface energy) surface of FA [3, 5, 35, 36, 39], was then built by adding vacuum along the $c$-axis. To avoid any unwanted interaction with the periodic images, the vacuum was fixed to $20 \AA$ above the uppermost atom along the $c$-axis of the supercell, as shown in Fig. 3-6. For AIMD simulations, due to the large size of the supercell, the $\Gamma$-point only was employed for sampling the Brillouin zone. The temperature was set at 300 K, and a Nosé-Hoover thermostat [73-75] was used. A time step of 1 femtosecond (fs) was 
employed and 40000 steps were realized to reach a total simulation time of 40 picoseconds (ps).
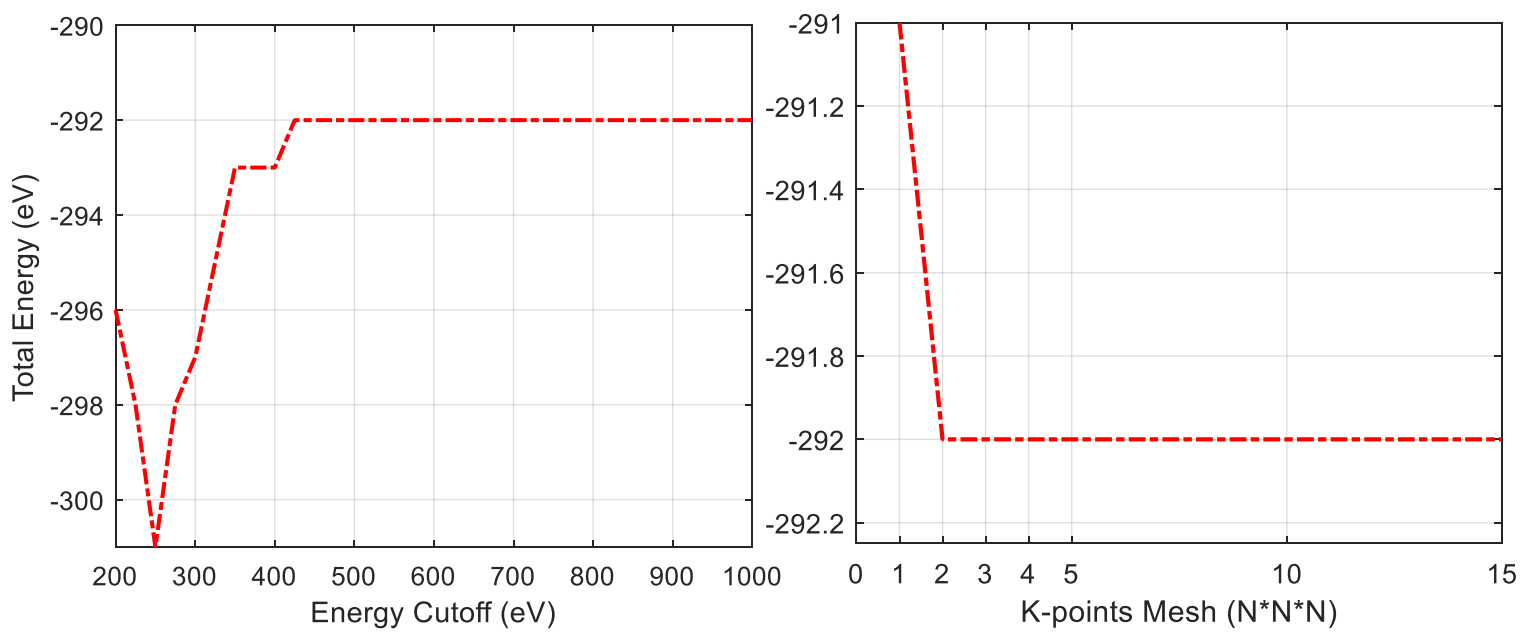

Figure 3-4: ENCUT and K-point mesh $\left(\mathrm{N}^{*} \mathrm{~N}^{*} \mathrm{~N}\right)$ versus total energy for FA unit-cell.

Moreover, for all AIMD calculations, a set of 20 atoms including $8 \mathrm{Ca}$ and $12 \mathrm{O}$ atoms at the bottom layer of the supercell were frozen to the bulk positions to avoid any unwanted drift of the FA slab. The adsorption energy of either the hydrolysis products or collectors on the mineral surface was determined based on Eqs. (7) \& (8) [36]:

$$
\begin{aligned}
& \Delta \mathrm{E}_{\mathrm{ads}}=\mathrm{E}_{(\text {slab }+ \text { collector } / \text { hydrolysis product })}-\mathrm{E}_{(\text {slab })}-\mathrm{E}_{(\text {collector } / \text { hydrolysis product })} \\
& \Delta \mathrm{E}_{\mathrm{ads}}=\mathrm{E}_{(\text {slab }+ \text { collector }+ \text { hydrolysis products })}-\mathrm{E}_{(\text {slab }+ \text { hydrolysis product })}-\mathrm{E}_{(\text {collector })}
\end{aligned}
$$

Three collectors were investigated in the current study, i.e., BHA and OHA, the short-chain and long-chain HA collector, respectively, and $\mathrm{NaOl}$. For the AIMD simulations, in order to reduce the computational complexity and cost, sodium octanoate (SC) was used instead of $\mathrm{NaOl}$ since they both own the same functional group while the chain length does not affect significantly the adsorption mechanism and behavior [76]. Considering the $\mathrm{pK}_{\mathrm{a}}$ values of the collectors (BHA: 8.6 [77], OHA: 9.5 [78], NaOl: 4.9 [79]), at $\mathrm{pH}=9$, BHA and OHA are present in their both neutral and anionic forms, while fatty acid collector is present only in its anionic form. As such, in the AIMD simulations, HA collectors were investigated in their both neutral and anionic forms, while the fatty acid collector was studied in its anionic form. The 
molecular demonstrations of the three collector molecules as their free anionic form [80] are presented in Fig. 3-7.

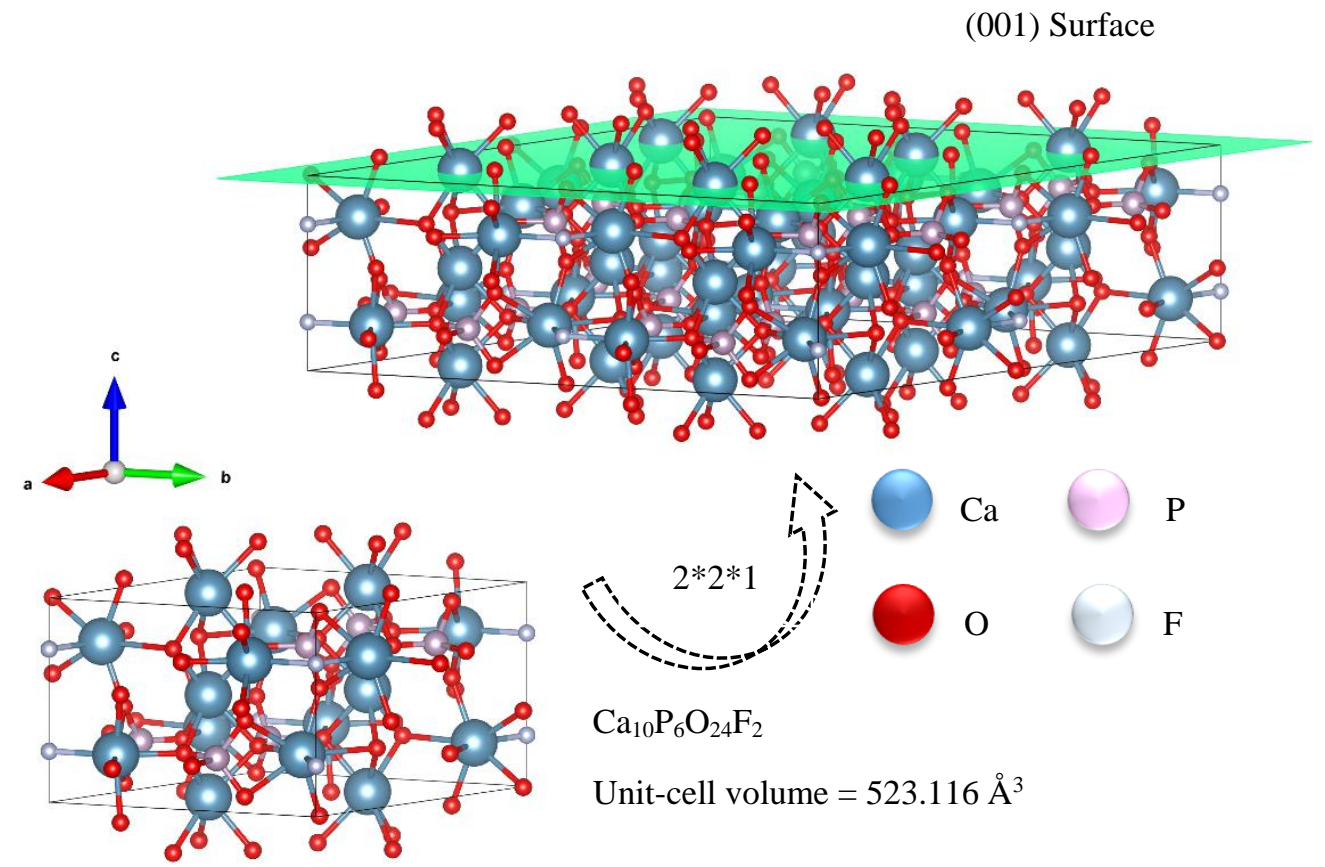

Figure 3-5: The FA mineral unit-cell and slab used for the current study.

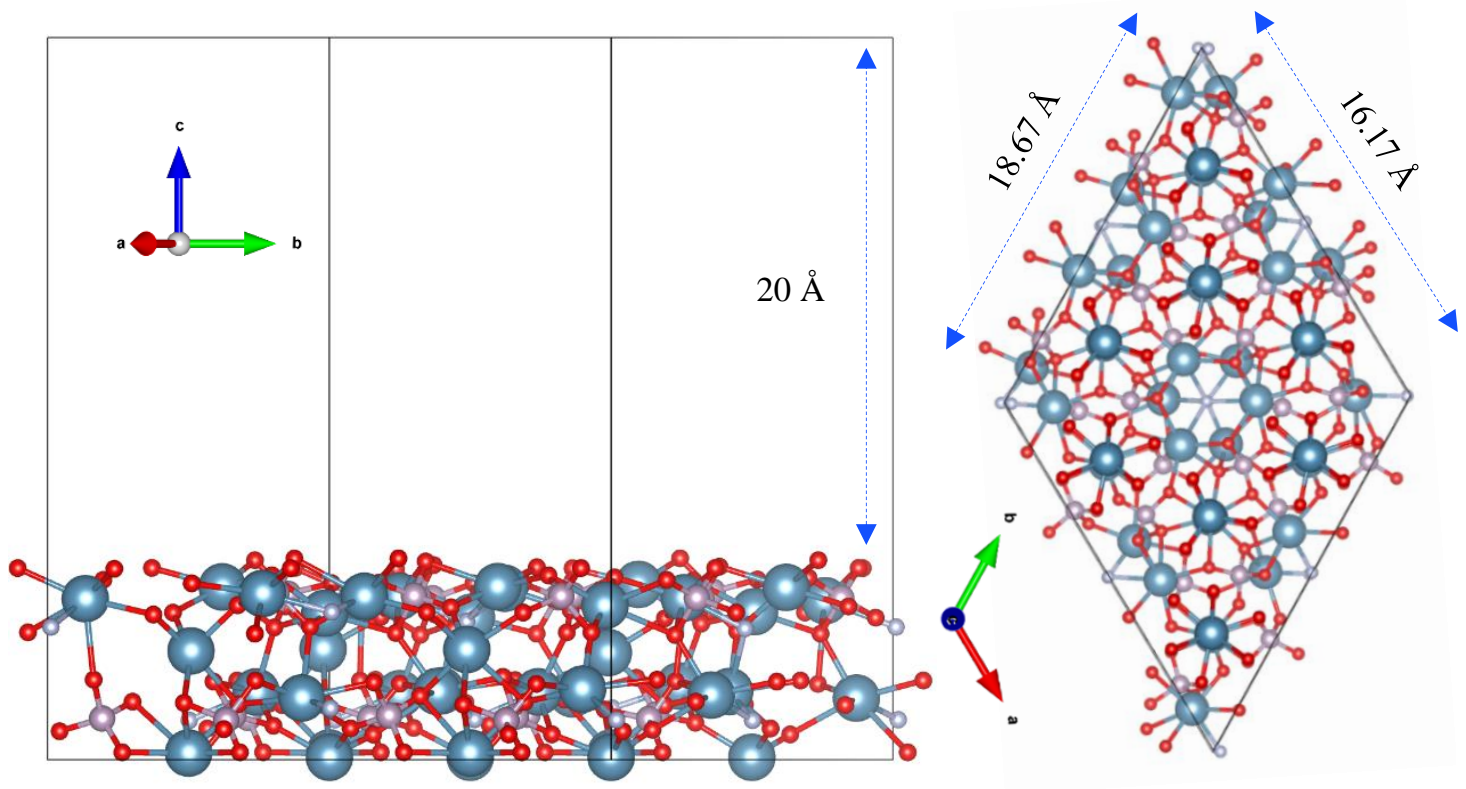

Figure 3-6: The dimensions of FA supercell employed for the current study. 


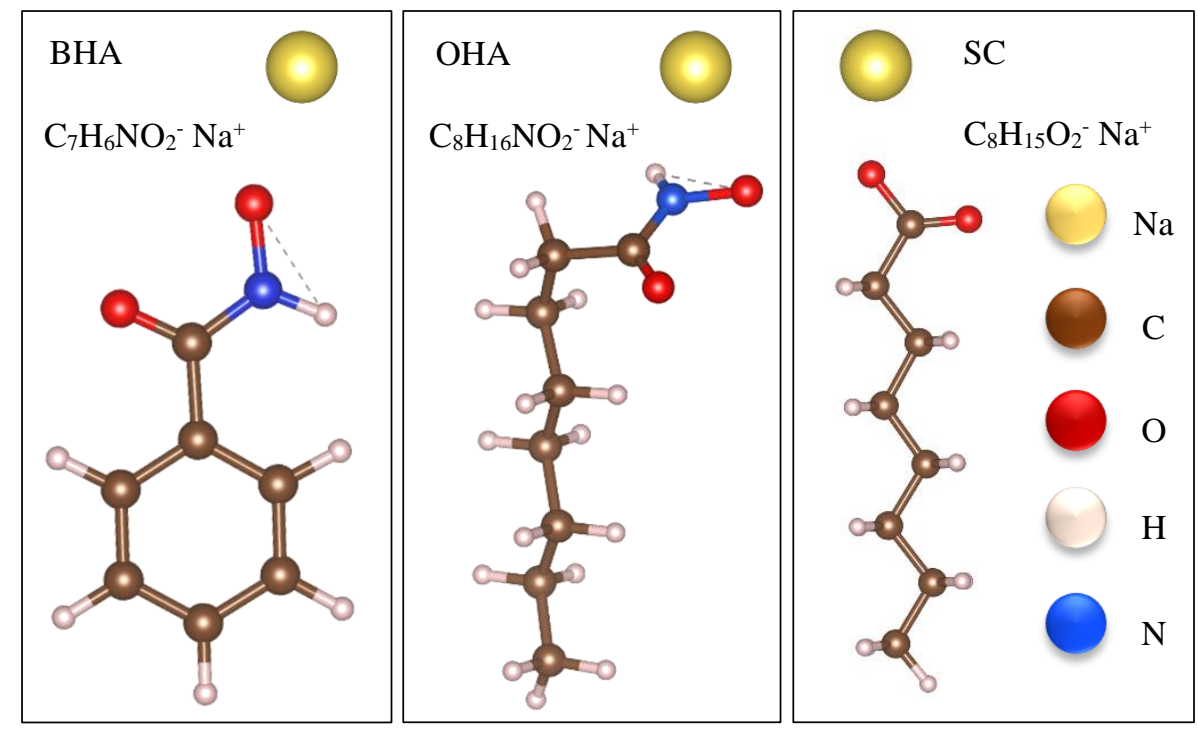

Figure 3-7: Molecular models of the target collectors in their free anionic forms.

To obtain the hydrolysis products of $\mathrm{Al}^{3+}$ and $\mathrm{Mg}^{2+}$ metal ions under the flotation conditions, i.e., at $\mathrm{pH}=9,\left[\mathrm{M}^{\mathrm{n}+}\right]$ тот $=1.0 \mathrm{~mol} . \mathrm{L}^{-1}, \mathrm{pCO}_{2}=10^{-3.5}$ atm at $1 \mathrm{~atm}$, and $\mathrm{T}=25{ }^{\circ} \mathrm{C}$, we constructed speciation diagrams for the two ions using Medusa-Hydra chemical equilibrium software [81] (Fig. 3-8). According to the speciation diagrams, the hydrolysis products of $\mathrm{Al}^{3+}$ and $\mathrm{Mg}^{2+}$ ions at the target conditions are $\mathrm{Al}(\mathrm{OH})_{3}$ and $\mathrm{MgCO}_{3}$, respectively. Therefore, $\mathrm{Al}(\mathrm{OH})_{3}$ and $\mathrm{MgCO}_{3}$ were considered in AIMD simulations for $\mathrm{Al}^{3+}$ and $\mathrm{Mg}^{2+}$ species, respectively, and were designed and generated using the IQmol software [82], as shown in Fig. 3-8. Avogadro software [83] was employed to properly import and place the target collector molecule(s) and/or metal ion species into the vacuum space at a minimum 2.5 $\AA$ distance above the uppermost atoms on the surface of the FA slab. Considering the inevitable presence of $\mathrm{Na}^{+}$ions in the flotation environment due to the $\mathrm{pH}$ adjustment using $\mathrm{NaOH}$, in the AIMD simulations of both fatty acid and HA collectors, $\mathrm{Na}^{+}$as the counter-cation was placed at a more than $5 \AA$ distance from the anionic molecule above the surface. The infrared spectroscopy supported by atomistic simulations have shown that the counter-ion plays a crucial role in the adsorption process via initiating the formation of the surface layer, and in stabilizing the adsorption of the free anionic collector molecule [80]. Thus, we also investigated the role of the sodium counter-ion in the adsorption of the target collector molecules on both the bare and treated FA surfaces. Finally, AIMD simulations were performed for each individual target configuration to obtain the ultimate atomic structure of 
the systems and the corresponding energy, which later were employed to determine the adsorption energies and mechanisms. VESTA molecular visualization software [84] was used for constructing the molecules/ slabs as well as visualizing the ultimate configurations obtained from AIMD simulations.
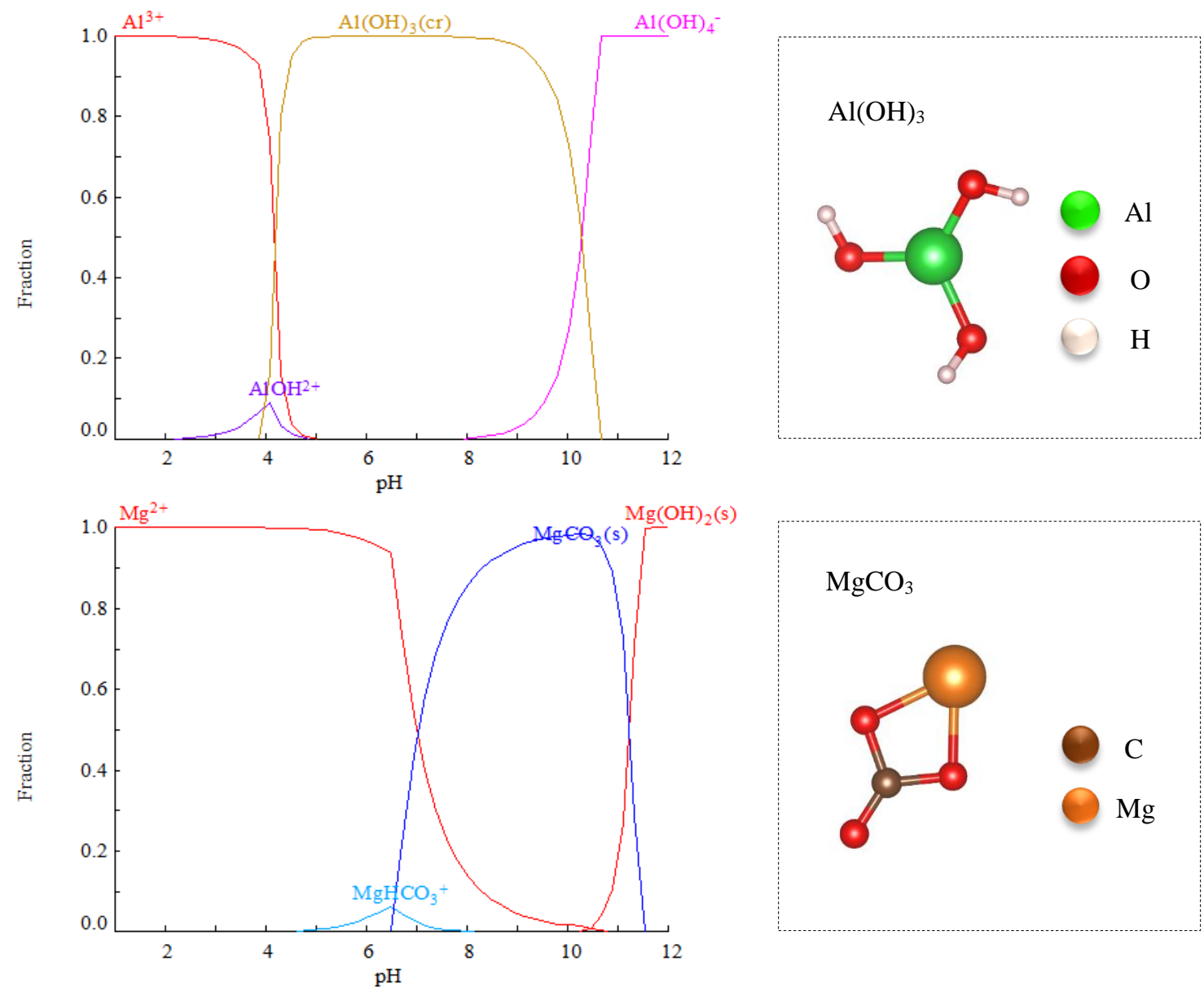

Figure 3-8: Speciation diagrams and molecular demonstrations of $\mathrm{Al}^{3+}$ and $\mathrm{Mg}^{2+}$ ions in water; total concentration: $\left[\mathrm{Al}^{3+}\right]$ тот $=1.0 \mathrm{mM},\left[\mathrm{Mg}^{2+}\right]$ тот $=1.0 \mathrm{mM}, \mathrm{pCO}_{2}=10^{-3.5}$ atm at 1 atm and $\mathrm{T}=25^{\circ} \mathrm{C}$.

\section{Micro-flotation experiments}

The $+38-53 \mu \mathrm{m}$ size fraction of FA powder was used for the micro-flotation experiments. In order to ensure that the particles were free of any contamination, the mineral sample was washed with $\mathrm{H}_{2} \mathrm{SO}_{4}(2.5$ vol. \%) and $\mathrm{NaOH}(2.5$ wt. \%) and then rinsed thoroughly with DI water. The washed mineral sample was then dried and kept sealed for the experiments. Flotation tests were performed using a $\sim 75 \mathrm{~mL}$ modified Partridge-Smith micro-flotation cell (Fig. 3-9). For each experiment, $1 \mathrm{~g}$ of dried powder sample was placed in a glass beaker 
containing $50 \mathrm{~mL}$ DI water with an adjusted $\mathrm{pH}$ value, stirred using a magnetic stirrer and a magnet bar. The $\mathrm{pH}$ of the solution was readjusted to the desired value prior to the addition of the flotation reagents, which were added sequentially. Each reagent was conditioned for $\sim 2$ minutes at room temperature, followed by the addition of the frothing agent, which continued to be conditioned for 1 more minute. The suspension $\mathrm{pH}$ was monitored and maintained in real-time during conditioning. The ultimate suspension was then transferred into the flotation cell mounted on top of a magnetic stirrer, using an extra $25 \mathrm{~mL}$ of $\mathrm{pH}$-adjusted DI water. With the aim of keeping the material in suspension inside the cell, a magnet bar was placed directly on top of the frit. The flotation process was performed for 1 minute by passing the gas at a flowrate of $30 \mathrm{~mL} \cdot \mathrm{min}^{-1}$ through the porous frit. Pure nitrogen $\left(\mathrm{N}_{2}\right)$ gas was employed instead of lab air to eliminate carbonate precipitation in the solution due to $\mathrm{CO}_{2}$ interference. Synthetic metal ion aqueous solutions of $10^{-3} \mathrm{~mol} . \mathrm{L}^{-1} \mathrm{Mg}^{2+}$ or $\mathrm{Al}^{3+}$ were used as the base solution for the experiments that aimed to investigate the effect of the metal ions on the flotation of FA. Floated and non-floated fractions were collected, dried, weighed, and analyzed to calculate the mineral grade and recovery. Reported result for each flotation experiment is the mean value of three replicate tests. A standard deviation value of 2.62 was obtained.

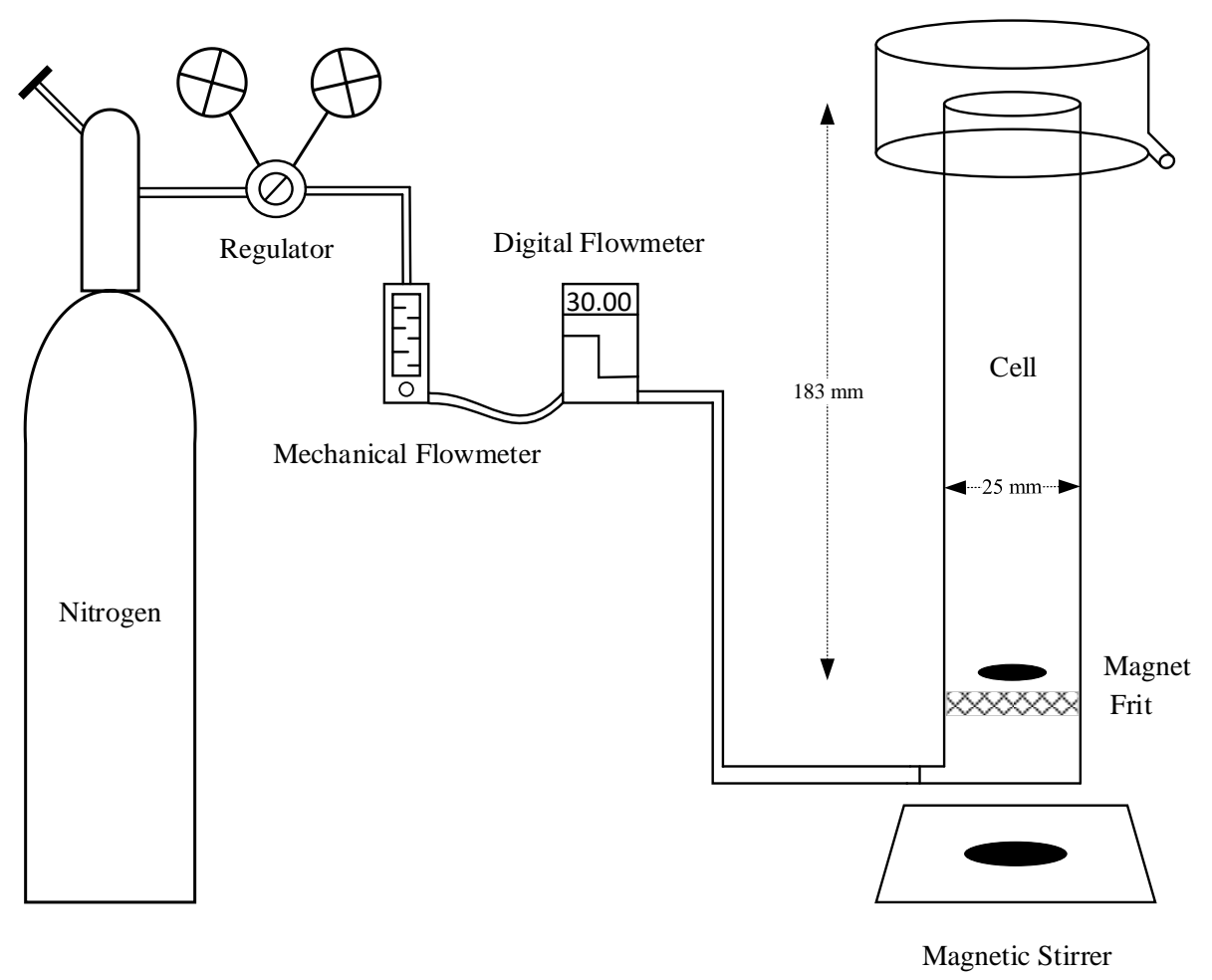

Figure 3-9: Schematic diagram of the micro-flotation apparatus. 


\section{Results and Discussion}

\section{Effect of $\mathrm{Al}^{3+}$ and $\mathrm{Mg}^{2+}$ on zeta potential of $\mathrm{FA}$}

The evolution of the zeta potential of FA as a function of the solution $\mathrm{pH}$ is compared for the three different scenarios, i.e., bare mineral in DI water, in $1 \times 10^{-3} \mathrm{~mol} . \mathrm{L}^{-1} \mathrm{Mg}^{2+}$, and in $1 \times 10^{-3}$ mol. $\mathrm{L}^{-1} \mathrm{Al}^{3+}$ in Fig. 3-10. The presence of the metal ions results in a change in the zeta potential of FA, slightly in the case of $\mathrm{Mg}^{2+}$ and significantly for $\mathrm{Al}^{3+}$. The isoelectric point (IEP) of FA shifts from around 3 for the bare mineral to 3.5 and 6.5 in the presence of $\mathrm{Mg}^{2+}$ and $\mathrm{Al}^{3+}$, respectively. Within the $\mathrm{pH}$ range of 3 to 6.5 , the zeta potential of FA tends to be positive in the presence of $\mathrm{Al}^{3+}$ metal ions compared to the bare mineral, while this range is significantly tighter in the case of $\mathrm{Mg}^{2+}$, i.e., $\mathrm{pH} 3$ to $\mathrm{pH} 3.5$. Such changes in the zeta potential values can be attributed to the compression of the electrical double-layer (EDL) under high IS conditions [85]. This could be ascribed to the adsorption of the hydrolysis species of the metal ions on the mineral surface [7]. It is also shown that the presence of the metal ions does not cause overcharging in the EDL or electro-kinetic charge reversal on the FA surface [24].

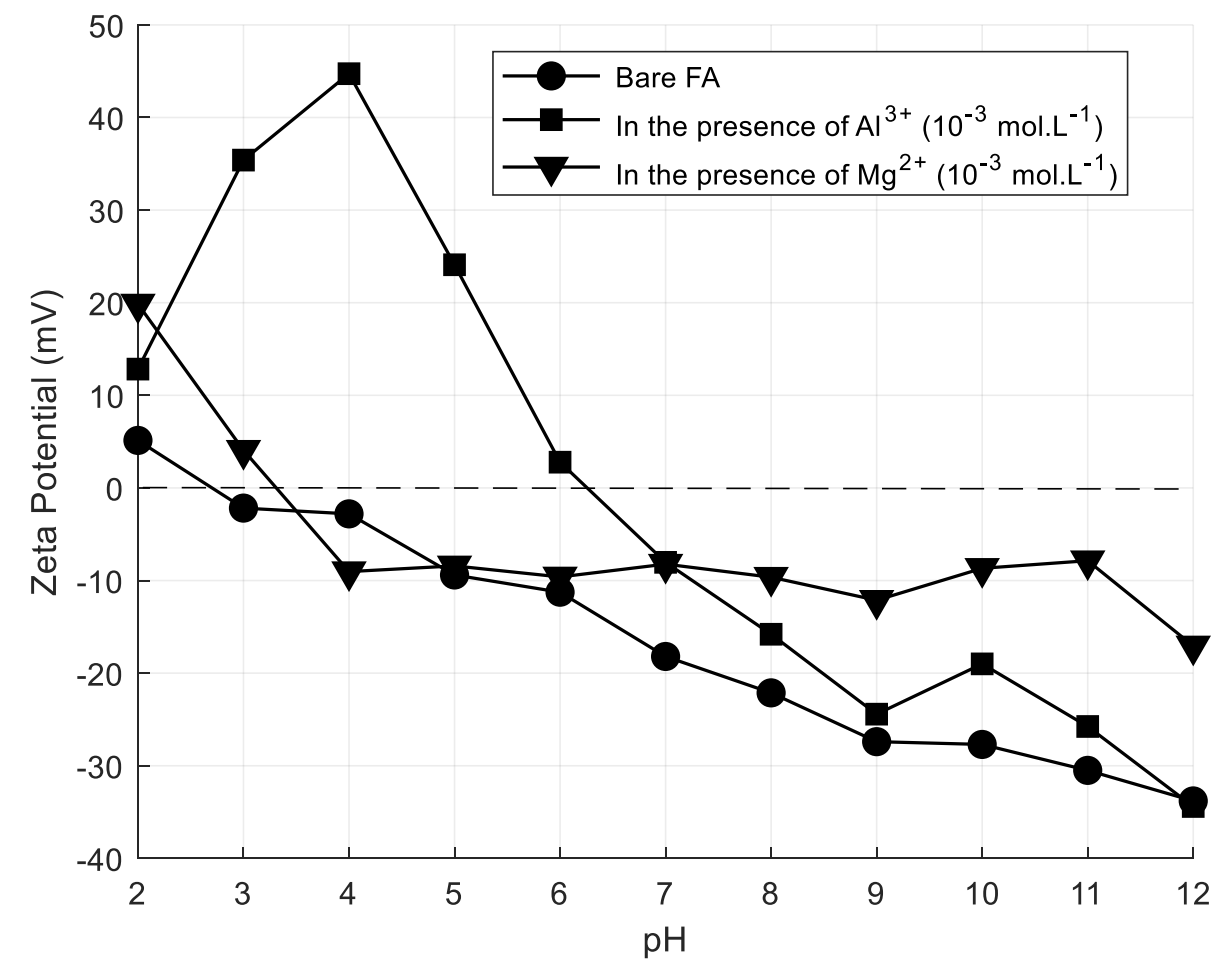

Figure 3-10: Zeta potential of FA as a function of solution $\mathrm{pH}$ in the presence and absence of $\mathrm{Al}^{3+}$ and $\mathrm{Mg}^{2+}$. 


\section{XPS measurements}

XPS technique was employed to further identify if the metal ions react with the FA surface, as it was assumed when the mineral is exposed to an $\mathrm{Al}^{3+} / \mathrm{Mg}^{2+}$-rich solution. Hence, the surface composition of FA was determined before and after being treated with the metal ions. The results are presented in the form of survey spectra, high-resolution spectra, and atomic concentrations of various elements on the surface, in Figs. 3-11 \& 3-12, and Table 3-3, respectively. The survey spectra in Fig. 3-11 show the major characteristic peaks of the elements present at the bare FA mineral surface, which are $\mathrm{C}, \mathrm{O}, \mathrm{Ca}, \mathrm{P}$, and $\mathrm{F}$. Comparing the survey spectra for the bare and $\mathrm{Al} / \mathrm{Mg}$-treated mineral surface, the peak locations of $\mathrm{Al} 2 \mathrm{p}$ at $74.9 \pm 0.1 \mathrm{eV}$ and $\mathrm{Mg} 1 \mathrm{~s}$ at $1304.9 \pm 0.1 \mathrm{eV}$ obtained from the detailed XPS scans suggest the formation of the $\mathrm{Al}^{3+}$ and $\mathrm{Mg}^{2+}$ valence state via $\mathrm{Al}-\mathrm{O}$ and $\mathrm{Mg}-\mathrm{O}$ bonds, which confirms that $\mathrm{Al} / \mathrm{Mg}$ atoms are attached to the framework through oxygen bonding [86]. The detailed high-resolution $\mathrm{Al} 2 \mathrm{p}$ and $\mathrm{Mg}$ 1s peaks in Fig. 3-12 show that the amount of the metal ions adsorbed onto the mineral surface increases with an elevated concentration of these ions in the solution. This is further supported by semi-quantitative XPS-determined surface atomic compositions of the FA treated with different concentrations of the metal ions, as presented in Table 3-3. It is also seen from Table 3-3 that in conformity with the increase in the amount of $\mathrm{Mg}$ atoms identified on the mineral surface, the amount of $\mathrm{C}$ and $\mathrm{O}$ atoms increases as well. This supports the adsorption of $\mathrm{Mg}^{2+}$ on the FA surface as its carbonate form. Similarly, consistent with the increase in the amount of $\mathrm{Al}$ atoms adsorbed on the mineral surface, the amount of $\mathrm{O}$ identified on the surface also increases, which supports that $\mathrm{Al}^{3+}$ adsorbs under its hydroxide form. One noteworthy fact here is that in order for the electro-neutrality of the mineral surface to be met, the adsorption of metal ions is necessarily accompanied by the adsorption of their counter-ions [87]. From a thermodynamic perspective, under the given physicochemical condition, i.e., $\mathrm{pH}$ 9, free metal ions in the solution react with carbonate or hydroxide ions forming $\mathrm{MgCO}_{3}$ or $\mathrm{Al}(\mathrm{OH})_{3}$ species, which are probably adsorbed on the mineral surface during treatment. Hence, the increased presence of $\mathrm{C}$ and $\mathrm{O}$ on the mineral surface can be explained by the adsorption of the metal ions in the form of their hydrolysis products. Another striking point that can be inferred from Table 3-3 is that at $10^{-3}$ mol.L $\mathrm{L}^{-1}$ concentration, $\mathrm{Al}^{3+}$ species almost fully coat the mineral surface so that the concentrations of 
the FA lattice elements, i.e., $\mathrm{Ca}, \mathrm{P}$ and $\mathrm{F}$ drop from $16.8,11.1$ and $4.0 \%$ on the bare surface to 4.0, 4.1 and $1.6 \%$ on the treated surface, respectively.
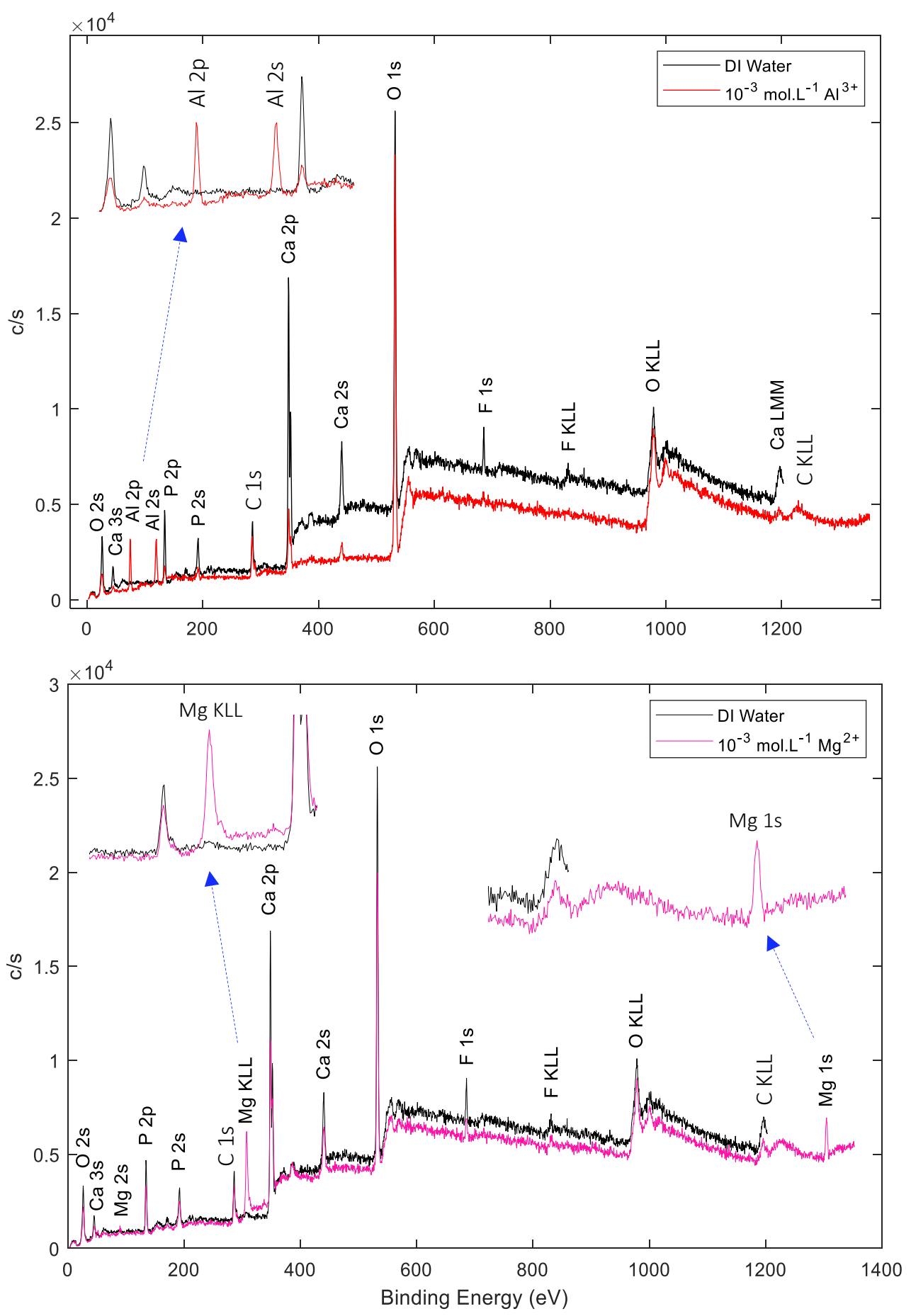

Figure 3-11: XPS survey spectrums of FA in the presence and absence of (a): $\mathrm{Al}^{3+}$, and (b): $\mathrm{Mg}^{2+}$ metal ions. 

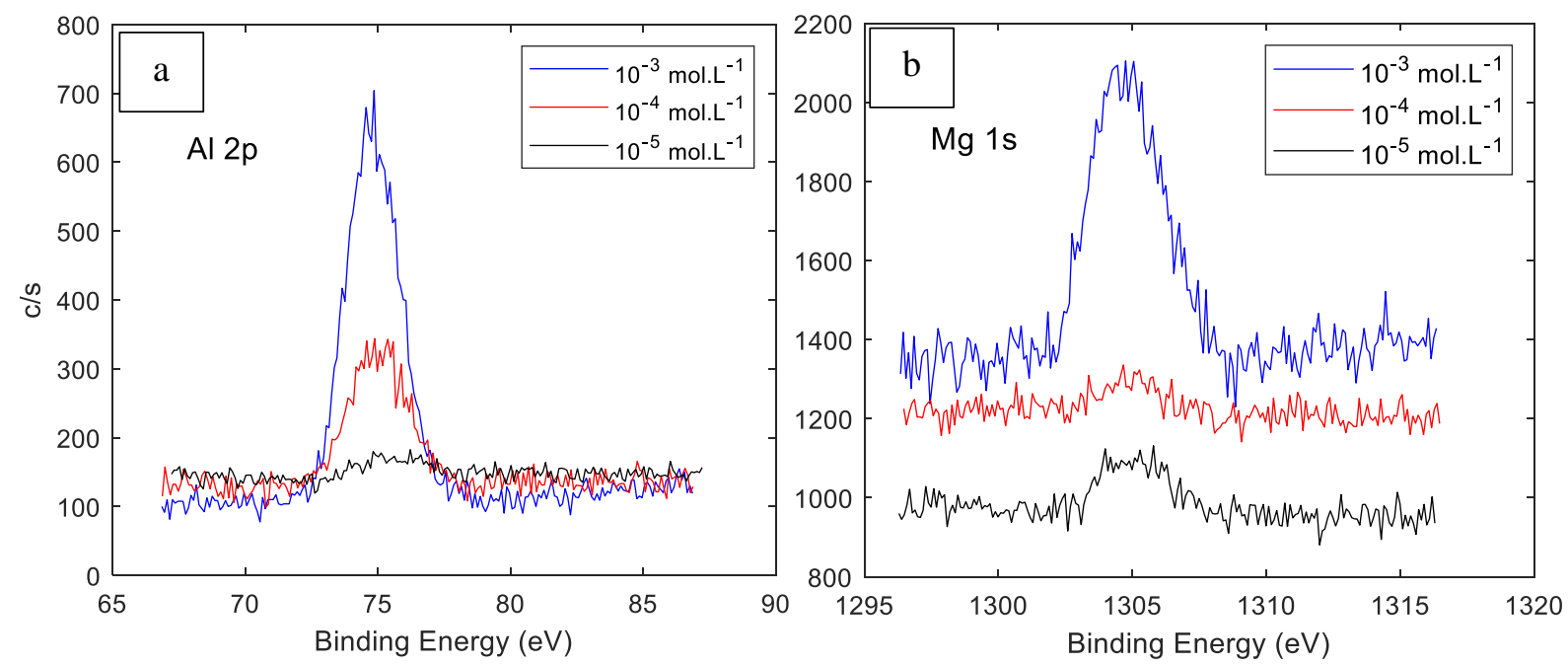

Figure 3-12: XPS detailed scans of FA at various concentrations of (a): $\mathrm{Al}^{3+}$, and (b): $\mathrm{Mg}^{2+}$ metal ions.

Table 3-3: FA surface composition after treatment with solutions of various $\mathrm{MgCl}_{2} / \mathrm{AlCl}_{3}$ concentrations.

\begin{tabular}{lccccccc}
\hline & \multicolumn{7}{c}{ Apatite surface composition (at. \%) } \\
\cline { 2 - 8 } Dosage (mol.L $\left.{ }^{-1}\right)$ & $\mathrm{C}$ & $\mathrm{O}$ & $\mathrm{F}$ & $\mathrm{Mg}$ & $\mathrm{Al}$ & $\mathrm{P}$ & $\mathrm{Ca}$ \\
\hline Bare FA & 13.6 & 54.6 & 4.0 & 0 & 0 & 11.1 & 16.8 \\
\hline $10^{-5} \mathrm{MgCl}_{2}$ & 13.9 & 51.2 & 4.9 & 1.5 & 0 & 11.7 & 16.8 \\
$10^{-4} \mathrm{MgCl}_{2}$ & 14.5 & 51.8 & 4.9 & 2.5 & 0 & 10.7 & 15.6 \\
$10^{-3} \mathrm{MgCl}_{2}$ & 16.1 & 52.3 & 3.1 & 4.3 & 0 & 10.0 & 14.2 \\
\hline $10^{-5} \mathrm{AlCl}_{3}$ & 12.9 & 53.8 & 3.7 & 0 & 2.5 & 11.1 & 16.0 \\
$10^{-4} \mathrm{AlCl}_{3}$ & 12.4 & 57.0 & 2.9 & 0 & 7.9 & 8.8 & 11.1 \\
$10^{-3} \mathrm{AlCl}_{3}$ & 12.0 & 61.7 & 1.6 & 0 & 16.6 & 4.1 & 4.0 \\
\hline
\end{tabular}

\section{Adsorption density measurements}

For adsorption density measurements using UV-Vis spectroscopy, first, full wave scanning was performed to obtain the target $\lambda$ for each selected reagent, followed by establishing the calibration curves, the results of which are presented in Fig. 3-13. As shown, the $\lambda$ for $\mathrm{NaOl}$ and BHA/OHA was determined as $192.5 \mathrm{~nm}$ and $503 \mathrm{~nm}$, respectively. The obtained $\lambda$ values, along with the calibration curves, were then employed to quantify the adsorption densities of $\mathrm{NaOl}$ and the hydroxamates in the presence and absence of the metal ions. The purpose was to investigate how the presence of these multivalent ions influences the adsorption of the target reagents onto the surface of FA under specified flotation conditions. The adsorption density measurement results are presented in Fig. 3-14. As seen, the adsorption density for $\mathrm{NaOl}$, BHA, 
and OHA on the FA mineral surface in the absence and presence of $\mathrm{Al}^{3+}$ and $\mathrm{Mg}^{2+}$ metal ions changes in the order of $\mathrm{Mg}^{2+}$-treated $\mathrm{FA}>\mathrm{Al}^{3+}$-treated $\mathrm{FA}>$ bare $\mathrm{FA}$. This suggests that the adsorption of both fatty acid and HA collectors on the FA mineral surface is favored by the presence of $\mathrm{Mg}^{2+}$ and $\mathrm{Al}^{3+}$ metal ions, with however a higher effect of the former compared to the latter. For BHA adsorption on $\mathrm{Al}^{3+}$-treated mineral surface, however, it is shown that the adsorption density experiences a very slight (almost negligible) increase as opposed to the bare mineral surface. This could be due to the poor tendency of BHA to interact with $\mathrm{Al}^{3+}$ at the mineral surface. This will be further discussed later in the following sections.
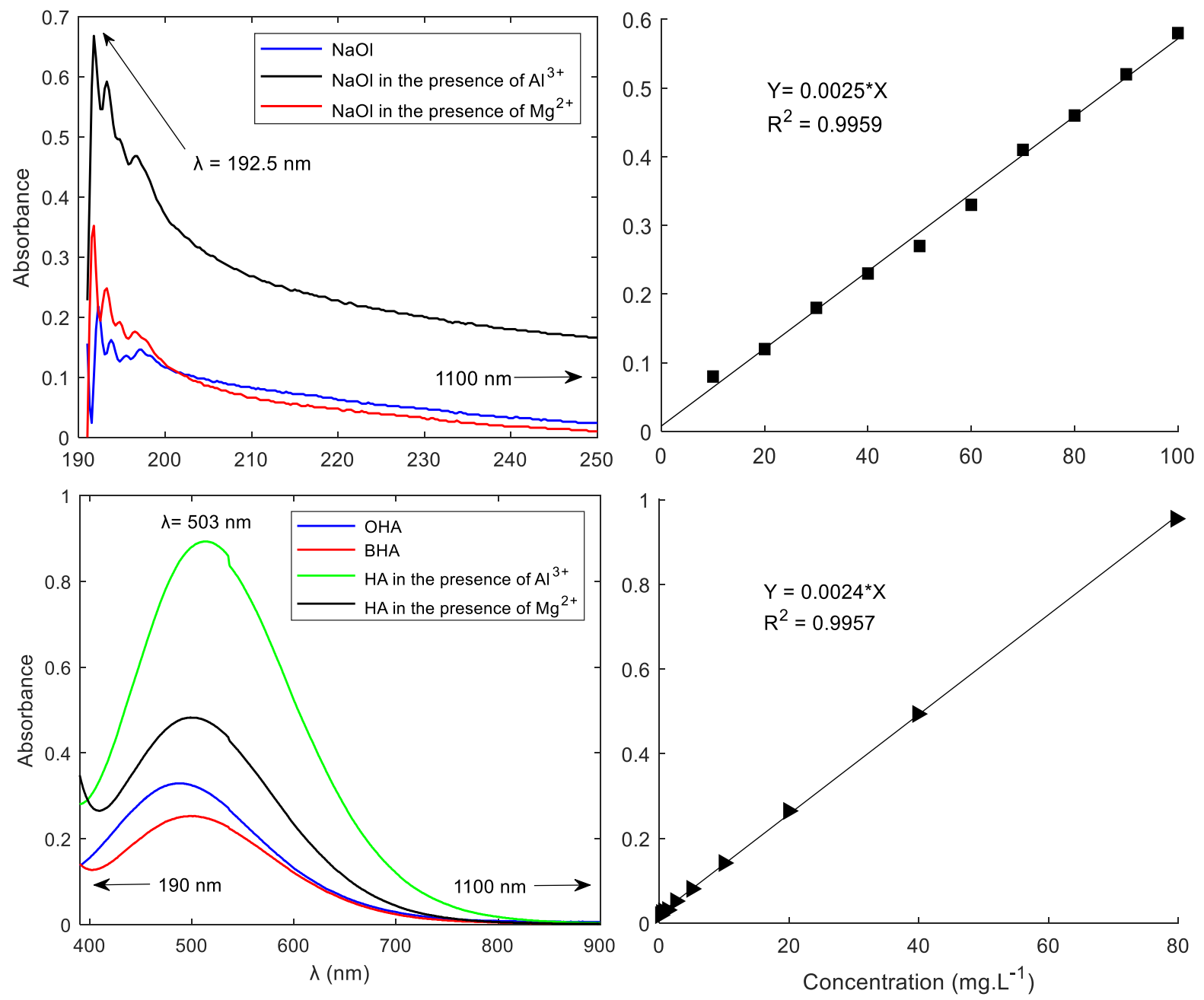

Figure 3-13: Full wave scanning and calibration curves obtained for $\mathrm{NaOl}$ and BHA/ OHA collectors in the presence and absence of the metal ions. 


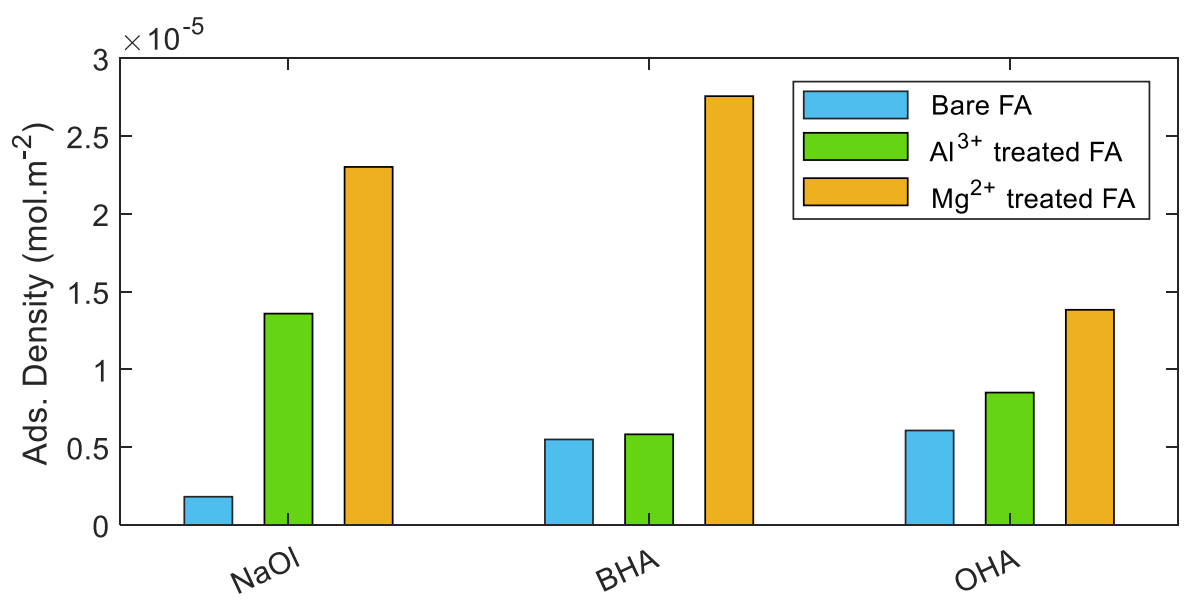

Figure 3-14: Adsorption densities of $\mathrm{NaOl}, \mathrm{BHA}$, and $\mathrm{OHA}$ collectors in the presence and absence of the metal ions.

The differences in the amounts of the three collectors adsorbed on the bare mineral surface could be attributed to the coexistence of the neutral and free anionic forms of HA collectors at $\mathrm{pH}$ 9. Such coexistence can induce a stabilization of the adsorption layer by reducing the polar repulsions between the polar groups of the collector molecules while maintaining strong chainchain lateral interactions. This results in a more compact layers of adsorption on the surface compared to fatty acid, which is only present in its anionic form at $\mathrm{pH} 9$ [88]. As well, such difference in the adsorption amount of the different collectors could owe to the difference in the packing area of the molecules that induce the compacity of the adsorption layers [89, 90]. After the adsorption of the $\mathrm{Al}^{3+} / \mathrm{Mg}^{2+}$ species on the surface, however, the formation of new adsorption sites are induced, which reduces the polar repulsion between fatty acid functional heads. Hence, the adsorption layer is tightened resulting in a higher adsorption density of fatty acid, as indicated in Fig. 3-14.

\section{AIMD simulations}

Results of the AIMD simulations are presented in Figs. 3-15 and 3-16, and Table 3-4. Adsorption configurations of SC, BHA, and OHA molecules in their free anionic forms accompanied by the sodium counter-ion on bare and $\mathrm{Al}^{3+} / \mathrm{Mg}^{2+}$-treated FA (001) surfaces are presented in Fig. 3-15. It is shown that $\mathrm{SC}$ as the fatty acid molecule adsorbs on the mineral surface through a bidentate bonding of $\mathrm{O}^{2-}$ atoms of the carboxyl group $\left(\mathrm{COO}^{-}\right)$to the $\mathrm{Ca}^{2+}$ cationic sites $(\mathrm{Ca}-\mathrm{O}: 2.21 \AA)$ along with a $\mathrm{Na}^{+}$-mediated $\mathrm{O}-\mathrm{O}$ bonding. This indicates that $\mathrm{Na}^{+}$counter-ion contributes to the adsorption of fatty acid on the FA surface through mediating 
the $\mathrm{O}-\mathrm{O}$ boding between the molecule and the mineral surface. For the hydroxamates, i.e., BHA and OHA, a mono-dentate bonding of an $\mathrm{O}^{2-}$ atom of the HA to a $\mathrm{Ca}^{2+}$ cationic site (BHA: $\mathrm{Ca}-\mathrm{O}: 2.16 \AA$, OHA: $\mathrm{Ca}-\mathrm{O}: 2.07 \AA$ ) is established. Unlike for $\mathrm{SC}$, the $\mathrm{Na}^{+}$ion does not contribute to the adsorption of the HA molecules on the bare FA surface. For chelating collectors, the adsorption on mineral surfaces is known to be a frontier-orbital-controlled reaction, accompanied by charge transfer or covalent/ coordination bond formation [91]. Fatty acid collectors are well known to interact strongly in their carboxylate form with $\mathrm{Ca}^{2+}$ ions at the mineral surface and in solution [37]. As the result of such interaction, the carboxylate molecule forms a mono/ multi-layer of Ca-dicarboxylate on the surface depending on its concentration in the solution $[37,85,92]$. Such adsorption of fatty acid molecules on Cabearing mineral surfaces is believed to occur under chemisorption mechanism, as welldocumented in the literature $[32,36,37,43,80]$. The adsorption energies of SC, BHA, and OHA molecules on the bare FA surface were obtained as $-392.7,-235.4$, and $-176.3 \mathrm{~kJ} \mathrm{~mol}^{-1}$, respectively, as presented in Table 3-4. This indicates that SC establishes stronger and more favorable chemisorption (more negative binding energy) with the FA surface compared to the HA collectors. The adsorption energies indicate that SC exhibits a relatively stronger chelating ability with $\mathrm{Ca}^{2+}$ FA surface lattice metal ions [93, 94]. It is further supported by the relatively shorter $\mathrm{Ca}-\mathrm{O}$ bond length obtained for SC adsorption. Such stronger interaction of SC molecule with the FA surface could also be linked to the preferential contribution of sodium counter-ion to its adsorption on the mineral surface [80]. Despite its relatively more selective affinity than OHA for FA surface, BHA is known to be a weaker hydrophobing agent on Cabearing minerals, e.g., FA, compared to fatty acids and OHA [11, 94, 95]. The superior hydrophobing capability of OHA compared to BHA can be attributed to the establishment of more chain-chain interactions by OHA that favors the adsorption density. This will be further discussed later on in the following section through the experimental micro-flotation results. For fatty acid, despite its significant adsorption energies, it is adsorbed in lesser amount on the bare surface compared to HAs. This could be because fatty acids establish less chain-chain interaction, and therefore the formation of multi-layer adsorption is less favored despite high interaction energies of the functional head. As well, fatty acids have a higher packing area, and therefore the compacity of their adsorption layer is smaller [89, 90]. 

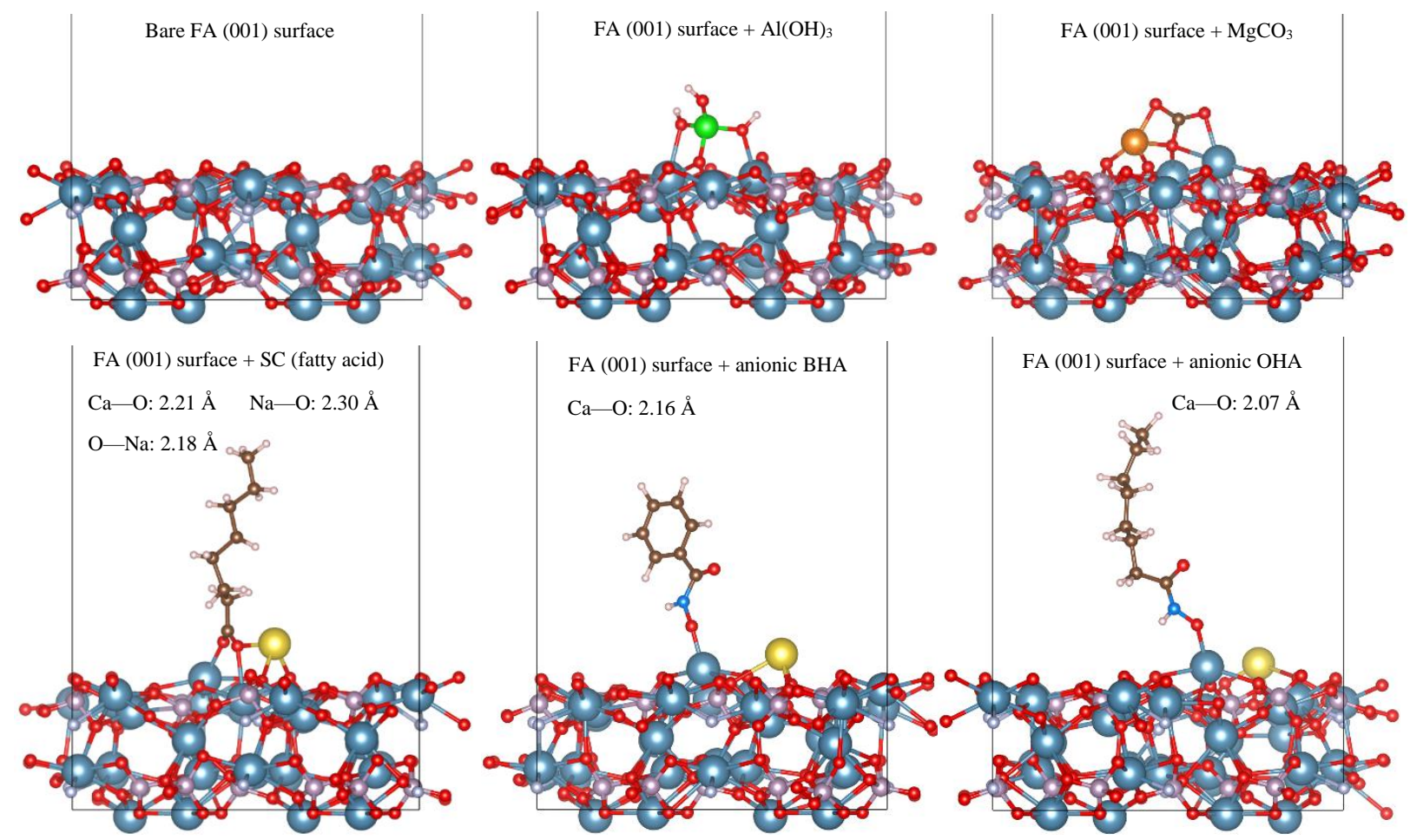

FA (001) surface + anionic OHA
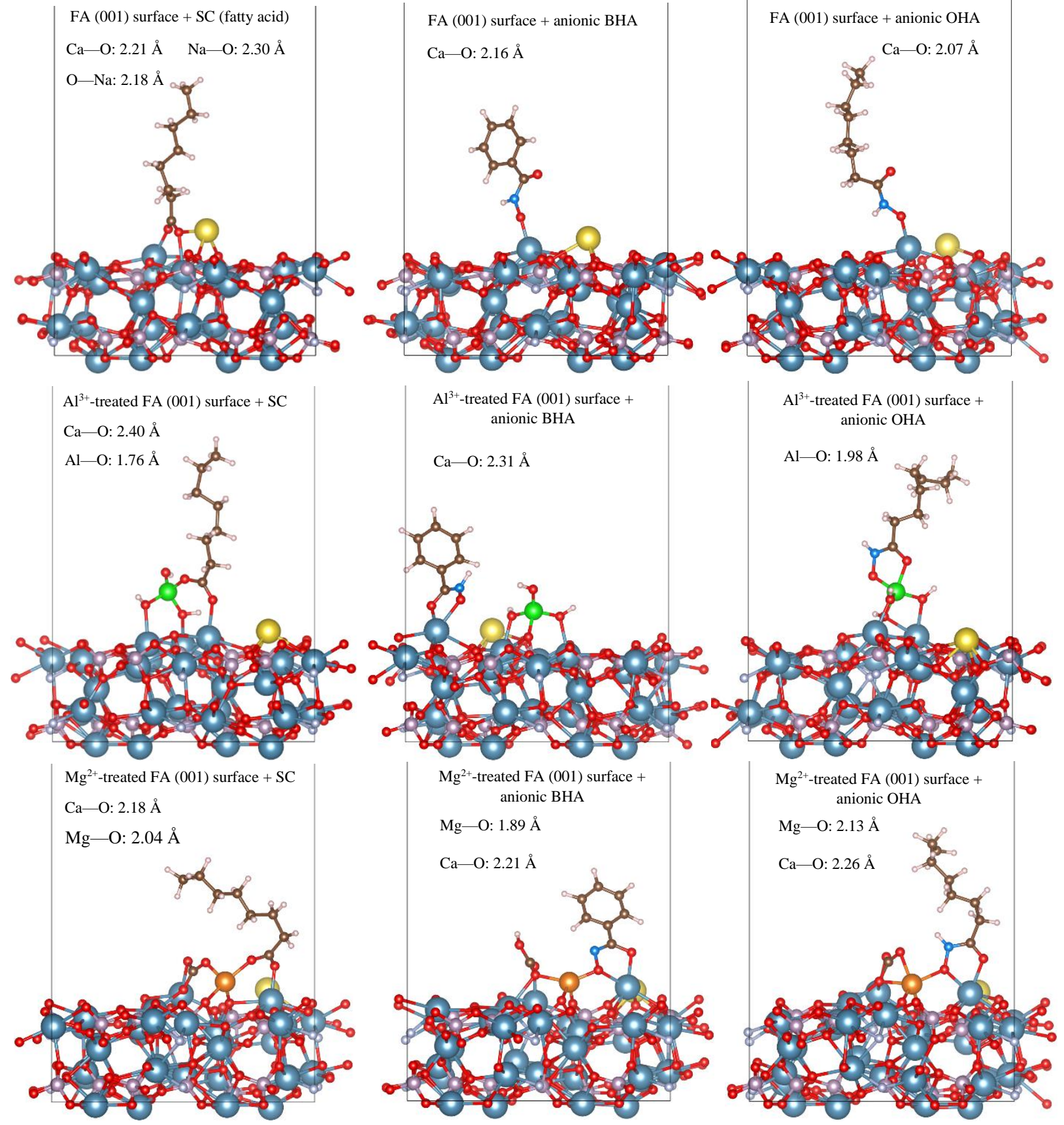

Figure 3-15: Adsorption configurations of the fatty- and hydroxamic acid collectors on bare and $\mathrm{Al}^{3+} / \mathrm{Mg}^{2+}$-treated FA (001) surfaces. 
On $\mathrm{Al}^{3+}$-treated FA (001) surface, at the first glance, it is seen that OHA preferentially adsorbs through a bidentate bonding of oxygen atoms of the functional group to the $\mathrm{Al}^{3+}$ cationic site at the treated surface. For SC, a bidentate bonding to both the $\mathrm{Al}^{3+}$ site as well as the $\mathrm{Ca}^{2+}$ lattice site is established. However, BHA unlike the other two reagents, prefers $\mathrm{Ca}^{2+}$ lattice cationic site over $\mathrm{Al}^{3+}$ to interact via a bidentate bonding. This is in line with the results of the adsorption density measurements where no considerable change in the BHA density of adsorption on the FA surface was observed when treated with $\mathrm{Al}^{3+}$. The adsorption energies of SC, OHA and BHA molecules on the $\mathrm{Al}^{3+}$-treated FA surface were obtained as -431.4 ( $\mathrm{Al}$ O: $1.76 \AA$; $\mathrm{Ca}-\mathrm{O}: 2.40 \AA$ ), $-355.2\left(\mathrm{Al} — \mathrm{O}: 1.98 \AA\right.$ ), and $-295.8\left(\mathrm{Ca}-\mathrm{O}: 2.31 \AA\right.$ ) kJ.mol ${ }^{-1}$, as presented in Table 3-4. Hence, SC as the fatty acid collector establishes a stronger and more favorable interaction with the $\mathrm{Al}^{3+}$-treated surface compared to the HA collectors.

Comparing the binding energies along with the $\mathrm{Al}-\mathrm{O}$ bond lengths for the adsorption of $\mathrm{SC}$ and $\mathrm{OHA}$ molecules on the bare and $\mathrm{Al}^{3+}$-treated FA surface, the precipitation of $\mathrm{Al}-$ hydroxide specie on the FA surface is beneficial for the adsorption of these collectors. In the case of BHA, as noted earlier, the obtained visual configuration shows that the $\mathrm{Al}^{3+}$ site is not preferable for adsorption, whereas comparing the adsorption energies and configurations, it is obvious that BHA builds a stronger interaction with FA surface via a bidentate $\mathrm{Ca}-\mathrm{O}$ bonding in the presence of Al-hydroxide specie. This could possibly be attributed to the influence of the effect of $\mathrm{Al}^{3+}$ metal ion on the FA mineral surface charge [24], as supported by the electrokinetic measurements presented in Fig. 3-10, on the BHA-FA interaction. A more thorough insight into this matter may deserve a separate investigation e.g. Bader charge analysis [96], which can be the focus of a future study by the authors. Moreover, it is seen that the sodium ion does not contribute to the adsorption of neither fatty acid nor HA molecules on the $\mathrm{Al}^{3+}$ treated FA surface. Looking at the adsorption configurations of the collector molecules on the $\mathrm{Mg}^{2+}$-treated FA surface, $\mathrm{SC}$ establishes a bidentate coordination bonding between two $\mathrm{O}^{-2}$ ions of its carboxyl group and $\mathrm{Mg}^{2+}(\mathrm{Mg}-\mathrm{O}: 2.04 \AA)$ as well as $\mathrm{Ca}^{2+}(\mathrm{Ca}-\mathrm{O}: 2.18 \AA)$ cations on the treated surface. SC as a fatty acid interacts with $\mathrm{Mg}^{2+}$ at the mineral surface or in solution with the solubility product of magnesium di-carboxylate to be 10.8 compared to 12.4 for calcium di-carboxylate $[37,97]$. The adsorption energy of SC on the $\mathrm{Mg}^{2+}$-treated FA surface was obtained as $-589.5 \mathrm{~kJ} \cdot \mathrm{mol}^{-1}$, which speaks of a relatively more stable and stronger interaction. Comparing the bond lengths, it is evident that SC establishes a stronger interaction 
with $\mathrm{Mg}^{2+}$ than with $\mathrm{Ca}^{2+}$ ion, which can be attributed to the smaller size of magnesium ion $[37,98]$. This finding is consistent with the findings reported by Hirva and Tikka [98].

BHA and OHA adsorb on the $\mathrm{Mg}^{2+}$-treated FA surface through a bidentate coordination bonding between two $\mathrm{O}^{-2}$ ions of their functional group and $\mathrm{Ca}^{2+}$ lattice cation (BHA: $\mathrm{Ca}-\mathrm{O}$ : $2.21 \AA$; OHA: $\mathrm{Ca}-\mathrm{O}: 2.26 \AA$ ) along with a mono-dentate bonding to the adsorbed $\mathrm{Mg}^{2+}$ site (BHA: $\mathrm{Mg}-\mathrm{O}: 1.89 \AA$ A ; OHA: $\mathrm{Mg}-\mathrm{O}: 2.13 \AA$ A). Considering $\mathrm{Mg}-\mathrm{O}$ and $\mathrm{Ca}-\mathrm{O}$ bond lengths for $\mathrm{SC}, \mathrm{BHA}$ and $\mathrm{OHA}$, it can be speculated that the $\mathrm{Mg}$ bonding is stronger. Comparing these configurations with the mono-dentate adsorption of both BHA and OHA on the bare FA surface, it can be inferred that the adsorption of $\mathrm{Mg}^{2+}$ on the mineral surface increases the active cationic sites that interact with the functional groups of HA collectors, contributing to the improved FA floatability. The adsorption energies of BHA and OHA on the $\mathrm{Mg}^{2+}$-treated FA surface were determined as -485.9 and $-436.4 \mathrm{~kJ} \mathrm{~mol}^{-1}$, which supports that BHA forms a stronger interaction with FA compared to OHA. On overall, fatty acid establishes a stronger interaction with the $\mathrm{Mg}^{2+}$-treated FA surface than the HA collectors. It is also shown that in the presence of $\mathrm{Mg}^{2+}$ specie adsorbed on the FA surface, sodium counter-ion does not contribute to the adsorption of either fatty acid or HA collectors.

As noted earlier, with regard to the coexistence of both the neutral and free anionic forms of the HA collectors at $\mathrm{pH}=9$, the adsorption mechanisms of the neutral HA collector molecules on bare and the treated FA surfaces were also investigated, and the results are presented in Fig. 3-16 and Table 3-4. The adsorption energies and configurations of the HA molecules in their neutral form on the FA surfaces were compared with those obtained for their free anionic form accompanied by the sodium counter-ion (Fig. 3-15). It is seen that the HA molecules build stronger interactions with the mineral surface in their anionic form (more negative binding energies). This is further supported by the obtained $\mathrm{Ca}-\mathrm{O}$ and/ or $\mathrm{Mg}-\mathrm{O}$ bond lengths. For BHA on the $\mathrm{Al}^{3+}$-treated surface, being in the free anionic form supports the stronger $\mathrm{Ca}-\mathrm{O}$ interaction by forming the bidentate bonding instead of the mono-dentate bonding in its neutral form. In a similar fashion, for $\mathrm{OHA}$, being in its anionic form brings about a bidentate $\mathrm{Al}-\mathrm{O}$ interaction compared to the mono-dentate bonding with $\mathrm{Al}^{3+}$ site in its neutral form. Moreover, for both $\mathrm{OHA}$ and $\mathrm{BHA}$ on the $\mathrm{Mg}^{2+}$-treated surface, the anionic molecule forms a stronger interaction owed to the tridentate $\mathrm{Ca}-\mathrm{O}$ and $\mathrm{Mg}-\mathrm{O}$ bonding (Fig. 3-15) compared to the 
bidentate bonding of the neutral molecule with the mineral surface (Fig. 3-16). This is also supported by the shorter $\mathrm{Ca}-\mathrm{O} / \mathrm{Mg}-\mathrm{O}$ bond lengths for the anionic molecule. From Fig. 316 , it is also obvious that for the neutral molecules of the HA collectors, any adsorption configuration with either bare or treated surface is accompanied by a hydrogen bonding between an $\mathrm{H}$ atom of the $\mathrm{HA}$ to an $\mathrm{O}$ site at the FA surface, represented by a dashed line.
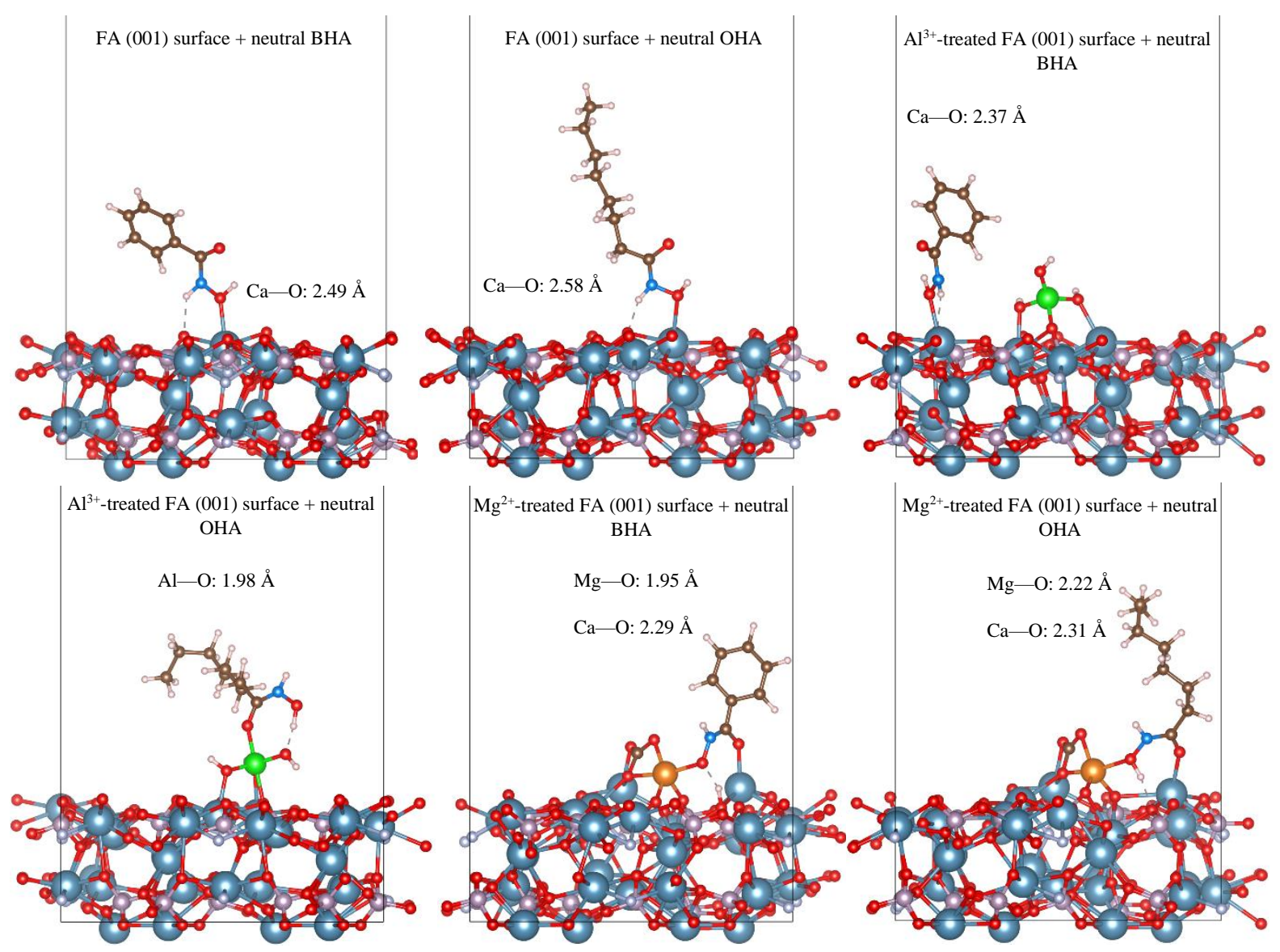

Figure 3-16: Adsorption configurations of the neutral forms of the HA collectors on bare and $\mathrm{Al}^{3+} / \mathrm{Mg}^{2+}$-treated (001) FA surface. The dashed lines indicate hydrogen bonds.

The adsorption energies for the target configurations mentioned above are visually presented and compared with the corresponding adsorption densities obtained from the UVVis spectroscopy in Fig. 3-17. As can be seen, for the three target collectors under various scenarios except for BHA in the presence of $\mathrm{Al}^{3+}$, as discussed earlier, the amount of collector adsorbed on the mineral surface experiences a rise in which the adsorption energy reveals a more stable and stronger collector-mineral interaction. 
Table 3-4: The adsorption energy of different collector molecules and species on FA (001).

\begin{tabular}{|c|c|c|c|}
\hline Reagent/ Species & Substrate & \multicolumn{2}{|c|}{ Ads. Energy $\left(\mathrm{kJ} \cdot \mathrm{mol}^{-1}\right)$} \\
\hline \multirow[t]{2}{*}{$\mathrm{SC}$} & & \multicolumn{2}{|c|}{-392.7} \\
\hline & \multirow{5}{*}{ Bare (001) FA surface } & anionic & neutral \\
\hline BHA & & -235.4 & -80.2 \\
\hline $\mathrm{OHA}$ & & -176.3 & -48.0 \\
\hline $\mathrm{Al}(\mathrm{OH})_{3}$ & & \multicolumn{2}{|c|}{-171.9} \\
\hline $\mathrm{MgCO}_{3}$ & & \multicolumn{2}{|c|}{-280.0} \\
\hline SC & \multirow{4}{*}{$\begin{array}{l}\mathrm{Al}^{3+} \text {-treated }(001) \mathrm{FA} \\
\text { surface }\end{array}$} & \multicolumn{2}{|c|}{-431.4} \\
\hline & & anionic & neutral \\
\hline BHA & & -295.8 & -156.1 \\
\hline OHA & & -355.2 & -201.5 \\
\hline \multirow[t]{2}{*}{$\mathrm{SC}$} & \multirow{4}{*}{$\begin{array}{c}\mathrm{Mg}^{2+} \text {-treated (001) FA } \\
\text { surface }\end{array}$} & \multicolumn{2}{|c|}{-589.5} \\
\hline & & anionic & neutral \\
\hline BHA & & -485.9 & -293.4 \\
\hline $\mathrm{OHA}$ & & -436.4 & -257.2 \\
\hline
\end{tabular}

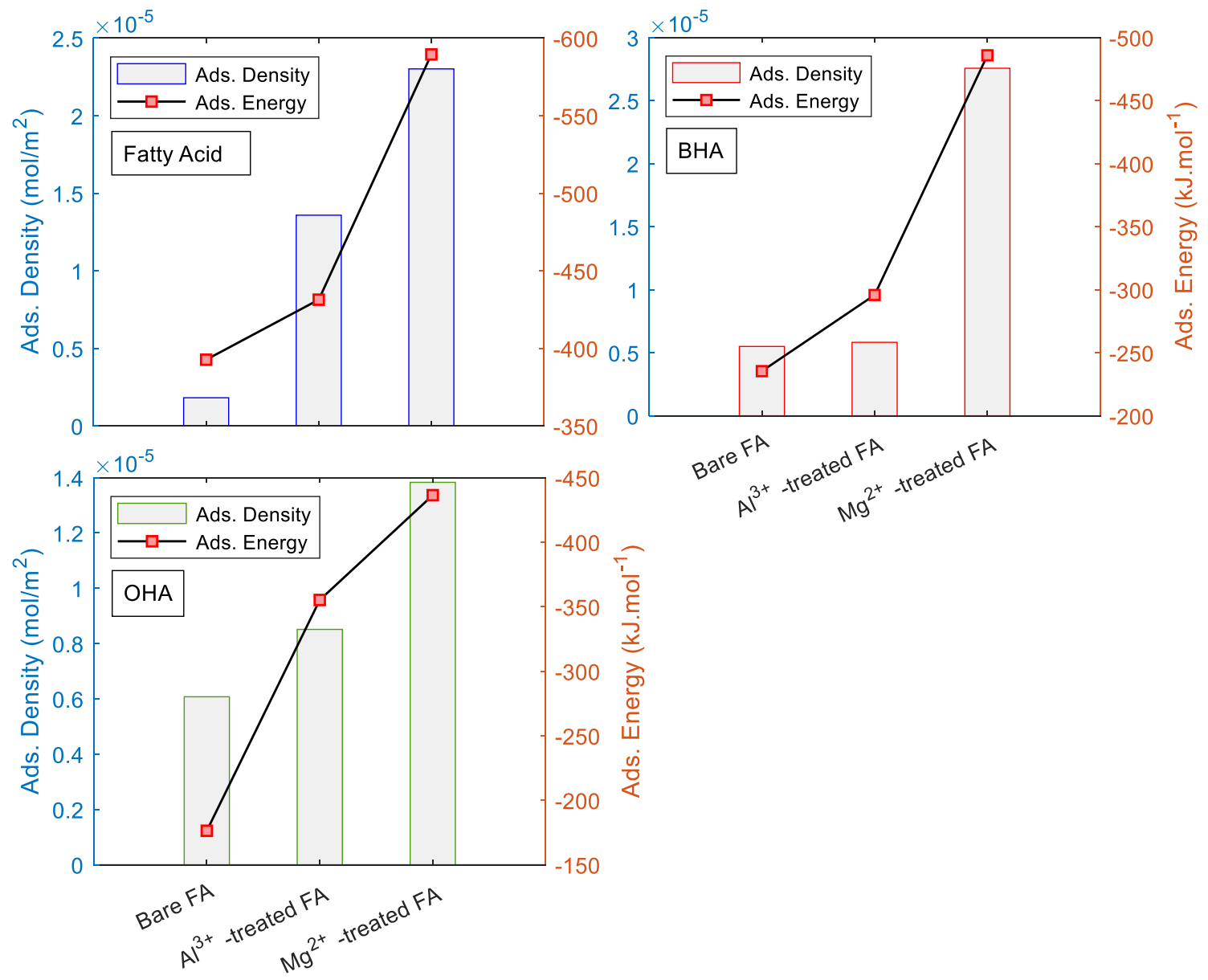

Figure 3-17: The adsorption energies and densities for different collector molecules on the FA surface. 


\section{Micro-flotation tests}

To assess how the obtained fundamental insights align with the froth flotation performance under the studied conditions, micro-flotation experiments were conducted, and the results are presented in Fig. 3-18. For fatty acid collector, FA flotation recovery enhances in the presence of the metal ions following the order of $\mathrm{Mg}^{2+}>\mathrm{Al}^{3+}$. This is in line with the trend of the adsorption energies obtained from the AIMD simulations, as shown in Fig. 3-18, as well as with the results of the adsorption density measurements presented in Fig. 3-14. These altogether confirm that the presence of $\mathrm{Al}^{3+}$ and $\mathrm{Mg}^{2+}$ metal ions in the flotation environment is beneficial for the flotation of FA using a fatty acid collector, with the latter being more favorable. For OHA, similar to the fatty acid collector, FA flotation recovery increases, even though very slightly, in the presence of the metal ions in the order of $\mathrm{Mg}^{2+}>\mathrm{Al}^{3+}$. It is again consistent with the results of the adsorption density measurements (Fig. 3-14) and the adsorption energies as well as configurations obtained from the AIMD simulations, as compared in Fig. 3-18.

For BHA, flotation recovery encounters respectively a decline and a rise when $\mathrm{Al}^{3+}$ and $\mathrm{Mg}^{2+}$ metal ions are present in the solution compared to their absence, i.e., in DI water. These results are in agreement with the results obtained for BHA from adsorption density measurements and AIMD simulations with a partial exception for the presence of $\mathrm{Al}^{3+}$ metal ions. The decline in the flotation recovery using BHA in the presence of $\mathrm{Al}^{3+}$ is consistent with the corresponding adsorption configuration obtained from AIMD simulations where it is shown that the BHA molecule prefers $\mathrm{Ca}^{2+}$ lattice sites over the $\mathrm{Al}^{3+}$-treated site for adsorption. Adsorption density measurements also revealed that the presence of $\mathrm{Al}^{3+}$ ions does not benefit the amount of BHA adsorbed on the FA surface. However, the obtained adsorption energy for BHA on the $\mathrm{Al}^{3+}$-treated FA surface does not coincide well with the experimental results, including both flotation recovery and adsorption density.

This, as mentioned earlier, could possibly be attributed to the modified mineral surface charge due to the precipitation of Al-hydroxide species on the surface, as confirmed by the zeta potential measurements. A separate investigation, as noted earlier, into different aspects of this finding seems to be worthwhile. Moreover, considering the adsorption density measurements, AIMD simulations, and the flotation results, it is interesting to observe that the 
HA moiety behaves distinctively different towards $\mathrm{Al}^{3+}$ metal ions in the form of BHA and OHA compounds. This may raise the question of whether such discrepancy is induced by their class of hydrocarbon group, i.e., aliphatic or aromatic. As known, BHA has an NHydroxybenzamide structure with benzamide being an aromatic amide, while OHA is an NHydroxyoctanamide compound with an octanamide as an aliphatic fatty acid amide [79]. The question, in other words, is if the chelating ability of HAs is influenced by their hydrocarbon group arrangement, especially with trivalent metals. This is yet to be explored in the context of froth flotation.

Besides, the presence of the gangue metal ions in a flotation environment is linked to the presence of sparingly soluble gangue minerals. This, according to the results of the current study, means that a competitive consumption of the collector molecules available in the solution by both FA as the valuable and its associated gangue minerals that host these metal ions is unavoidable in a real flotation separation system. To that end, in order to obtain a more industrially applicable knowledge, different aspects of the effects of the metal ions on the flotation behavior of the gangue minerals for FA, e.g., dolomite, calcite, quartz, and clays in the presence of both fatty and hydroxamic acid collectors should also be investigated. This can develop the pathway to the design and development [99] of specially tailored reagents for the selective flotation of FA as the most characterized P-rich mineral from the troublesome lowgrade secondary resources such as WC. 


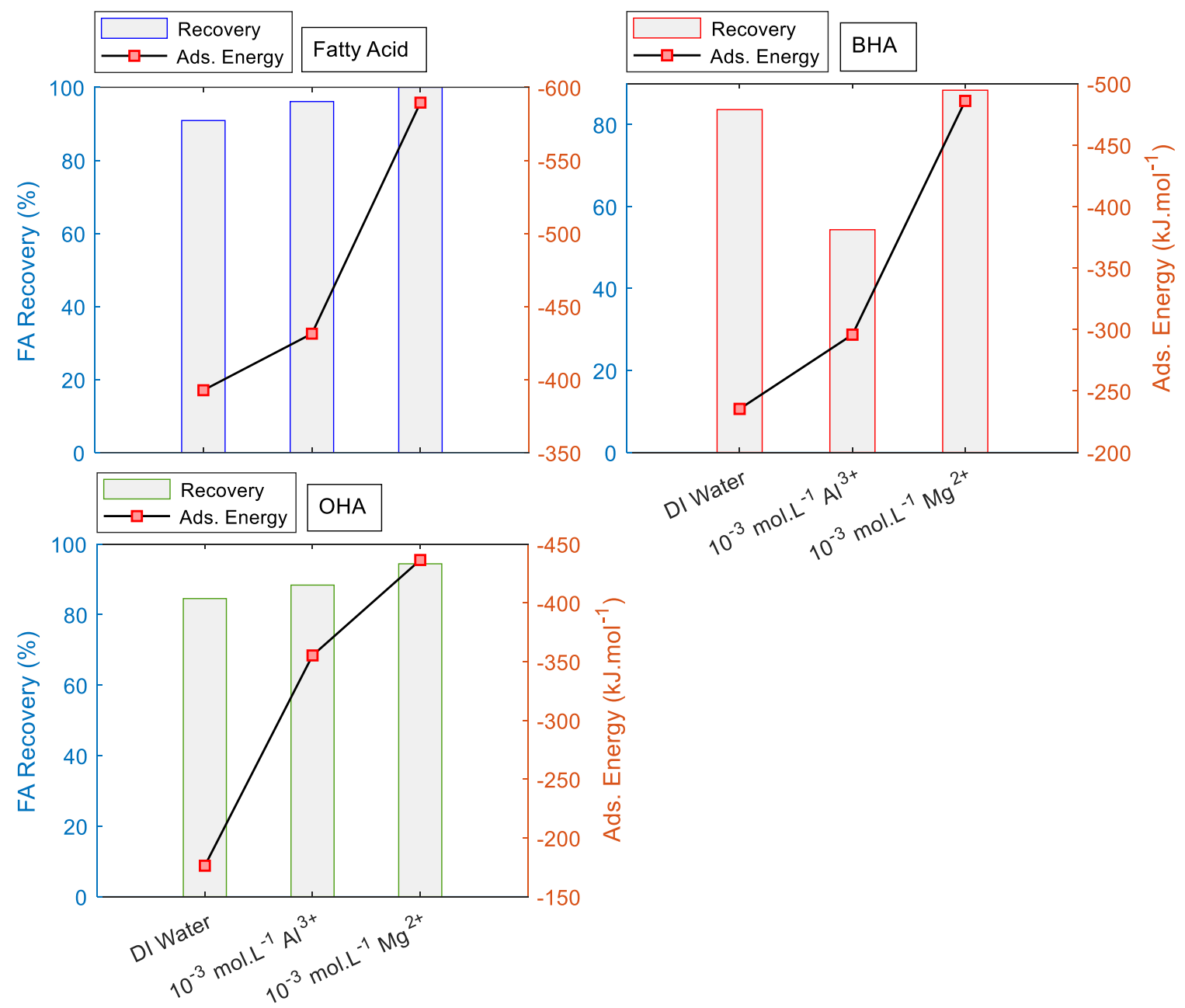

Figure 3-18: Experimental FA flotation results compared with the theoretical adsorption energies for different collectors in the absence and presence of the metal ions.

\section{Conclusive remarks}

This study aimed to unravel how the presence of $\mathrm{Al}^{3+}$ and $\mathrm{Mg}^{2+}$ metal ions influences the interaction of the collector reagents with the FA surface, and thereby its selective flotation performance. AIMD simulations helped understand interaction energies and adsorption configurations of both collectors and hydrolysis species of the metal ions with the mineral surface. Electro-kinetic measurements shed light on the surface charge modifications owed to the presence of the metal ions. XPS surface scanning revealed the type and the mechanism of the adsorption of the metal ions on the mineral surface. UV-Vis adsorption density measurements were conducted to determine the amount of the collector adsorbed on the mineral surface in the absence and presence of the metal ions. Finally, micro-flotation 
experiments showed how the fundamental experimental and theoretical insights would manifest in a real flotation environment. This study showed that:

- Fatty acid collector adsorbs on the bare FA surface through a bidentate $\mathrm{Ca}-\mathrm{O}$ bonding along with a $\mathrm{Na}^{+}$-mediated $\mathrm{O}-\mathrm{O}$ bonding. For the HA collectors, however, a monodentate $\mathrm{Ca}-\mathrm{O}$ bonding is established.

- $\mathrm{Na}^{+}$counter-ion contributes to the interaction of fatty acid collector with the bare FA surface via mediating the $\mathrm{O}-\mathrm{O}$ bonding between the collector and the mineral surface.

- Fatty acid collector adsorbs on the $\mathrm{Al}^{3+}$-treated FA surface through the bidentate interaction with both adsorbed $\mathrm{Al}^{3+}$ and lattice $\mathrm{Ca}^{2+}$ ions through $\mathrm{Al}-\mathrm{O}$ and $\mathrm{Ca}-\mathrm{O}$ bonds, respectively.

- The presence of $\mathrm{Al}^{3+}$ results in a stronger OHA-mineral interaction through a bidentate $\mathrm{Al}-\mathrm{O}$ bonding, and therefore an enhanced flotation performance. For BHA, however, the presence of $\mathrm{Al}^{3+}$ cations deteriorates the collector adsorption on the FA surface and thereby leads to a declined flotation performance.

- For fatty acid and HA collectors, the adsorption of $\mathrm{Mg}^{2+}$ species on the surface leads to the stronger mono-dentate and bidentate, respectively, $\mathrm{Ca}-\mathrm{O}$ interaction of the collector molecule with a lattice $\mathrm{Ca}^{2+}$ ion along with a mono-dentate $\mathrm{Mg}-\mathrm{O}$ bonding to the adsorbed $\mathrm{Mg}^{2+}$ site. BHA forms a stronger interaction with the FA surface in the presence of $\mathrm{Mg}^{2+}$ in comparison with OHA.

- Fatty acid collector establishes a more stable and stronger interaction with the bare as well as $\mathrm{Al}^{3+} / \mathrm{Mg}^{2+}$-treated FA mineral surface, as opposed to OHA and BHA.

- Both $\mathrm{Al}^{3+}$ and $\mathrm{Mg}^{2+}$ ions are beneficial for the adsorption of the fatty acid collector on the FA surface, and thereby its flotation. For both fatty acid and hydroxamates, $\mathrm{Mg}^{2+}$ is more favorable than $\mathrm{Al}^{3+}$ in apatite flotation.

- HA collectors build a stronger collector-mineral interaction with either bare or the treated FA surface in their free anionic form compared to their neutral form.

- Interestingly, even though $\mathrm{Al}^{3+}$ deters the functionality of BHA on the FA surface, it contributes to a stronger BHA-mineral interaction through a bidentate $\mathrm{Ca}-\mathrm{O}$ bonding. This could possibly be due to the modified mineral surface charge density owing to the precipitation of $\mathrm{Al}^{3+}$ species. In addition, such a discrepancy between the behavior of the two HA collectors towards the presence of $\mathrm{Al}^{3+}$ cations could be attributed to the 
type of the hydrocarbon group arrangement, i.e., aliphatic or aromatic. It can be the focus of a separate study.

- A competitive consumption of the collector molecules by both FA and its gangues is inevitable during an actual flotation separation based on the current study's findings. Thus, in order to obtain a more industrially sound insight, the effects of the metal ions on the collector consumption by known gangue minerals, and thereupon on the flotation selectivity should also be investigated in the future endeavors.

\section{Acknowledgements}

We acknowledge the use of Thorny Flat High Performance Computing cluster, West Virginia University Research Computing (WVU-RC), and the use of the WVU Shared Research Facilities.

\section{References:}

[1] Pan, Y. and Fleet, M.E., 2002. Compositions of the apatite-group minerals: substitution mechanisms and controlling factors. Reviews in mineralogy and geochemistry, 48(1), pp.13-49.

[2] Salvi, S., Williams-Jones, A.E., Linnen, R.L. and Samson, I.M., 2005. Alkaline granitesyenite deposits. Geological Association of Canada Short Course Notes, 17, pp.315341.

[3] Cui, W., Song, X., Chen, J., Chen, Y., Li, Y. and Zhao, C., 2020. Adsorption behaviors of different water structures on fluorapatite (001) surface: A. DFT study. Front. Mater, 7.

[4] Chander, S. and Fuerstenau, D.W., 1979. Interfacial properties and equilibria in the apatite-aqueous solution system. Journal of Colloid and Interface Science, 70(3), pp.506-516.

[5] Nan, N., Zhu, Y., Han, Y. and Liu, J., 2019. Molecular modeling of interactions between $\mathrm{N}$-(Carboxymethyl)-N-tetradecylglycine and fluorapatite. Minerals, 9(5), p.278.

[6] Forsling, W. and Wu, L., 1993. Surface complexation at hydrous fluorapatite. Aquatic sciences, 55(4), pp.336-346.

[7] Ruan, Y., Zhang, Z., Luo, H., Xiao, C., Zhou, F. and Chi, R., 2018. Effects of metal ions on the flotation of apatite, dolomite and quartz. Minerals, 8(4), p.141.

[8] Wills, B. A. \& Finch, J. A. 2016. Froth Flotation. In: Wills' Mineral Processing 
Technology, 8th edition. Boston, MA: Butterworth-Heinemann.

[9] Mohammadkhani, M., Noaparast, M., Shafaei, S.Z., Amini, A., Amini, E. and Abdollahi, H., 2011. Double reverse flotation of a very low grade sedimentary phosphate rock, rich in carbonate and silicate. International Journal of Mineral Processing, 100(3-4), pp.157-165.

[10] Miller, J.D., Wang, X. and Li, M., 2002, October. Bench scale flotation of sedimentary phosphate rock with hydroxamic acid collectors. In Proceedings of the engineering foundation conference, beneficiation of phosphates III: fundamentals and technology (pp. 93-101).

[11] Wang, L., Tian, M., Khoso, S.A., Hu, Y., Sun, W. and Gao, Z., 2019. Improved Flotation Separation of Apatite from Calcite with Benzohydroxamic Acid Collector. Mineral Processing and Extractive Metallurgy Review, 40(6), pp.427-436.

[12] Fuerstenau, M.C., 2005. Chelating agents as flotation collectors. C. Young, JJ.

[13] Fuerstenau, D.W., Herrera-Urbina, R. and McGlashan, D.W., 2000. Studies on the applicability of chelating agents as universal collectors for copper minerals. International Journal of Mineral Processing, 58(1-4), pp.15-33.

[14] Lee, K., Archibald, D., McLean, J. and Reuter, M.A., 2009. Flotation of mixed copper oxide and sulphide minerals with xanthate and hydroxamate collectors. Minerals engineering, 22(4), pp.395-401.

[15] Sreenivas, T. and Padmanabhan, N.P.H., 2002. Surface chemistry and flotation of cassiterite with alkyl hydroxamates. Colloids and Surfaces A: Physicochemical and Engineering Aspects, 205(1-2), pp.47-59.

[16] Yoon, R.H., Nagaraj, D.R., Wang, S.S. and Hildebrand, T.M., 1992. Benefication of kaolin clay by froth flotation using hydroxamate collectors. Minerals Engineering, 5(35), pp.457-467.

[17] Sis, H.I.K.M.E.T. and Chander, S., 2003. Reagents used in the flotation of phosphate ores: a critical review. Minerals Engineering, 16(7), pp.577-585.

[18] Zhang, P., Liang, H., Jin, Z. and DePaoli, D., 2017. The ultimate mineral processing challenge: Recovery of rare earths, phosphorus and uranium from Florida phosphatic clay. Minerals \& Metallurgical Processing, 34(4), pp.183-188.

[19] Zhang, P., Snow, R., Yu, Y. and Bogan, M., 2001. Recovery of phosphate from Florida phosphatic clays. Final report, FIPR Publication, pp.02-096.

[20] Eskanlou, A. and Huang, Q., Phosphatic waste clay: Origin, composition, physicochemical properties, challenges, values and possible remedies-A 
review. Minerals Engineering, 162, p.106745.

[21] Zhou, F., Liu, Q., Liu, X., Li, W., Feng, J. and Chi, R.A., 2020. Surface Electrical Behaviors of Apatite, Dolomite, Quartz, and Phosphate Ore. Front. Mater. 7: 35. doi: 10.3389/fmats.

[22] Ejtemaei, M., Irannajad, M. and Gharabaghi, M., 2012. Role of dissolved mineral species in selective flotation of smithsonite from quartz using oleate as collector. International Journal of Mineral Processing, 114, pp.40-47.

[23] Bulut, G. and Yenial, Ü., 2016. Effects of major ions in recycled water on sulfide minerals flotation. Minerals \& Metallurgical Processing, 33(3), pp.137-143.

[24] Raji, F., Ejtemaei, M. and Nguyen, A.V., 2020. Resolving the mystery of the second charge reversal on solid surfaces in the presence of divalent heavy metal ions. Applied Surface Science, 529, p.147128.

[25] Al-Fariss, T.F., Ozbelge, H.O. and Abdulrazik, A.M., 1991. Flotation of a carbonate rich sedimentary phosphate rock. Fertilizer research, 29(2), pp.203-208.

[26] Wonyen, D.G., Kromah, V., Gibson, B., Nah, S. and Chelgani, S.C., 2018. A review of flotation separation of $\mathrm{Mg}$ carbonates (dolomite and magnesite). Minerals, 8(8), p.354.

[27] dos Santos, M.A., Santana, R.C., Capponi, F., Ataíde, C.H. and Barrozo, M.A., 2010. Effect of ionic species on the performance of apatite flotation. Separation and Purification Technology, 76(1), pp.15-20.

[28] Al-Thyabat, S. and Al-Zoubi, H., 2012. Purification of phosphate beneficiation wastewater: Separation of phosphate from Eshydia Mine (Jordan) by column-DAF flotation process. International Journal of Mineral Processing, 110, pp.18-24.

[29] Elgillani, D.A. and Abouzeid, A.Z., 1993. Flotation of carbonates from phosphate ores in acidic media. International Journal of Mineral Processing, 38(3-4), pp.235-256.

[30] Sis, H.İ.K.M.E.T. and Chander, S., 2003. Adsorption and contact angle of single and binary mixtures of surfactants on apatite. Minerals Engineering, 16(9), pp.839-848.

[31] Liu, X., Li, C., Luo, H., Cheng, R. and Liu, F., 2017. Selective reverse flotation of apatite from dolomite in collophanite ore using saponified gutter oil fatty acid as a collector. International Journal of Mineral Processing, 165, pp.20-27.

[32] Horta, D. and de Mello Monte, M.B., 2016. The effect of dissolution kinetics on flotation response of apatite with sodium oleate. International Journal of Mineral Processing, 146, pp.97-104.

[33] Foucaud, Y., Badawi, M., Filippov, L., Filippova, I. and Lebègue, S., 2019. A review of atomistic simulation methods for surface physical-chemistry phenomena applied to 
froth flotation. Minerals Engineering, 143, p.106020.

[34] Mkhonto, D., Ngoepe, P.E., Cooper, T.G. and de Leeuw, N.H., 2006. A computer modelling study of the interaction of organic adsorbates with fluorapatite surfaces. Physics and chemistry of minerals, 33(5), pp.314-331.

[35] Xie, J., Zhang, Q., Mao, S., Li, X., Shen, Z. and Li, L., 2019. Anisotropic crystal plane nature and wettability of fluorapatite. Applied Surface Science, 493, pp.294-307.

[36] Xie, J., Li, X., Mao, S., Li, L., Ke, B. and Zhang, Q., 2018. Effects of structure of fatty acid collectors on the adsorption of fluorapatite (001) surface: A first-principles calculations. Applied Surface Science, 444, pp.699-709.

[37] Filippova, I.V., Filippov, L.O., Lafhaj, Z., Barres, O. and Fornasiero, D., 2018. Effect of calcium minerals reactivity on fatty acids adsorption and flotation. Colloids and Surfaces A: Physicochemical and Engineering Aspects, 545, pp.157-166.

[38] Zheng, R., Ren, Z., Gao, H., Chen, Z., Qian, Y. and Li, Y., 2018. Effects of crystal chemistry on sodium oleate adsorption on fluorite surface investigated by molecular dynamics simulation. Minerals Engineering, 124, pp.77-85.

[39] Rulis, P., Yao, H., Ouyang, L. and Ching, W.Y., 2007. Electronic structure, bonding, charge distribution, and x-ray absorption spectra of the (001) surfaces of fluorapatite and hydroxyapatite from first principles. Physical Review B, 76(24), p.245410.

[40] Pavan, B., Ceresoli, D., Tecklenburg, M.M. and Fornari, M., 2012. First principles NMR study of fluorapatite under pressure. Solid state nuclear magnetic resonance, 45, pp.5965.

[41] Wang, X., Zhang, Q., Mao, S. and Cheng, W., 2019. A Theoretical Study on the Electronic Structure and Floatability of Rare Earth Elements (La, Ce, Nd and Y) Bearing Fluorapatite. Minerals, 9(8), p.500.

[42] Chaïrat, C., Schott, J., Oelkers, E.H., Lartigue, J.E. and Harouiya, N., 2007. Kinetics and mechanism of natural fluorapatite dissolution at $25 \mathrm{C}$ and $\mathrm{pH}$ from 3 to 12. Geochimica et Cosmochimica Acta, 71(24), pp.5901-5912.

[43] Rao, K.H., Antti, B.M. and Forssberg, E., 1990. Mechanism of oleate interaction on salttype minerals, Part II. Adsorption and electrokinetic studies of apatite in the presence of sodium oleate and sodium metasilicate. International Journal of Mineral Processing, 28(1-2), pp.59-79.

[44] Nduwa-Mushidi, J. and Anderson, C.G., 2017. Surface chemistry and flotation behaviors of monazite-apatite-ilmenite-quartz-rutile-zircon with octanohydroxamic acid. Journal of Sustainable Metallurgy, 3(1), pp.62-72. 
[45] Villars, P., Cenzual, K., Okamoto, H., Hulliger, F. and Iwata, S., 2012. PAULING FILE Multinaries Edition-2012.

[46] Ptáček, P., 2016. Introduction to Apatites. In Apatites and their synthetic AnaloguesSynthesis, structure, properties and applications. IntechOpen.

[47] Ptáček, P., 2016. Identification, characterization and properties of apatites. Apatites and Their Synthetic Analogues-Synthesis, Structure, Properties and Applications, pp.111175.

[48] Dorozhkin, S.V., 2012. Dissolution mechanism of calcium apatites in acids: A review of literature. World journal of methodology, 2(1), p.1.

[49] White, T.J. and Dong, Z., 2003. Structural derivation and crystal chemistry of apatites. Acta Crystallographica Section B: Structural Science, 59(1), pp.1-16.

[50] Hughes, J.M. and Rakovan, J., 2018. 1. The Crystal Structure of Apatite, Ca5 (PO4) 3 (F, OH, Cl). Phosphates, pp.1-12.

[51] Hughes, J.M., 2015. The many facets of apatite. American Mineralogist, 100(5-6), pp.1033-1039.

[52] Moreno, E.C., Kresak, M. and Zahradnik, R.T., 1974. Fluoridated hydroxyapatite solubility and caries formation. Nature, 247(5435), pp.64-65.

[53] Rey, C., Combes, C., Drouet, C. and Sfihi, H., 2008. Fluoride-Based Bioceramics. In Fluorine and Health (pp. 279-331). Elsevier.

[54] Chin, K.A. and Nancollas, G.H., 1991. Dissolution of fluorapatite. A constantcomposition kinetics study. Langmuir, 7(10), pp.2175-2179.

[55] Dorozhkin, S.V., 1997. Surface reactions of apatite dissolution. Journal of colloid and interface science, 191(2), pp.489-497.

[56] Hochrein, O. and Zahn, D., 2011. On the molecular mechanisms of the acid-induced dissociation of hydroxy-apatite in water. Journal of molecular modeling, 17(6), pp.1525-1528.

[57] Broom-Fendley, S., Styles, M.T., Appleton, J.D., Gunn, G. and Wall, F., 2016. Evidence for dissolution-reprecipitation of apatite and preferential LREE mobility in carbonatitederived late-stage hydrothermal processes. American Mineralogist, 101(3), pp.596-611.

[58] Ptáček, P., 2016. Substituents and dopants in the structure of apatite. Apatites and their synthetic analogues-synthesis, structure, properties and applications. InTech, Open Acces monograph, pp.289-334.

[59] Crawford, R.J., Harding, I.H. and Mainwaring, D.E., 1996. The zeta potential of iron 
and chromium hydrous oxides during adsorption and coprecipitation of aqueous heavy metals. Journal of Colloid and interface science, 181(2), pp.561-570.

[60] Greczynski, G. and Hultman, L., 2020. X-ray photoelectron spectroscopy: Towards reliable binding energy referencing. Progress in Materials Science, 107, p.100591.

[61] Gier, S. and Johns, W.D., 2000. Heavy metal-adsorption on micas and clay minerals studied by X-ray photoelectron spectroscopy. Applied Clay Science, 16(5-6), pp.289299.

[62] Wagner, C.D., 1990. Photoelectron and Auger energies and the Auger parameter: a data set. Practical surface analysis.

[63] Natarajan, R. and Fuerstenau, D.W., 1983. Adsorption and flotation behavior of manganese dioxide in the presence of octyl hydroxamate. International Journal of Mineral Processing, 11(2), pp.139-153.

[64] Raghavan, S. and Fuerstenau, D.W., 1975. The adsorption of aqueous octylhydroxamate on ferric oxide. Journal of colloid and interface science, 50(2), pp.319-330.

[65] Hendricks, S.B., Jefferson, M.E. and Mosley, V.M., 1932. The crystal structures of some natural and synthetic apatite-like substances. Zeitschrift für KristallographieCrystalline Materials, 81(1-6), pp.352-369.

[66] Kresse, G. and Hafner, J., 1993. Ab initio molecular dynamics for liquid metals. Physical Review B, 47(1), p.558.

[67] Perdew, J.P., Burke, K. and Ernzerhof, M., 1996. Generalized gradient approximation made simple. Physical review letters, 77(18), p.3865.

[68] Kohn, W. and Sham, L.J., 1965. Self-consistent equations including exchange and correlation effects. Physical review, 140(4A), p.A1133.

[69] Kresse, G. and Furthmüller, J., 1996. Efficient iterative schemes for ab initio totalenergy calculations using a plane-wave basis set. Physical review B, 54(16), p.11169.

[70] Kresse, G. and Joubert, D., 1999. From ultrasoft pseudopotentials to the projector augmented-wave method. Physical review b, 59(3), p.1758.

[71] Methfessel, M.P.A.T. and Paxton, A.T., 1989. High-precision sampling for Brillouinzone integration in metals. Physical Review B, 40(6), p.3616.

[72] Georg, K., 2011. VASP Group, Theoretical Physics Departments, Vienna. Retrieved February, 21.

[73] Nosé, S., 1984. A molecular dynamics method for simulations in the canonical ensemble. Molecular physics, 52(2), pp.255-268. 
[74] Nosé, S., 1984. A unified formulation of the constant temperature molecular dynamics methods. The Journal of chemical physics, 81(1), pp.511-519.

[75] Hoover, W.G., 1985. Canonical dynamics: Equilibrium phase-space distributions. Physical review A, 31(3), p.1695.

[76] Foucaud, Y., Lebègue, S., Filippov, L.O., Filippova, I.V. and Badawi, M., 2018. Molecular insight into fatty acid adsorption on bare and hydrated (111) fluorite surface. The Journal of Physical Chemistry B, 122(51), pp.12403-12410.

[77] Khalil, M.M. and Mahmoud, R.K., 2008. New Insights into M (II)- Hydroxamate Interactions: The Electro-Analytical Behavior of Metal (II) Complexes Involving Monohydroxamic Acids and Diamines in an Aqueous Medium. Journal of Chemical \& Engineering Data, 53(10), pp.2318-2327.

[78] Nduwa-Mushidi, J. and Anderson, C.G., 2017. Surface chemistry and flotation behaviors of monazite-apatite-ilmenite-quartz-rutile-zircon with octanohydroxamic acid. Journal of Sustainable Metallurgy, 3(1), pp.62-72.

[79] https://www.pubchem.ncbi.nlm.nih.gov/.

[80] Foucaud, Y., Lainé, J., Filippov, L.O., Barrès, O., Kim, W.J., Filippova, I.V., Pastore, M., Lebègue, S. and Badawi, M., 2021. Adsorption mechanisms of fatty acids on fluorite unraveled by infrared spectroscopy and first-principles calculations. Journal of Colloid and Interface Science, 583, pp.692-703.

[81] Danna, Z., 2015. Applications of Chemical Equilibrium Diagram Software HYDRA/MEDUSA in Teaching College Chemistry. University Chemistry, p.04.

[82] Gilbert, A.T.B., 2012. IQmol molecular viewer; http://iqmol.org; accessed 27 May 2021.

[83] Hanwell, M.D., Curtis, D.E., Lonie, D.C., Vandermeersch, T., Zurek, E. and Hutchison, G.R., 2012. Avogadro: an advanced semantic chemical editor, visualization, and analysis platform. Journal of cheminformatics, 4(1), pp.1-17.

[84] Momma, K. and Izumi, F., 2011. VESTA 3 for three-dimensional visualization of crystal, volumetric and morphology data. Journal of applied crystallography, 44(6), pp.1272-1276.

[85] Amankonah, J.O., Somasundaran, P. and Ananthapadmabhan, K.P., 1985. Effects of dissolved mineral species on the dissolution/precipitation characteristics of calcite and apatite. Colloids and surfaces, 15, pp.295-307.

[86] Chastain, J. and King Jr, R.C., 1992. Handbook of X-ray photoelectron spectroscopy. Perkin-Elmer Corporation, 40, p.221. 
[87] Geneyton, A., Foucaud, Y., Filippov, L.O., Menad, N.E., Renard, A. and Badawi, M., 2020. Synergistic adsorption of lanthanum ions and fatty acids for efficient rare-earth phosphate recovery: Surface analysis and ab initio molecular dynamics studies. Applied Surface Science, 526, p.146725.

[88] Liu, X., Zhao, Y., Li, Q., Jiao, T. and Niu, J., 2016. Adsorption behavior, spreading and thermal stability of anionic-nonionic surfactants with different ionic headgroup. Journal of Molecular Liquids, 219, pp.1100-1106.

[89] Xu, L., Tian, J., Wu, H., Lu, Z., Sun, W. and Hu, Y., 2017. The flotation and adsorption of mixed collectors on oxide and silicate minerals. Advances in colloid and interface science, 250, pp.1-14.

[90] Nguyen, K.T., Nguyen, T.D. and Nguyen, A.V., 2014. Strong cooperative effect of oppositely charged surfactant mixtures on their adsorption and packing at the air-water interface and interfacial water structure. Langmuir, 30(24), pp.7047-7051.

[91] Albright, T.A., Burdett, J.K. and Whangbo, M.H., 2013. Orbital interactions in chemistry. John Wiley \& Sons.

[92] Somasundaran, P., Amankonah, J.O. and Ananthapadmabhan, K.P., 1985. Mineralsolution equilibria in sparingly soluble mineral systems. Colloids and Surfaces, 15, pp.309-333.

[93] Owens, C.L., Nash, G.R., Hadler, K., Fitzpatrick, R.S., Anderson, C.G. and Wall, F., 2019. Apatite enrichment by rare earth elements: a review of the effects of surface properties. Advances in colloid and interface science, 265, pp.14-28.

[94] Jiang, W., Gao, Z., Khoso, S.A., Gao, J., Sun, W., Pu, W. and Hu, Y., 2018. Selective adsorption of benzhydroxamic acid on fluorite rendering selective separation of fluorite/calcite. Applied Surface Science, 435, pp.752-758.

[95] Kupka, N. and Rudolph, M., 2018. Froth flotation of scheelite-A review. International Journal of Mining Science and Technology, 28(3), pp.373-384.

[96] Bader, R.F.W., 1990. Atoms in Molecules: A Quantum Theory. Oxford University Press: Oxford, UK.

[97] Somasundaran, P. and Zhang, L., 2000. Reagent Adsorption on Phosphates. Encyclopedia of Separation Science, 4.

[98] Hirva, P. and Tikka, H.K., 2002. Ab initio study on the interaction of anionic collectors with calcite and dolomite surfaces. Langmuir, 18(12), pp.5002-5006.

[99] Liu, G., Yang, X. and Zhong, H., 2017. Molecular design of flotation collectors: A recent progress. Advances in colloid and interface science, 246, pp.181-195. 


\section{CHAPTER 4}

Conclusions and Recommendations for Future Work 


\section{Key contributions and conclusions}

The recovery of $\mathrm{P}$ from Florida waste clay (WC) has been investigated in this MS thesis. For this thesis, a new strategy was adopted where the main body of thesis consisted of three independent chapters each seeking a unique set of goals. Eventually, the different findings obtained from each of the three chapters served altogether to satisfy the main objectives of the research work. In the following, the main contributions of this thesis are summarized:

Phosphatic waste clay: origin, composition, physicochemical properties, challenges, values and possible remedies - A review: this study (chapter 1) showed that: (i)-The most important values being lost to WC are P and REEs, which are both categorized as critical materials. For the recovery of these values from WC, two crucial attempts are the removal of extremely fine-sized clays, followed by the recovery of phosphate content, which according to the prior research endeavors, can pave the path for the recovery of REEs; (ii)Any scientific/ technological solution should, at the same time, be economically and, of course, environmentally attractive to the industry. As such, the first that comes to mind would be moving from mostly chemical separation processes to the primarily physical/ physicochemical processes with lower operational costs and environmental impacts.

$\bigcirc$ De-sliming followed by froth flotation for the recovery of phosphorus and enrichment of rare earth elements from Florida waste clay: this study (chapter 2) showed that: (i)The direct flotation of apatite using both fatty acid and hydroxamates, even in the presence of various regulating agents, does not offer a solution for the recovery of P from WC; (ii)Hydroxamic acid collectors, despite their capability in the selective flotation of apatite and REE-bearing minerals, do not produce a successful selective separation of phosphate minerals from WC; (iii)- The double-stage reverse flotation process in which the cationic removal of silicates is followed by the anionic rejection of carbonates both at fairly acidic conditions, becomes less attractive from the economic stance when the reagent consumption is taken as a determining factor. Added to this is the significant loss of REEs with this approach; (iv)- The single-stage process where only a cationic removal of silicates following the cyclone-assisted removal of clays are employed, offers a more economically viable route for the conditional recovery of $\mathrm{P}$ from $\mathrm{WC}$. This superiority also owes to its relative capability to avoid the loss of REEs as the other paramount value contained in WC; 
(v)-The removal of clays, silicates, and carbonates through the de-sliming followed by the single-stage reverse flotation process meets the specifications of the medium-grade phosphate ore that is routinely mixed with the high-grade ore to be sold to the fertilizer production industry; and (vi)- Removal of the associated gangues significantly alleviates the acid consumption in the subsequent chemical recovery of REEs from WC, which has long been alluded to by the industry and researchers as the limiting factor.

$\bigcirc \quad$ Effect of $\mathrm{Al}^{3+}$ and $\mathrm{Mg}^{2+}$ on the flotation of apatite using fatty- and hydroxamic-acid collectors - A multiscale investigation: this study (chapter 3) showed that: (i)- Fatty acid collector adsorbs on the bare FA surface through a bidentate $\mathrm{Ca}-\mathrm{O}$ bonding along with a $\mathrm{Na}^{+}$-mediated $\mathrm{O}-\mathrm{O}$ bonding. For the HA collectors, however, a mono-dentate $\mathrm{Ca}-\mathrm{O}$ bonding is established. $\mathrm{Na}^{+}$counter-ion contributes to the interaction of fatty acid collector with the bare FA surface via mediating the $\mathrm{O}-\mathrm{O}$ bonding between the collector and the mineral surface. (ii)- Fatty acid collector adsorbs on the $\mathrm{Al}^{3+}$-treated FA surface through the bidentate interaction with both adsorbed $\mathrm{Al}^{3+}$ and lattice $\mathrm{Ca}^{2+}$ ions through $\mathrm{Al}-\mathrm{O}$ and $\mathrm{Ca}-\mathrm{O}$ bonds, respectively. The presence of $\mathrm{Al}^{3+}$ results in a stronger OHA-mineral interaction through a bidentate $\mathrm{Al}-\mathrm{O}$ bonding, and therefore an enhanced flotation performance. For BHA, however, the presence of $\mathrm{Al}^{3+}$ cations deteriorates the collector adsorption on the FA surface and thereby leads to a declined flotation performance; (iii)For fatty acid and HA collectors, the adsorption of $\mathrm{Mg}^{2+}$ species on the surface leads to the stronger mono-dentate and bidentate, respectively, $\mathrm{Ca}-\mathrm{O}$ interaction of the collector molecule with a lattice $\mathrm{Ca}^{2+}$ ion along with a mono-dentate $\mathrm{Mg}-\mathrm{O}$ bonding to the adsorbed $\mathrm{Mg}^{2+}$ site. BHA forms a stronger interaction with the FA surface in the presence of $\mathrm{Mg}^{2+}$ in comparison with OHA; (iv)- Fatty acid collector establishes a more stable and stronger interaction with the bare as well as $\mathrm{Al}^{3+} / \mathrm{Mg}^{2+}$-treated FA mineral surface, as opposed to OHA and BHA; (v)- Both $\mathrm{Al}^{3+}$ and $\mathrm{Mg}^{2+}$ ions are beneficial for the adsorption of the fatty acid collector on the FA surface, and thereby its flotation; (vi)- For both fatty acid and hydroxamates, $\mathrm{Mg}^{2+}$ is more favorable than $\mathrm{Al}^{3+}$ in apatite flotation; and (vii)- HA collectors build a stronger collector-mineral interaction with either bare or the treated FA surface in their free anionic form compared to their neutral form. 


\section{Recommendations for future work}

Based on the findings of this MS research, the following perspectives could be considered in future studies:

- Assuming a 300 ppm TREE content, WC contains 600 thousand tons of REEs including 200 thousand tons of Y solely. To that end, the recovery of REEs from the enriched WC following the findings of the current study seems to be crucial due to the huge content of these critical elements in this reserve.

- The ionic liquids (ILs) as environmentally friendly green reagents have recently shown promising potential in the extraction of REEs from certain low-grade secondary resources via physical/ physicochemical beneficiation e.g. liquid-liquid extraction/ froth flotation, and chemical processing e.g. solvent extraction. Hence, from an environmental stand point, it seems to be worthwhile to investigate the recovery of REEs from WC using the ILs.

- Interestingly, even though $\mathrm{Al}^{3+}$ deters the functionality of BHA on the FA surface, it contributes to a stronger BHA-mineral interaction through a bidentate $\mathrm{Ca}-\mathrm{O}$ bonding. This could possibly be due to the modified mineral surface charge density owing to the precipitation of $\mathrm{Al}^{3+}$ species. In addition, such a discrepancy between the behavior of the two HA collectors towards the presence of $\mathrm{Al}^{3+}$ cations could be attributed to the type of the hydrocarbon group arrangement, i.e., aliphatic or aromatic. It can be the focus of a separate study.

- A competitive consumption of the collector molecules by both FA and its gangues is inevitable during an actual flotation separation based on the current study's findings. Thus, in order to obtain a more industrially sound insight, the effects of the metal ions on the collector consumption by known grange minerals, and thereupon on the flotation selectivity should also be investigated in the future endeavors. 


\section{Appendix A}

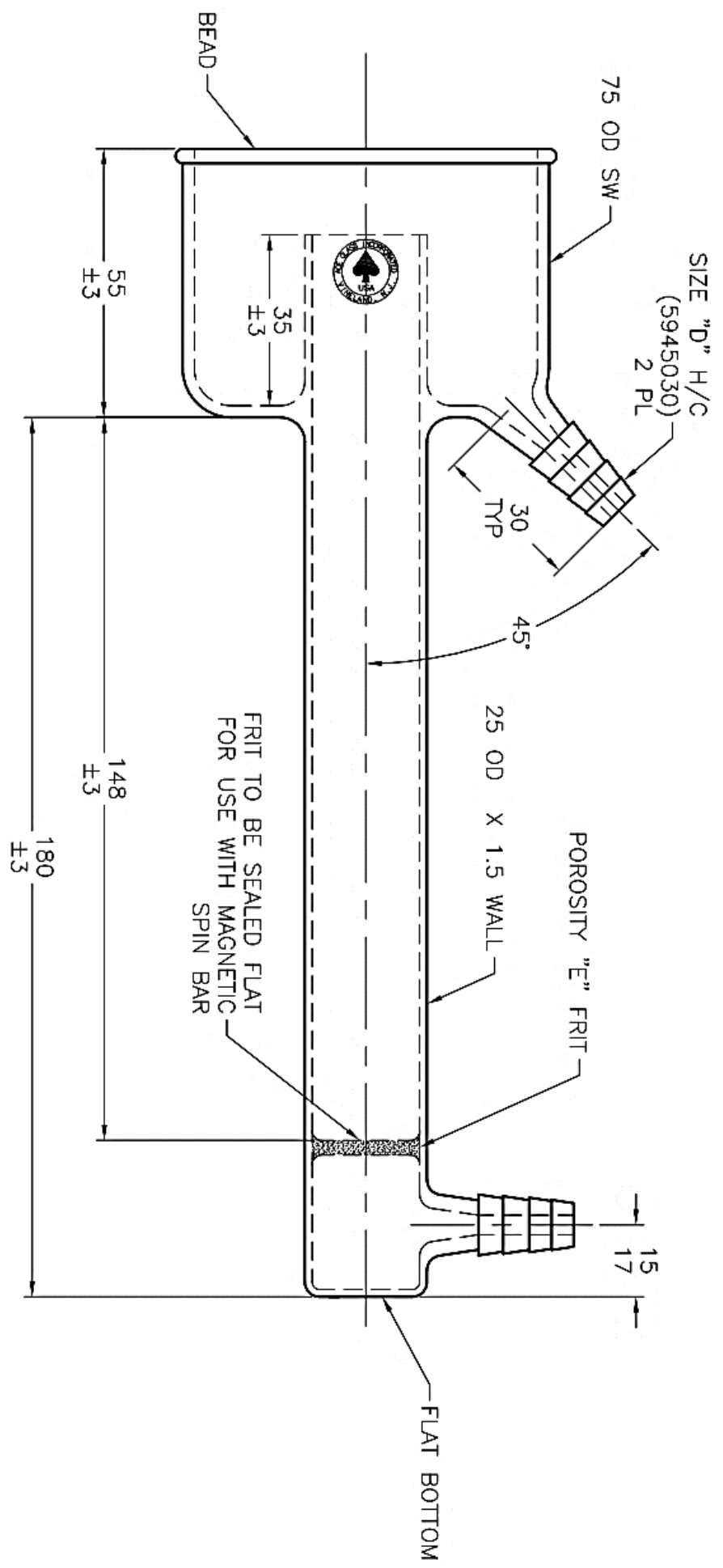

Figure A-1: Dimensions of the micro-flotation cell. 


\section{Appendix B}

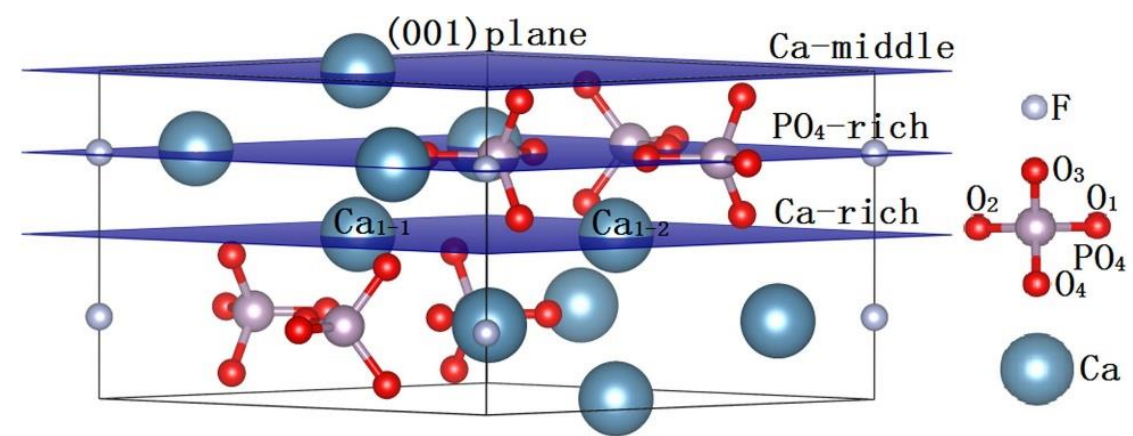

Figure B-1: Crystal structure of FA and the stacking sequence of its (001) surface layers [1].
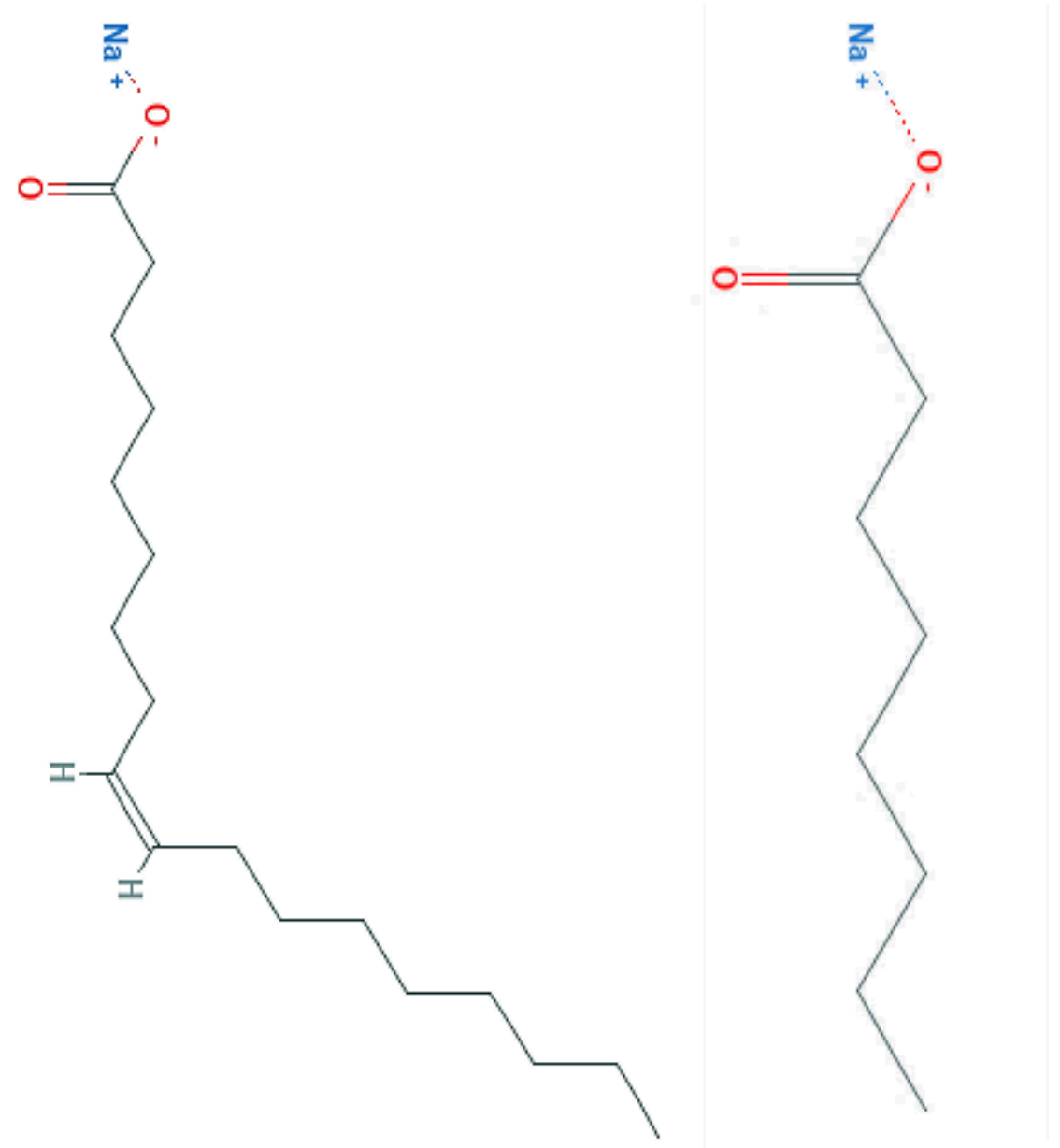

Figure B-2: Chemical structure of sodium oleate (left), and sodium octanoate (right) [2]. 

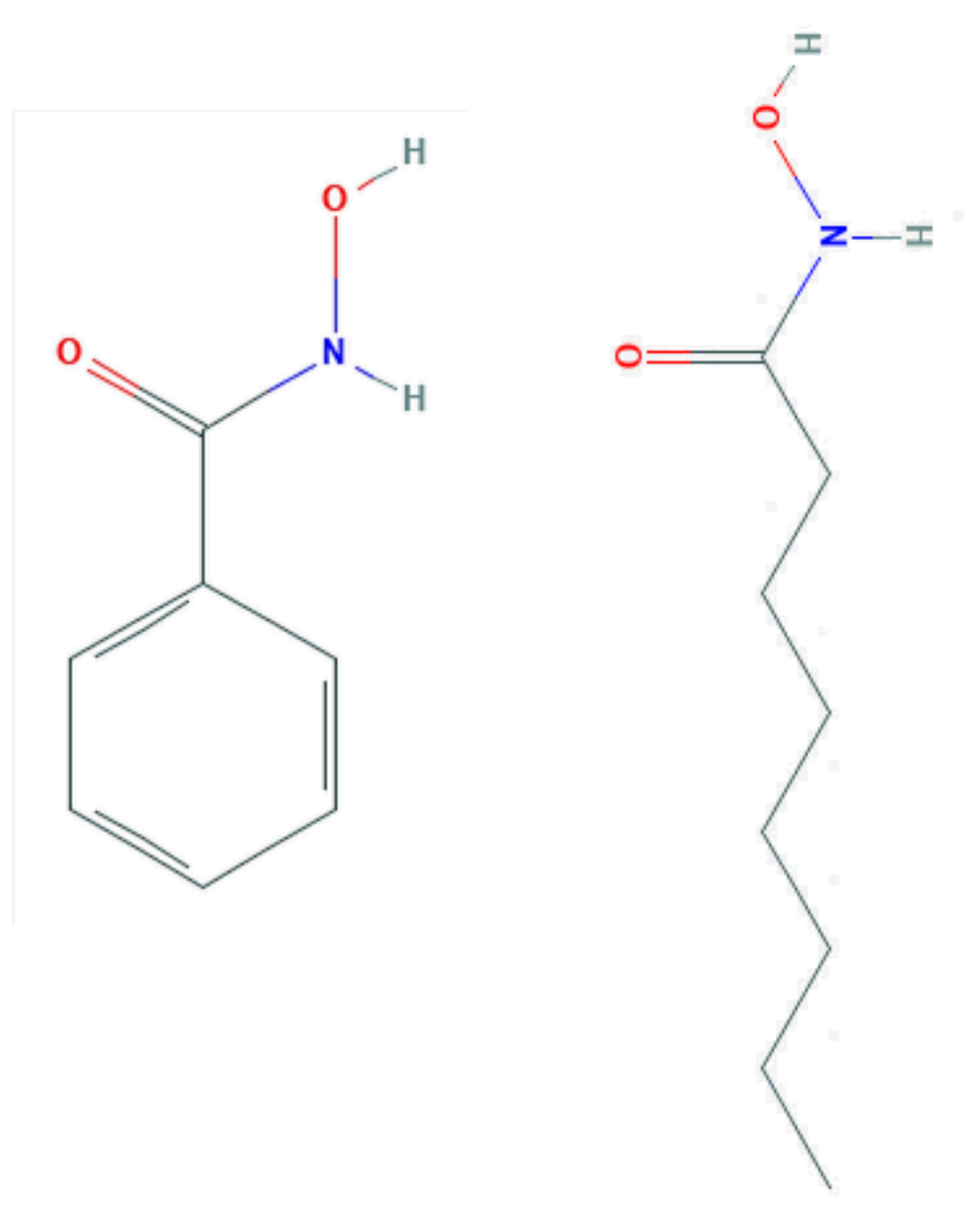

Figure B-3: Chemical structure of BHA (left), and OHA (right) [2]. 


\section{Appendix C}

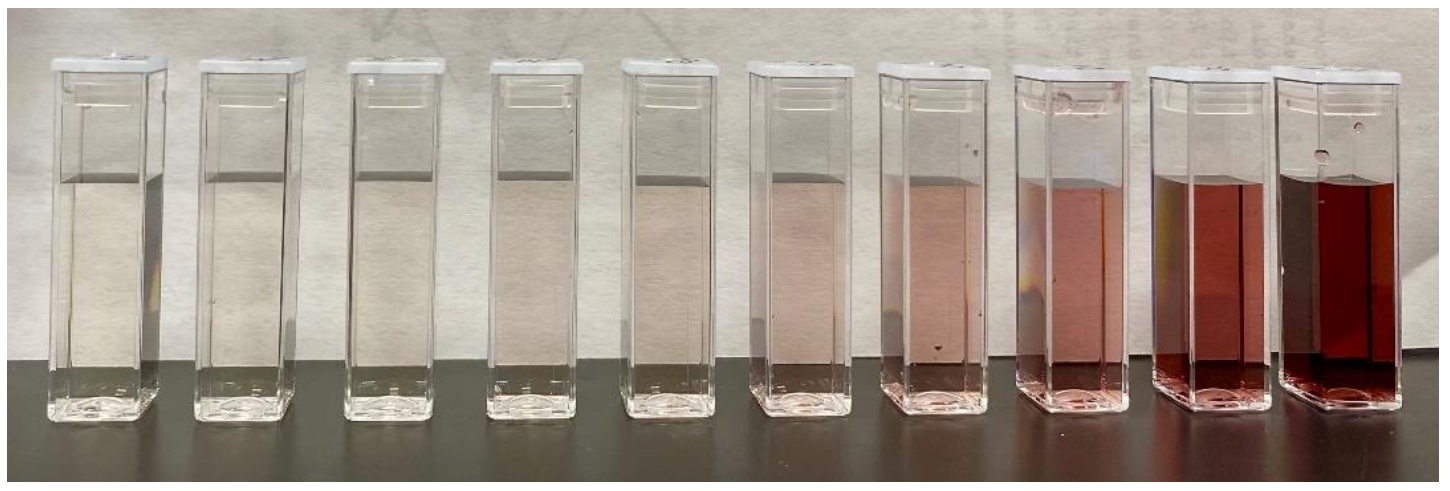

Figure C-1: Coloring of the ferric-hydroxamate solution at the different concentrations of HA (increasing from left to right).

\section{References:}

[1] Qiu, Y.Q., Cui, W.Y., Li, L.J., Ye, J.J., Wang, J. and Zhang, Q., 2017. Structural, electronic properties with different terminations for fluorapatite $\left(\begin{array}{lll}0 & 0 & 1\end{array}\right)$ surface: A first-principles investigation. Computational Materials Science, 126, pp.132-138.

[2] https://pubchem.ncbi.nlm.nih.gov/. 